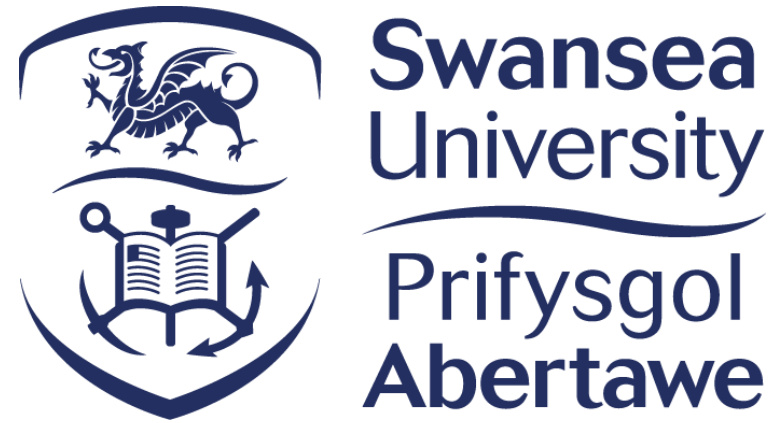

Redesigning the Scuba Diving Tourism System According to Principles of Sustainability

Caglar Bideci

Submitted to Swansea University in fulfilment of the requirements for Degree of Doctor of Philosophy

Swansea University

2021 


\title{
REDESIGNING THE SCUBA DIVING TOURISM SYSTEM ACCORDING TO PRINCIPLES OF SUSTAINABILITY
}

\begin{abstract}
Since the 1940s scuba diving tourism has become popular all over the world, however, this demand also has brought human-driven negative impacts on underwater surroundings. Reducing adverse effects on the marine environment and maximising the unique scuba diving experience depends on long-term socio-economic benefits and protecting natural and alternative marine resources. Over the last decade, system-based approaches have been developed by researchers to examine the interaction of scuba diving activities. However, a better understanding of principles of sustainability and practices and having a broad knowledge about how these are based on normative aspects can provide advantages for stakeholders in the system to reduce negative impacts. Therefore, this thesis aims to redesign the scuba diving tourism system thorough defining the normative aspects based on principles of sustainability. Investigating the research question "to what extent do the normative aspects of the scuba diving tourism system address principles of sustainability", this study uses an interpretive paradigm as the phenomenological qualitative research method. As a destination that has developed a distinctive but significant scuba diving tourism sector, the main research took place in the Mediterranean archipelago of Malta using face to face interviews with stakeholders and in-situ observation via active participation. As a result, a new systems approach as `Sustainable Scuba Diving Tourism System ' (S-SDTS) is proposed which is redesigned based on normative aspects founded on principles of sustainability.
\end{abstract}




\section{Declaration/Statements}

\section{DECLARATION}

This work has not previously been accepted in substance for any degree and is not being concurrently submitted in candidature for any degree.

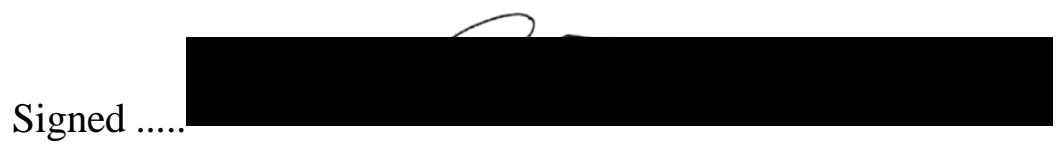

Date

21.06.2021

\section{STATEMENT 1}

This thesis is the result of my own investigations, except where otherwise stated. Where correction services have been used, the extent and nature of the correction is clearly marked in a footnote(s).

Other sources are acknowledged by footnotes giving explicit references. A bibliography is appended.

Signed

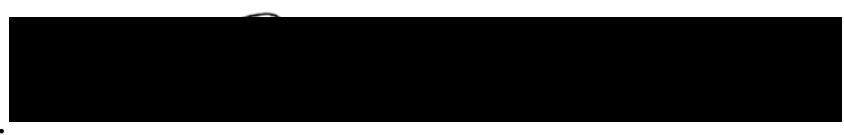

Date

21.06.2021

\section{STATEMENT 2}

I hereby give consent for my thesis, if accepted, to be available for photocopying and for inter-library loan, and for the title and summary to be made available to outside organisations.

Signed

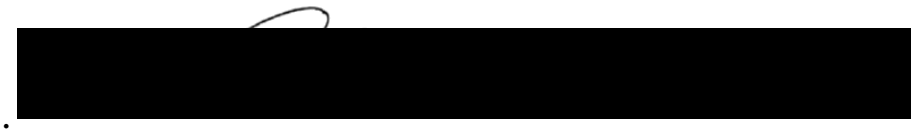

Date

21.06.2021 


\section{Table of Contents}

Declaration/Statements............................................................................................................ii

Acknowledgements .................................................................................................................................. viii

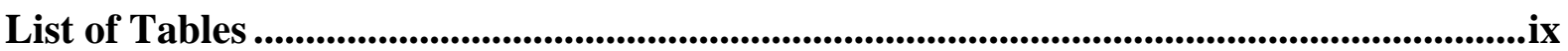

List of Figures..........................................................................................................................................

List of Appendices..........................................................................................................................................ii

List of Abbreviations ............................................................................................................................. xiii

Publications from this thesis ...................................................................................................................

CHAPTER 1. INTRODUCTION..................................................................................................1

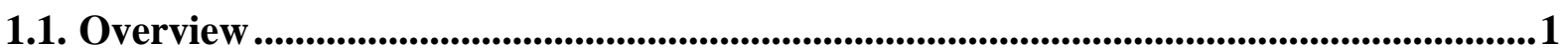

1.2. Introduction.........................................................................................................................................2

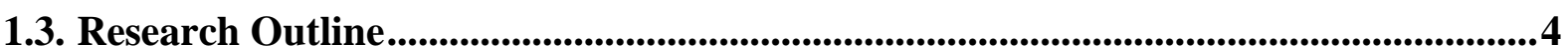

1.4. Chapter Reviews .......................................................................................................................6

CHAPTER 2: SCUBA DIVING TOURISM .........................................................................9

2.1. Introduction to Chapter 2 ...........................................................................................9

2.2. Discovering the Unknown Through Scuba Diving ...........................................................10

2.3. The Economy of Scuba Diving Tourism ................................................................................12

2.4. The Scuba Diving Tourism Experience ...................................................................................14

2.5. Current Issues in Scuba Diving Tourism ............................................................................19

2.6. Summary for Chapter 2 .........................................................................................................20

CHAPTER 3: SUSTAINABILITY IN THE SCUBA DIVING TOURISM .......................22

3.1. Introduction to Chapter 3 .............................................................................................................22

3.2. The Foundation of Sustainable Tourism Development.....................................................23

3.3. The Division of Sustainable Development in Tourism ......................................................24

3.4. The Concept of Sustainable Scuba Diving Tourism Development................................29

3.5. Sustainable Development Practices in Scuba Diving Tourism System........................32

3.5.1. Marine Protected Areas (MPAs) .........................................................................................35 


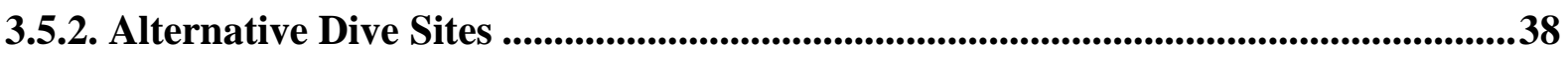

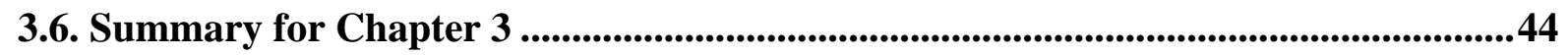

CHAPTER 4: THEORETICAL FOUNDATION.................................................................4

4.1. Introduction to Chapter 4 ....................................................................................................4 47

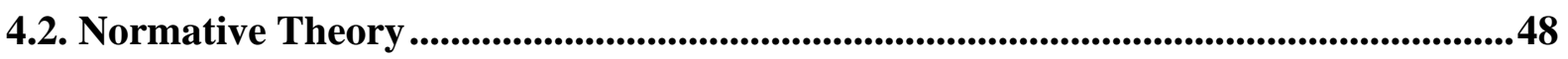

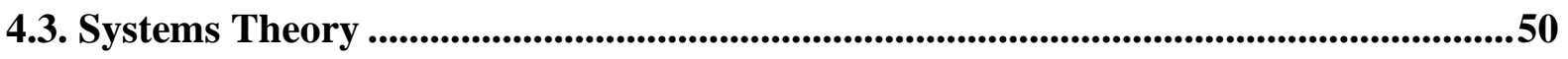

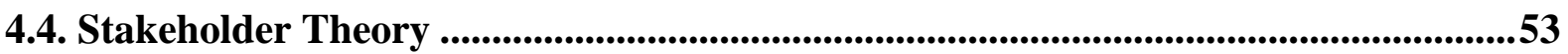

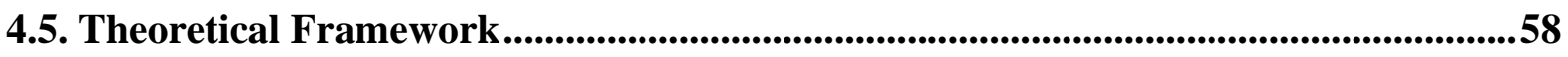

4.6. From Tourism System to Scuba Diving Tourism System (SDTS) ...............................66

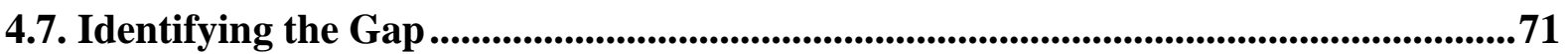

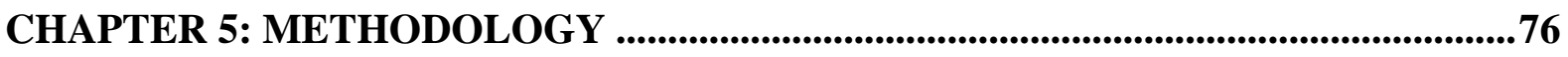

5.1. Introduction to Chapter 5 ..................................................................................................................76

5.2. Philosophical Considerations and Research Framework ..........................................77

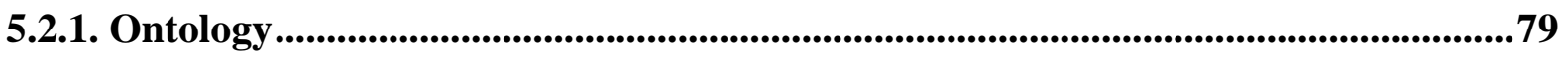

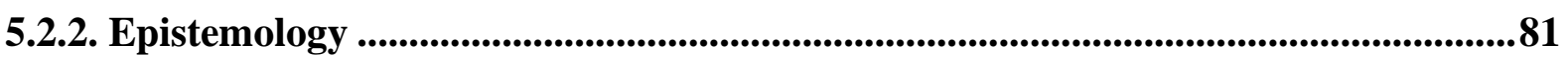

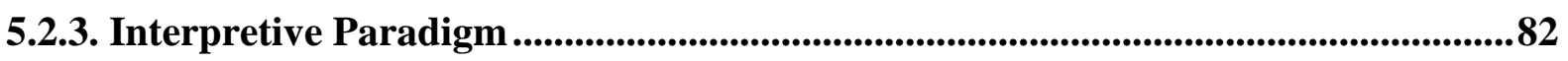

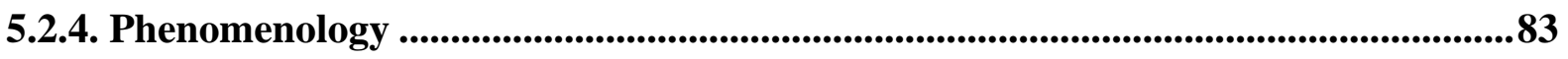

5.3. Research Strategy ...................................................................................................................8 86

5.3.1. Personal Interest and Development Background in Research ................................86

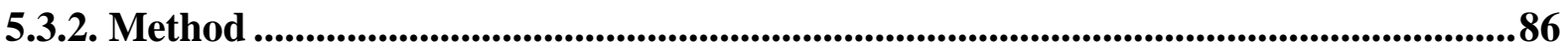

5.3.3. Interviews in Qualitative Methodology.....................................................................89

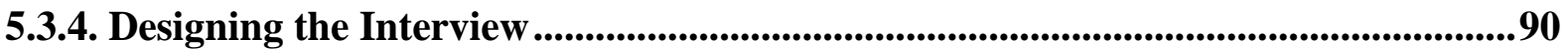

5.3.5. Sampling Method ...........................................................................................................................91

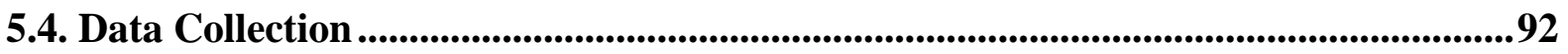

5.4.1. Interviewing Stakeholders..........................................................................................95

5.4.2. Active Participation and In-Situ Observation...........................................................96

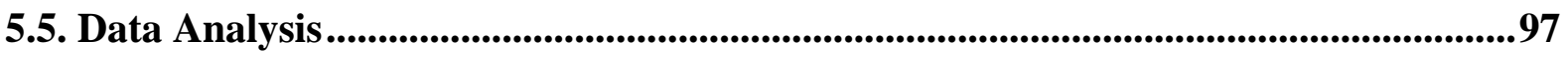


5.5.1. Reliability and Validity .............................................................................................................. 102

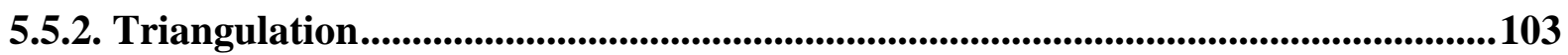

5.6. Research Ethics and Trustworthiness................................................................................ 104

5.6.1. Axiology and Ethics ................................................................................................104

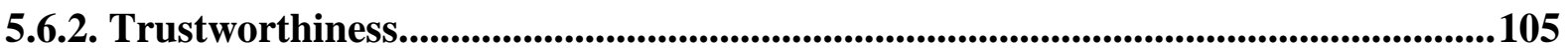

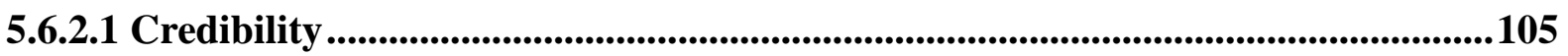

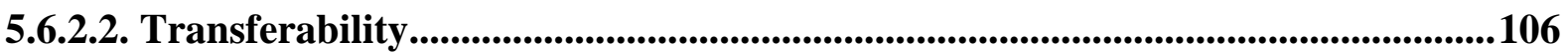

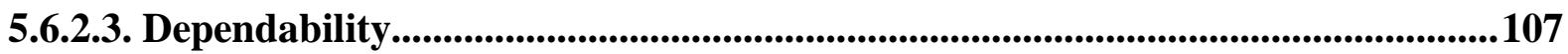

5.6.2.4. Confirmability .................................................................................................................................107

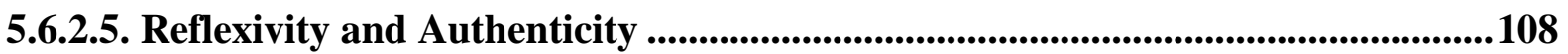

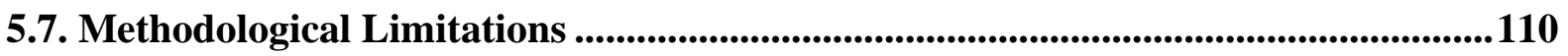

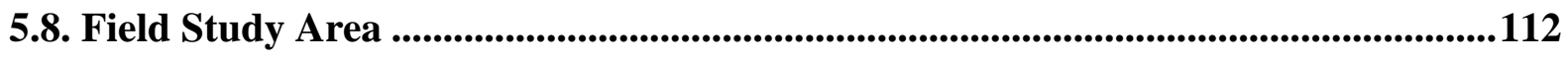

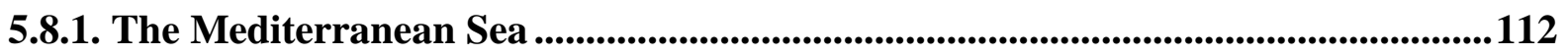

5.8.2. The Maltese Archipelago as Malta..............................................................................114

5.8.3. Scuba Diving Tourism in Malta................................................................................................... 115

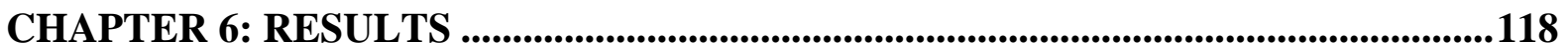

6.1. Introduction to Chapter 6 ................................................................................................118

6.2. Demographics of the Interviewees in This Study .....................................................119

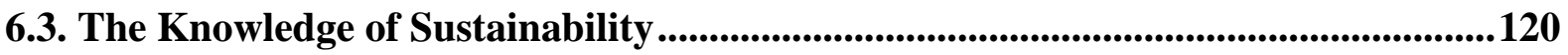

6.4. 5S Thematic Framework of Sustainability (5S Themes) ............................................... 123

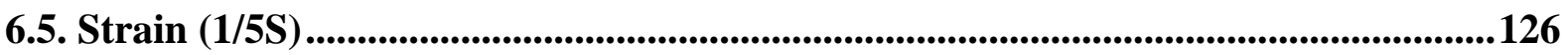

6.5.1 Controversial Threats.......................................................................................................... 127

6.5.2. Lack of Marine Life ............................................................................................................................ 130

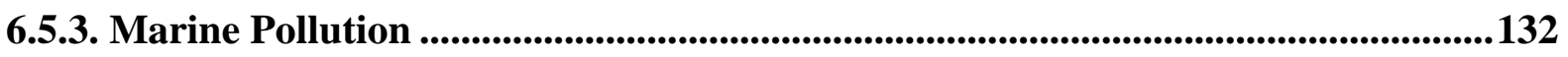

6.5.4. Summary for the Theme of Strain ................................................................................... 135

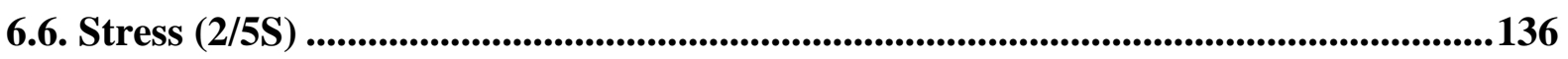

6.6.1. Carrying Capacity and Impacts of Sea Cave and Night Diving.............................136 
6.6.2. Scuba Diving Congestion as Jacuzzi Diving ......................................................................142

6.6.3. Lack of Knowledge About the Marine Ecosystem ....................................................144

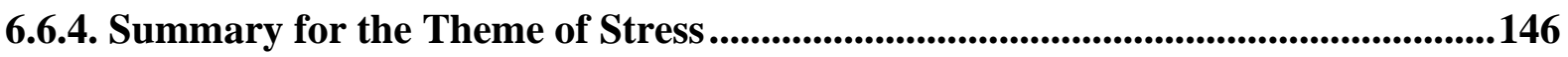

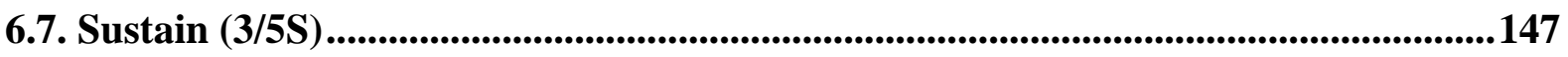

6.7.1. Scuba Divinvestment / Divinfrastructure ..........................................................147

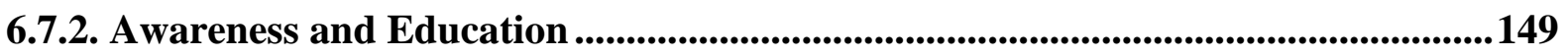

6.7.3. Marine non-Protected Areas (MnPAs) ...............................................................156

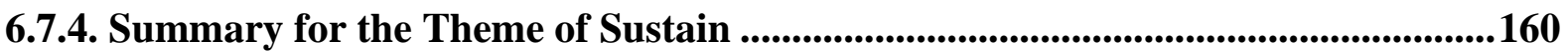

6.8. Supervision $(4 / 5 S)$........................................................................................................................161

6.8.1. Sustainable Practices for Scuba Diving Centres ..................................................162

6.8.2. Power of Pre-Diving Briefings ......................................................................... 165

6.8.3. Safety of Scuba Diving and Alternative Dive Sites .......................................................167

6.8.4. Summary for the Theme of Supervision ..............................................................................171

6.9. Support (5/5S) ................................................................................................................................ 172

6.9.1. The Feature of Alternative Dive Sites ................................................................172

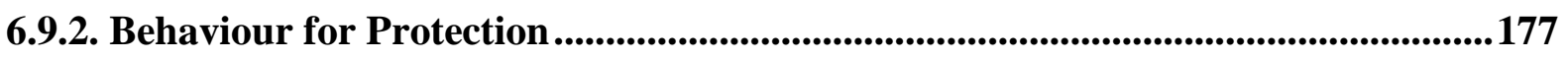

6.9.3. The Future of Scuba Diving Tourism System ..........................................................179

6.9.4. Summary of the Theme of Support .................................................................................. 182

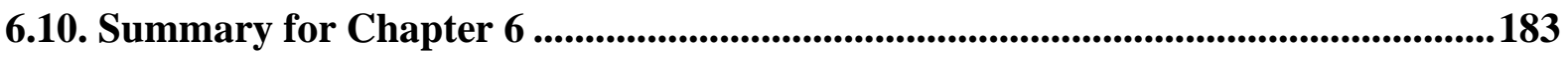

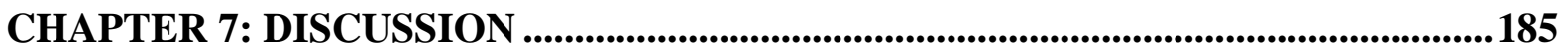

7.1. Introduction to Chapter 7 ....................................................................................................... 185

7.2. General Inferences of Research Findings ..............................................................186

7.3. Summary of Emergent Themes and Links to Literature ............................................... 188

7.4. Constituents and Foundations of the Scuba Diving Tourism System .........................200

7.5. Revisiting Sustainability Criteria in the SDTS ....................................................................203

7.6. The Sustainable Scuba Diving Tourism System (S-SDTS) .......................................208

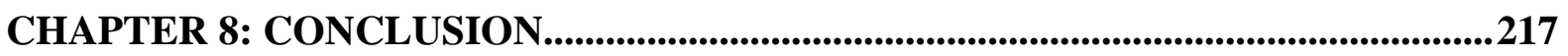


8.1. Introduction to Chapter 8 ....................................................................................................217

8.2. Answers to Research Questions.......................................................................................218

8.3. Philosophical Implications .................................................................................................224

8.4. Theoretical Implications..............................................................................................................225

8.5. Managerial and Practical Implications.......................................................................226

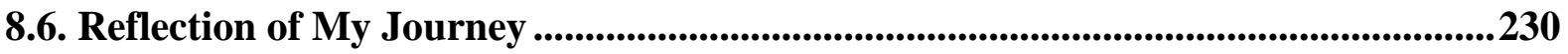

8.7. Limitations of the Thesis and Recommendation for Future Studies ........................231

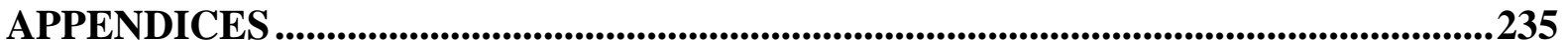

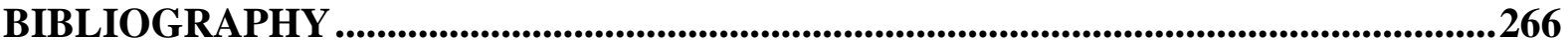

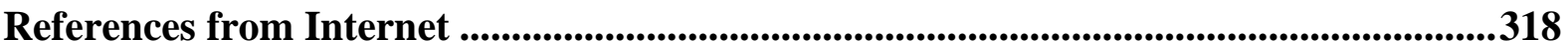




\section{Acknowledgements}

I would like to thank my supervisors, Dr Carl Cater and Professor Brian Garrod. They continuously provided support and encouragement and were always willing and enthusiastic to supervise in any way they could throughout my journey. I cannot thank enough to Dr Carl. He was always with me from the beginning to the end with his sympathy, patience and for his guidance through each stage of the research. He has always been a mentor to me with his attitude and way of understanding the world. I would like to express my gratitude to Prof Brian Garrod, who inspired me to do this thesis; enlightened my research path; supported my academic career.

I would also like to thank the interviewees in this study. Without their help, this thesis could not be completed. From the beginning to the end, they were always eager to share their knowledge and take part in this research in Malta. Special mention goes to Dive Systems Malta, Simon, and Alexia for providing me support and the opportunity to conduct my field research during my time in Malta.

I would like to give my sincere appreciation to my family who was always with me while I was writing this thesis. My grandmothers, Nebahat Bideci and Nurten Fin; my mom, Nuray Bideci; my father, Zeki Bideci; my brothers, Cagdas - Cagatay Bideci; and my eternal supporter Gulay - Can Erguzeloglu and Semra Fin and the rest of my family.

Finally, but by no means least, I dedicate this thesis to my drunk buddy, soulmate, caring and loving, wife, Mujde Bideci. Your encouragement when the times got rough was always there. I could not be here without you. 


\section{List of Tables}

Table 2.1. Studies Related Scuba Diving Tourism Experience .......................................... 17

Table 3.1. Examples Selected Alternative Dive Sites Around the World ..............................42

Table 4.1. Sustainability Criteria in SDTS According to Stakeholder Theory` Dimensions.. 63

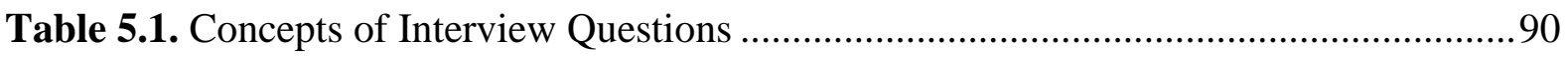

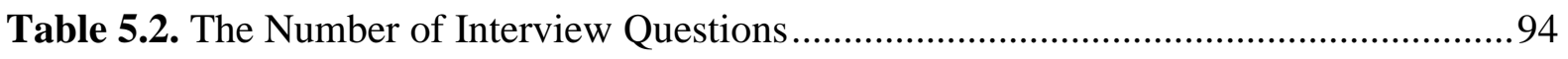

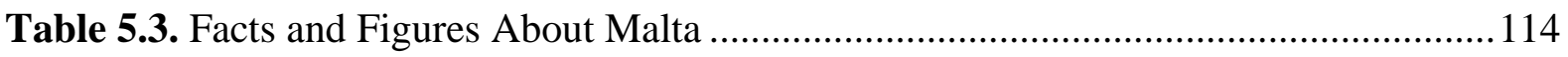

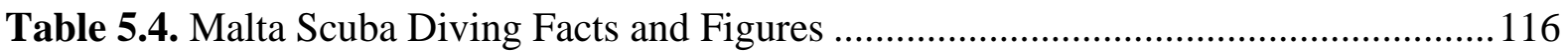

Table 6.1. 5S Thematic Framework of Sustainability in Scuba Diving Tourism System .... 125

Table 7.1. Revised Sustainability Criteria in SDTS According to Stakeholder Theory

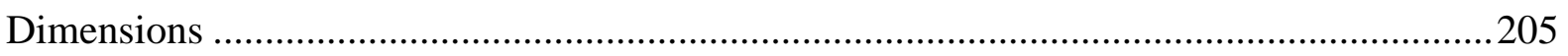




\section{List of Figures}

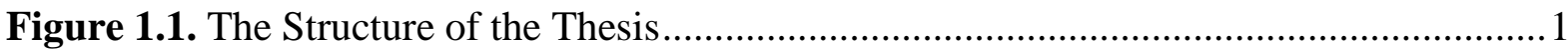

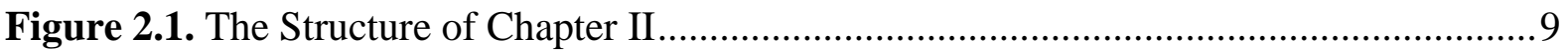

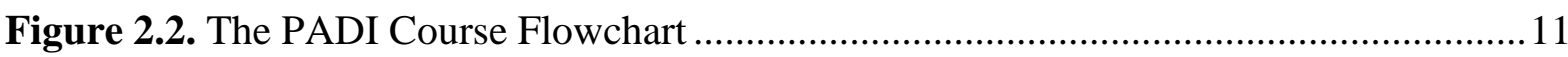

Figure 3.1. The Structure of Chapter III .......................................................................... 22

Figure 3.2. Example of Alternative Dive Sites Around the World ......................................43

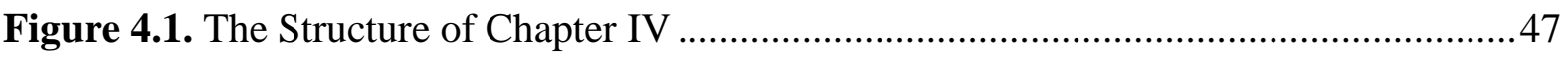

Figure 4.2. Three Aspects of Stakeholder Theory ...........................................................54

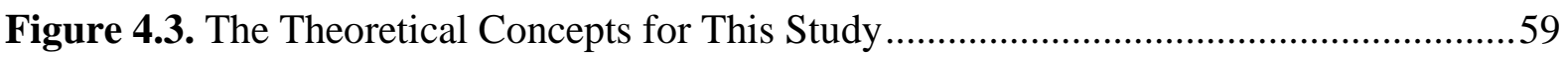

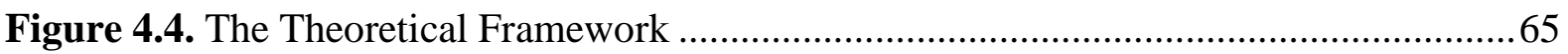

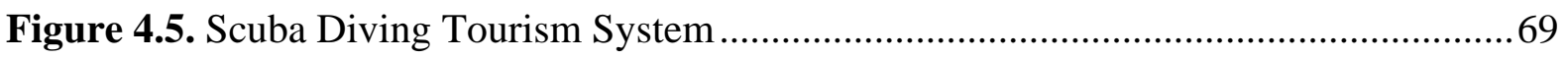

Figure 4.6. Scuba Diving System: Key Elements .......................................................... 70

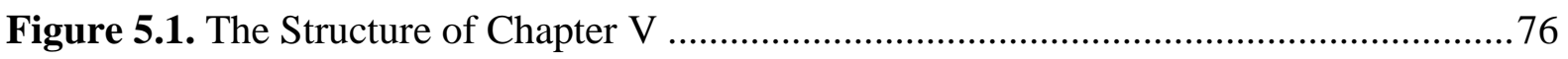

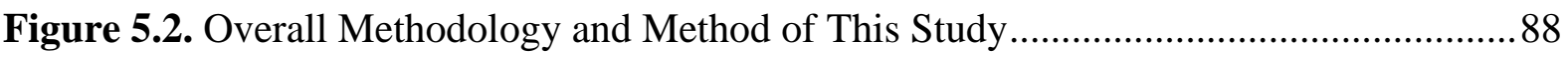

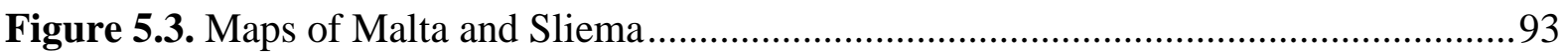

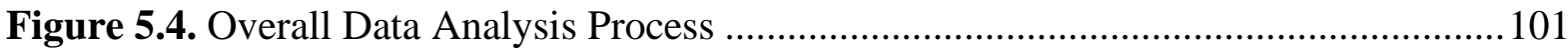

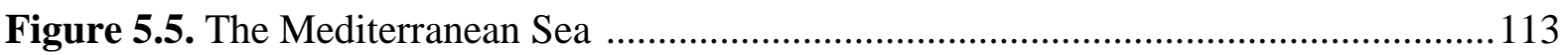

Figure 5.6. Malta, Gozo and Comino Popular Dive Sites................................................. 116

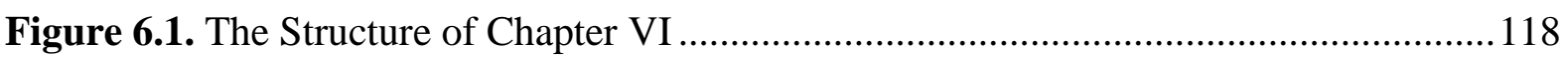

Figure 6.2. Word Cloud of Overall Meaning of Sustainability for Respondents .................121

Figure 6.3. The Garbage Dumps and Marine Pollution in Sliema...................................... 133

Figure 6.4. Recreational' Ashtray at the Front of Scuba Diving Centre .............................. 134

Figure 6.5. Air pockets Caused by Scuba Divers in Caves .............................................. 140

Figure 6.6. Night Diving Issue and Disturbance of the Marine Life ................................... 141

Figure 6.7. Scuba Diving Congestion as Jacuzzi Diving ................................................ 143

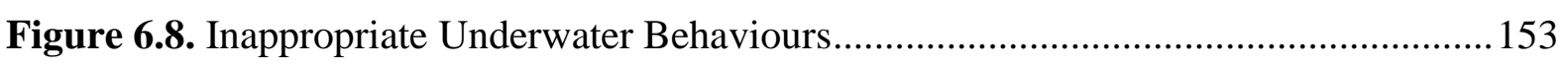

Figure 6.9. Example of Sustainable Practices in Scuba Diving Centre ................................ 162

Figure 6.10. Dive Against Debris Map \& Debris Around Malta............................................ 164

Figure 6.11. Example of Safety Issues About Wreck Diving ............................................. 169

Figure 6.12. Boat Traffic Around Scuba Diver's Entry and Exit Points .............................. 170

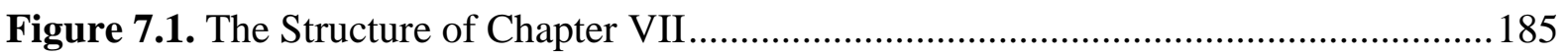

Figure 7.2. Constituents and Foundations of the Scuba Diving Tourism System ................201

Figure 7.3. Sustainable Scuba Diving Tourism System (S-SDTS) ...................................2 212 
Figure 8.1. The Structure of Chapter VIII

Figure 8.2. The End (Patrol Boat P29 -Boltenhagen- in Cirkewwa, Malta).

Note: All photographs taken and figures created by the researcher are subject to copyright. 


\section{List of Appendices}

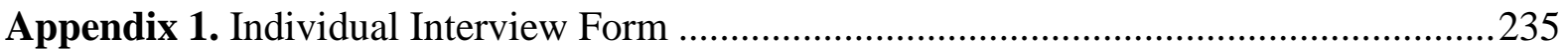

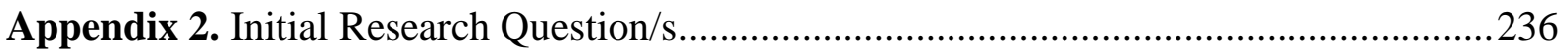

Appendix 3. Interview Questions for Malta Tourism Authority .........................................238

Appendix 4. Interview Questions for Scuba Diving Centres` Owners and Managers .........239

Appendix 5. Interview Questions for Scuba Diving Instructors .......................................241

Appendix 6. Interview Questions for Scuba Diving Interns .............................................242

Appendix 7. Interview Questions for Scholars in Tourism Field ......................................243

Appendix 8. Interview Questions for Scholars in Marine Biology......................................244

Appendix 9. Interview Questions for Scholars in Marine Archaeology ..............................247

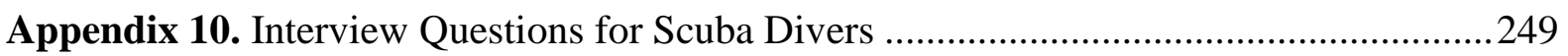

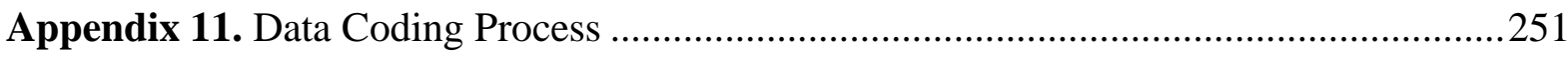

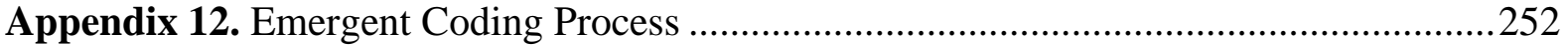

Appendix 13. Malta, Gozo and Comino Popular Dive Sites .............................................253

Appendix 14. Demographic Attributes of Interviewees ..................................................254

Appendix 15. Overall Interviewees`Knowledge of Sustainability .....................................262

Appendix 16. Governance and Enforcement for SDTS in Malta ........................................265 


\section{List of Abbreviations}

\begin{tabular}{|c|c|}
\hline Acronym & Original Name \\
\hline BSAC & British Sub Aqua Club \\
\hline CMAS & Confédération Mondiale des Activités Subaquatiques \\
\hline DAN & Divers Alert Network \\
\hline DEMA & Diving Equipment and Marketing Association \\
\hline DIV & Diver (Scuba Divers) \\
\hline ECOSOC & United Nations Economic and Social Council \\
\hline ERA & Environment \& Resources Authority of Malta \\
\hline FAD & Fish Aggregation Devices \\
\hline FAO & Food and Agriculture Organization \\
\hline GDP & Gross Domestic Product \\
\hline IANTD & The International Association of Nitrox and Technical Divers \\
\hline IMO & International Maritime Organisation \\
\hline INT & Scuba Diving Intern \\
\hline INS & Scuba Diving Instructor \\
\hline IOC & Intergovernmental Oceanographic Commission of UNESCO \\
\hline IUCN & International Union for Conservation of Nature \\
\hline MAR & Marine Archaeologist \\
\hline MBI & Marine Biologist \\
\hline $\mathrm{MCI}$ & Marine Conservation Institute \\
\hline MedPAN & Mediterranean Marine Protected Areas \\
\hline MPA & Marine Protected Area \\
\hline MSP & Marine spatial planning \\
\hline MTA & Malta Tourism Authority \\
\hline NAUI & National Association of Underwater Instructors \\
\hline NGO & Non-governmental organisations \\
\hline NOAA & National Oceanic and Atmospheric Administration \\
\hline NTP & National Tourism Policy \\
\hline OECD & Organisation for Economic Co-operation and Development \\
\hline OECM & Other effective area-based conservation measures \\
\hline OWN & The owner (Scuba diving centre) \\
\hline PADI & Professional Association of Diving Instructors \\
\hline PDSA & Professional Diving School Association of Malta \\
\hline PISCO & Partnership for Interdisciplinary Studies of Coastal Oceans \\
\hline RAC/SPA & Regional Activity Centre for Specially Protected Areas \\
\hline SCUBA & Self-Contained Underwater Breathing Apparatus \\
\hline SDT & Scuba Diving Tourism \\
\hline SDTS & Scuba Diving Tourism System \\
\hline SFIA & Sports \& Fitness Industry Association \\
\hline S-SDTS & Sustainable Scuba Diving Tourism System \\
\hline SSI & Scuba Schools International \\
\hline TUR & Tourism Scholar \\
\hline UK & The United Kingdom \\
\hline UN & United Nation \\
\hline UNDP & United Nations Development Programme \\
\hline UNEP-MAP & United Nations Environment Programme- Mediterranean Action Plan \\
\hline UNESCO & United Nations Educational, Scientific and Cultural Organization \\
\hline
\end{tabular}




\begin{tabular}{ll}
\hline UNWTO & United Nations-World Tourism Organization \\
USA & United States of America \\
WCED & World Commission on Environment and Development \\
WCPA & World Commission on Protected Areas \\
WEF & World Economic Forum \\
WTC & World Trade Centre \\
WTO & World Tourism Organization \\
\hline
\end{tabular}




\section{Publications from this thesis}

\section{Articles in peer-reviewed journals}

Bideci, C. \& Cater, C. (2019). Dive and novelty seeking in experimental artificial reefs, Journal on Tourism \& Sustainability, 3(1), 22-31.

\section{Book chapters}

Bideci, C. \& Bideci, M. (2021). Seeking the unusual but sustainable: Scuba diving experiences. Sharpley, R. (Ed) Routledge Handbook of the Tourist Experience, Routledge, pp. 378390.

Bideci, C. \& Cater, C. (2019). In Search of Underwater Atmosphere: A New Diving World on Artificial Reefs. Volgger, M. and Pfister, D. (Ed) Atmospheric Turn in Culture and Tourism: Place, Design and Process Impacts on Customer Behaviour, Marketing and Branding (Advances in Culture, Tourism and Hospitality Research, Vol. 16). Emerald Publishing Limited, pp. 245-257.

\section{Conference and workshops}

Bideci, C. \& Cater, C. (2019). Dive and novelty seeking in experimental artificial reefs, Sustainable Niche Tourism $10^{\text {th }}$ International Conference, Danang-Vietnam, 26-28 June. 


\section{CHAPTER 1. INTRODUCTION}

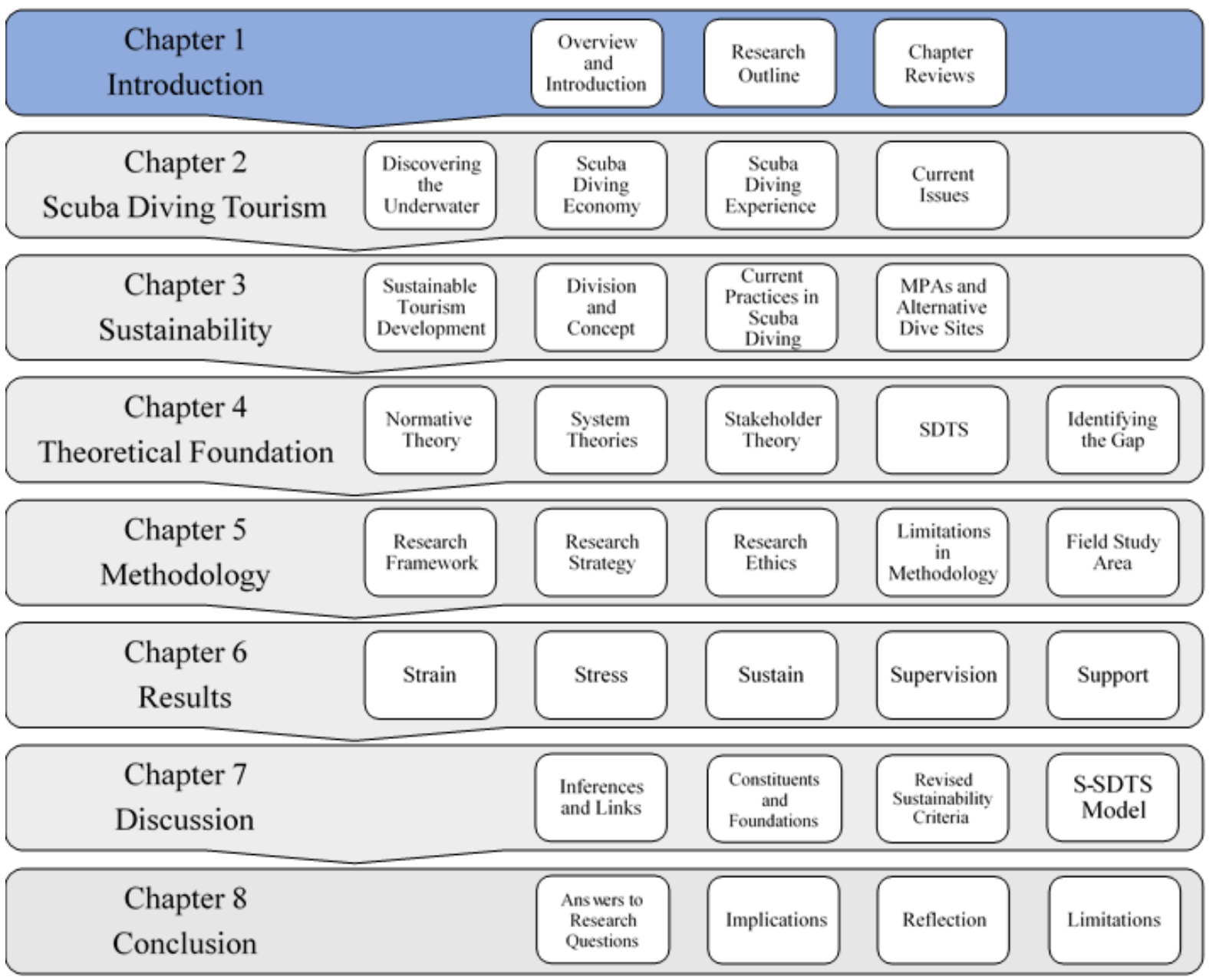

Figure 1.1. The Structure of the Thesis

\subsection{Overview}

This introduction presents the structure of this thesis, the research outline, and the chapter reviews. As can be seen in Figure 1.1, this chapter covers related knowledge and presents the overall insight into the thesis. A general introduction to the research paradigm, the outline of employed theories, methodological approach, research questions and a summary of the literature review will be given in this chapter. The above figure reflects the topic which will be discussed in the chapter. This figure will be seen before starting each chapter and highlighted in lighter blue to help to signal the structure better and join things up into a narrative chain. 


\subsection{Introduction}

Having a diverse marine environment abundant with various species, coral reefs, historical objects (Edney, 2012), mystery and beauty (Edney \& Boyd, 2020) of submerged structures; are the most important factors for scuba diving tourism (Stolk et al., 2005; Uyarra et al., 2009). However, people who intend to have this experience may sometimes cause negative influences on fragile and non-renewable biological, cultural, and artificial resources. Over the last decades, a number of studies found that there are considerable harmful effects on natural assets, fish populations, and habitats like seagrass beds (Posidonia), which are caused by unsustainable levels of activities and behaviour of active participants at scuba dive sites. These negative effects are documented by researchers as intentional contact, breaking the organisms by fins (Terrón-Sigler et al., 2016); intense use of scuba dive sites with less experienced scuba divers (Kirkbride-Smith et al., 2013); unregulated scuba diving activities and inadequate knowledge about the marine ecosystem (Higham \& Lück, 2007; Garrod, 2008). Such stresses on the marine environment are usually caused by individual actions, such as scuba divers`and scuba diving instructors` interventions. In addition to these, unsustainable activities of scuba diving centres and related stakeholders generate negative impacts to the marine surroundings which are derived from boat traffic, anchoring (Lucrezi et al., 2020) or various types of marine pollution. Despite all these negative consequences, creating a system for scuba diving tourism based on principles of sustainability can be a solution to minimise and control the adverse effects; protect the marine environment; and put into practice implementations related to principles of sustainability. Therefore, practices in accordance with principles of sustainability within a systems approach becomes an essential strategy to use this fragile environment while simultaneously protecting the marine surroundings, contributing to local livelihoods, and deriving economic profit.

A system is a complex and broad phenomenon by virtue of each participant and contributor having unique characteristics within the process. In other words, a system has a multifarious social network (Scott et al., 2008) such as both joint relations and mutual interests, alongside different experiences and expectations which add more complexity to the system (Baggio et al., 2010). For this reason, defining the system in a single line becomes difficult (Haywood, 1986). In this sense, a systems approach for scuba diving tourism, by comparison with other types of tourism, depends on different outputs and is constituted by a wide range of factors, including destination structure which provides the unique scene for scuba diving, 
which is the marine surroundings. Along with environmental resources like natural or alternative dive sites, multifarious stakeholders such as scuba divers, scuba diving centres, governments, associations, authorities, non-governmental organisations (NGOs), the host community or local people and interest groups play determining and important roles in the system. Therefore, the relationship among these groups; different interests and expectations; and the decision-making process are derived from various and multiple angles, and all these indicate how a system for scuba diving tourism will be shaped.

Musa and Dimmock (2013) first presented a systems approach for the Scuba Diving Tourism System (SDTS) which explained the components of the system and their relationships (shown on page 69). The three main components of scuba divers, the scuba diving industry and the environment overlap to facilitate the experience. Each constituent has been positioned regarding their level of interaction with each other and the model shows where the collective efforts are situated in the system. However, it is acknowledged that today sustainability is one of the main concerns among many stakeholders (Iniesta-Bonillo et al., 2016; Naidoo et al., 2018; Gerungan \& Chia, 2020). Knowledge and narratives in the sense of moral and ethical values, skills, limits, and practices regarding principles of sustainability are lacking in the existing SDTS proposed by Musa and Dimmock (2013) but included as a mutual interest. In this case, creating or determining the normative aspects of moral and ethical values (which are derived from principles of sustainability as will be indicated in this study) to increase the knowledge and awareness can help stakeholders to understand the system and contribute constructively and effectively to others (who are in the system or who are affected or who are interested in the system) and more importantly to the marine environment. In this sense, this study proposes a systems approach by redesigning the SDTS according to normative aspects based on principles of sustainability to enhance the meaning and functionality of the current system. This study has importance in theoretical and practical contributions by clarifying the existing systems approach and redesigning and categorising the degree of influence of constituents in this system through empirical work. Thus, the main justifications of this study are to develop a theoretical framework for SDTS and create a guideline for practitioners. In a broad sense, it is expected that general principles can be formed, and relations can be developed between the constituents which can lead to creating the values and standards which apply to the system in general (von Bertalanffy, 1949, 1950). By doing so, as Hammond (2002) highlights, these principles also can be used for understanding the concepts, ethical values, and 
models; stimulating groups to originate suitable theoretical models in the system; reducing the time-consuming efforts; and developing unity among stakeholders.

\subsection{Research Outline}

This study sets sight on principles of sustainability in scuba diving tourism to understand the current issues through a detailed examination of the SDTS. Ecological integrity, economic efficiency, and social equity were highlighted by The World Commission in 1987 as the triple bottom line related to achieving sustainability. The triple bottom line was used as the foundation of normative aspects to clarify the main values and the meaning of the SDTS for stakeholders in this research. Therefore, the main research question has been determined as 'to what extent do the normative aspects of the scuba diving tourism system address principles of sustainability? In accordance with this purpose and to illuminate the research phenomenon, as the theoretical background, first, Normative Theory (Jeager \& Sekznick, 1964) is examined to define the meaning of values and principles regarding the SDTS. Normative theory clarifies how values can be created among/for/by stakeholders and in the connection of principles of sustainability and how these values, which stand for the philosophical guideline of the system (Donaldson \& Preston 1995) for people or groups, can be used in the system (Ackerly, et al., 2018). Following this, General Systems Theory (von Bertalanffy, 1949) and Living Systems Theory (Miller, 1978) are employed to set the foundation of the scuba diving tourism system on the basis of principles of sustainability. As pointed out by von Bertalanffy (1972) an object, in this case, the marine environment (a unique living system), should be evaluated in its correlation or connection with the system constituents which originated from individual`s or groups understanding about fundamental values and principles. Therefore, the systems theory explains what the SDTS is; the relationship between the system and the marine environment; and how the system should be. Moreover, Stakeholder Theory (Freeman, 1984) with three grounds (normative, instrumental, and descriptive) indicated by Donaldson and Preston (1995) is taken as a guide to mark out the system values and principles; and is used for identifying the role of stakeholders in the SDTS.

Although the descriptive and instrumental aspects regarding stakeholder theory in the SDTS are well documented in previous papers (Musa \& Dimmock, 2013; Hillmer-Pegram, 2014; Dimmock \& Musa, 2015; Lucrezi et al., 2017; Scholtz \& Saayman, 2018), the current systems approach and practical implications employed by the scuba diving tourism industry 
are not addressing principles of sustainability sufficiently. Therefore, redefining the SDTS model by creating efficient management practices based on principles of sustainability (Dimmock \& Musa, 2015) and new research which employs multiple stakeholders from different perspectives (Lucrezi et al., 2017; Scholtz \& Saayman, 2018) are needed to better understand the uniqueness and sustainability of this activity in the sense of normative aspects. In this connection, what is meant by sustainability in the SDTS becomes the ontology of this study. Besides, what a system is about forms the main philosophical question of this thesis. In what sense and aspects do stakeholders understand the meaning of sustainability defines the main question of normative aspects of sustainability in/of the SDTS. In addition to the main research question, to what extent do the normative aspects of the scuba diving tourism system address principles of sustainability? Five sub-research questions have also been used to reveal the current situation: (1) How do stakeholders understand principles of sustainability in the scuba diving tourism system? (2) How do stakeholders prepare operational plans and provide regulations to manage the system with control activities for the sustainable use of scuba dive sites? (3) How do stakeholders address the triple bottom line of sustainability while interacting with the marine environment within the scuba diving tourism system? (4) How do stakeholders accommodate personal knowledge about principles of sustainability and their skills in the scuba diving tourism system? (5) How do stakeholders recognise the philosophical, theoretical, and managerial cores as the normative aspects of the scuba diving tourism system?

Overall, principles of sustainability are positioned as a fundamental contribution of this study and the core element of the SDTS to provide a new perspective. In this sense, the aim of this study is to redesign SDTS to fulfil the gap in the current literature which rely on the triple bottom line. Thus, the SDTS can be built upon a well internalised common ground to improve the sustainable practices in scuba diving tourism. In addition, creating normative aspects for SDTS which depends on the effective involvement of stakeholders can help authorities to manage the scuba dive sites more efficiently and reduce stress on the marine environment while providing a novel subaqueous scuba diving experience; optimising the economic incentives; and positively contributing to the local life. In line with this purpose, as the methodological background, a phenomenological approach based on qualitative research was adopted in the research by having semi-structured interviews which are examined by thematic analysis. Furthermore, the phenomenon in question is not only examined with scuba divers' perspectives in terms of the activity and future decisions but also with implications that have been driven 
by a range of stakeholders. In this regard, the current Scuba Diving Tourism System (SDTS) is redesigned and transformed based on grounded three groups of theories of this thesis into Sustainable Scuba Diving Tourism System (S-SDTS) following the suggestion by Dimmock and Musa (2015). The new model is presented according to the individual field of specialized knowledge of stakeholders, systems theory and stakeholder theory emphasising the normative aspects. To do this, the structure of this thesis is divided into the following seven chapters which provide a wide knowledge according to the order and course of the important elements to investigate normative aspects based on principles of sustainability in the SDTS.

\subsection{Chapter Reviews}

Chapter 2 Scuba Diving Tourism: This chapter provides fundamental knowledge in order to explore what scuba diving tourism actually is. A historical context, definition and constituents of scuba diving tourism are given in this chapter. The economic importance of scuba diving tourism and the characteristics of the scuba diving experience are also discussed within the course of the literature review. Moreover, this chapter addresses the current issues of negative effects on the marine environment which comes from scuba diving tourism activities and unsustainable practices of associated stakeholders.

Chapter 3 Sustainability in Scuba Diving Tourism: This section presents a framework of principles of sustainability, values, existing practices in scuba diving tourism and possible future implications to minimise the adverse effects on natural and alternative scuba diving assets. While indicating the progress of sustainability in scuba diving tourism, this section also notes details of adverse impacts on marine surroundings to better understand the foundations of sustainable scuba diving tourism development principles and the importance of the marine environment. For this reason, the application of sustainable practices in scuba diving tourism such as sustainable management approaches, Marine Protected Areas (MPAs) with their practical contributions and alternative dive sites are examined as effective ways of implementing principles of sustainability.

Chapter 4 Theoretical Foundation: This chapter aims to provide a set of knowledge of theoretical background for redesigning the scuba diving tourism system according to principles of sustainability through defining the normative aspects. In this sense, Normative Theory (Jeager \& Sekznick, 1964) is used to explain the meaning of the system`s values and principles. 
General Systems Theory (von Bertalanffy, 1949) and Living Systems Theory (Miller, 1978) assess the foundation of the scuba diving tourism system on the basis of principles of sustainability. Stakeholder Theory (Freeman, 1984) based on three grounds (Donaldson \& Preston, 1995) examines how stakeholders can understand and employ values, principles, and codes of conduct into the system. Moreover, the current literature about the scuba diving tourism system (SDTS) is also introduced in this chapter to give an understanding of the research phenomenon in scuba diving tourism. Lastly, this chapter gives an insight into the gap which is identified by the researcher.

Chapter 5 Methodology: This chapter presents an overall methodological insight into this study. In this respect, the methodology of this study is chosen as the phenomenological approach from an interpretive paradigm via evaluation of the current issue in the sense of the qualitative research method. The reason for employing this method is to reveal the understanding of sustainability which are hidden in statements of active participants and stakeholders` knowledge in SDTS. For this purpose, semi-structured interviews with different groups of stakeholders are used to have a better interpretation of the current situation. In addition to this, in-situ observation and personal experience as active participation are used for this thesis to better understand the gaps between the statements and reality. The methodology chapter also emphasises the research questions and steps taken to seek answers. Furthermore, details of the case study area are provided in this chapter. The case study area is determined as Malta which is suited to the research objectives in this study due to varied scuba dive sites, access, and location in the Mediterranean. The study was conducted between July 2019 and August 2019, which was the peak season for scuba diving tourism in Malta, to reach the most diverse scuba divers and have the opportunity to interview all associated stakeholders.

Chapter 6 Results: In this chapter, the outcomes of this study are presented in the 5S Thematic Framework of Sustainability in Scuba Diving Tourism System, in short, 5S Themes. This is a systematic contribution illustrating the key issues facing the implementation of sustainability in scuba diving tourism in Malta. The results were categorised respectively, the strain refers to external impacts to the marine environment that negatively affected scuba diving tourism; stress represents the impacts of the scuba diving tourism industry; sustain explains issues that need to be managed; supervision addresses the required practices; and support provides information about the future of scuba diving tourism in Malta. All themes 
derived from the field study of this research are interdependent in terms of achieving an optimal level of sustainability in SDTS.

Chapter 7 Discussion: In the discussion part, normative aspects of scuba diving tourism are discussed through the research findings and literature review and interpreted over the main outcomes. For example, according to data, abundant marine life; well-managed operations in dive sites and the destination; variety in scuba diving areas; displaying professionalism in guiding; safety measures; offering alternative dive sites; and effective pre-diving briefings are the most important instruments for SDTS to ensure sustainability. This chapter revisits the constituents and foundations of the STDS to have a better insight into the current systems approach. Moreover, 19 new sustainability criteria are added as a result of research findings into the SDTS literature based on descriptive, instrumental and normative grounds of stakeholder theory. Lastly, a new comprehensive and broad systems approach is presented in this chapter named Sustainable Scuba Diving Tourism System (in short S-SDTS) as the main contribution of this thesis. The new model covers different stakeholders and normative aspects for achieving the optimal level of sustainability in scuba diving tourism.

Chapter 8 Conclusion: In conclusion, this thesis summarises the study findings in the sense of the sustainable systems approach in the scuba diving tourism system. In general, this study searches for an answer to the research questions by covering the explanations of S-SDTS and the outline of implications. As a result of this study, the importance of S-SDTS in various ways and contributions are highlighted within the philosophical, theoretical, managerial, and practical implications. Besides the researcher`s own reflection, the limitations of this thesis and recommendations for future studies are given in this chapter. In philosophical implication, this thesis addresses the normative aspects of this study which indicated for S-SDTS. In theoretical implication, this study refers to the three grounded theoretical contributions. In managerial and practical implications, this thesis emphasises recommendations and main implications based on principles of sustainability of practical and managerial contributions to marketers, managers, and decision-makers in the proposed S-SDTS. 


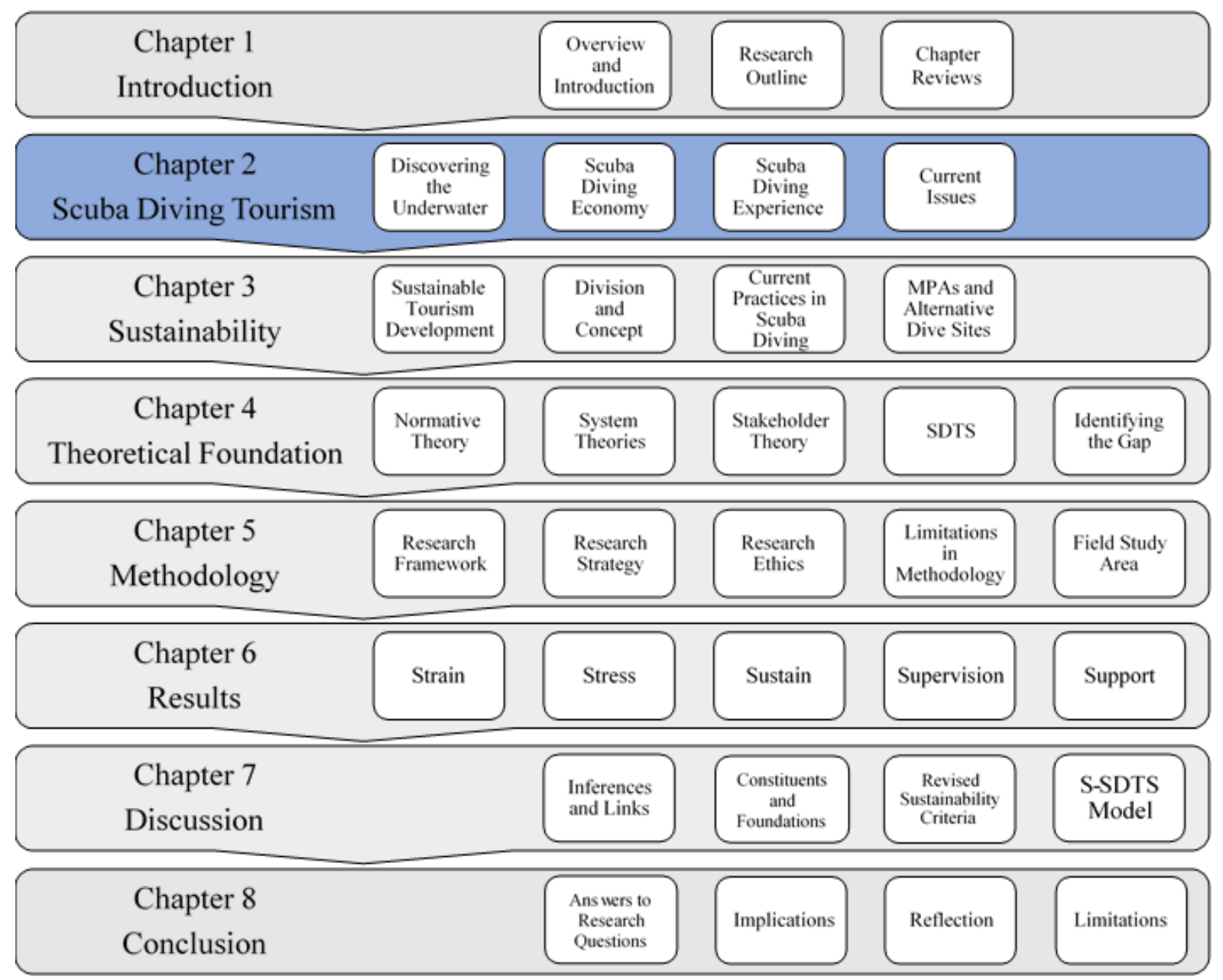

Figure 2.1. The Structure of Chapter 2

\subsection{Introduction to Chapter 2}

Chapter 2 outlines the literature review by picturing the body of knowledge about scuba diving tourism. As can be seen in Figure 2.1, the context addresses an insight to scuba diving tourism with the historical journey; the economy of scuba diving tourism; scuba diving experience; and current issues in scuba diving tourism, respectively. Scuba diving is a naturedependent activity, therefore the marine environment and underwater surroundings become the most important constituents for the scuba diving activity. However, the increasing popularity of scuba diving tourism puts stress on the marine ecosystem. As indicated in Chapter 1, this study aims to redesign the scuba diving tourism system according to principles of sustainability. To be able to create a structured systems approach, first, a better understanding of scuba diving tourism becomes essential to carry out the research. 


\subsection{Discovering the Unknown Through Scuba Diving}

French Navy diver Jacques-Yves Cousteau and French engineer Émile Gagnan in 1943 heralded a new era for underwater exploration via the aqua-lung, best known as 'SCUBA' (the self-contained underwater breathing apparatus). In the decades since the Second World War (Clément, 1996), scuba diving has become a popular recreational activity (Garrod \& Gössling, 2008), as well as offering novel subaqueous experiences, entertainment, and sportive dimensions. In the course of time, through developments of technology (more advanced scuba diving equipment); affordable prices; a revival of interest in underwater exploration; increasing social interaction (using both social and visual media tools); awareness; education; and accessibility has incentivised people to practice scuba diving in many marine environments (Bideci \& Cater, 2019b; Bideci \& Bideci, 2021).

The most popular scuba dive sites are regarded as coral reefs and their surroundings, where the fish populations are abundant and various marine species can be seen, which are largely located in tropical and subtropical waters. These include regions such as the Great Barrier Reef - in Australia; the Coral Triangle - in Southeast Asia; and the Red Sea - in Egypt. At present, at least 91 destinations are promoting their coral reef assets (Dimmock \& Musa, 2015) for scuba diving attractions. Today, there are thousands of underwater places which attract people beneath the water to practice scuba diving, not only in the ocean and sea but also in lakes and rivers (Musa \& Dimmock, 2013); different natural marine sites; wildlife marine (protected) areas; and alternative or planned scuba diving areas like artificial wrecks (Medio et al., 1997; Rouphael \& Inglis, 1997, 2001, Barker \& Roberts, 2004; Rouphael \& Hanafy, 2007); manufactured reefs; marine protected areas (MPAs); and underwater caves for example (Bideci $\&$ Bideci, 2021). More recently, underwater cultural heritage areas such as shipwrecks (such as The Yongala, Australia; Thistlegorm, Egypt); sunken cities (Kekova, Turkey); relics located both in museums and in-situ (Vasa in Stockholm, Sweden or Uluburun and Glasswreck in Bodrum, Turkey); and other human-driven remains (harbours, specific structures) also invite people (Bideci \& Cater, 2019a) for a recreational scuba diving purpose.

In an early definition, Tabata (1989) described recreational scuba divers as those who dive less than 30 metres deep (today the depth ratio is 40 metres for certified recreational scuba divers as advanced open water) and seek diverse marine assets and marine biology (Rouphael \& Hanafy, 2007). Scuba divers are willing to have unusual, natural, historical, and cultural 
experiences (Cater \& Cater, 2007; Dimmock, 2009; Bideci \& Cater, 2019a; 2019b) in pristine natural resources or well-planned underwater marine environments by discovering the unseen, unknown or, in other words, the alien environment. In a sense, scuba divers have been described as a group of people who are "hardy adventurists" (Musa \& Dimmock, 2012, p. 1) or can be defined as "curious borderline" (Scitovsky, 1992, p. XIII). Scuba diving attracts both inexperienced (beginners, novice) and experienced (certified or advanced) participants, from try dives to dive-packers, who travel for scuba diving or doing scuba diving while travelling. As an illustration, according to PADI (2021), -the Professional Association of Diving Instructors, as the largest certifying agency- there are more than twenty-eight million certified scuba divers, which have been issued since 1967, and every year about one million people train to have a certificate for scuba diving. It is estimated that there are at least six million active scuba divers worldwide (DEMA, 2020), and over two and a half million scuba divers in the USA alone in 2019 (SFIA, 2020). This vogue also brings along a diverse range of scuba diving activities and courses from training to certification, such as from open water, night, to technical and adventure diving (e.g., wreck and deep scuba diving) or underwater navigator and advanced rebreather diver, along with different master classes for both recreationists and professionals, as can be seen in Figure $2.2^{1}$.

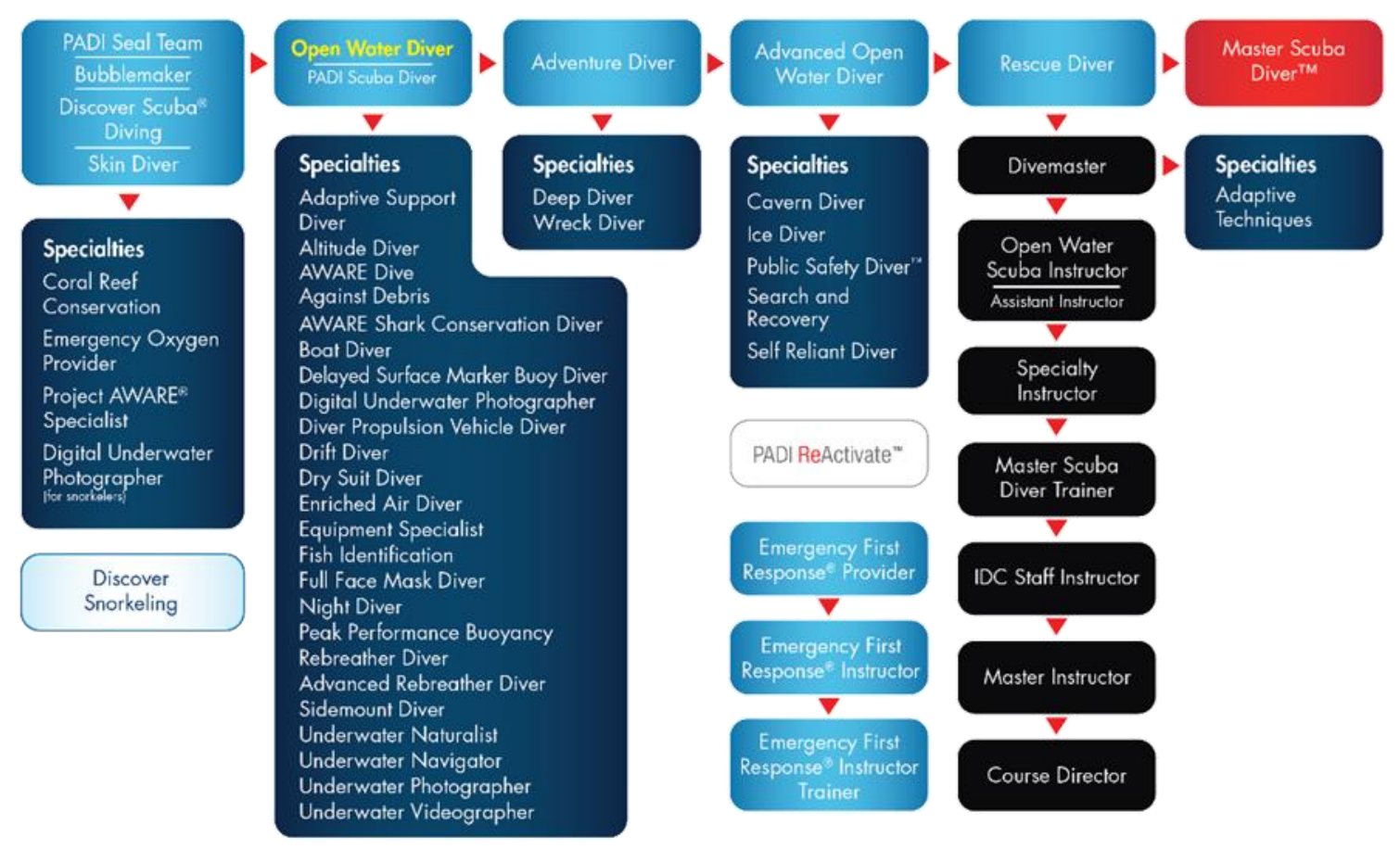

Figure 2.2. The PADI Course Flowchart (PADI, 2021) 
Therefore, the definition of a scuba diver is diverse according to the experience level and specialised attributes. Rather than identifying themselves as an (ordinary) scuba diver, people often tend to introduce themselves with reference to their level of certification or area of specialisation of the scuba diving classes, such as advanced open water; wreck diver; rescue diver; or master scuba diver. In the meantime, destinations set up their marketing strategies according to their specified or specialised type of scuba diving areas. As a result, the popularity of scuba diving has gradually increased by means of a wide range of scuba diving areas with products and services; various marine assets; unique destinations; accessibility; the level of scuba diving; and the number of dives for scuba divers. For a better understanding of the current phenomenon, in this study, it is preferred to use a certain characterisation and description for identifying scuba diving. First, diving can imply quite a few marine or water-based tourism activities such as free diving; Olympic sports (plunging into water); technical diving, ice diving; rescue diving and more. For this reason, scuba diving is used throughout the study as a definition of recreational diving which refers to a touristic or leisure attraction to avoid confusion among these different specifications of the diving types. Because of that diver/s who attend/s this attraction will be defined as scuba diver/s throughout the thesis. On that account, the preferences of recreational scuba divers generate important economic incentives (Spalding et al., 2017; Tynyakov et al., 2017) for local communities and countries`GDP in scuba diving destinations as indicated in the next section.

\subsection{The Economy of Scuba Diving Tourism}

The economic value of marine tourism can be substantial (Cater, 2008). According to Organisation for Economic Co-operation and Development (OECD) (2016), marine and coastal tourism will account for about twenty-six per cent of the total value in the ocean economy by 2030. Today the revenue of touristic activities just in coral reefs, for example, is worth about US\$36 billion in the tourism sector, representing the total of within-country expenditure by both domestic and international tourists (Spalding et al., 2017). This economic scale is constituted by over 350 million people travelling for different purposes to these environments (Oceanwealth, 2020) and provides a lot of benefits for various stakeholders (Anderson \& Loomis, 2011). Within marine tourism attractions, scuba diving tourism is an important source of recurring revenue for countries and one of the fastest-growing recreational tourism activities (Ong \& Musa, 2012; Schoeman et al., 2016), following cruise and coastal tourism developments. In addition to this, scuba diving has contributed to being the third 
greatest driver for coastal tourism destinations, especially in recent decades (Dimmock \& Musa, 2015). Therefore, scuba diving becomes lucrative business for the local economy (Stolk et al., 2007) with accommodation facilities and ancillary services such as transportation; food and beverage; health care (like a decompression chamber for hyperbaric medicine for scuba divers); other businesses such as restaurants; scuba diving gear suppliers; and most importantly along with different levels of scuba diving business centres and schools.

Although some early researchers have defined scuba diving tourism as a `niche market segment (Davis \& Tisdell, 1995; Arin \& Kramer, 2002; Dimmock, 2009) among other tourism types and touristic products, in this day and age, scuba diving tourism with both natural coral reefs and alternative dive sites have turned from a niche market into a billion-dollar tourism industry (Cope, 2003; Hawkins et al., 2005; De Groot \& Bush, 2010; Wongthong \& Harvey, 2014; Lucrezi et al., 2017; Albayrak et al., 2019). Indeed, as Garrod and Gössling (2008) note, in some areas scuba diving tourism may be regarded as a form of mass tourism. As an example, in the Similan Islands (Thailand) the annual revenue of using coral reefs as a scuba diving attraction accelerated more than 20 times from US\$22 thousand to US\$460 thousand between 1999 and 2003 respectively (Tapsuwan \& Asafu-Adjaye, 2008). In Australia in 2015, the total scuba diving spending was AUS\$2.2 billion with a further AUS\$4.2 billion economic contributions (Beaver \& Keily, 2015). In Malta, in 2019, the per-scuba divers' expenditure was $€ 476.44$ while the total income was over $€ 222$ million (MTA, 2020a). In Mexico, the yearly revenue was about US\$725 million, in 2019 (Arcos-Aguilar, et al., 2021).

As an illustration of a different perspective, alternative dive sites such as artificial wrecks and reefs have become major scuba diving attractions in some coastal destinations, especially for those who are interested in having novel scuba diving experiences (Bideci \& Cater, 2019b) as in Australia (Stolk et al., 2005); Barbados (Kirkbride-Smith et al., 2013); Taiwan (Chen et al., 2013); Israel (Shani et al., 2012; Belhassen et al., 2017); Turkish coasts (Genc et al., 2017); Malta (as studied in this research); and the state of Florida, USA (Huth et al., 2015). For example, the economic value of more than 3,330 artificial reefs generates US $\$ 3.1$ billion output from human-driven reef structures in state and federal waters in the state of Florida. These reef constructions provide over 39,000 jobs, accrue US\$1.3 billion in income, and produce US\$250 million in state revenues for Florida and Floridians (Huth et al., 2015) in the sense of tourism, fisheries and other sectors. Within these figures, scuba diving tourism creates over 13,000 jobs, in excess of US\$1 billion output, about US\$417 million income and 
approximately US\$80 million state revenue which constituted over thirty-three per cent income in this coastal tourism economy. Similarly, as Chen et al. (2013) reported, the estimated average consumer surplus around artificial wrecks area in Penghu, Taiwan was about US $\$ 348.5$ per dive. This amounted to US\$52 million yearly revenue according to tourist numbers in the region. This considerable economic role has resulted from unique experiences regarding scuba diving tourism; therefore, the next section provides an insight into scuba diving tourism experiences.

\subsection{The Scuba Diving Tourism Experience}

Before continuing to the scuba diving tourism experience, this study offers a short insight into the general experience phenomenon to better understand the experience context in tourism. In a broad sense, the experience can be a knowledge or practice from the past or present that people perceived, understood, and remember. In this respect, there are a few fundamental questions that need to be asked such as: 'What does experience mean to us?'; 'What do we experience?'; 'How do we have an experience?'; 'Does experience still stand for the experience that we know?'. The phenomenon of experience is to initially try a new thing or something different from daily routines (Pine \& Gilmore, 1998). As Scitovsky (1992) notes, "the chance to try out new things and new sources of satisfaction is a serious matter; indeed, it is essential if society is to make good use of its economic opportunities and growing affluence in its search for the good life" (p. 11). Therefore, trying something new and good and satisfaction out of what we do are significant components of the experience and its economy.

Experience is defined in many ways and has more than one meaning according to different disciplines. For example, experience, in science, refers to universal knowledge for all, whereas a common experience varies from person to person and is distinct to the individual (Walls et al., 2011). From a philosophical perspective, experience expresses personal attitudes and individual's expectations. However, people should experience "the unexpected" which differ from "already known" (Scitovsky, 1992, p. 57). This process can be translated into

getting new "knowledge (common sense)" (Carù \& Cova, 2003, p. 269). However, in the sense of getting an experience, new knowledge requires personal involvement by doing something (new) for a reason which can be actualised through active participation or observation during the events or activities. Moreover, this knowledge can have a characteristic such a unique form and the knowledge can be shaped by (non)controllable variables and personal encounters 
(Pullman \& Gross, 2004), at the exact moment of experiencing. Besides, feelings about the moment are based on the originality of individual sensory perception and varied interests. These variables can be the degree of involvement and interactions; emotions; cultural backgrounds; personality; characteristics; perceived value; and other circumstances (Belk, 1975; Hirschman \& Holbrook, 1982; Bitner, 1992; Schmitt \& Simonson, 1997; Schmitt, 1999; Walls et al., 2011) while having an experience.

According to the aforementioned reference, the definition of the tourist experience is often linked to some degree of out of the ordinary, more specifically, for example, peak experience (Maslow, 1964); the flow experience (Csikszentmihalyi, 1990); the extraordinary experience (Arnould \& Price, 1993; Mossberg, 2008); or the memorable tourism experience (Pine \& Gilmore, 1999; Tung \& Ritchie, 2011; Kim \& Ritchie, 2014) and is shaped by individual encounters with products, services, and businesses. Common characteristics of these definitions of the experience are being sat in planned (business) physical environments. Because service providers have the ability to control the process of formation and delivery of experience/s. In this regard, a tourist can get a positive experience without trying to change the nature of the environment presented to them (Oh et al., 2007) in the sense of the 'esthetic' realm of experience perspective. Therefore, feelings and experiences can have certain features which satisfy the tourists in these controlled and planned environments.

However, when the underwater scenery is taken into account, experience occurs in an unplanned, unknown and mysterious environment. The structure of an experience is affected by not only the personal knowledge, interests and interactions or providing services but also the environment itself and active surroundings as this is in a constant state of flux. From this point of departure, scuba diving experiences can be seen as "dynamic and emergent, not static and discrete" (Kler \& Moskwa, 2013, p. 140) by the reason of taking place in a changing and erratic underwater environment. Even if there are planned underwater scenes such as manufactured reefs or artificial wrecks, the surrounding of the structure can be shaped in various ways, and this can add variety to the perceived experience. Therefore, scuba diving tourism experience or underwater experience should be considered, evaluated, and reinterpreted in its own unpredictable merits and specified dimensions of scuba divers characteristics. These include a great variety of scuba diving motivations and preferences which are shaped by various stakeholders and more importantly the underwater surroundings, as can be seen in the body of current literature. 
Since the 1970s, researchers have studied scuba diving tourism to define the experience characteristics of this activity. According to this trend, early studies were published in the late 1970s regarding the understanding of the perceived risk. Over the following years, experience and motivation have been a dominant point of departure for scuba diving tourism studies. As for the last decade, most researchers have continued interest in scuba divers' behaviours and attitudes. This tendency aligned with the early stage of scuba diving tourism; the rise of popularity of scuba diving tourism and alternative dive sites; and the increase in better understanding of scuba divers` underwater behaviour. The current subjects, in the order of historical trends, are listed below in Table 2.1. All this body of literature is related to the understanding of scuba divers' experience and attitudes towards underwater surroundings. In general, the table can be divided into four parts according to the trends and narratives. In the first part (light blue) from 1979 to 2006 the early body of scuba diving tourism literature was dedicated to identifying the scuba diving tourism and experience of scuba divers. Defining scuba diving tourism; to what extent it is a risky activity; what the main motivations of scuba divers are to participate in scuba diving activities; and the degree of satisfaction was questioned within this period.

The second part (light orange) from 2006 to 2012 was dominated by classifying the scuba divers` attitudes and behaviours in terms of the scuba diving experience. In this period the speciality of the scuba diving experience was considered from different aspects. In the third period (light gold) from 2012 to 2018, the value of the scuba diving experience has been discussed by researchers. The perceived value of the scuba diving experience and in-situ behaviours became the point of departure to better understand the scuba diving experience and its effects on marine surroundings. Moreover, sustainability becomes the main interest of the research on the scuba diving tourism experience in the later periods. As the last part (light green), since 2019 contemporary topics have been started to examine the specific angle of the scuba diving tourism experience. This trend is regarding such as negative issues which affect scuba diving tourism experience in the sense of principles of sustainability; managing the scuba dive sites; understanding of scuba divers` underwater behaviour; scuba diving experience in MPAs; and attractiveness of the alternative sites. 
Table 2.1. Studies Related Scuba Diving Tourism Experience (Adopted by The Researcher)

\begin{tabular}{|c|c|c|}
\hline Author/s & Year & Subject/s \\
\hline Roos & 1979 & Perceived Risk in Scuba Diving Tourism \\
\hline Wilks & 1991 & Risk in Scuba Diving Tourism \\
\hline Todd, Graefe \& Mann & 2002 & Motivation and Skill in Scuba Diving Tourism \\
\hline Meyer, Thapa \& Pennington-Gray & 2002 & Motivation in Scuba Diving Tourism \\
\hline Miller \& Taubman-Ben-Ari & 2004 & Risk-Taking in Scuba Diving Tourism \\
\hline Stolk, Markwell \& Jenkins & 2005 & Perceptions of Artificial Reefs in Scuba Diving \\
\hline Musa, Kadir \& Mann & 2006 & Satisfaction in Scuba Diving Tourism \\
\hline Tschapka & 2006 & Motivation in Scuba Diving Tourism \\
\hline Thapa, Graefe \& Meyer & 2006 & Specialised Marine Based Environmental Behaviours \\
\hline Maccarthy, O'Neill \& Williams & 2006 & Satisfaction in Scuba Diving Tourism \\
\hline Meisel-Lusby \& Cottrell & 2008 & Motivations and Expectations \\
\hline Cater & 2008 & Embodiment in Scuba Diving \\
\hline Dimmock & 2009 & Comfort (Adventure) in Scuba Diving Tourism \\
\hline Musa, Seng, Thirumoorthi \& Abessi & 2011 & Underwater Behaviour in Scuba Diving Tourism \\
\hline Anderson \& Loomis & 2011 & Specialization and Behaviour Norms \\
\hline Szuster, Needham \& McClure & 2011 & Perceptions and Evaluations of Crowding Underwater \\
\hline Ong \& Musa & 2011 & Underwater Behaviour in Scuba Diving Tourism \\
\hline Ong \& Musa & 2012 & Underwater Responsible Behaviour \\
\hline Kler \& Tribe & 2012 & Pursuit in Scuba Diving Tourism \\
\hline Paterson, Young, Loomis \& Obenour & 2012 & Satisfaction in Scuba Diving Tourism \\
\hline Edney & 2012 & Characteristics, Motivations and Attitudes \\
\hline Salim, Bahauddin \& Mohamed & 2013 & Underwater Behaviour in Scuba Diving Tourism \\
\hline Kirkbride-Smith, Wheeler \& Johnson & 2013 & Experience Levels and Perceptions \\
\hline Lamb, True, Piromvaragorn \& Willis & 2014 & The Intensity of Scuba Diving Activities and Damage \\
\hline Toyoshima \& Nadaoka & 2015 & Environmental Briefing and Buoyancy Control \\
\hline Schoeman, Van der Merwe \& Slabbert & 2016 & Perceived Value of Scuba Diving Experience \\
\hline Bentz, Lopes, Calado \& Dearden & 2016 & Motivation and Specialization \\
\hline Kirkbride-Smith, Wheeler \& Johnson & 2017 & Accessing to Artificial Reef and MPAs \\
\hline Huang \& Coelho & 2017 & Understanding of Sustainability Performance \\
\hline Tynyakov, Rousseau, Chen \& et al. & 2017 & Spreading the Pressure on Coral Reefs \\
\hline Naidoo, Ramseook-Munhurrun \& Li & 2018 & Sustainability Based on Online Reviews \\
\hline Mylonopoulos \& Moira & 2019 & Motivation in Scuba Diving Tourism \\
\hline Gregory \& Edney & 2019 & The Mature Aged Female Diver \\
\hline Verkoeyen \& Nepal & 2019 & Response to Coral Bleaching \\
\hline Albayrak, Caber \& Cater & 2019 & Motivation in Scuba Diving Tourism \\
\hline Bideci \& Cater & 2019 & Understanding of Experience in Artificial Reef Diving \\
\hline Lucrezi, Milanese, Cerrano \& Palma & 2019 & Scuba Diving Site Management \\
\hline Dimopoulos, Queiros \& van Zyl & 2019 & Understanding the Risk Impacts in Scuba Diving \\
\hline Bideci \& Cater & 2019 & Scuba Diving Experience in Alternative Dives Sites \\
\hline Brauwer, Gordon, Shalders \& et al. & 2019 & Understanding of Underwater Photography Effects \\
\hline Cater, Albayrak, Caber \& Taylor & 2020 & Satisfaction in Scuba Diving Tourism \\
\hline Brander, van Beukering, Nijsten, \& et al. & 2020 & Scuba Diving Tourism in MPAs \\
\hline Lucrezi, Ferretti, Milanese, Sarà \& Palma & 2020 & Scuba Divers' Underwater Behaviour \\
\hline Giglio, Luiz \& Ferreira & 2020 & Ecological Impacts and Management of Scuba Diving \\
\hline Garcia \& Cater & 2020 & Understanding of the Ocean Literacy \\
\hline Edney \& Boyd & 2021 & Scuba Divers` Behaviour in Wreck Dive Sites \\
\hline Edney, Dimmock \& Boyd & 2021 & Understanding Scuba Divers` Behaviours \\
\hline Edney, Dimmock \& Boyd & 2021 & Wreck Diving Motivation and Attitudes \\
\hline Bideci \& Bideci & 2021 & Seeking Sustainability in Scuba Diving Tourism \\
\hline
\end{tabular}


The scuba diving experience is often described as unique and exciting (Cater \& Cater, 2007; Dimmock, 2009) in the sense of touristic activity. Because of the distinctive underwater natural settings, each dive has a different, special, and unique experience (Kruger \& Jakes, 2003; Kler \& Moskwa, 2013) and offers scuba divers a new knowledge incomparable to the preceding one. From this standpoint, Kler and Moskwa (2013:135) define the scuba diving experience as "positive feelings of excitement, adventure, freedom and relaxation" and "... excitement within limits is pleasant ...” (Scitovsky, 1992, p. 41) which “... clearly play an important role in both focusing our attention and determining the pleasantness of stimulation" (Scitovsky, 1992, p. 45). Therefore, to a certain extent, the scuba diving experience is regarded and perceived as adventurous, thrilling, or unusual. Thus, scuba diving can be an attractive point of departure for excitation within the context of individual experience.

In the opinion of the nature of scuba diving experience, in comparison to other types of adventure sports like surface water sports, paragliding, mountain or rock climbing; scuba divers cannot see what is happening underwater until they actively dive in and become part of the environment, and even then, the range of vision will be limited and indefinite. Moreover, this takes place in an unfamiliar environment and relies on essential life support, which is the air. At the same time, scuba diving offers a kind of free movement against gravity. In aspects of gravity control and aesthetic pleasure (Musa \& Dimmock, 2013), unlike other sports, people can move in three dimensions like a fish or bird (Musa \& Dimmock, 2013), but within the limitation of movement ability and depth. Although human beings have limitations in the underwater environment, scuba diving encourages people to discover the new and unusual. What makes scuba diving special and distinctive is to instigate curiosity with individual values and emotions; to enjoy the sense of wonder in the underwater environment by attributing symbolic meaningful characters through a discover-it-yourself performance which may lead to having a meaning shaped by "personal connection to place" (Kler \& Moskwa, 2013, p. 140); and to have a piece of knowledge about the surroundings by identifying natural scenes and settings, at the same time. In a sense, scuba divers are motivated by searching for difference and a kind of an alien environment for the human race (Cater, 2008), and scuba diving accumulates this attractiveness and novelty by offering a unique experience at every turn. For all reasons above, it can be said that scuba diving is such an activity like provides irresistible attractiveness with learning and being limited in an unknown environment which stimulates the novel subaqueous experience. 


\subsection{Current Issues in Scuba Diving Tourism}

Besides the increasing popularity of scuba diving tourism, over the last decades, studies have shown that there is increasing damage on marine life such as corals, sponges, bryozoans, and gorgonians (Barker \& Roberts, 2004; Chung et al., 2013; De la Nuez-Hernandez et al., 2014) because of intensive scuba diving activities in particular places (Riegl \& Riegl, 1996; Zakai \& Chadwick-Furman, 2002). "The most frequently reported types of diver damage are cumulative effects related to reduction in organismal abundance, body size and colony size, as well as distributional patterns altered from occurrence on exposed reef surfaces to persistence only in cryptic, shaded habitats" (Giglio et al., 2020, p. 4). In addition to intensified activity, willingness to take photography underwater has the potential to cause negative effects which are not originated by specifically photographic flash, but the scuba divers' presence and photography without flash. Moreover, manipulating the marine life, such as feeding the fish during taking a picture, may lead to "chronic stress, increased energy requirements, and reduced fitness in photographed animals" (De Brauwer et al., 2019, p. 7). In a sense, indeed, reducing these unsustainable and inappropriate behaviours depend on interest in learning about the marine environment and increasing understanding which leads to awareness (Chawla, 1998) regarding eliminating the negative influences. Increasing ocean literacy (Fauville et al., 2019; Garcia \& Cater, 2020) and developing responsible underwater behavioural skills for protecting the marine environment (Fryxell \& Lo, 2003) with an empathetic perspective (Hungerford \& Volk, 1990; Halpenny, 2010) on the basis of principles of sustainability can be effective solutions in practice for scuba diving tourism.

Appropriate knowledge plays a key role to reduce negative impacts (Lindsay et al., 2008) and controlling or changing scuba divers` unsustainable behaviours (Cottrell \& Graefe, 1997; Townsend, 2003; Thapa et al., 2005). In addition to this, better knowledge related to the marine environment can encourage scuba divers and stakeholders to develop their skills and use these skills to decrease the detrimental impact of scuba diving tourism activities (Amyx et al., 1994; Huang \& Shih, 2009). The knowledge can also provide motives to protect in a sense of individual degree while increasing positive actions (Huang \& Shih, 2009). For example, the main reason for damage to coral reefs is incompetence and scuba divers` resistance to change their behaviour (Rouphael \& Inglis, 1995; Allison, 1996; Hawkins \& Roberts, 1997; Medio et al., 1997) due to lack of skill or insufficient understanding of the importance of marine environment. However, 45 minutes of theoretical education for scuba divers followed by in- 
water practised performance may help the active participants to reduce their detrimental effects on the marine environment (Medio et al., 1997). In addition to self or intense education, prediving briefings also have a positive contribution to changing scuba divers` behaviour. Instead of one-sentence information (Barker \& Roberts, 2004), like 'do not touch` which has no significant effect, a proper pre-diving briefing can also help to reduce the detrimental impacts of active participation. This is because, educated or informed scuba divers and related stakeholders about the marine environment is more likely to show sympathy for the underwater surroundings (Cheng \& Wu, 2015) and take sustainable self-regulation while participating in the activity (Wurzinger \& Johansson, 2006). In return, participants`actions may become more beneficial rather than becoming detrimental to the environment (Steg \& Vlek, 2009) such as developing the proper sustainable measurement to resolve current problems (Huang \& Yore, 2005; Chao \& Lam, 2011), take safety precautions and develop sustainable implications in the future. Therefore, a better understanding of principles of sustainability becomes the key tool to reduce detrimental effects on the marine environment derived from scuba diving tourism.

\subsection{Summary for Chapter 2}

Chapter 2 introduced an overall insight into scuba diving tourism from the general definitions, economic importance to scuba diving experience. Scuba diving tourism with growing economic incentives provides a contemporary tourist experience for scuba divers while leading people to travel to specific destinations and discover underwater sceneries in unpredictable surroundings. The quality of the scuba diving tourism experience is the most significant element of marine-based tourism destinations (Garrod, 2008), this facilitates an increase in customer satisfaction, as well. Within this process, on the one hand, uncontrollable environmental factors (such as the wind; quality of water visibility; outside and underwater temperature; ocean currents; and fish and marine species encountered) can play an important role. On the other hand, attitudes of the guides, dive instructors and scuba diving centre staff; the trip characteristics; the quality of the equipment; and previous experiences can have an influence on the quality of the scuba diving experience in the sense of individual and external attributes. In combination, scuba diving tourism relies on not only personal characteristics, motivations, and attitudes, but also external environmental conditions such as wildlife, geographic identifiers, limits, and different (interested and associated) stakeholders. Therefore, current numbers and statistics have shown that scuba diving tourism is getting more popular, and destinations invest in this tourism to get economic benefits. However, unplanned scuba 
diving tourism developments; inappropriate on-water or in-water behaviours; and intensifying of the activities with unsustainable management practices put pressure on marine environments and negatively affect the surroundings. As a result of this trend, principles of sustainability in scuba diving tourism have become a major point of departure for researchers, gradually over the last decades. Having sustainable planning, regulations, management, and development can reduce adverse effects, maximise economic profit and provide a unique experience for scuba divers while local people and businesses are benefitting in scuba diving tourism. For this purpose, the following chapter aims to provide the background of principles of sustainability and sustainable development goals in scuba diving tourism. 


\section{CHAPTER 3: SUSTAINABILITY IN THE SCUBA DIVING TOURISM}

\begin{tabular}{|c|c|c|c|c|c|}
\hline $\begin{array}{l}\text { Chapter } 1 \\
\text { Introduction }\end{array}$ & & $\begin{array}{l}\text { Overview } \\
\text { and } \\
\text { Introduction }\end{array}$ & & & \\
\hline $\begin{array}{c}\text { Chapter } 2 \\
\text { Scuba Diving Tourism }\end{array}$ & $\begin{array}{l}\text { Discovering } \\
\text { the } \\
\text { Underwater }\end{array}$ & $\begin{array}{l}\text { Scuba } \\
\text { Diving } \\
\text { Economy }\end{array}$ & $\begin{array}{l}\text { Scuba } \\
\text { Diving } \\
\text { Experience }\end{array}$ & $\begin{array}{l}\text { Current } \\
\text { Issues }\end{array}$ & \\
\hline $\begin{array}{c}\text { Chapter } 3 \\
\text { Sustainability }\end{array}$ & $\begin{array}{c}\text { Sustainable } \\
\text { Tourism } \\
\text { Development }\end{array}$ & $\begin{array}{l}\text { Division } \\
\text { and } \\
\text { Concept }\end{array}$ & $\begin{array}{c}\text { Current } \\
\text { Practices in } \\
\text { Scuba } \\
\text { Diving }\end{array}$ & $\begin{array}{l}\text { MPAs and } \\
\text { Alternative } \\
\text { Dive Sites }\end{array}$ & \\
\hline $\begin{array}{l}\text { Chapter } 4 \\
\text { Theoretical Foundation }\end{array}$ & $\begin{array}{l}\text { Normative } \\
\text { Theory }\end{array}$ & $\begin{array}{l}\text { System } \\
\text { Theories }\end{array}$ & $\begin{array}{l}\text { Stakeholder } \\
\text { Theory }\end{array}$ & SDTS & $\begin{array}{l}\text { Identifying } \\
\text { the Gap }\end{array}$ \\
\hline $\begin{array}{c}\text { Chapter } 5 \\
\text { Methodology }\end{array}$ & $\begin{array}{l}\text { Research } \\
\text { Framework }\end{array}$ & $\begin{array}{l}\text { Research } \\
\text { Strategy }\end{array}$ & $\begin{array}{l}\text { Research } \\
\text { Ethics }\end{array}$ & $\begin{array}{l}\text { Limitations } \\
\text { in } \\
\text { Methodology }\end{array}$ & $\begin{array}{l}\text { Field Study } \\
\text { Area }\end{array}$ \\
\hline $\begin{array}{c}\text { Chapter } 6 \\
\text { Results }\end{array}$ & Strain & Stress & Sustain & Supervision & Support \\
\hline $\begin{array}{l}\text { Chapter } 7 \\
\text { Discussion }\end{array}$ & & $\begin{array}{l}\text { Inferences } \\
\text { and Links }\end{array}$ & & $\begin{array}{l}\text { Revised } \\
\text { Sustainability } \\
\text { Criteria }\end{array}$ & $\begin{array}{c}\text { S-SDTS } \\
\text { Model }\end{array}$ \\
\hline $\begin{array}{l}\text { Chapter } 8 \\
\text { Conclusion }\end{array}$ & & & Implications & Reflection & Limitations \\
\hline
\end{tabular}

Figure 3.1. The Structure of Chapter 3

\subsection{Introduction to Chapter 3}

Chapter 3 presents the foundation of sustainable development in the scuba diving tourism context. Sustainability and sustainable development goals are the core topic of this study because this thesis claims that the best solution to achieve better scuba diving tourism is to be established on principles of sustainability. For this reason, this chapter sets up fundamental knowledge about sustainability in a broad insight to sustainable tourism development; division of sustainable development in tourism; the concept of sustainability in scuba diving tourism; current issues and practices with MPAs; and alternative dive sites as can be seen in Figure 3.1. Through having enough knowledge about sustainable development practices and their implications in scuba diving tourism, stakeholders can support the sector and maintain the benefits. Based on the triple bottom line (environmental, economic, and social) stakeholders can protect the marine environment, ensure the optimal/marginal 
economic benefits and incentives, and improve quality of social life, at the same time. Therefore, it is the aim of this thesis to provide knowledge for stakeholders for having a better understanding of the current phenomenon, developing skills and start acting in accordance with principles of sustainability in scuba diving tourism.

\subsection{The Foundation of Sustainable Tourism Development}

The origin of sustainable tourism development is based on the description of sustainable development as suggested in 1987 by the World Commission on Environment and Development (WCED), Our Common Future or more widely known as The Brundtland Report. This report defines the principles of sustainability through addressing many aspects (Brundtland et al., 1987, p. 43) on a global scale as:

"Sustainable development that meets the needs of the present without compromising the ability of future generations to meet their own needs ... Thus, the goals of economic and social development must be defined in terms of sustainability in all countries - developed or developing, market-oriented or centrally planned".

More specifically, The World Commission (1987) has presented 3 main aspects (also known as three pillars of sustainability or the triple bottom line) to explain the codes and fundamentals of sustainable development concept which are still under discussion:

1. Ecological Integrity: Protecting ecosystem with its biological and genetic diversity.

2. Economic Efficiency: Optimising economic revenue while promoting responsible use of natural resources and eliminating unfavourable practices.

3. Social Equity: Ensuring equal access to resources while taking into consideration protecting culture, heritage, and future generation` needs.

The knowledge of sustainable development outcomes as mentioned above, with the publication of the Brundtland Report in 1987, these three fundamental bases have been taken into consideration to enhance the quality of life for locals; improve economic benefits; and environmentally friendly use principles through comprehensive management strategies all over the world (Simão \& Partidário, 2012, Domínguez-Gómez \& González-Gómez, 2017; Su \& Swanson, 2017). The basic established principles of sustainable development include, as a summary: Economically, the concept of sustainable development at a global scale aims to accelerate the incomes of residents and provide locals with a standard of living. Socially, the 
main aim is to ensure a better life quality for local communities and redress the balance between policymakers and locals. Environmentally, in terms of development, the sustainability approach tries to protect and preserve the natural habitat in areas, where organising and promoting economic activities are active.

\subsection{The Division of Sustainable Development in Tourism}

For the tourism industry, having economic benefits, ensuring social equity, and providing non-consumptive ecological integrity depends on the well-being of the ecosystem is supported by principles of sustainability (Sharpley, 2020). Without a doubt, sustainability is a common interest and benefit to create a better place for everyone (Lindsey, 2011). As a consequence, over the last decades, sustainability has been situated as a core paradigm for the objective of development practices (Lafferty \& Eckerberg, 2013; Sharpley, 2020), especially in tourism. In other respects, however, as Higham and Lück (2007) and Garrod (2008) point out, the level of knowledge in the matter of what sustainability really means is limited, therefore, acting in an environmentally friendly manner has not yet reached a satisfactory level (Passafaro, 2020). Although, there are various definitions with regards to sustainability in tourism research, a new approach that is widely accepted and addresses the fundamental principles of everyone`s requirements need to be revealed and discovered. Since principles of sustainability and its development goals have been still contested and has been employed in tourism research recently, the main principles, codes and knowledge still need to be improved in order to internalise, manage, implement and understand. Therefore, understanding what principles of sustainability are and how they may be achieved in the tourism industry become important dynamics, in terms of producing, managing and consuming (Sharpley, 2020) touristic products or participating in associated activities.

In 2019, global travel and tourism were responsible for 10.4\% of global GDP (US\$9.2 trillion) with $10.6 \%$ of all jobs (334 million) worldwide. The visitor economy reached US\$1.7 trillion which accounted for $6.8 \%$ of total exports, $27.4 \%$ of global exports in services (WTTC, 2021). However, the rapid growth of tourism globally and unplanned mass or intensive other touristic visits brought fundamental questions regarding the destructive impacts on local economies and social life of residents; income distribution and their benefits; cultural backgrounds; and more importantly surroundings of natural environments (Sirakaya et al., 2001; Domínguez-Gómez \& González-Gómez, 2017; Su \& Swanson, 2017). According to the 
United Nations Environment Programme (UNEP) (2015); soil erosion; increasing pollution (air, soil and marine); natural habitat loss; creating more pressure on endangered species; and forest fires can pose a threat to the environment for example. These impacts stand for global issues however, these dimensions such as pollution; negative pressure on species; and loss of habitat are also generated by tourism activities unless it is well planned within a systems approach. A substantial majority of impacts result from unplanned construction and management of tourism infrastructures (Rukuižienè, 2014) and over-incentivised tourism markets, with about 1.5 billion tourists arriving internationally in 2019 (UNWTO, 2020). To set an example, as Lenzen et al. (2018) state, the consequence of global tourism activities and related travel intensity is significant. In 2013 international travel movements caused about 23 per cent of the global carbon footprint of tourism with an estimate of 3 per cent annual growth between 2009 and 2013, and the global carbon footprint of tourism accounted for about 8 per cent of global greenhouse gas emissions.

Besides distressing environmental impacts, unplanned and unsustainable tourism developments induce social inequality; economic disparity and inequality in income distribution; poverty; increasing living expenses for locals; class discrimination among tourists and hosts; and dissatisfaction for visitors at the same time. Moreover, as Rukuižienè (2014) notes that "commodification and cheapening of culture and traditions" (p. 174) increases the imbalance between selective and less popular tourist destinations which may result in losing the cultural identity. To sum up, as UNEP and WTO - United Nations Environment Programme and formerly World Tourism Organisation- (2005, p. 10) identified the negative influences as a result of tourism can:

- "Place direct pressure on fragile ecosystems causing degradation of the physical environment and disruption to wildlife.

- Exert considerable pressure on host communities and lead to dislocation of traditional societies.

- Compete for the use of scarce resources, notably land and water.

- Be a significant contributor to local and global pollution.

- Be a vulnerable and unstable source of income, as it is often very sensitive to actual or perceived changes to the environmental and social conditions of destinations". 
However, if developed from the sustainable tourism development principles, tourism can make a positive contribution to environmental protection, social equality, economic benefits, and increase public awareness, in contrast to these detrimental and negative challenges. Through a collaborative process among governments, stakeholders, researchers, and practitioners, authorities can try to find solutions to eliminate the adverse effects of unsustainable practices (Sheldon \& Park, 2011; Su \& Swanson, 2017) and ensure the marginal benefits by using existing resources. By common consent, the possible solution to ensure marginal benefits and minimise adverse effects is to employ sustainable tourism development principles. For example, as a consequence of raising environmental awareness through tourism (Needham, 2010; Ong \& Musa, 2012; Simão \& Partidário, 2012; Lucrezi et al., 2013; Domínguez-Gómez \& González-Gómez, 2017), global sustainability goals regarding the triple bottom line have been started to apply to tourism destinations in the name of sustainable tourism. According to The World Conservation Union, in 1996, sustainable tourism is defined as environmentally friendly travel patterns and visits to natural and cultural areas while maximising the feeling of enjoyment and appreciation of these resources. This should be conducted in a way that tourism can promote conservation; have a low visitor impact; and provide for local people beneficially active socio-economic involvement by providing benefits for local communities in the destinations. For instance, similarly, UNEP and WTO also identified a few positive influences as a result of tourism which can:

- "Provide a growing source of opportunities for enterprise development and employment creation as well as stimulating investment and support for local services, even in quite remote communities.

- Bring tangible economic value to natural and cultural resources. This can result in direct income from visitor spending for their conservation, and an increase in support for conservation from local communities.

- Be a force for intercultural understanding and peace” (UNEP \& WTO, 2005, p. 10).

The achievement of sustainable tourism development is subject to creating an effective systems approach, especially for the localised level of sustainability. In order to create a suitable balance and ensure long-term sustainability, The World Tourism Organisation (UNWTO, 2013) suggests that sustainable tourism should promote the following three dimensions: (1) Ethical, responsible, and optimal use of ecological resources by maintaining and conservation; (2) respect to social life and the host community; and (3) long-term economic 
and socio-economic benefits to all. Therefore, “... achieving sustainable tourism is a continuous process and it requires constant monitoring of impacts, introducing the necessary preventive and/or corrective measures whenever necessary (UNWTO, 2013, p. 17). In addition to that, sustainable tourism development “... should also maintain a high level of tourist satisfaction and ensure a meaningful experience to the tourists, raising their awareness about sustainability issues and promoting sustainable tourism practices amongst them" (UNWTO, 2013, p. 18). For this purpose, UNWTO proposed an agenda with 12 principles for sustainable tourism development for the future. These are (2013:18):

1. Economic Viability to ensure the viability and competitiveness of tourism destinations and enterprises, so that they are able to continue to prosper and deliver benefits in the long term.

2. Local Prosperity to maximize the contribution of tourism to the economic prosperity of the host destination, including the proportion of visitor spending that is retained locally.

3. Employment Quality to strengthen the number and quality of local jobs created and supported by tourism, including the level of pay, conditions of service and availability to all without discrimination by gender, race, disability or in other ways.

4. Social Equity to seek a widespread and fair distribution of economic and social benefits from tourism throughout the recipient community, including improving opportunities, income, and services available to the poor.

5. Visitor Fulfilment to provide a safe, satisfying and fulfilling experience for visitors, available to all without discrimination by gender, race, disability or in other ways.

6. Local Control to engage and empower local communities in planning and decision making about the management and future development of tourism in their area, in consultation with other stakeholders.

7. Community Wellbeing to maintain and strengthen the quality of life in local communities, including social structures and access to resources, amenities, and life support systems, avoiding any form of social degradation or exploitation.

8. Cultural Richness to respect and enhance the historic heritage, authentic culture, traditions, and distinctiveness of host communities.

9. Physical Integrity to maintain and enhance the quality of landscapes, both urban and rural, and avoid the physical and visual degradation of the environment. 
10. Biological Diversity to support the conservation of natural areas, habitats, and wildlife, and minimize damage to them.

11. Resource Efficiency to minimize the use of scarce and non-renewable resources in the development and operation of tourism facilities and services.

12. Environmental Purity to minimize the pollution of air, water and land and the generation of waste by tourism enterprises and visitors.

It is expected that tourism should contribute positively, equally and be based upon long term sustainable benefits to local, regional, and global economies. To be more precise, UNEP (2014) has identified eight characteristic contributions to ensure sustainable tourism development in the destination. The first one is to adopt sustainability into tourism development by establishing the economic, environmental, and socio-cultural benefits. The second is to contribute to biodiversity conservation by creating communication-based on sustainability knowledge. The third is to sustain the well-being of local people by ensuring both economic and moral values. The fourth is to support people and organisations with a learning experience. The fifth one refers to encouraging responsible actions on the part of tourists and the tourism system. The sixth and seventh are about delivering the products or services primarily to small and medium groups by small and medium scale businesses and requiring the lowest consumption of non-renewable resources. The last one is to stress the local involvement, enterprise, and business opportunities, particularly for less developed regions.

Although, the main purpose of sustainability is well-noted theoretically; in practice; “... it will remain critically important in tourism research as well as reality” (Buckley, 2012, p. 537). However, the perceived success of sustainability in tourism takes months or even years (Cater et al., 2015) in terms of establishing a proper systems approach and implementing this in the destination. The reason is that principles of sustainability refer to long-term establishments (Townsend, 2008), which need to be addressed in many fields by introducing comprehensive, integrated, and collaborative approaches. In addition to this, sustainable tourism development should represent an opportunity to make long-term protection in terms of safeguarding the environment (Buckley, 2012; He et al., 2018); maintaining the economic benefits; and preserving the quality of life for all which has become the most priorities of countries all over the world, for today and the future. Therefore, achieving sustainable tourism outcomes rely on an effective systems approach for planning, policymaking and management that integrates both social and ecological principles (Plummer \& Fennel, 2009; Dimmock \& 
Musa, 2015) by protecting the interests of the local, regional, and global in company with the collaboration of stakeholders.

In brief, sustainable tourism development and its systems approach should encourage possible and practical collaboration (Štetić \& Šimićević, 2008) with authorities to create a fair touristic market and treatment for local people while tourists are willing to use and consume resources during the visits (Jepson \& Edwards, 2010; Jalani, 2012; Curiazi, 2014; DomínguezGómez \& González-Gómez, 2017). Although, unless specifically stated otherwise, tourists and locals might also intend to make tourism more sustainable (Dolnicar et al., 2008; Miller et al., 2010), people are usually unaware of the consequence of unsustainable behaviours (Juvan \& Dolnicar, 2014). Moreover, as Bentz et al. (2016b) state, the lack of an integrated strategy and management for tourism may result in unsustainable development and ultimately cause to loss of future benefits. As a result, lack of manageable protection and little or non-existent sustainable development within the system or systems affects not only tourism prospects but also tourists, guests, and the local environment (Cater, 1995), negatively. A solution offered can be, as a point of departure regarding sustainable tourism development, a systematic approach can be established based on long-term planning, understanding the needs, interests, and value of local communities, and an effective relationship between stakeholders (Salvador et al., 2011). In addition to that, the sense of belonging; shared responsibilities with common resources; and active participation in decision-making (Curiazi, 2014) can all be included in sustainable tourism development principles.

\subsection{The Concept of Sustainable Scuba Diving Tourism Development}

Marine environments are under many threats such as pollution; the danger of extinction of species; and global warming. Specifically, threats are cyclones; high temperatures brought along by climate change; ocean acidification; diseases (Hawkins et al., 1999; Lucrezi et al., 2013); other human-driven factors such as injury, disruption of feeding patterns and mating behaviours of marine species (Hawkins et al., 2005; Thurstan et al., 2012; Bentz et al., 2016b); and trampling on natural resources like coral reefs (Dearden et al., 2007; Roman et al., 2007). Among these threats, human interactions rarely have a significant effect alone, however, cumulatively they become a significant problem (Viduka, 2006). To set an example, coral reefs have been in existence for 225 million years in the Mesozoic era, and some individual coral reefs may be up to 2.5 million years old (Moberg \& Folke, 1999). They have significant 
importance for coastal protection, fish population, recreational use, medicines, biodiversity, and aesthetic value (Bryant et al., 1998). However, rapid coastal development; the addition of nutrients through pollution from recreational crafts (Koop et al. 2001); and feeding fish which introduces extra nutrients into the oligotrophic ecosystem that corals require (while also reducing the number of competing algae and sponges eaten by the fish) (Koop et al., 2001; Ledlie et al., 2007) all impact coral ecosystems. Urban and rural area watershed-based pollution; insufficient marine or coastal management; running out of nutrition and the aquarium trade (Burke et al., 2012; Huang \& Coelho, 2017); garbage disposal (Dearden et al., 2007); boat anchors (Hale \& Olsen, 1993: Dinsdale \& Harriott, 2004); agricultural wastes and wastewater; dense housing; and uncontrolled intensive fishing and recreational activities are other negative impacts on coral reefs. As a result, it is estimated that in the region of 60 per cent of all reefs globally have been adversely affected (Thapa et al., 2005) in this manner.

As (recreational) human-driven impacts, a substantial number of studies have shown that scuba diving activities also have some detrimental effects on the marine surroundings (Dearden et al., 2007) and natural habitats (Ward, 1990; Davis \& Tisdel, 1995; Hawkins \& Roberts,1992, 1997; Hawkins et al., 2005; Uyarra \& Côté, 2007; Ong \& Musa, 2011). These can be actualised in different aspects such as by damaging (Au et al., 2014); increasing the degree of shock and stress (Klint et al., 2012); and causing diseases on natural ecosystems (Lamb et al., 2014) because of deliberate or unknowing contacts. More precisely, for example, losing buoyancy control (direct impact/s) (Rouphael \& Inglis, 2001); inappropriate finning techniques (Thapa et al., 2006); kicking up sediment (directly touching) (Worachananant et al., 2008; Catlin \& Jones, 2010; Camp \& Fraser, 2012); inadequate education or guiding; the use of sunscreens and other personal care products (Danovaro et al., 2008); overcrowding or intense scuba diving activities (Lucrezi et al., 2013); generating waste; damaging both wildlife and vegetation; and disturbing marine life by collecting souvenirs (Su \& Swanson, 2017) are directly related to unsustainable scuba diving tourism practices which have been documented over the last years. Therefore, when engaging in these activities irresponsibly, especially on the basis of actual activity results in destructive consequences due to scuba divers` interventions in the surroundings of the marine environment.

In addition to interfering with natural formations directly, indirect interactions may also cause detrimental effects on the layer of protective marine growth covering which supports marine life, as well as the other submerged or artificial structures (Jewell 2004). As other 
marine attractions such as historic shipwrecks and alternatively manufactured marine inventories are also non-renewable and limited resources they cannot be repaired once damaged (Vrana \& Mahoney 1995; Edney 2016). As Edney (2006) pointed out and Edney et al., (2021) documented recently, exhaled air bubbles accelerate corrosion on the structure surfaces and damage the stability and longevity of the existing ecosystem, both natural and manufactured. Air bubbles, or air pockets, may adversely influence the submerged structure in three ways: damaging the layer of marine growth; removing the protective layer of rust; and accelerating the corrosion rate. However, along with these three threats, air pockets also have negative impacts on marine organisms. This is because air pockets create a shield that is filled with carbon dioxide between the living creature and the water. This layer cuts the link among them and slowly nullify the life source which has settled there. As a consequence, these layers of aforementioned damage may not be significant in the manner of an individual effect alone. However, with the increased intensity of scuba diving activities (Guzner et al., 2010; Lamb et al., 2014) with large numbers of groups of scuba divers in one dive (Szuster et al., 2011) and limited carrying capacity in scuba diving areas (Davis \& Tisdell, 1995) extensive and irreparable damage can result.

As noted above, marine environments are under the pressure of a wide range of natural and anthropogenic threats caused by scuba diving activities and scuba divers' inappropriate behaviours (Hodgson, 1999; Nyström et al., 2000; Chabanet et al., 2005; Fitzsimmons, 2009). On the other hand, many studies suggested that the solution to reduce damage is to put into practice sustainable management principles for scuba diving tourism and implement them in related destinations. Among the wide range of sustainability policies, implementation of a `nouse zone` (Epstein et al., 1999); limiting the number of divers to below the carrying capacity (Hawkins \& Roberts, 1994); pre-diving environmental briefings for scuba divers (Medio et al., 1997; Worachananant et al., 2008; Camp \& Fraser, 2012; Krieger \& Chadwick, 2013); and promoting alternative dive sites like marine friendly artificial reefs can reduce negative effects derived from scuba diving tourism (Polak \& Shashar, 2012). These suggestions aim to ensure both protection of the natural balance, the resource, habitat, cultural heritage, recreation values of marine sites while ensuring better scuba diving experiences (Edney, 2016) with sustainable benefits as implementable management practices. In these connections, the following section indicates current practices related to sustainable development practices based on the triple bottom line implemented in scuba diving tourism. 


\subsection{Sustainable Development Practices in Scuba Diving Tourism System}

Scuba diving tourism gives countenance to support non-consumption uses (Harritott et al., 1997; Fabinyi, 2008; Lucrezi et al., 2013), sometimes called 'green consumption' (Swarbrooke, 1999; Kastenholz, 2004; Budeanu \& Chesworth, 2007; He et al., 2018), which aims to preserve, maintain, promote, respect and improve the quality (Townsend, 2008; De Groot \& Bush, 2010; Mota \& Frausto, 2014; Hillmer-Pegram, 2014; Wongthong \& Harvey, 2014; Dimmock \& Musa, 2015; Lucrezi et al., 2017; Su \& Swanson, 2017) on the basis of the triple bottom line. Ensuring sustainable development in scuba diving tourism systems depends on effective management strategies and practices. However, unattended management implications are not enough to achieve these development goals in the manner of sustainability. Therefore, when managing the scuba dive sites or implementing principles of sustainable development in scuba diving destinations, there is a need for a proper systems approach in terms of adaptive planning, associated enforcement, and continuous monitoring. This is because, achieving sustainable development in such places requires long-term strategies, implementations, and useful outcomes for associated stakeholders along with process assessments in the systems approach.

In this connection, sustainable scuba diving tourism development relies on various strategies and commitments, which require broad and collaborative efforts between the active and associated stakeholders, who are local communities; scuba divers; administrators; institutes; government agencies; organisations or non-profit associations; and scuba diving centres. However, setting up the relationship within the system among these parties is a tough question. For example, $\mathrm{Ng}$ et al. (2017) found out that three groups of scuba diving tourism stakeholders (tourists, residents, and local government) are inclined to accuse each other and hand over the responsibility to another in the aspect of unsustainable practices. On the one hand, local people believe that inappropriate behaviour of tourists such as uneducated scuba diving practices and leaving litter can cause a detrimental effect on coral reefs even if scuba diving is supposed to be a non-consumptive (Lucrezi \& Saayman, 2017) form of marine-based tourism. Therefore, local people accuse scuba divers to make destruction on marine life due to their unsustainable behaviours. On the other hand, tourists think that stakeholders, local people, and government should take more protection measurements in the area. They believe that the responsibility for protection belongs to the local government in the destination ( $\mathrm{Ng}$ et al., 2017). 
With the above-mentioned points, there are some widely accepted applications for scuba diving tourism in terms of sustainable development. However, because of its "strong nature-based orientation" (Stolk et al., 2005, p. 154) with marine surroundings, applying sustainable frames in the scuba diving tourism system is challenging. Practically, existing methods might promote the protection and pursue the balance between the economic benefit and potential ecological threats as a consequence of constant scuba diving tourism activities, such as physical influences and social and economic effects (Seaman \& Jensen, 2000 cited by Shani et al., 2012). Roche et al. (2016) suggest that some precautions can be taken notice of and advised to decision-makers and operators to manage scuba dive sites effectively. One of these solutions is to understand scuba diving tourism development by detailing the characteristics of scuba divers and their motivations (Edney, 2012). Identification of different tourists`motivations can become beneficial for planning, managing, marketing scuba diving tourism (Hvenegaard, 2002) in a particular destination. This can be also a useful method to find the balance between resource capabilities and management interventions (Catlin \& Jones, 2010). For example, prior research has identified the motivations for tourists to go scuba diving are, which is to be found at different stages (Duffus \& Dearden, 1990), such as observing, seeing and exploring the marine life (Ditton et al., 2002; Meyer et al., 2002; Edney, 2012); adventure, excitement, learning, social interaction, fun, escape, relaxation (Dearden et al., 2006; Meisel-Lusby \& Cottrell, 2008; Kler \& Tribe, 2012); social interaction, stature, personal challenge (Todd et al., 2002); enjoyment (Shafer \& Inglis, 2000; Lucrezi et al., 2013); or education, esteem, expertise, escape, and embodiment (Cater, 2008). On the whole, scuba diving motivations vary from person to person and differ according to time, location, season and types of the area.

Understanding the preferences, motivations, and attitudes of scuba divers towards natural and alternative marine resources are important tools for developing effective sustainable management strategies (Uyarra et al., 2009) in the scuba diving tourism system. From a different point of view, scuba divers' motivations also show a tendency to develop their skills because scuba diving requires the skills gained throughout the activity (Cater, 2008) and have a better knowledge of marine environments (Todd et al., 2002; Worachananant et al., 2008; Hammerton et al., 2012). This personal and knowledge development can reduce detrimental effects on the marine environment which are caused by scuba divers' direct interaction (Cater \& Cater, 2007; Worachananant et al., 2008; Lucrezi et al., 2019). Moreover, 
the tendencies of scuba divers are one of the important incentives for sustainable scuba diving tourism development among associated stakeholders. Cater (2008) finds out that there are three antecedents of scuba divers`attitudes, they are personal motivations; seeking memorable scuba diving experiences; and reflections on the social aspects of scuba diving. A better understanding of these three bases of scuba divers` behaviour is also important in the sense of assisting decision-makers to have a comprehensive approach and assessments for the future management plans in scuba diving tourism and associated activities.

Besides understanding scuba divers' motivations and preferences, setting up a guideline or codes of conduct for the in-situ management implications are regarded as useful strategies to ensure sustainable development in such areas. For instance, managing or limiting the access by restricting the number of scuba divers by assessing the carrying capacity at a certain time; regulating the scuba dive sites; and controlling the types of equipment used are the common implications. As a guide, the initiative of Green Fins, which is coordinated internationally by The Reef-World Foundation in partnership with the UNEP can be considered as a useful tool for sustainable development in scuba diving tourism. The initiative aims to maintain and protect marine resources through promoting environmentally-friendly guidelines relating to sustainable practices in scuba diving tourism. Since 2004, initiatives of Green Fins have been adopted by over 550 scuba diving centres worldwide. Fundamentally, this organisation recommends common guidelines as codes of conduct regarding sustainability for scuba diving centres, scuba divers and related parties, like suggested precautions and behaviours provided by Green Fins ${ }^{2}$ for both operators and tourists, from no stepping on coral; no littering; no spearfishing; strategies for mooring; and to join in conversation projects like Project AWARE 3 organised by PADI (which mainly based on active and constant scuba diving against marine debris and fundraising campaigns for the protection of the marine surroundings). In the meantime, there have been a set of suggested methods for controlling the behaviour of scuba divers (Ong \& Musa, 2011, 2012) while interacting with the fragile marine environment, for example, pre-dive briefings or specialised education (Davis \& Tisdell, 1995; Medio et al., 1997; Barker \& Robert, 2004; Worachananant et al., 2008), or creating a reference area (Rouphael \& Hanafy, 2007). The reference area refers to scuba dive sites where the marine life is limited and which can be used to divert scuba divers`attention from pristine areas to such (sacrificial) sites (Pickering \& Buckley, 2003; Fitzsimmons, 2009; Agardy, 2010; Zeppel, 2011; Cheung, 2013), as is known to all in practice. These areas may be used for the scuba 
diving education process especially for those who would like to do scuba diving for the first time and experienced scuba divers who would like to recall their past skills after a long wait.

The other point is that as well as offering restricted access or a limited number of visitors allowed to these sites, applying an admission fee is also considered to manage and protect the areas (Kirkbride-Smith et al., 2016) and to ensure they remain protected as being suitable for the purpose of designation of the site. However, the connection between the personal involvement of tourists and the protection of the natural area (Marine Environment or Marine Protected Areas) is complicated and requires a long-term process for managing such sites. As Fath (2015) and Rodríguez (2017) suggest that understanding the relationships and conflicts between scuba divers` behaviour and protecting the natural resources can help to find an efficient way to manage areals in the sense of the triple bottom line of principles of sustainability. In addition to these, designating Marine Protected Areas (MPAs) inclusive of designed recreational activities and offering alternative dive sites such as artificial (manufactured) structures as wrecks or artificial reefs may provide an advantage to the planned and pre-structured sustainable scuba diving tourism development goals. Moreover, "if the region manages to balance expanding tourism demand with environmental and developmental sustainability it will continue to improve its competitiveness" (WEF, 2019, p. 30). All these strategies can assist authorities to create quite an integrated scuba diving experience sustainably for both tourists and all participants as stakeholders who are involved in this system from scientific research to the marketing field and scuba diving centres (Bideci\& Bideci, 2021). Furthermore, if such MPAs are arranged along with alternative dive sites or appointed selected artificial wrecks primarily as recreational resources (Edney, 2006, 2016) for scuba diving tourism, that can create more effective and adaptive sustainable management implications for such areas. In this connection, the following sub-sections will develop a set of knowledge about MPAs and alternative dive sites.

\subsubsection{Marine Protected Areas (MPAs)}

Countries with coastal areas increasingly try to create sustainable management programmes and strategies for their unique, pristine, and non-renewable natural, cultural and manufactured marine resources. As the United Nations, Economic and Social Council (ECOSOC) indicated the importance of the marine environment, and the protection of these sites have been highlighted in the global Sustainable Development Goals (SDGs). In this scope, 
Goal 14 is dedicated to "Conserve and Sustainably Use the Oceans, Seas and Marine Resources for Sustainable Development". For this purpose, a broadly accepted sustainable and management strategy for these resources is to designate certain marine zones as Marine Protected Areas (MPAs). In the current literature, they have also named no-take zones; marine sanctuaries; ocean sanctuaries; or marine parks according to different terms and conditions regarding the purpose of use or designation of the area. International Union for Conservation of Nature (IUCN) and World Commission on Protected Areas (WCPA) (2018), define MPAs as: "A clearly defined geographical space, recognised, dedicated, and managed, through legal or other effective means, to achieve the long-term conservation of nature with associated ecosystem services and cultural values" (p. 1). As well as protecting the zone is the primary goal, MPAs can be used for other reasons such as replenishing centres for fish and marine populations; fisheries; reducing risk on vulnerable species; and certain scientific purposes.

According to ECOSOC (2019, p. 19), "the global mean percentage of each marine key biodiversity area covered by protected areas increased from 31.2 per cent in $2000 \ldots$ to 45.7 per cent in 2018". However, according to Marine Conversation Institute, currently, $6.4 \%$ global of the ocean is protected with only $2.7 \%$ is fully protected (MCI, 2021), and within these figures, only $1.89 \%$ is covered as no-take MPAs (IUCN, 2021). Within these areas, the Mediterranean Sea has a considerable number of protected zones. On the authority of MedPAN (2019, p. 53), "there are 1215 MPAs in the Mediterranean Sea, all designations combined, covering $171,362 \mathrm{~km}^{2}$ or 6.81 per cent of the Mediterranean Sea"4. This is still increasing as of 2020 there are 1231 MPAs and OECMs covering 179,798 $\mathrm{km}^{2}$ which places a surface of 7.14 per cent of the Mediterranean Sea.

The benefits of protected marine environments depend on their reliable conditions with diverse natural areas, healthy wildlife, and nature and authentic or enriched cultures (Leung et al., for WCPA, 2018). Besides, understanding of sustainability in the use of marine environments has largely remained limited in terms of aquaculture and fish production; preserving genetic resources; protecting the scenic area; planning and recreational use of coastal areas; and enjoying the natural heritage. Therefore, MPAs can establish a balance in order to optimal benefit between users of these areas and the protection of the marine environments, within the limits such as carrying capacity or restriction of uses. The balance can be aimed to maintain, restore, and sustain the biodiversity of marine surroundings in a more efficient way. In this sense, for example, providing protection advantages (Selig \& Bruno, 
2010; Johnson \& Sandell, 2014; Leenhardt et al., 2015), increasing the size and biomass of fish species (Varkey et al., 2012; Caselle et al., 2015; Sciberras et al., 2015) have been observed in MPAs. The benefits from MPAs are listed as (1) protection of marine ecosystems (Hoyt, 2018); (2) replenishment of fish and biomass (Hoyt, 2018); (3) climate control and carbon storage (WCPA, 2018); (4) reducing the risk of natural disasters and protecting coastal areas with its population (WCPA, 2018); (5) restoring the marine ecosystems (Hoyt, 2018), marine organisms, marine diversity and abundance (Kelleher \& Kenchington, 1992; Jones, 1994; Gubbay, 1995); (6) protecting historical, cultural or other human-driven areas (WCPA, 2018); (7) promoting education (Bennett et al., 2017) and research (Ballantine, 1999); and (8) benefiting economically from tourism, recreational and other activities (WCPA, 2018), which around 1.4 and 2.7 times higher than their costs (Brander et al., 2020).

MPAs can offer direct and indirect benefits for individuals, communities, and societies (Torland et al., 2015; Moyle et al., 2017). For example, in Vanuatu MPAs provide benefits for the local community through creating tourism businesses (Pascal et al., 2018). In general, MPAs in Pacific Islands provide benefits to local people while improving economic incentives like fisheries; ensuring better governance of the area and community organisation by strengthening integration, resilience, security and health facilities; creating alternative livelihoods where local people can gain from social, educational, and cultural benefits; and contribute to empowerment for women through the development of the tourism (Bennett \& Dearden, 2014). From an economic perspective, by 2015, there were over 17,000 MPAs all over the world (Thomas et al., 2014) which generate between 150,000 and 180,000 jobs and around US\$930 billion in economic benefits (Brander et al., 2015). This unity-in-diversity within one designated area may help to create and sustain not only a protected environment for the marine ecosystem but also economically and socially sustainable tourism development in the long-term at both local and global scales. MPAs may, therefore, become a key weapon to achieve a global marine conservation strategy in sustainable scuba diving tourism development goals. As a matter of fact, scuba diving tourism practices in MPAs can provide a fundamental form of the protected marine environment in the destination and encourage residents and visitors to make an effort for conservation through connection with values that are the case. 


\subsubsection{Alternative Dive Sites}

The massification of recreational scuba diving activities has brought negative impacts, but at the same time has had a positive effect on protecting the marine environment (Bethencourt et al., 2018) and helped to create public awareness against the unsustainable use of this kind of reserves. As a result of this increasing demand and attention towards environmental issues, management strategies of quite a few scuba diving areas also have given rise to creating alternative dive sites, in a variety of ways. In addition to having experimental and observational positive outcomes derived from management practices in MPAs, alternative dive sites can also provide sustainable tourism development standards for scuba diving tourism. Such alternative dive sites like `artificial underwater scenery` (Van Treeck \& Eisinger, 2008) can enhance and improve the sustainable principles of recreational scuba diving (Stolk et al., 2007) and be a good example and practice for promoting sustainable tourism management within the scuba diving tourism systems approaches.

The term alternative dive sites refer to structures that are placed or sunk underwater artificially or unintentionally. They can be found as a human-created underwater structure or sunk due to unfortunate events such as war, storms, or headed to misled routes. They are called artificial reefs, manufactured reefs, or artificial wrecks. An alternative dive site can be found in the form of historic objects like shipwrecks (Lück, 2008) or designed and manufactured for different purposes, such as artificial wrecks or artificial reefs for scuba diving attraction. For example, as Cater and Cater (2007, p. 55) note "an alternative resource that is seeing increasing intervention and development in order to reduce pressure on natural reefs is that of artificial reefs". In general, alternative dive sites have significant potential to increase the biodiversity of habitats around where they are placed (Pickering et al., 1999). By composing shelter for fish and other marine species and replicating certain characteristics of a natural reef as 'new reefs ' (Stolk et al., 2005) they can help to form new reef organisms. They can also substitute for coral reefs to reduce damage to natural resources (Toyoshima \& Nadaoka, 2015).

From a socio-economic aspect, alternative dive sites attract people to visit and create a marine tourism demand, which may mean marine conservation and promote more scuba diving areas within the destination. This provides a subaqueous scuba diving attractiveness that may be available with a great variety of benefits. Scuba divers prefer to go scuba diving into specific areas where there are the best possible biological diversity and natural resources can be seen. 
As Kirkbride-Smith et al. (2013), Tynyakov et al. (2017) and Edney et al. (2021) mention, scuba divers would prefer to do scuba diving in alternative dive sites areas because of the concentrated and planned opportunity to view underwater marine life and increased photographic opportunities. Alternative structures can originate from a wide range of materials such as historically sunken objects; from 3D printing technology-based advanced materials and obsolete; now-defunct or non-commercial ships, vessels, wrecks, or other end-of-life vehicles; iron, wooden, concrete (also known as bio-rock or reef ball in the literature); and even generated from human remains ${ }^{5}$. Whether being artificial or historically sunken wrecks or other types of alternative forms, they are particularly useful for creating and promoting scuba diving tourism. In a broad sense, alternative dive sites can be used for promoting new economic areas for local people; creating new job opportunities; helping to create sustainable management practices for marine areas; encouraging new research areas for the scientist and educational institutes; creating attractions for underdeveloped areas; addressing new tourism products; and reassuring to protect cultural heritage and history (to a certain extent).

Alternative dive sites are usually located somewhere with easy to access positions, within the limits of recreational scuba diving which are up to 40 meters deep (unless specifically designed for technical scuba diving). In terms of recreational use, they offer themed and intensive scuba diving experience (Shani et al., 2012; Kirkbride-Smith et al., 2013; Tynyakov et al., 2017; Bideci \& Cater, 2019a) providing an area or scuba diving attraction where is a lack of natural coral reefs. In many destinations, where the sea temperature is average or cold (not a suitable fertile environment for natural coral reefs habitat), authorities try to set up new businesses for tourism and create new scuba dive sites around such alternative structures which are sunken deliberately or historical (Cater, 2008). In addition to their feature of scuba diving attraction, artificial reefs or wrecks areas are also used for both consumptive (like fisheries) and non-consumptive purposes (such as snorkelling, swimming, kayaking, sailing, scientific research and motor boating). In terms of scientific, practical, and planning perspectives, they also offer well-protected marine biodiversity (Garcia \& Barreiros, 2018) with fish and another marine creature abundancy in the sense of environmental benefits; effective nature conservation tools, centre for feeding, and shelter for reproduction (Jensen et al., 2020). These types of structures often supply a resource-efficient substratum, like a foundation stone, in unused habitats that were previously and relatively unproductive or had poor natural resource development. An artificial structure is gradually colonised by plant and 
animal communities resembling those of a naturally occurring reef. They can adapt themselves to create a diverse range of biota (Cater, 2008) and have formed a planned area that accelerates wildlife within natural settings (Stolk et al., 2007). These sites can act like Fish Aggregation Devices (FAD) and increase fish abundance (Rountree, 1989; Schneider et al., 2021; Vivier et al., 2021). In return, all these positive contributions increase scuba diving opportunities with a novel subaqueous experience around the sites with an aesthetic pleasure for scuba divers.

On the one hand, a world of culture resides underwater (Smith \& Couper, 2003). According to UNESCO (2021), it is estimated that over 3 million undiscovered shipwrecks are spread across ocean floors around the planet. Of all the types of underwater cultural sites and historic shipwrecks represent one of the most important historic underwater values in terms of their number; naval history (e.g., Ships from both World War I and II); size (e.g., Titanic); and variety with cultural richness (e.g., Ancient or Hellenistic). Shipwrecks are important not only for the vessel itself but also for their cargo and in some cases the human remains (UNESCO, 2001) and they are considered as `time capsules`(Clément, 1996). Historic shipwrecks are found underwater for many reasons such as misadventure, storms, war, or unknown causes. For whatever reason it might be, they have significance in their cultural values which include their archaeological, social (Craig, 2015), anthropological, historical, cultural values (Edney, 2012) and natural assets, as well. Like one a popular scuba diving spot, 100 years old example shipwreck in the Red Sea known as Kingston Shipwreck, along with the archaeological site, is home to different creatures and simulates features of the natural reef structure (Perkol-Finkel et al., 2006). Therefore, exploring shipwrecks provide local economies with significant revenue in the global tourism share (Edney, 2012). Moreover, As Jewell (2004) states Underwater Cultural Heritage sites are noteworthy not only as a good example of a sustainable management system in-situ for the protection of cultural heritage but also for the tourism economy.

On the other hand, the other form of the alternative dive sites is (manufactured) artificial wrecks and artificial reefs which can be found or created ubiquitously in any kind of water such as salt and fresh waters, deep or shallow water, tropic, or polar regions and even on and under the mainland (Edney, 2017). They offer an alternative, authentic, cultural, and historic experiences (Van Treeck \& Schuhmacher, 1998; Edney, 2006; Edney, 2016; Edney, 2017) with economic benefits to businesses, organisations (Edney \& Howard, 2013; Edney \& Spennemann, 2014) and the destinations. The increasing rate of alternatively submerged structures challenges countries to develop new methods of using them as a touristic attraction, 
more precisely as scuba diving areas. These days, alongside a wide range of alternative dive sites, artificial reef and wrecks types, there are also commercial and scientific underwater facilities such as underwater hotels (Manta Resort in Zanzibar; Atlantis the Palm, Dubai), underwater cultivation of plants like a farm (Nemo's Garden), underwater wineries (Edivo, Croatia; Crusoe Treasure, Spain), underwater restaurants (Under, Norway; Ithaa-Conrad, Maldives) or underwater research lab like Aquarius Reef Base (run by NASA in the USA) in onshore and offshore coastlines all over the world.

Today, there are hundreds of different marine parks and alternative areas like underwater sculpture parks (in Grenada) or reef ball areas (in Maiden Island, Antigua), which have created an artificial reef structure, as can be seen in Figure 3.2. These are used for different purposes such as creating a marine area for training (Garrod \& Gössling, 2008); sometimes for implementing coastal defence (López et al., 2016); or establishing scuba diving tourism areas, over the last five decades as can be seen in Table 3.1. Among these alternative dive sites structures, artificial wrecks are drawn significant attention in order to appeal to tourists and manageability by authorities. Therefore, in accordance with this trend, recently, there is a popular trend in many destinations to sink underwater shipwrecks to use for recreational purposes (Fabi et al., 2015). Artificial wrecks can offer scuba divers interesting, challenging, diverse (Edney, 2017), accessible, attractive and safe scuba diving experiences. These sites are novel settings in natural underwater environments (Stolk et al., 2007) with some picturesque opportunities (Edney, 2006) that change over time. Moreover, scuba divers can observe natural effects on these objects; discover unseen mysteries; and see an abundance of marine life inhabiting wreck areas. Scuba divers prefer to do scuba diving besides their structural value, for their distinct wildlife (Edney, 2012) and diversity of marine life (Viduka, 2006) that is offered as a place of interest. Ustica - Italy; Angra - Azores / Portugal; Cayman Islands; Queensland - Australia; Oahu - Hawaii; Bali - Indonesia; Salt Islands - British Virgin Islands; The Yongala - Australia; Sharm El Sheikh, Thistlegorm, Shark and Yolanda Reef - Egyptian the Red Sea; The USAT Liberty - Bali / Indonesia; President Coolidge - Vanuatu; The Zenobia - Cyprus; Blockship Tabarka, Scapa Flow, Orkney - Scotland; Fujikawa Maru -Chuuk Lagoon, San Francisco Maru - Truk Lagoon / Micronesia; Hilma Hooker - Bonaire; HMS Hermes - Sri Lanka can be given as examples of most popular alternative scuba diving areas and their environments around the world. 
Table 3.1. Examples of Selected Alternative Dive Sites Around the World (Compiled by the researcher)

\begin{tabular}{|c|c|c|c|}
\hline Name & Structure & Location & Year \\
\hline Biorock & Construction & Different Locations & Since 1979 \\
\hline Oro Verde & Ship & Cayman Islands & 1980 \\
\hline High Island A389A & Oil Platform & Gulf of Mexico, USA & 1981 \\
\hline The Cedar Pride & Ship & Aqaba, Jordan & 1985 \\
\hline Thunderbolt & Ship & Florida Keys, USA & 1986 \\
\hline Rainbow Warrior & Ship & Cavalli Islands, New Zeland & 1987 \\
\hline USCGC Duane & Ship & Florida Keys, USA & 1987 \\
\hline YO 257 & Ship & Hawaii & 1989 \\
\hline Wreck Alley & Ships & San Diego, USA & 1992 \\
\hline HMCS Chaudiere & Ship & British Columbia, Canada & 1992 \\
\hline Reef Balls & Construction & Different Locations & 1993 \\
\hline Juan Escutia & Ship & Mexico & 1996 \\
\hline M40 - Royal Jordanian & Tank & Gulf of Aqaba & 1999 \\
\hline Imperial Eagle & Ship & Gozo, Malta & 2000 \\
\hline Redbird & Subways & Cape May, New Jersey & 2001 \\
\hline The Spiegel Grove & Ship & Florida Keys, USA & 2002 \\
\hline MV Dania & Ship & Mombasa, Kenya & 2002 \\
\hline Gran Roque & Ship & Guabina Bay, Venezuela & 2003 \\
\hline The Scylla & Ship & Cornwall, England & 2004 \\
\hline HMNZS Wellington & Ship & Wellington, New Zealand & 2005 \\
\hline The Oriskany & Ship & Pensacola, Florida, USA & 2006 \\
\hline James Caudle Memorial Reef & APCs & Myrtle Beach, South Carolina & 2006 \\
\hline Texas Clipper & Ship & South Padre Island, Texas & 2007 \\
\hline Tamar Reef & Construction & Eilat, Israel & 2007 \\
\hline Liberty & Ship & Protaras, Cyprus & 2007 \\
\hline Neptune Memorial Reef & Sculpture & Key Biscayne, Florida, USA & 2008 \\
\hline Bass Grounds & Subways & Ocean City, Maryland & 2008 \\
\hline Redbird Reef & Subways & Delaware & 2008 \\
\hline Blackfish Bank Reef & Subways & Chincoteauge, Virginia & 2008 \\
\hline TCSG-117 & Ship & Side, Turkey & 2008 \\
\hline Gen. Hoyt S. Vandenberg & Ship & Florida Keys, USA & 2009 \\
\hline Tugboats & Ship & Key West, Florida, USA & 2009 \\
\hline Dakota Plane & Plane & Kas, Turkey & 2009 \\
\hline The Silent Evolution & Sculpture & Cancun and Isla Mujeres & 2010 \\
\hline T-69 Armored & Tanks & Gulf of Thailand & 2010 \\
\hline HTMS Sattakut & Ship & Koh Tao, Thailand & 2011 \\
\hline Kiitiwake & Ship & Cayman Islands & 2011 \\
\hline TCSG 119 & Ship & Kas, Turkey & 2011 \\
\hline Temple Adventures & Construction & India & 2012 \\
\hline MBARA & Construction & Mexico Beach & 2013 \\
\hline Hermenegildo Capelo & Ship & Portugal & 2013 \\
\hline Nemesis II & Ship & Protaras, Cyprus & 2013 \\
\hline Koh Tao Reef Cubes & Construction & Gulf of Thailand & 2015 \\
\hline HMCS Annapolis & Ship & British Columbia, Canada & 2015 \\
\hline Kyrenia & Ship & Agia Napa, Cyprus & 2015 \\
\hline USS Clamagore & Submarine & Florida Keys, USA & 2018 \\
\hline MV Anina & Ship & Grenada, Caribbean & 2018 \\
\hline
\end{tabular}




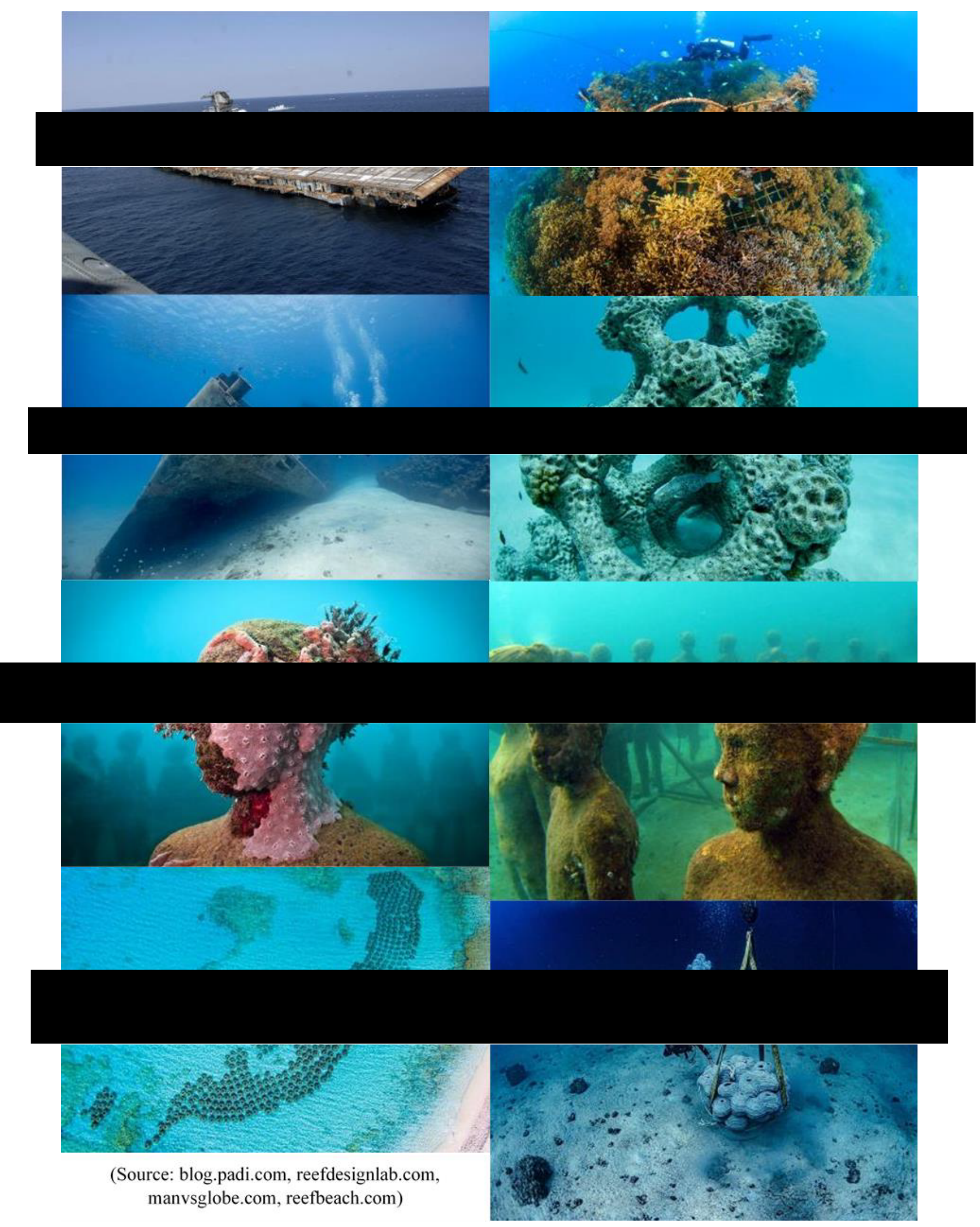

Figure 3.2. Example of Alternative Dive Sites Around the World (The Last Date Accessed to The Sources: 18.05.2020) 
Artificial wrecks are usually considered environmentally safe and environmentally friendly in comparison with the historic wrecks from conflict or marine disasters, which could be a significant source of pollution to the marine environment (Monfils et al., 2006). To mitigate these risks, before being sunk as artificial wrecks, vehicles are technically purified from hazardous chemicals such as oil, fuel, acid, and other components, and controlled for the environment in terms of safety. However, using wrecks as scuba diving attractions has some safety risks (Fabi et al., 2015) which need to be carefully considered before sunken or opening to recreational scuba diving activity. In terms of accessibility, there are needs for planning such as regulating the entry and exit points, providing an opportunity of going inside, consideration of potentially harmful sharp materials, whether the structure itself purifies chemicals or release poison, and deployed position. For example, as happened in Queensland, Australia (HMAS Tobruk in July 2018), if the scuttled object is sunk incorrectly, it may be limited for scuba divers, cause a safety issue, and minimise the possibility of invading habitat ${ }^{6}$. Besides being sunk the wrong way around, poorly planned artificial reef areas can cause adverse effects on natural habitats as happened in Florida with 700,000 artefacts and in Cape of Antibes and the Lérins Islands France with 25,000 old rubber tires or tyres as debris. Eventually, it emerged that they were causing detrimental effects on the marine environment due to releasing toxic ingredients and causing pollution ${ }^{7-8}$ and later began a process to remove from the seabed. In this sense, all categories of alternative dive sites should be created and operated in accordance with the material itself; the feature and characteristics of the area where will be deployed; depth; surrounding underwater habitat; the life cycle of the foundation structure; possible risk; unforeseen circumstances; and sustainable management plans according to positive and negative aspects of the present and prospective implications. Otherwise, each one of the uncared steps or process can cause detrimental effects and unwanted consequences, while trying to protect the area or minimise the risks.

\subsection{Summary for Chapter 3}

As a means of sustainable scuba diving tourism development strategies, countries have an expectation to create reasonable solutions to diminish detrimental effects on the marine environment; improve the quality of social life; and maintain economic profits (Dearden et al., 2007; Blancas et al., 2010; Blancas et al., 2011; Lozano-Oyola et al., 2012). Implementation of principles of sustainability in such touristic markets and tourism systems can be recognized and taken into consideration as an important position in the future long-term tourism 
development that is necessary to ensure in-situ protection and preservation of common values at the destination. From the viewpoint of tourism and touristic purposes, alternative dive sites and MPAs can create significant social and economic values. For example, diving in MPAs or artificial wreck diving opens access for scuba divers to understand inimitable natural reserves in-situ (Edney, 2006; Edney, 2012) which are (re)created by underwater marine environments. These alternative dive sites can move away from negative effects of scuba divers from fragile marine environments (Polak \& Shashar, 2012; Kirkbride-Smith et al., 2013; Belhassen et al., 2017; Tynyakov et al., 2017), provide sustainable management (plan) for natural marine environments and raise the satisfaction of scuba divers (Anderson \& Loomis, 2011). In other words, by means of promoting alternative dive sites and MPAs, stakeholders can develop their learning capacity through the observational or experimental processes, and this can provide marine-oriented management cores for the system which also represent the sustainable development standards (Bideci \& Cater, 2019b; Bideci \& Bideci, 2021). Moreover, while increasing the ecological integrity with developing awareness, these such sites can stimulate economic benefit by offering novel and 'magic' atmospheres (Bideci \& Cater, 2019a).

However, the attitudes towards marine protected areas/environments and alternative dive sites may differ according to the interests of stakeholders, such as universities, research institutes, other institutions, tourism authorities, media partners, marine biologists, tourism scholars, local people, scuba diving businesses, scuba divers and other types of tourists (Stoep et al., 1997). Fundamentally, the different interests depend on the amount of benefit for each side. For this reason, having the aim of better understanding of different perspectives (Cater et al., 2015) can become a key to addressing solutions for using these resources, repairing natural marine resources, and preserving marine life, as well as trying to be implementing sustainable tourism principles in scuba diving practices. With this design, the scuba diving tourism system/s should be well-conceived in accordance with sustainable development, and strategies should focus on addressing the interest of stakeholders, meeting the needs of tourists, and keeping the experience of scuba divers at a certain level (Dimmock \& Musa, 2015). In this sense, for the scuba diving tourism system the main theme of sustainable tourism development is to identify and sustain economic benefits for tourism systems without sacrificing any revenues by putting initiatives and precautions to mitigate adverse environmental impacts into practice. In addition to this, sustainable development in such areas should aim to preserve natural and cultural resources for local people, current tourists and future generations of both 
residents and tourists (Dolnicar et al., 2008) and maintain the future viability of tourism as an incentive-based conservation mechanism (Dearden \& Manopawitr, 2011; Augustine et al., 2016). Therefore, the concept of the sustainable scuba diving tourism system in terms of ecological integrity can be identified as recognising the significance of natural resources and artificial attractions; creating conditions for the preservation of these areas in the future (Girard \& Nijkamp, 2009); and aiming for the least distortion of the natural resource base.

In this connection, a sustainable systems approach that is well-planned with an equal extent of involvement and integration including stakeholders, communities and capacity of local resources can help to ensure sustainable developments for the better (Chaperon \& Bramwell, 2013; Canavan, 2016). Addressing gaps and understanding the current phenomenon, implementation, and management may not be the only way to look at a solution for protecting the marine environment. However, successful management and enforcement policies within the sustainable systems approach may ensure optimal developments of these sites. For this reason, a broad systems approach with the combination of normative theory and stakeholder theory, as will be indicated in the next chapter, can become an efficient and effective method to supervise these easily damageable scuba diving areas both for maintaining ecological reserves and promoting sustainable scuba diving tourism practices by meeting stakeholders` interests and addressing local communities` needs. 
CHAPTER 4: THEORETICAL FOUNDATION

\begin{tabular}{|c|c|c|c|c|c|}
\hline $\begin{array}{c}\text { Chapter } 1 \\
\text { Introduction }\end{array}$ & & $\begin{array}{c}\begin{array}{c}\text { Overview } \\
\text { and } \\
\text { Introduction }\end{array} \\
\end{array}$ & $\begin{array}{l}\text { Research } \\
\text { Outline }\end{array}$ & $\begin{array}{l}\text { Chapter } \\
\text { Reviews }\end{array}$ & \\
\hline $\begin{array}{c}\text { Chapter } 2 \\
\text { Scuba Diving Tourism }\end{array}$ & $\begin{array}{l}\begin{array}{c}\text { Discovering } \\
\text { the } \\
\text { Underwater }\end{array} \\
\end{array}$ & $\begin{array}{c}\text { Scuba } \\
\text { Diving } \\
\text { Economy }\end{array}$ & $\begin{array}{c}\text { Scuba } \\
\text { Diving } \\
\text { Experience }\end{array}$ & $\begin{array}{l}\text { Current } \\
\text { Issues }\end{array}$ & \\
\hline $\begin{array}{c}\text { Chapter } 3 \\
\text { Sustainability }\end{array}$ & $\begin{array}{c}\text { Sustainable } \\
\text { Tourism } \\
\text { Development }\end{array}$ & $\begin{array}{l}\text { Division } \\
\text { and } \\
\text { Concept }\end{array}$ & $\begin{array}{c}\text { Current } \\
\text { Practices in } \\
\text { Scuba } \\
\text { Diving } \\
\end{array}$ & $\begin{array}{l}\text { MPAs and } \\
\text { Alternative } \\
\text { Dive Sites }\end{array}$ & \\
\hline $\begin{array}{l}\text { Chapter } 4 \\
\text { Theoretical Foundation }\end{array}$ & $\begin{array}{c}\text { Normative } \\
\text { Theory }\end{array}$ & $\begin{array}{l}\text { System } \\
\text { Theories }\end{array}$ & $\begin{array}{l}\text { Stakeholder } \\
\text { Theory }\end{array}$ & SDTS & $\begin{array}{l}\text { Identifying } \\
\text { the Gap }\end{array}$ \\
\hline $\begin{array}{c}\text { Chapter } 5 \\
\text { Methodology }\end{array}$ & $\begin{array}{l}\text { Research } \\
\text { Framework }\end{array}$ & $\begin{array}{l}\text { Research } \\
\text { Strategy }\end{array}$ & $\begin{array}{l}\text { Research } \\
\text { Ethics }\end{array}$ & $\begin{array}{c}\begin{array}{c}\text { Limitations } \\
\text { in } \\
\text { Methodology }\end{array} \\
\end{array}$ & $\begin{array}{c}\text { Field Study } \\
\text { Area }\end{array}$ \\
\hline $\begin{array}{l}\text { Chapter } 6 \\
\text { Results }\end{array}$ & Strain & Stress & Sustain & Supervision & Support \\
\hline $\begin{array}{l}\text { Chapter } 7 \\
\text { Discussion }\end{array}$ & & $\begin{array}{l}\text { Inferences } \\
\text { and Links }\end{array}$ & $\begin{array}{c}\begin{array}{c}\text { Constituents } \\
\text { and } \\
\text { Foundations }\end{array} \\
\end{array}$ & $\begin{array}{c}\text { Revised } \\
\text { Sustainability } \\
\text { Criteria }\end{array}$ & $\begin{array}{c}\text { S-SDTS } \\
\text { Model }\end{array}$ \\
\hline $\begin{array}{c}\text { Chapter } 8 \\
\text { Conclusion }\end{array}$ & & $\begin{array}{l}\text { Ans wers to } \\
\text { Research } \\
\text { Questions }\end{array}$ & Implications & Reflection & Limitations \\
\hline
\end{tabular}

Figure 4.1. The Structure of Chapter 4

\subsection{Introduction to Chapter 4}

This chapter aims to develop the conceptual framework of this thesis and to clarify the research paradigm and research questions. The theoretical foundation of this thesis is grounded in three different, but interrelated theories as can be seen in Figure 4.1. First, the normative theory is employed to establish the core knowledge of principles of sustainability and accommodate the moral and ethical values of the system and the interests of stakeholders in scuba diving tourism. Following this, systems theory is examined in order to set up a fund of knowledge for the fundamentals of the scuba diving tourism system. Lastly, stakeholder theory is reviewed to find out the role of stakeholders and comprehend the function of the system. The reason for looking through three different bodies of theories is to discover the theoretical background applicable to the current phenomenon. The systems theory reveals the fundamental 
inputs the system requires, while normative theory grounds the value and meanings inherited in the system. Stakeholder theory clarifies the capacity of the associated individuals and groups in the system. By doing this, this thesis aims to design a new systematic approach for the scuba diving tourism system based on these three interrelated theoretical bodies according to principles of sustainability.

\subsection{Normative Theory}

The normative theory explains the optimum value for individuals or groups in order to avoid conflicts and develop a mutual agreement. Normative theory underpins the ideal behaviour within the systems in the specific environment by describing the value judgements (Morgenstern, 1972). In other words, the purpose of normative theory used in this study is to clarify the meaning and narratives in systems to make perceptions interpretable and useful. In this study, the relationship between systems theory and normative theory is to create a conceptual framework while outlining the cognitive mindset of people who are the stakeholders in the scuba diving tourism system. This conceptual framework can help groups in the system to have a meaningful perspective and adapt themselves towards critical thinking towards their environment and its surroundings. The basic systems approach aims to solve conflicts between the needs of interest groups and the environment which could be biological, social, economic, or natural. Therefore, "(1) the purpose of the system; (2) the purpose of its parts; and (3) the purpose of the system of which it is a part" (Ackoff, 1981, p. 23) should be defined based on normative aspects to find a mutual way to protect and maintain the relationships among associated groups within the system.

While the concept of sustainability has historically attracted scholars, the normative distinction between sustainable and unsustainable practices or prerequisites in the system has been increasingly questioned (Amsler, 2009). A system depends on logical decisions derived from actions of learning, thinking, knowing, and remembering within the process. That is "an attempt to bind together in a systematic fashion the knowledge that one has of some particular aspects of the world of experience" (Honderich, 2005, p. 914). In a sense, people are conscious to select their activities (Scitovsky, 1992; Creswell, 1994; Moran, 2019), create interests (Jeager \& Sekznick, 1964) and determine their needs. From the interpretive view (Berger \& Luckman, 1966; Morgan \& Smircich, 1980), "people socially and symbolically construct and sustain their organisational realities" (Gioia \& Pitre, 1990, p. 588). This is the way to give 
something that people do, or are involved in, with symbolic and meaningful values. However, the language of the organisation; conceptual schemes; metaphors; images; and subjective and objective values of the groups may differ from individual to individual (Wicks et al., 1994) or systems to systems. Therefore, the normative aspects can become relatively more important to be able to influence the constituents of the organisation and help to create a 'reasonable strategic action` (Jones \& Wicks, 1999) among associated groups in the system.

Moreover, between objective and subjective values, there is a significant bond within the conceptual framework of the system. In general, objective values are determined in the system by a group decision to act. Subject values, however, are affected independently from objective values by the surroundings of the group or social arrangements of individuals. Both have different capacities of values to encourage the group to act (Jeager \& Sekznick, 1964). Addressing these values make groups available to be part of a system while generating symbolic meanings which are important and create a mutual ground among associated groups and form `symbolic-meaningful systems`. The symbolic-meaningful system is a term that refers to behavioural change (Jeager \& Sekznick, 1964) and creating the ideal notion of acting among associated groups through organisational learning. The concept of these systems which relies on normative cores and knowledge becomes the most important element which makes it able to increase the cognitive awareness and interpretation capacity (Jeager \& Sekznick, 1964) as values and ideals of the group, for all participants and the system. As Lilienfeld (1978) highlights, the world is an organisation, therefore, principles and standards must influence the attitude of interest groups; enhance scientific thoughts through knowledge; and make practices more meaningful.

In a sense, a mutually agreed normative interpretation towards organisational moral and ethical values may differ from situation to situation. The normative aspects can keep relations interactive and associated groups connected. As Jeager and Sekznick (1964) state, the closer organisations come to the notion of a system, to the modes of knowledge and information that give symbolic meaning to the associated groups and characterise a way of acting, the more meaningful are actions and results to be realised. In other words, through raising knowledge and awareness the more educated stakeholders are the more sophisticated and meaningful actions can be done and obtained positive results out of the practices. Specifying the normative aspects for associated groups and stakeholders is important (Goodpaster, 1991; Goodpaster \& Holloran, 1994; Boatright, 1994; Clarkson, 1995; Quinn \& Jones, 1995) for creating a narrative 
account for their moral behaviour and following ethical behaviours through the interpretation of these narratives (Jones \& Wicks, 1999). In this sense, the narrative interpretation may be considered as setting up primary moral values for the organisation or the system which are the universal objective and subjective judgements. However, the fundamental issues of narrative interpretation, such as ontological assumptions (the nature of organisational phenomena), epistemology (the nature of knowledge about organisational phenomena), and methodology (the nature of appropriate means of studying organisational phenomena) (Morgan \& Smircich, 1980; Gioia \& Pitre, 1990; Jones \& Wicks, 1999) have not been agreed on creating a paradigm consensus among social scientists.

The normative theory has had limited use in the body of tourism studies, but it has been used in identifying the norms regarding tourists' demographics and their meaning of experiences (Snepenger et al., 2004; Wang et al., 2021); and to characterise the meaning of crowding and optimal (acceptable) visitor numbers (Manning, 2013; Manning, 2018) in recreational settings. Moreover, the normative theory has been used to define tourists' experiential capacities (Alazaizeh et al., 2016) and tourism resource conditions to determine the standard visitor features in archaeological park visits. Normative research or normative theory has been a useful tool towards a better understanding of tourists` behaviour in outdoor recreation (Heywood et al, 2002) to improve the planning and management conditions. Normative perspectives have also been used in scuba diving settings in order to identify resource conditions, level of visibility underwater and future effects on coral reefs as a result of touristic activities (Anderson \& Loomis, 2012) and optimal management actions and strategies (Needham \& Szuster, 2011). However, the normative theory has had been employed with a limited interest in connection with providing moral and ethical justification for the notion of the scuba diving tourism systems approach. Therefore, this study is aimed to employ the normative theory in the sense of creation and justification of moral and ethical values for the scuba diving tourism system in order to fill this gap that exists in the current literature.

\subsection{Systems Theory}

The concept of a system may become advantageous when trying to understand internal and external factors which are associated with social, economic, and environmental elements of their functional organisation. With this design, the systems theory becomes an effective tool for a wide range of needs or concerns to illustrate the influence on organisations and 
surroundings while exploring problems and their causes with input and output functions (Heil, 2018). In the system, each element or function has an influence on a certain part of the system or its entirety. Moreover, each element affects the other either directly or indirectly (Ackoff, 1981) before, during or after interactions. These constituents may change over the course of interaction (depending on when, where, with who, why, what, and how it takes place) within the group or in the environment and affect the behaviour of the organisation as the system itself (Hall \& Fagen, 1956). Therefore, understanding what is meant by a system in broad and different aspects becomes an important and effective phenomenon for this thesis.

Over the last century, a number of researchers have propounded a wide range of systems perspectives, such as General Systems Theory (von Bertalanffy, 1949); Living Systems Theory (Miller, 1978); Mathematical Systems Theory (Mesarovic, 1964); Cybernetics (Rosenblueth et al., 1943); Social Systems Theory (Parsons, 1970); Philosophical Systems Theory (Laszlo \& Clark, 1972). "At its simplest level, a system is an integrated whole whose essential properties arise from the relationships between its constituent parts" (Hall, 2008, p. 69). In the system, laws and principles shape the nature of the relationship between parts and create a specific model which aims to represent the relationships in the real world (von Bertalanffy, 1947; von Bertalanffy, 1955; von Bertalanffy, 1972). Systems theory is a theoretical framework that explains (meaningful) sole relationships or interrelationships, in general, and the empirical worlds, in a multidisciplinary and interdisciplinary approach. The systems theory also integrates various constituent parts and develops a systematic ground to solve problems and make decisions. In this regard, "a system may be defined as a set of elements standing in interrelation among themselves and with the environment" (von Bertalanffy, 1972, p. 417).

In a broad management sense, two main systems theories are applicable to social science `General Systems Theory` established by Ludwig von Bertalanffy in 1949 and 'Living Systems Theory founded by James Grier Miller in 1978. The general systems theory seeks "(1) set of elements; (2) the set of relationships between the elements; and (3) the set of relationships between these elements and the environment" (Hall, 2008, p. 71). The general systems theory focuses on the philosophical aspect to understand the scientific structure (von Bertalanffy, 1972). Alternatively, the Living Systems Theory is also known as Miller`s Living Systems Theory, focuses not only on a basic system theme (which is biologically emphasised by von Bertalanffy) but also on social systems and how they react to changes, develop themselves and maintain their position (Adams, 2012). According to Miller (1978), living 
systems have eight different but interrelated hierarchal elements which are (1) cells; (2) organs; (3) organisms; (4) groups; (5) organisations; (6) communities; (7) societies; and (8) supranational systems. These elements manifest an open and self-organising system, originated through exchanging knowledge, the interaction between the parts and relationship with the surroundings. A foundation regarding the base of systems can be constructed within associated groups, practitioners, and the environment to set a working and proper system (Adams, 2012; Adams et al., 2014). In this, there are seven grounds, Centrality; Contextual; Design; Goal; Information; Operational; and Viability (Adams, 2012, p. 220). These cores help to set up a model for the system, which is grounded on interconnected, interdependent, and interacting (Laszlo \& Krippner, 1998, p. 20) relationships among the constituents.

Centrality refers to how the system is going to be centralised and internalised in the meaning of the system in terms of conveying the message and creating communication that controls the system. The contextual tries to find answers for some questions such as what does the system work for or what are the external factors that help associated groups to understand the current situation? These basic questions create a set of knowledge for the system to control the existing and unforeseen circumstances. The design gives a control ability for associated groups to guide the relationship and ensure the benefits which result from their contributed actions. The goal demonstrates a specific purpose. Rather than seeking the answer for what the system works for, the goal is to ask what the purpose of this system is to achieve a result and improve the performance. Moreover, a goal creates a certain aim for associated groups, brings them together and encourages them to work for a reason. The information provides knowledge that is required to run the system and be part of one of the associated groups. According to Adams (2012), information is important for a system to achieve specific goals like creating, possessing, transferring, and modifying knowledge. The operational explains the main question of how the system will be managed in-situ. Improving the performance and creating desired behaviour to achieve certain results requires a better ability to operate and control the circumstances. The viability caters for creating a better design, process and system, existing circumstances need to be addressed properly, which are approved by all associated members of the group to ensure a working and operational system.

Overall, the general systems theory or living systems theory explains what the system is, what components there are and how they work systemically. However, unsettled interdependent relationships, complex external factors, disconnected subsystems (if they exist), 
lack of awareness, uncollaborative planning and unspecialized perspectives make it difficult to manage systems. Therefore, the systems theory may correspond to becoming knowledgeable about the situation, because as is indicated, this can maintain and define the system more systematically. For this reason, a further normative establishment is needed to understand the characteristics of the (designed) systems. In this sense, normative aspects can provide the understanding and predictive ability (Adams, 2012) that enable thinking, decision, action, and interpretation with respect to systems. The systems approach needs the normative aspects to define conceptual frameworks which generate meaning for the system and help to develop strategies for effective operation among the associated groups or organisations. These are associated with "acts of perception, interpretation, conceptualization, reflection, contemplation, explanation, articulation, and communication" (Laszlo \& Krippner, 1998, p. 23). Because, without knowledge, information transfer, and communication, systems are of no use due to a lack of feedback and interrelations (Heil, 2018). However, creating a system and transferring the knowledge depends on a group of constituents who will be affected and affect the purpose of the system. To better understand who or which are these constituents within the system can provide more broad knowledge about how a system becomes established and how it can be. Therefore, in the following section, stakeholder theory is used to identify the individuals or associated groups who are involved and have active roles with responsibilities in the system to better understand the phenomenon in discussion throughout this study.

\subsection{Stakeholder Theory}

Stakeholders are a group of people who create an organisation set where overlap their interests, needs and point of view (Friedman \& Miles, 2006; Fontaine et al., 2006). These stakeholders are "any group or individual who can affect or is affected by the achievement of the organization's objectives" (Freeman, 1984, p. 46) and "those groups who are vital to the survival and success" (Freeman, 2001, p. 129). The stakeholder theory suggests that interested groups have the guidelines to run the system in an effective way. In other words, stakeholder theory is a managerial approach that “... essentially consists of understanding and predicting the behaviour and actions of stakeholders and devising strategies to ethically and effectively deal with them" (De Lopez, 2001, p. 48). In the system, these groups can be as varied as consumers; suppliers; business owners; local people; authorities; local and national governments and government officials; scientists; media; investors; employees; interest groups; NGOs; regulators; financiers (lenders or banks); insurers; business associations; other 
interest groups; non-human stakeholders like the environment; and other interrelated groups and bodies according to the characteristics of the organisations. Furthermore, time is a factor, as present consumers, and future customers, in the same line present and future host communities (Byrd, 2007) can be counted as stakeholders who constitute the system.

Donaldson and Preston (1995) divided the stakeholder theory into three perspectives which are nested within each other to examine practical and theoretical principles, the descriptive, the instrumental and the normative, as can be seen in Figure 4.2. The descriptive perspective refers to how stakeholders respond to reality which is placed as an inclusionary position and tries to explain the relationship with the outside system. The instrumental perspective indicates how stakeholders create a relationship among other parties and increase the performance which is in the middle as control actions. These actions stem from specific practices; "if certain practices are carried out, then certain results will be obtained" (Donaldson $\&$ Preston, 1995, p. 74). The normative perspective, as the central core of stakeholder theory, questions what knowledge and moral codes are behind stakeholders` behaviour and their actions (Theodoulidis et al., 2017) and "recognition of these ultimate moral values and obligations give stakeholder management its fundamental normative base" (Donaldson \& Preston 1995, p. 74) in the stakeholder theory.

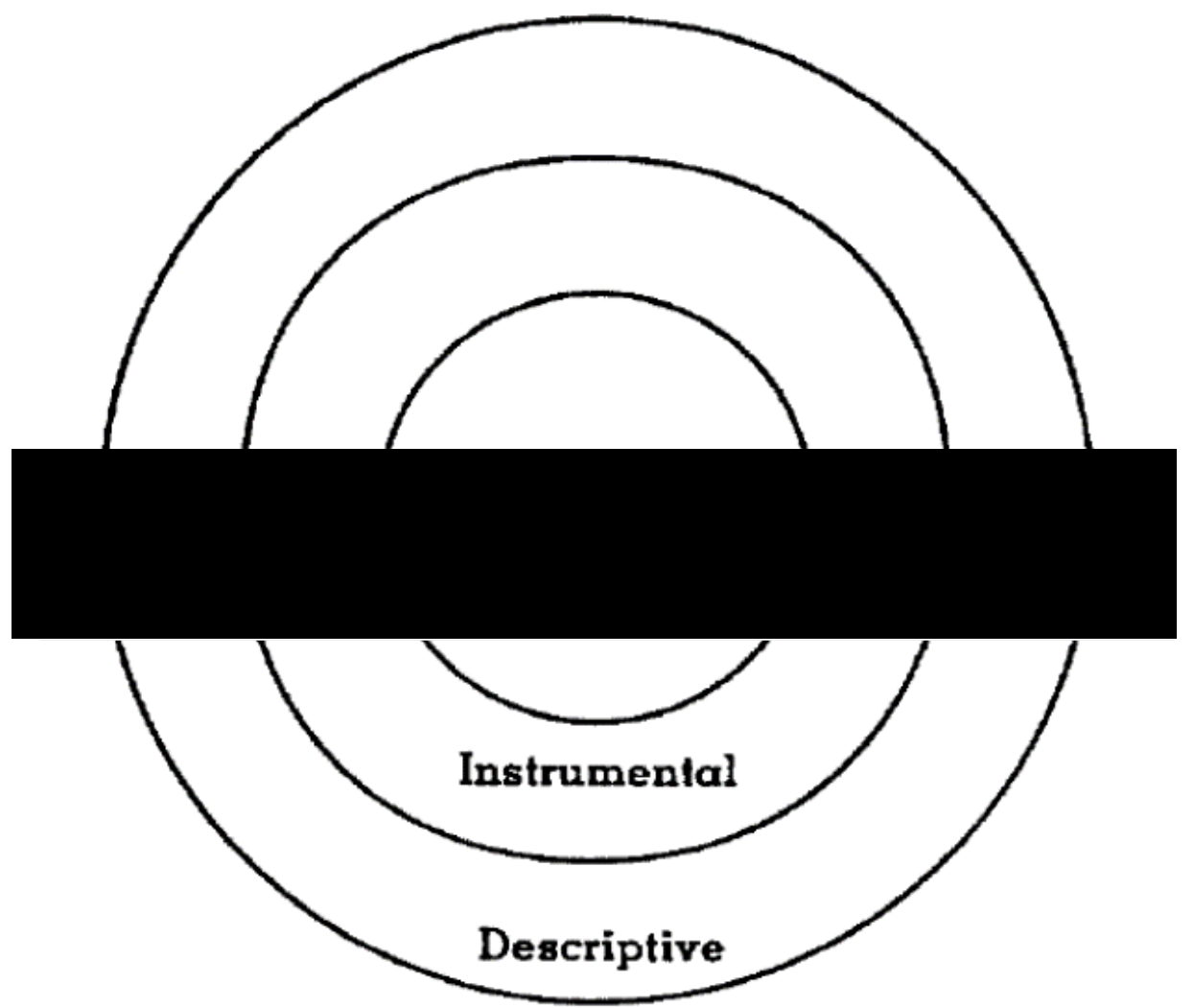

Figure 4.2. Three Aspects of Stakeholder Theory (Source: Donaldson \& Preston, 1995, p. 74) 
With this connection, the normative core becomes the background of the theoretical foundation of this thesis that is nested along with the systems theory and stakeholder theory. The normative core in stakeholder theory stands for knowledge, moral and ethical aspects for stakeholders to internalise and understand the aims of the organisation or the system. The main question in terms of the normative core of this theory is how stakeholders should act and view the purpose of the organisation or system (Friedman \& Miles, 2006) which is based on ethical and moral principles (Nicolaides, 2015). The normative core accounts for describing the basic functions of the system and the responsibilities of the organisation (Freeman, 1994) which is referred to as a philosophical perspective; therefore, the objective of the normative core is linked to values. This clarifies the purpose of business and moral justifications of stakeholder theory (Freeman \& Gilbert, 1988; Goodpaster, 1991; Argandoña, 1998; Reed, 1999). In line with this objective, it is expected that each company, system, or organisation identifies the core moral principles to address the interest of stakeholders. For this reason, the normative aspects have been taken into account by Donaldson and Preston (1995) and Freeman (1998) as the substantial element of this theory to determine managerial aspects of the organisation; stimulate the knowledge and organisational learning capacity; and assist challenges which stakeholders face and affect their financial and social performance (Verbeke \& Tung, 2013).

In a general sense, the descriptive section demonstrates the way that the world is (in some sense of reality) and the instrumental perspective links mean and ends (Freeman, 1999). From a descriptive perspective, evidence shows that stakeholders "do not behave as if stakeholders had morally valid claims" (Jones \& Wicks, 1999, p. 208) on the system. This can be due to a lack of knowledge. Therefore, knowledge can also affect the 'intrinsic justice (Jones, 1994, p. 100) of stakeholders and explains the meaning of their behaviour which originated from decision making and values (Brenner \& Cochran, 1991). However, the normative core is considered as the moral ground, yet the degree of morality is not certain, and sometimes this changes over time (Jones \& Wicks, 1999) as it may become as "too abstract, or too idealistic, to be of any practical value" (Weaver \& Trevifio 1994, p. 132). Without clear normative cores, stakeholders may fail in practice and have difficulty not only in meeting their interests at a satisfactory level (Jones \& Wicks, 1999) but also cause harm to business, organisation, and enterprise (Foley, 2005).

The stakeholder theory can be used to determine stakeholders` role in the system and the degree to which extent they can contribute (Garriga, 2014). Besides, the normative aspects 
can help stakeholders to accommodate personal knowledge and skills into the system and generate strategies (Freeman \& McVea, 2001) and prescribe how the setting (a business, system or an organisation) can be (Freeman, 1999). The strategies via knowledge and skills can turn into values in the system based on the moral and ethical understanding of stakeholders within the process in time. For example, all decision processes rely on the moral and ethical understanding of the associated groups and individuals themselves; and it is expected to be constituted by fair and commonly acceptable behavioural principles (Friedman \& Miles, 2006). However, as indicated above, values may vary from individuals` understanding, built relations, the background of the system, and the degree of influence of stakeholders according to their knowledge and interests. In addition, the values may change or develop over time with independent, dependent, or exogenous variables such as environments, other systems, businesses, and organisations (Freudenreich et al., 2020).

Therefore, the values which is sustainability-oriented for the organisation can be a solution if represent all stakeholders' interests and employs shared benefits (Parmar et al., 2010). In terms of the involvement of the stakeholders in the system, there are five core values, these are fairness, efficiency, knowledge, wisdom, and stability (Susskind \& Cruikshank 1987; Nicodemus 2004; Byrd, 2007). As for knowledge, it is expected that all stakeholders have the same level of knowledge (Nicodemus 2004) regarding shared values and mutual interests regarding principles of sustainability. By doing so, stakeholders can have not only the marginal economic income but also, they can have better standards on quality improvements. Moreover, stakeholders can have enough knowledge and become educated to meet their mutual interests (Hörisch et al., 2014). This can promote an optimal relationship that is needed among the stakeholders and provide indispensable core values to achieve and meet the purpose of the organisation, as well. In addition to this, each part can have a role in determining the future direction (Evan \& Freeman, 1988), with respect to achieving the ideal sustainable development in the system and for maintaining the organisation. This is not limited to the economic benefit for maximizing the profit or generating high revenues (Fontaine et al., 2006) but also creating moral commitments while also considering the environment and social equity as the core values among stakeholders within the system.

Before moving on to the theoretical framework, it will be useful to understand the situation under discussion by identifying the stakeholders related to the scuba diving tourism system for a better examination of the issue. On the one hand, stakeholders in the scuba diving 
tourism system can be categorised into 2 groups. The first is interest groups who seek benefits from the scuba diving tourism activities and can be identified as (1) governments (local, regional, or national governments) who are expected to create jobs for local people; to promote tourism to attract more tourists; and to increase the standard of living. (2) Institutions like universities that are interested in enhancing the research facilities and increasing awareness of marine environments. (3) Other businesses such as suppliers, hotels and related tourism enterprises expect to have a benefit from scuba diving tourism. The other group can be denominated as the active group which is constituted by scuba divers, scuba diving centres and employees as scuba diving instructors. Scuba divers intend to have the best, novel subaqueous experience, while scuba diving centres are seeking an optimal/marginal economic benefit. Thus, scuba diving instructors become the intermediary in this process of exchanging the knowledge and interests of scuba diving centres while guiding scuba divers. Besides PADI and CMAS (Confédération Mondiale des Activités Subaquatiques), and a few other worldwide associations are present in the scuba diving tourism industry to provide training material and education for skill development to access underwater. Such as BSAC -the British Sub Aqua Club; NAUI -the National Association of Underwater Instructors; SSI -Scuba Schools International are responsible for standardisation of the training process and they are key partners for the scuba diving tourism industry (Musa \& Dimmock, 2013) in the sense of knowledge exchange/transfer between the active group of stakeholders.

In this connection, the collaborative relations among these groups can contribute to sustainable development first-hand in the scuba diving tourism system. Therefore, finding a balance between these groups within the system becomes an important tool to promote principles of sustainability based on the triple bottom line. Besides, interest and active groups are related and depend on each other. For example, active groups are influenced by governments` regulations and restrictions. On the other hand, in the system, there may also be human and non-human stakeholders as local people, the fishing industry and more importantly the marine environment. As De Wit (1982) emphasised, if the system is large, different participants will be involved in the system. Not only their position but also the number, size, age, gender, level of education and stage of knowledge will influence the system to some degree due to a variety of actions and different attitudes. For this reason, finding a mutual ground among independent but interrelated groups is the fundamental interest for designing a proper system for scuba diving tourism which is the main purpose of this thesis. 


\subsection{Theoretical Framework}

Principles of sustainability are "the formulation, implementation, and evaluation of both environmental and socioeconomic sustainability-related decisions and actions" (Starik \& Kanashiro, 2013, p. 12). Thus, establishing principles of sustainability become important normative aspects that create the ethical foundation (Freeman, 1994; Freeman et al., 2004) for the system. In this sense, As Hörisch, Freeman and Schaltegger (2014) highlight, three principles can be employed to ensure sustainable development among stakeholders and a proper system model. (1) all stakeholders should understand sustainability and create a mindset; (2) an organisation should have sustainable interests which are aligned with stakeholders' interests; and (3) along with social equity and economic efficiency, ecological integrity should be taken into account more specifically. Stakeholder theory argues constituents in terms of legal, economic, political, and moral challenges perspectives; however, it does not emphasise what is to be the principles of sustainability as normative aspects (Jones and Wicks, 1999). Therefore, "we must redraw the picture in a way that accounts for the changes" (Freeman, 1984, p. 24), about "how organisations can succeed in the current and future business environment" (Freeman, 1984, p. 25). Similarly, as Garvare and Johannson (2010) pinpoint, there is still a gap between principles of sustainability and stakeholder theory, which needs to be filled to ensure quality management for the system as normative aspects.

In accordance with the theoretical and practical backgrounds in question, this study aims to redesign the scuba diving tourism system following principles of sustainability through exploring normative aspects as moral and ethical values. Therefore, the main research question of this research was grounded according to value in terms of creating a mutual ground for individuals and groups. As can be seen in Figure 4.3, the purpose of using these theories is to explain the basic functions of the system (General Systems Theory and Living Systems Theory); to establish knowledge and the justification of the system (Normative Theory); and to identify core aspects (Stakeholder Theory) of the scuba diving tourism system. By doing this, it is aimed to define how stakeholders can associate, make meaning, and build a relationship within the system. Moreover, describing the system; clarifying the moral and ethical values; defining the normative aspects; and accommodating the acknowledgement of the system became the core acts of this study. As well as descriptive and instrumental cores for the organisation and the system, the value was addressed with regard to the interests of every associated individual and group and their constructive capacity. 

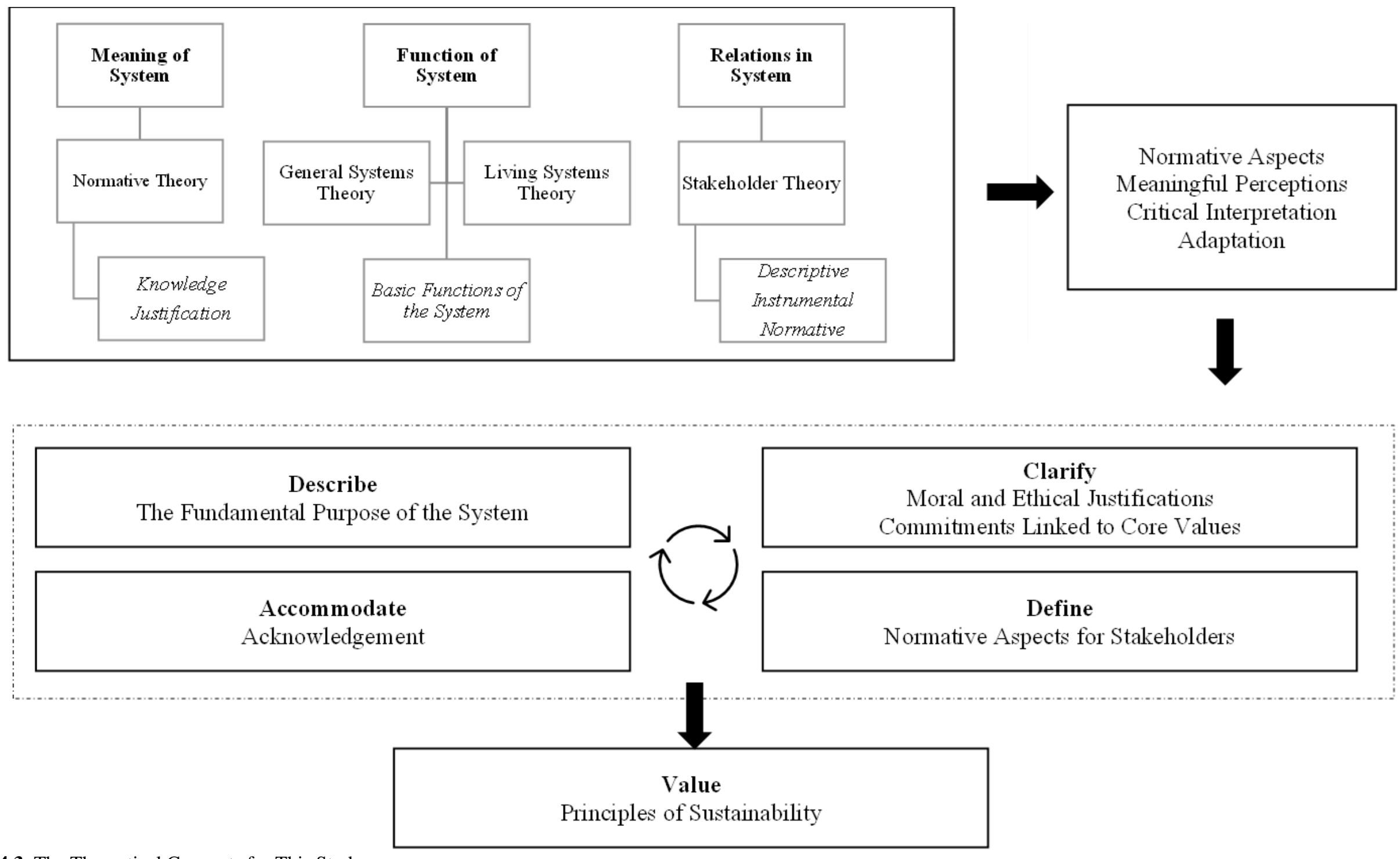

Figure 4.3. The Theoretical Concepts for This Study 
The concepts above draw a guideline for the theoretical foundation which illustrates why and how theories are used and justified. In this study, first, knowledge, values, and justification of the system in relation to principles of sustainability are examined. Followingly, the role of stakeholders involved in the scuba diving tourism system is explained according to the grounds of the systems approach. By doing so, fundamental goals and values are illustrated for the system as normative grounds, meaningful perception, critical interpretation, and adaptation. This also helps to identify the gap in the current phenomenon by clarifying the role of stakeholders and values related to the system. Moreover, defining the normative aspects for the system and accommodating the principles of sustainability are the key components of the process to design an ideal system for scuba diving tourism.

A number of researchers have employed stakeholder theory in many different sectors and contexts in planning (Gunn 1994; Ioannides 1995; Hardy \& Beeton 2001; Byrd, 2007; Starik \& Kanashiro, 2013). In terms of sustainability, even if development plans address prosperity, equality or concern the environment more than ever before, economic affairs with the other principles of sustainable development have many contradictions (Sharpley, 2020). Therefore, determining normative aspects can become a solution to rebalance all these interests which are represented by global ethical values within a systems approach. Besides, behavioural transformation (Sharpley, 2020) and structural changes within the organisation may be needed revisiting to achieve sustainable development goals in one place. Collective behaviour and collaborative thinking (Jamal \& Getz 1995; Yuksel et al., 1999) can be enhanced by education and shared responsibility (Sautter \& Leisen 1999), in the tourism organisation among stakeholders. Taking joint action is an indispensable part of behaviour towards sustainable development in the tourism industry (Bramwell \& Lane, 2000; Beritelli, 2011). However, how stakeholders choose to contribute or how they create normative aspects according to their knowledge on sustainable development is still limited in the existing literature. For this reason, developing policies that fitted with the interests of stakeholders (Byrd, 2007) or increasing the body of knowledge (Yuksel et al., 1999) may be the other effective solutions that can strengthen the meaning of the organisation and improve the normative analysis capacity within the system.

The phrase of the triple bottom line of sustainability has grown into a broad approach as to the principle for reducing the overuse of natural resources and ensuring economic development for the benefit of equity in social quality within the scope of stakeholders collective and concerted actions. In this connection, as Parmar et al. (2010) state, the 
stakeholder theory has centred on understanding how to manage an organisation in the contemporary era; creating moral and ethical values for responsible behaviour and sustainability in an economic environment; developing skills to become successful in the business community. In this sense, as suggested by Purnell and Freeman (2012), in the body of stakeholder literature the concept of the normative aspects can be applied in three schemes, named as Philosophical; Theoretical; and Managerial. The philosophical justification represents the values of the organisation and the system. These values can be inputs; outputs; feedback; processes; innovation; evolution; learning; collaboration; persistency; solidity; flexibility; rationality; empathy; responsibility; decency; reflection (Starik \& Kanashiro, 2013); accountability; and knowledge as normative principles of stakeholders. The theoretical sense refers to the principles used in activities and proper actions organisations towards sustainable development goals. The managerial application reflects the values for sustainable management by stakeholders in which beliefs and ideas become a set of narratives (Freeman 1994). According to Smith and Lewis (2011), if these principles of schemes and values are ideally described, predicted, integrated, and prescribed in the system, a dynamic balance can be achieved. Therefore, sustainable management can be established in the system based on building stakeholder capacity in the normative aspects of learning, creativity, flexibility, and resilience.

However, in terms of principles of sustainability in scuba diving tourism destinations, the general attitude was discussed by many researchers from either descriptive and empirical aspects (e.g., Agle et al., 1999; Jawahar \& McLaughlin, 2001; Wallis, 2006; Sangle \& Ram Babu, 2007) or instrumental aspects (e.g., Jones, 1995; Berman et al., 1999; Johnson \& Greening, 1999; Mathur et al., 2008) of stakeholder theory to identify the main objectives and practices of sustainability. This body of literature focused on managerial perspectives to understand organisational effectiveness and assess the performance of stakeholders about sustainable development objectives, generating income and capacity building (Hörisch et al., 2014). It is assumed that all stakeholders have sustainability interests to some extent, hence, it is necessary to set up sustainable development-based interests in order to avoid conflicts (Starik, 1995) among associated groups of stakeholders. Moreover, it is also anticipated that each stakeholder, as an individual or a group, has a particular value on a different scale and significance (Nicolaides, 2015) at the scuba diving tourism destination. Not surprisingly, the success of sustainable development objectives in the scuba diving tourism system relies on 
effective activities carried out by stakeholders (Vincent, 1990). At the same time, these stakeholders will have different interests, varied expectations, and dissimilar profiles. To deal with these nonmutual interests, establishing criteria related to principles of sustainability can give the advantage to find the solutions. Moreover, the normative aspects can create a model within a sustainable systems approach for stakeholders and help to find a middle ground with numerous requests to facilitate their interest and overcome the obligations (Jones \& Wicks, 1999). Thus, stakeholders can maximise the mutual benefits along with considering the needs of the social and natural environment.

In above mention connection, Table 4.1 illustrates the criteria related to principles of sustainability in the scuba diving tourism system (SDTS) which are categorised under the three grounds of stakeholder theory. These are important indicators in the SDTS shaped by various factors which contribute to scuba diving tourism and sustainable management principles in the destination. Items are situated in Table 4.1 were adopted from the current literature on scuba diving tourism based on Donaldson and Preston's (1995) three perspectives of nested practical and theoretical principles, which are descriptive, instrumental, and normative. According to this, instrumental cores constituent the highest percentage of the subject of concern in the scuba diving tourism system, followed by the descriptive core. However, normative aspects have not been sufficiently emphasised. In general, descriptive grounds are related to precautions; understanding of impacts from different stages and influences; some practices. The instrumental grounds are exemplified by implications; how to support the industry; build relationships; and promote alternative solutions. The normative grounds are related to raising awareness and developing knowledge in environmental issues. How to raise awareness and create a fund of knowledge for the scuba diving tourism system are needed to be researched with further empirical studies. Because for descriptive and instrumental grounds, knowledge, and values in terms of morals and ethics are the fundamental tools to start acting. Therefore, establishing the moral and ethical values; enhancing knowledge; and a better understanding of the current phenomenon is determined as the fundamental contribution of this study. 
Table 4.1. Sustainability Criteria* in SDTS According to Stakeholder Theory` Dimensions

\begin{tabular}{|c|c|}
\hline Descriptive Grounds of SDTS & Instrumental Grounds of SDTS \\
\hline $\begin{array}{l}\text {-Analyse attitudes and behaviours of scuba } \\
\text { divers } \\
\text {-Understand past experiences of scuba divers } \\
\text {-Understand perceptions of impacts of scuba } \\
\text { divers } \\
\text {-Identify preferences of inexperienced scuba } \\
\text { divers } \\
\text {-Categorise accidental and deliberate impacts } \\
\text {-Create self-reported/self-controlled divers` } \\
\text { behaviour } \\
\text {-Determine references for activities } \\
\text {-Monitor the environment } \\
\text {-Monitor the quality of social life } \\
\text {-Monitor annual revenues } \\
\text {-Determine the carrying capacity } \\
\text {-Create and manage MPAs } \\
\text {------------ }\end{array}$ & $\begin{array}{l}\text {-Reward sustainable business performances } \\
\text {-Measure conservation tools } \\
\text {-Systematically analyse scuba diving tourism } \\
\text {-Develop relationships among stakeholders } \\
\text {-Sponsor and fund new scuba diving areas } \\
\text {-Provide training for stakeholders } \\
\text {-Self-advocacy and representativeness of all } \\
\text { stakeholders } \\
\text {-Form compensation or negotiation at the local } \\
\text { level } \\
\text {-Minimise the negative impacts caused by scuba } \\
\text { divers } \\
\text {-Limit access to marine areas as if required } \\
\text {-Restrict intensive fishing practices in scuba } \\
\text { diving areas } \\
\text {-Promote scuba diving } \\
\text {-Adopt marketing tools to local capacities } \\
\text {-Generate market diversification } \\
\text {-Exploit new marketing channels } \\
\text {-Ensure the service quality on a local basis } \\
\text {-Stimulate artificial reef and wrecks areas } \\
\text {-Establish product diversifications } \\
\text {-Agreement in planning and management } \\
\text {-Adjust regulations and restrictions } \\
\text {-Plan long-term management plans and } \\
\text { strategies } \\
\text {-Promote scientific reports and master plans } \\
\text {-Address scuba diving specialization } \\
\text {-Guide underwater behaviours of scuba divers } \\
\text {-Cooperate between stakeholders and residents } \\
\text {-Transparency with respect to revenue } \\
\text {-Put together tourism services } \\
\text {-Make effective pre-dive briefings } \\
\text {-Govern and/or self-regulation, actively } \\
\text {-Create socially responsible programs } \\
\text {-Reduce economic leakages }\end{array}$ \\
\hline
\end{tabular}

* Items are adapted from Harritott et al., 1997; Swarbrooke, 1999; Badalamenti et al., 2000; Daily, 2000; Kastenholz, 2004; Parham; 2006; Leujak \& Ormond, 2007; Budeanu \& Chesworth, 2007; Fabinyi, 2008; Townsend, 2008; Di Franco et al., 2009; Sorice et al., 2009; De Groot \& Bush, 2010; Young \& Loomis, 2010; Heyman et al., 2010; Thur, 2010; Haddock-Fraser \& Hapton, 2012; Jentoft et al., 2012; Biggs et al. 2012a; Biggs et al., 2012b; Edney, 2012; Dimmock et al., 2013; Musa \& Dimmock, 2013; Lucrezi et al., 2013; Romani \& Grappi, 2014; Mota \& Frausto, 2014; Hillmer-Pegram, 2014; Wongthong \& Harvey, 2014; Rees et al., 2015; Dimmock \& Musa, 2015; Bennett et al., 2017; Lucrezi et al., 2017; Hammerton, 2017; Su \& Swanson, 2017; He et al., 2018; Scholtz \& Saayman, 2018; Lee \& Jan, 2019; Bideci \& Cater, 2019a; Bideci \& Cater, 2019b; Lucrezi et al., 2019; Edney \& Boyd, 2020; Cater, Albayrak, Caber \& Taylor, 2020; Brander, van Beukering, Nijsten, \& et al., 2020; Lucrezi, Ferretti, Milanese, Sarà \& Palma, 2020; Giglio, Luiz \& Ferreira, 2020; Garcia \& Cater, 2020; Yolal et al., 2021; Edney \& Boyd, 2021; Edney et al., 2021a; Edney et al., 2021b; Bideci \& Bideci, 2021. 
In accordance with this purpose, as can be seen in Figure 4.4, the framework of this study has been established on three interrelated bodies of theories to fill the gap in question. Due to the fact that the systems theory and normative theory were employed as a theoretical background to develop the fundamental narratives of the scuba diving tourism system. Stakeholder theory was used to identify the individual perceptions and contributions of stakeholders towards sustainable development goals in scuba diving tourism destinations. Subsequently, a field study was conducted to disclose the current phenomenon to have a better understanding of controversial issues in the existing systems approaches. Results were used to assess and improve the scuba diving tourism system in a manner of principles of sustainability. Normative aspects were examined in three fundamentals as philosophical, theoretical, and managerial. Regarding this, the body of scuba diving tourism (SDT) and principles of sustainability literature are examined and analysed to increase understanding of current issues. As a consequence, the scuba diving tourism system is reinterpreted according to stakeholder theory through the findings of this thesis and revised based on principles of sustainability, following the calls of Hillmer-Pegram (2014, p. 609) “... certain dive tourism systems seem to be undergoing a decoupling (or unlinking) of the environmental and social components ..." therefore, as Dimmock and Musa (2015, p. 56) emphasise "further research is also needed to refine the model and analyse its efficacy in ensuring SDT has a sustainable future".

Figure 4.4 identifies the main research components derived from the literature review and the current phenomenon that is under enquiry in this research. This theoretical framework can be divided into two divisions. In the first part (marked with black font colour), the boxes represent the extant literature review and are connected with dashed lines. These show unrevealed relationships between the subjects and identify the gaps claimed in this study. The dashed black lines specify the direct relations, while accent double arrows with accent grey boxes outline the supportive roles of the employed theories in this study. The second part of this figure is related to the stakeholder theory. While the first part is related to normative aspects of stakeholder theory and the main topic of this study; the second part demonstrates the existing studies which are not used in this study. As has been shown above, in terms of the scuba diving tourism system, instrumental ground and descriptive core are already well examined by previous studies (see page 17 Table 2.1 for reference). Therefore, the normative aspects are specifically discussed and examined in this study to strengthen the fundamental understanding of the scuba diving tourism system. Next, the scuba diving tourism system will be examined. 


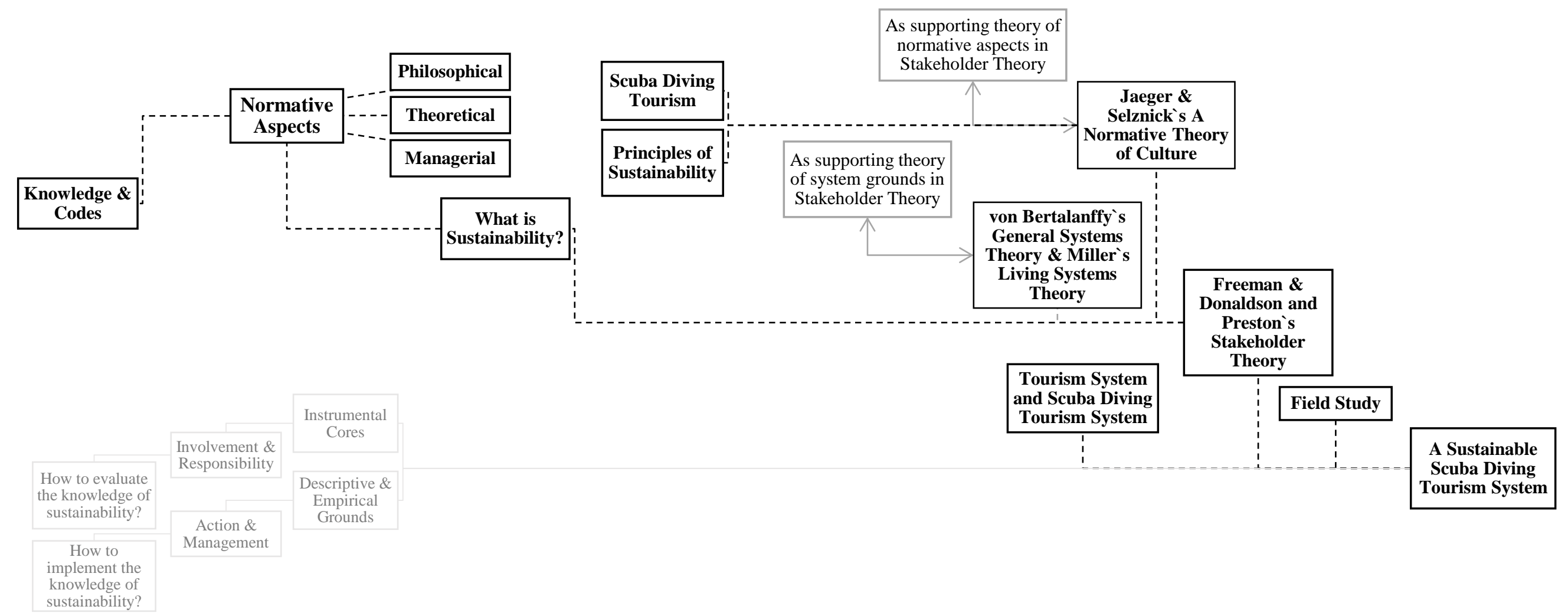

Figure 4.4. The Theoretical Framework 


\subsection{From Tourism System to Scuba Diving Tourism System (SDTS)}

The tourism system, in a general manner, is comprised of guidance for the effective management principles of the destination (Leiper, 2004; Plummer \& Fennell, 2009; StricklandMunro et al., 2010; Dimmock et al., 2014; Dimmock \& Musa, 2015). Policy-level decisions (Atkins et al., 2011), collaboration and shared responsibility (Plummer \& Fennell, 2009) are the main applications of the tourism systems. In this respect, each stakeholder takes responsibility regarding their capacities and interests while interacting with the system. The interaction brings exchanging ideas to a certain extent and creates collaborative actions among stakeholders with their unique viewpoints inside the system (Ku \& Chen, 2013). Therefore, the notion of the tourism system has been used since the 1970s, arguably the heyday of the spatial sciences (e.g., Preobrazhensky et al., 1976; Leiper 1989; Farrell \& Twining-Ward 2004; Hall $\&$ Page 2014). In a general sense, the tourism system is divided into four parts, they are market (where the tourist come from); travel (how tourists come to destination); destination (where the main activity and supporting activities take place); and marketing (how strategies are being used to promote the destination) (Mill \& Morrison, 1985). However, in a broad sense, the tourism system is far more complex compared to four subdivisions.

The tourism system is comprised of the combination of expectations of tourists; entrepreneurship; human capital; capital of investors; local authority; host community; attitudes of local people; main attractions; supporting resources; external factors such as currency rate and competition; external impacts such as economic and ecological effects; and interests of stakeholders (Le Pelley \& Laws, 1998). Moreover, non-tourism businesses; other interest groups; and supporting industries also play an important role in tourism planning (Hall, 2008) and create complexity in the system. For this reason, implementations, relations between stakeholders, economic factors, environmental indicators, and changes become significant constituents to understand and execute the tourism system (Hall \& Butler, 1995). However, even if there is an implemented tourism system, it is not certain that social and economic benefits will last forever (Hall \& Butler, 1995). Therefore, within the systems approach, principles of sustainability become essential subjects to re/consider for the success of tourism planning. As a basis, the question of "what is being sustained for whom" (Hall \& Butler, 1995, p. 103) in accordance with decisions; governing (Hall et al., 2004); and desired outcomes can be answered to define the purpose of the system. 
The tourism system stands for a formulation of policy which constituted by legal; social; political; economic phase and affects tourists; associated businesses; national and local governments; related organisations; and the host community with interest groups which are also part of stakeholders of this system (Goeldner \& Ritchie, 2009). For example, governmental organisations can play an important role in affecting tourism supply negatively or constructively and direct the tourism demand in accordance with the interest of the tourism system (Fletcher et al., 2018). In this sense, destination planning; visitor management; and market positioning can be affected by this formulation of policy and its process. The policy formation as the fundamental of tourism system has eight subcomponents (Goeldner \& Ritchie, 2009, p. 443): (1) Definition explains the system itself. (2) Philosophy refers to the aim of the system. (3) Vision stands for the position in the future. (4) Positioning/branding strategy represents the value of the destination or business. (5) Development addresses a plan. (6) Competitive/collaborative analysis provides a systematic approach to evaluate the current situations. (7) Monitoring and evaluation help to improve the system. (8) Destination audit identifies the destination future as of subsidiary details.

In the tourism system, the level of benefit derived from a destination can be varied according to the mutual outcomes as a result of particular and associated stakeholders' actions during a certain period (Le Pelley \& Laws, 1998) and the composition of this many-sidedness of understanding the issues (Hall, 2008). Like other business systems, the tourism system has been established on economic activity as a combination of power and attributes by social institutes (Freeman, 2001). The tourism system "by its nature creates interdependencies" (American Law Institute, 1994, p. 72) to one and another and governments; suppliers; customers; employees; owners; shareholders; stockholders; managers; and local communities are needed to work together. Ensuring the common ground of the system relies on addressing associated stakeholders` needs and interests, however, this may bring conflicts among stakeholders due to unequal share in income distribution, for example. Therefore, the system management in tourism can be established on primarily "simultaneous attention to legitimate interests of all appropriate stakeholders, both in the establishment of organizational structure and general policies and in case-by-case decision making" (Donaldson \& Preston, 1995, p. 67) without compromising the benefits and interests over another (Donaldson \& Preston, 1995). Because of the nature of tourism, individual perceptions; knowledge; values; actions; and interests become the main subjects and determinants of the system (Zimmermann, 1951) and 
individual positions in the system may differ from active (who can affect or be affected) to the non-participating status of the parties (remain outside) (Singh et al., 2003).

In the modern era, when it comes to scuba diving tourism since the system has more complex features than traditional management approaches, it is no longer sufficient because it has comprehensive approaches and systems depend not only on stakeholders but also on nature. In order to improve the system, "first, we must find out the 'nature of the beast', what is meant by 'systems`, and how systems are realised at the various levels of the world of observation" (von Bertalanffy, 1972, p. 421). In this sense, what the 'nature of the beast' is in scuba diving tourism becomes a systematic problem due to the dilemma of whether to create adverse effects or generate economic benefits derived from the complicated relationship between the stakeholders and the marine environment. In theory, identifying the components of scuba diving tourism provide advantages for stakeholders to have key knowledge about the practices and future implications. The key knowledge can also help to create a mutual ground among the stakeholders who influence the main components of scuba diving tourism. Thus, current issues can become more understandable and meaningful in order to minimise the adverse effects and improve the positive aspects. In line with this objective, researchers have created a contemporary systems approach for scuba diving tourism, named 'Scuba Diving Tourism System` (SDTS). The SDTS provides fundamental knowledge (regarding descriptive and instrumental) to explore the narratives which rise to the surface from beneath the water. In order to better understand the current phenomenon and identify the gap, current SDTS approaches are discussed below in order of the current literature and the applications.

The first SDTS framework has been proposed by Musa and Dimmock in 2013. As can be seen in Figure 4.5 (Musa \& Dimmock, 2013:4), there are three key elements in this concept. They are environment (marine environment awareness and conservation management); scuba diving tourism industry (business management); scuba divers (service delivery and customer satisfaction management). Rather than determining a core element for the system, collective dynamics such as type of diving; scuba divers`satisfaction; accessibility; climate change; and sustainability constitute the centre of the elements. History (of scuba diving tourism) and geography (landscapes, coral reefs, and other scuba diving areas) establish the subject of environment. Experience, motivation, and behaviour are the main components of the scuba divers' part. Health and safety, training, education, and scuba diving impact are the common interests between dimensions of environment and scuba divers. As to scuba diving tourism, 
businesses are the only constituent of this element. On the one hand, training, education, and standards are evaluated with scuba divers, on the other hand, scuba diving impacts are related to the environment.

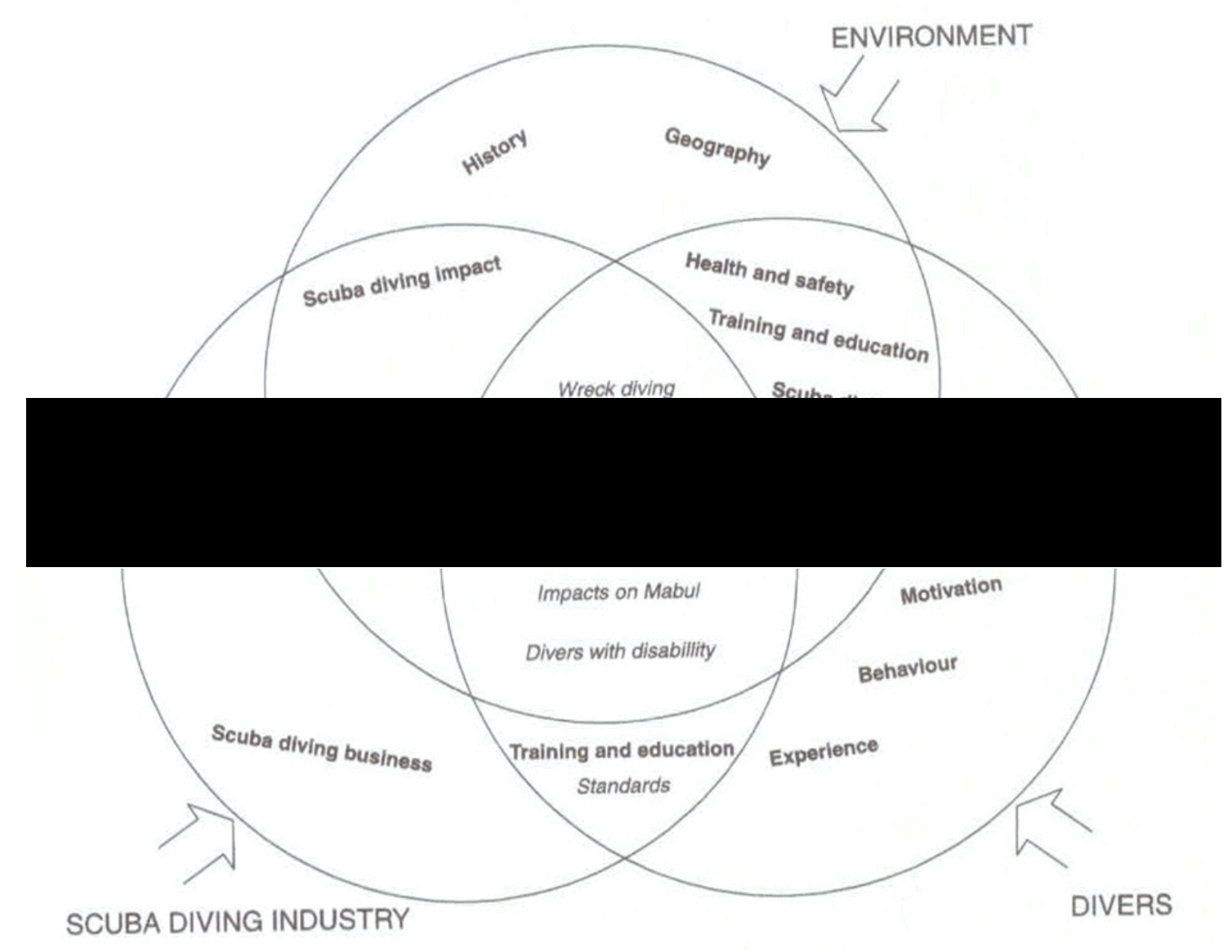

Figure 4.5. Scuba Diving Tourism System (Source: Musa \& Dimmock, 2013, p. 4)

A revised concept of the SDTS has been conceptualised by Hillmer-Pegram (2014) based on resilience theory to understand the threats due to the complex change and the way of responding to scuba diving tourism. "Resilience is the capacity of a system to absorb disturbances while maintaining its fundamental structure and function" (Hillmer-Pegram, 2014, p. 601). In this sense, the proposed resilient dive tourism system is a "fundamental function of providing livelihoods is emphasized because these livelihoods are one of the system's main benefits and largely define the desirability of its current state" (Hillmer-Pegram, 2014, p. 603). In the general sense, this concept has established two components which are ecological as the marine environment and society, as scuba divers and scuba diving operators. As a result, this study put down the fact that scuba diving tourism needs a broad approach to minimise the negative effects in the sense of environmental, economic, and social, and maintain 
the fundamental functions of scuba diving tourism with benefits. However, as the author claims, further research is needed to clarify the link between environmental and social constituents for application in sustainable management implications.

Following this work, the SDTS has been revisited by Dimmock and Musa in 2015, defining the management and leadership aspects regarding stakeholders. In this revised systems approach, they try to identify the key elements of scuba diving tourism. As can be seen in Figure 4.6 (Dimmock \& Musa, 2015, p. 53), there are four main characters in this new SDTS version. These are the marine environment, host community, scuba divers and scuba diving tourism itself. The marine environment constitutes the core element of the concepts. This is because all scuba diving activity takes place in these surroundings. The other key elements of the system are interwoven and interconnected to each other but still rely on the marine environment depending on their roles and responsibilities. The roles of the parts in the system have been denominated as demand (scuba divers); suppliers (service providers who are scuba diving operators, charter operators, associations, and other touristic services); and managerial background as communities, social and cultural resource organisations (authorities, stakeholders, decision-makers, governance, and related managers).

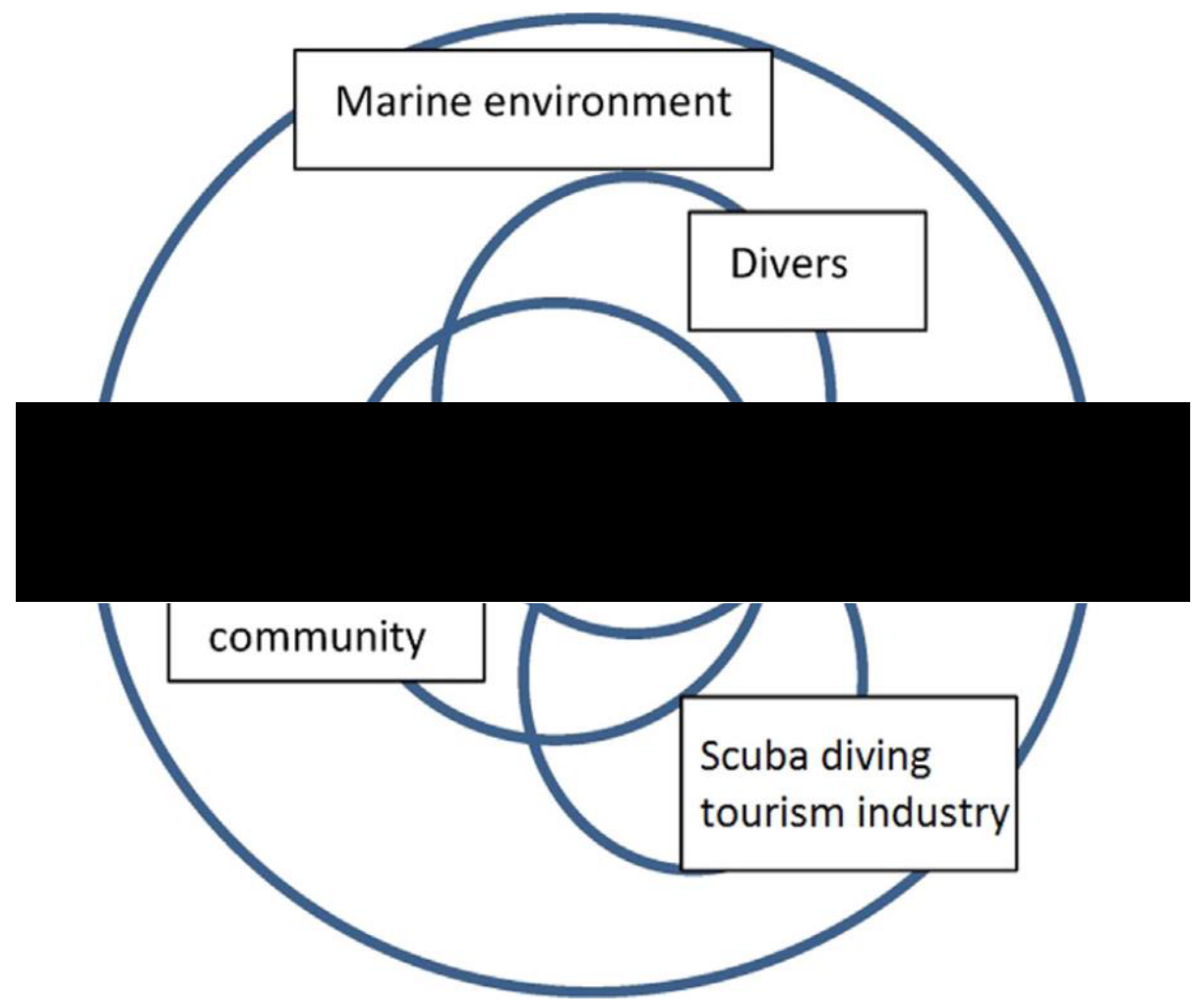

Figure 4.6. Scuba Diving System: Key Elements (Source: Dimmock \& Musa, 2015, p. 53) 
However, as Dimmock and Musa highlight, in terms of sustainability "little research has included the scuba diving industry" $(2015$, p. 52), particularly in the local and regional base with providing benefits for each part in terms of protecting the environment; enriching the living standards for the host community; and ensuring profitability while maximising the scuba diving experience for scuba divers. According to Dimmock and Musa (2015), "further research is also needed to refine the model and analyse its efficacy in ensuring SDT (Scuba Diving Tourism) has a sustainable future" (p. 56). The main benefit of using the systems approach for scuba diving tourism is to stimulate the practices and principles of management. Integration of the stakeholders can become easier by means of common grounded policies. This also enhances innovation and creativity in decision making and the process of problem-solving (Fabinyi, 2008; Wongthong \& Harvey, 2014). However, the complexity of the system remains as it is, therefore in order to carry on the system successfully, a broad and integrated effort is needed that involves all stakeholders in this tourism system.

Two years later of Dimmock and Musa's study (2015), the SDTS has been studied and applied by Lucrezi et al. in 2017 in two MPAs located in different continents and countries. This study aimed to understand the perceptions of scuba diving tourism actors towards SDTS and evaluate the relationship between other key elements in the system in a sense of 'causeeffect and matter-solution/action relationships`(Lucrezi et al., 2017). Unlike other conceptual studies, the field study of this work was conducted in MPAs. According to findings, the complexity of the system emerged because of the lack of capacity for communication and collaboration between key elements. For success in the common ground, the centrepiece of this system can create a strong network among stakeholders with constant communication. The other requirement to succeed in the SDTS is to share a mutual interest with local communities.

\subsection{Identifying the Gap}

The existing literature showed that scuba diving tourism causes negative effects on fragile and non-renewable biological, cultural, and manufactured resources because of unsustainable practices. Over the last decades, a number of studies found that there are considerable harmful effects on underwater assets, which are caused by unsustainable levels of scuba diving activities at popular sites (e.g. Zakai \& Chadwick-Furman, 2002; Hasler \& Ott, 2008; Au et al., 2014; Toyoshima \& Nadaoka, 2015), because of scuba divers` behaviour such as touching, breaking by fins (e.g. Hasler \& Ott, 2008; Polak \& Shashar, 2012; Au et al., 2014; 
Lamb et al., 2014; Toyoshima \& Nadaoka, 2015; Roche et al., 2016; Terrón-Sigler et al., 2016; Spalding et al., 2017; Tynyakov et al., 2017) and "intensity of use by scuba divers and a lack of diving experience" (Kirkbride-Smith et al., 2013, p. 1). Moreover, as indicated in this study, there are also external factors such as marine pollution, unattended marine activities and lack of management capacity that cause additional stress on the underwater surroundings. To be able to use these resources without causing harm depends on eliminating negative environmental effects by providing effective management capacity to the areas (Medio et al., 1997; Musa, 2002) and economic benefits (Hillmer-Pegram, 2014) while maximising the scuba diving tourism experience in the sense of sustainability. Therefore, principles of sustainability and implementing these applications into the fragile underwater environment become crucial.

In addition to this, the foundation of scuba diving tourism relies on compatibility between addressing participants' needs and expectations. Better understanding the dimensions of the scuba diving experiences are important for setting up management standards (Bentz et al., 2016a) which can also help to create a sustainable tourism development with an attractive choice of investment opportunity (Dikou \& Troumbis, 2006). With this regard, scuba diving tourism may develop sustainable experiences according to the needs of the scuba divers and local requirements for the marine environment with certain strategies and practices in the long term. However, simply emphasizing the needs and requirements is not enough to achieve sustainable development goals or standards in scuba diving tourism, therefore, joint, and collaborative actions with stakeholders are essential to ensure desired outcomes in such destinations. Through the improvement of sustainable-based scuba diving activities, authorities and associated stakeholders can get marketing initiatives and competitive advantage (Schoeman et al., 2016), and have better risk management (Cater, 2008). To implement these management models, there is a need for a systems approach that includes several dimensions to play a role in the scuba diving tourism for a certain purpose. Addressing all these constituents in this system may give an advantage for the success of the sustainable scuba diving tourism development that can provide benefits for associated groups from scuba divers to the local community while increasing awareness of protecting the marine environment (Arin \& Kramer 2002; Lück 2003; Musa \& Dimmock, 2013).

In this connection, the specifications, and characteristics of SDTS have been considered from various aspects and the main objective of previous SDTS has been established on descriptive and instrumental practices. On the one hand, the descriptive core has tried to explain 
how managers may address and represent the interests of stakeholders in different stages in both competitive and cooperative environments in the SDTS. How stakeholders can behave and revise their actions and roles (Fontaine et al., 2006) constitutes the main question for descriptive principles. Descriptive aspect has three grounds which can be used to explain the role in stakeholder theory, they are (1) to analyse the stakeholders to find out their nature; (2) to find out what kind of circumstances stakeholders face or will face the circumstances in terms of organisational operations and decision makings; and (3) to decide which strategies can be employed to deal with issues (Phillips et al., 2003). To sum up, the descriptive aspect of stakeholder theory explains how companies can be managed; identifies relevant stakeholders (Agle et al., 1999; Jawahar \& McLaughlin, 2001; Wallis, 2006; Sangle \& Ram Babu, 2007).

On the other hand, the instrumental core has focused on how stakeholders evaluate different laws and regulations to achieve corporate goals in the SDTS. The instrumental ground deals with stakeholders from the governance perspective. For instrumental principles of the stakeholder theory, how stakeholders can act regarding their interests become the main theme of this core. Instrumental aspects in stakeholder theory highlight the effects of stakeholder management on the achievement of common objectives (Jones, 1995; Berman et al., 1999; Johnson \& Greening, 1999; Mathur et al., 2008). In a general sense, the descriptive and instrumental grounds are about improving the management perspectives and both approaches were well documented in existing SDTS literature. The descriptive core of SDTS was indicated by Musa and Dimmock in 2013 and Hillmer-Pegram in 2014. Following, instrumental cores were identified by Dimmock and Musa in 2015 and Lucrezi et al. in 2017. However, although the normative core was the primary source of knowledge, normative aspects of the scuba diving tourism systems in a manner of principles of sustainability have yet been studied sufficiently. Without providing fundamental knowledge based on normative aspects with a theoretical approach, understanding the meaning and functionality of the system becomes limited in the existing SDTS models.

Moreover, the relationship between sustainability and the SDTS has attracted insufficient attention in the current literature (Dimmock \& Musa, 2015) from a systematic approach. Evidence on the ground showed that while the priority of principles of sustainability among stakeholders is high, but it is observed that for non-related stakeholders principally the economic benefit becomes a priority (Haddock-Fraser \& Hampton, 2012). As a result, further research has become a requirement to understand the fundamentals of the SDTS and 
management plans to control current situations and prospects. Within this framework, knowledge becomes a key function as a principle that generates the main structure of the system with essential elements, inputs, outputs, and character (Checkland, 1981) which are the sets of knowledge and essential to protect and enhance the system. Therefore, this thesis focuses not only on practical and managerial implications, but normative aspects based on moral and ethical values to create a better systems approach based on knowledge with theoretical backgrounds. Once the basic meaning of the systems is understood by associated groups, their behaviour can start changing and turn into positive and constructive contributions to the dynamics of the system in the manner of principles of sustainability. In line with this definition, widely defined structures will create more accurate systems which enable the specification of the components of the value in different scales (Laszlo \& Krippner, 1998).

In order to be able to make a better clarification of the current situation in scuba diving tourism, the bond between the fundamental meanings of the system and its functionality is the key subject of this study. In this respect, this thesis aims to reveal the fundamental set of knowledge about individual perception of principles of sustainability among stakeholders in scuba diving tourism to create a body of knowledge as the normative ground of the system. For this purpose, Goeldner and Ritchie`s eight subdivisions (2009:443) will be employed to explain what a system is and how it works, respectively: (1) System will be defined. (2) Philosophy of the system will be established. (3) Vision will be created. (4) Positioning/branding strategy of the destination and stakeholders will be specified. (5) A plan will be developed. (6) A systematic approach will be analysed for competitive and collaborative advantages. (7) Monitoring and evaluation indicators of the system will be established. (8) Destination audit will be identified. These attempts will also establish seven grounds that help the system to set up the model for every associated group of members as suggested by Adams (2012, p. 220): (1) The centrality of the system will be established to understand the main function of the system. (2) Context of the system will be redesigned and redrawn according to the system needs. (3) The design will be determined with regards to stakeholders` role and responsibility. (4) The goal of the system will be clarified. (5) Information channels will be created with constant communication in the system. (6) The operational capacity of the system will be discussed. (7) Viability of the newly redesigned system will be addressed. By doing so, it is aimed to create a more systematic and functional systems approach for scuba diving tourism researchers and stakeholders which coherent principles of sustainability and standards. 
As a result, achieving optimal sustainable scuba diving tourism development goals is dependent on a well-planned comprehensive and contemporary systems approach. Regular and long-term communications between stakeholders (Lucrezi et al., 2017), collaborative management initiatives (Giglio et al., 2020), background for sharing responsibility (SharmaWallace et al., 2018), continuous monitoring (Sterling et al., 2017), activity plan and guidelines and education for enforcement standards (Trave et al., 2017) must be established not only for effective system model with socio-economic benefits but also promoting unique scuba diving experience (Wongthong \& Harvey, 2014). Therefore, this study focuses on understanding and revealing the normative aspects based on the moral and ethical values of the SDTS under the principles of sustainability. By doing so, it is aimed to fill the gap in the existing literature and contribute the scuba diving tourism and its knowledge by redesigning this system according to principles of sustainability through defining the normative aspects. For this purpose, the theoretical framework of this study is established on providing a guideline to achieve certain sustainable development goals or standards in the scuba diving tourism system. Knowledge and normative aspects are positioned as the main interest of this study based on the triple bottom line of sustainability. The main reason normative aspects are chosen is to explain the meaning of the system and identify the degree/level of the functionality of the SDTS, which is limited in the existing literature. In this context, in the next section, general views on methodological approaches based on an exploratory qualitative study are given to reveal the important aspects of this research. 


\section{CHAPTER 5: METHODOLOGY}

\subsection{Introduction to Chapter 5}

\begin{tabular}{|c|c|c|c|c|c|}
\hline $\begin{array}{c}\text { Chapter } 1 \\
\text { Introduction }\end{array}$ & & $\begin{array}{c}\begin{array}{c}\text { Overview } \\
\text { and } \\
\text { Introduction }\end{array} \\
\end{array}$ & $\begin{array}{l}\text { Research } \\
\text { Outline }\end{array}$ & $\begin{array}{l}\text { Chapter } \\
\text { Reviews }\end{array}$ & \\
\hline $\begin{array}{c}\text { Chapter } 2 \\
\text { Scuba Diving Tourism }\end{array}$ & $\begin{array}{l}\text { Discovering } \\
\text { the } \\
\text { Underwater }\end{array}$ & $\begin{array}{c}\text { Scuba } \\
\text { Diving } \\
\text { Economy }\end{array}$ & $\begin{array}{c}\text { Scuba } \\
\text { Diving } \\
\text { Experience }\end{array}$ & $\begin{array}{l}\text { Current } \\
\text { Issues }\end{array}$ & \\
\hline $\begin{array}{c}\text { Chapter } 3 \\
\text { Sustainability }\end{array}$ & $\begin{array}{c}\begin{array}{c}\text { Sustainable } \\
\text { Tourism } \\
\text { Development }\end{array} \\
\end{array}$ & $\begin{array}{l}\text { Division } \\
\text { and } \\
\text { Concept }\end{array}$ & $\begin{array}{c}\text { Current } \\
\text { Practices in } \\
\text { Scuba } \\
\text { Diving } \\
\end{array}$ & $\begin{array}{l}\text { MPAs and } \\
\text { Alternative } \\
\text { Dive Sites }\end{array}$ & \\
\hline $\begin{array}{l}\text { Chapter } 4 \\
\text { Theoretical Foundation }\end{array}$ & $\begin{array}{l}\text { Normative } \\
\text { Theory }\end{array}$ & $\begin{array}{l}\text { System } \\
\text { Theories }\end{array}$ & $\begin{array}{l}\text { Stakeholder } \\
\text { Theory }\end{array}$ & SDTS & $\begin{array}{l}\text { Identifying } \\
\text { the Gap }\end{array}$ \\
\hline $\begin{array}{c}\text { Chapter } 5 \\
\text { Methodology }\end{array}$ & $\begin{array}{l}\text { Research } \\
\text { Framework }\end{array}$ & $\begin{array}{l}\text { Research } \\
\text { Strategy }\end{array}$ & $\begin{array}{l}\text { Research } \\
\text { Ethics }\end{array}$ & \begin{tabular}{|c|c|c|}
$\begin{array}{c}\text { Limitations } \\
\text { in } \\
\text { Methodology }\end{array}$ \\
\end{tabular} & $\begin{array}{c}\text { Field Study } \\
\text { Area }\end{array}$ \\
\hline $\begin{array}{l}\text { Chapter } 6 \\
\text { Results }\end{array}$ & Strain & Stress & Sustain & Supervision & Support \\
\hline $\begin{array}{l}\text { Chapter } 7 \\
\text { Discussion }\end{array}$ & & $\begin{array}{l}\text { Inferences } \\
\text { and Links }\end{array}$ & $\begin{array}{l}\text { Constituents } \\
\text { and } \\
\text { Foundations }\end{array}$ & $\begin{array}{c}\text { Revised } \\
\text { Sustainability } \\
\text { Criteria }\end{array}$ & $\begin{array}{c}\text { S-SDTS } \\
\text { Model }\end{array}$ \\
\hline $\begin{array}{c}\text { Chapter } 8 \\
\text { Conclusion }\end{array}$ & & $\begin{array}{l}\text { Ans wers to } \\
\text { Research } \\
\text { Questions }\end{array}$ & Implications & Reflection & Limitations \\
\hline
\end{tabular}

Figure 5.1. The Structure of Chapter 5

This thesis aims to redesign the scuba diving tourism system according to principles of sustainability through defining the normative aspect. This chapter covers the overall methodological approach of this study, by starting to explain the research framework and identifying the research questions (see Figure 5.1). Following, research strategy and the interpretive paradigm as phenomenology approach will be indicated in detail. The related information regarding the method of this study, semi-structured interviews, and active participation as well as interview and question design will be provided later in this chapter. The data analysis process and research ethics along with reliability and validity analyses and trustworthiness of this study and method will also be explained in detail. Last, the field study area, which is Malta, will be given end of this chapter. 


\subsection{Philosophical Considerations and Research Framework}

This study aims to redesign the scuba diving tourism system according to principles of sustainability through defining normative aspects within a systems approach from the perspectives of stakeholders. In detail, this study aims to evaluate outcomes and the degree of principles of sustainability in the scuba diving tourism system through the stakeholders experience. As Abercrombie et al., (2006, p. 86) stated “... an empirical statement is one which can be tested by some kind of evidence drawn from experience". However, before examining the empirical fieldwork, this study first establishes the research paradigm - "a basic set of beliefs" - (Guba, 1990, p. 17) that frame the research question/s. The ontology (that is the current world view), the epistemology (that is the relationship between researcher and subjects), the axiology (that is the ethical practices), and the methodology and method that are used in this research. More specifically, basic definitions of paradigmatic approaches used in this study (Stanley \& Wise, 1990; Heron \& Reason, 1997; Jennings, 2010; Sarantakos, 2013; Taylor et al., 2016; Moran, 2018; Howitt, 2019) can be seen as below:

i. Ontology is the study of beings or their being, what is or the real world and the nature of reality.

ii. Epistemology is the study of knowledge, how we know or what is the relationship between subject, object, participant, or researcher.

iii. The interpretive paradigm is an empathetic description of subjects` perceptions.

iv. Phenomenology is the study of our experience, in terms of how we experience and understand by giving meaning.

v. The methodology is the process of collecting data and getting knowledge, as a research strategy to answer the question of how we conduct research.

vi. A method is a tool denominated as data collection, interpretation, or analysis.

vii. Logic is the study of valid reasoning, how to reason.

viii. Axiology and ethics are the study of right and wrong, how we should act, what is the value of knowing.

Together these "translate ontological and epistemological principles into guidelines that show how research is to be conducted" (Sarantakos, 2013, p. 30). When applied to this research, the paradigm provides the researcher knowledge to design the framework between data and phenomena (Jennings, 2010) which will uncover the stakeholders` understanding and 
experiences. In this respect, according to the research paradigm, phenomenological analysis as the interpretive paradigm is used in this study to explain how stakeholders perceive the meaning of principles of sustainability and define normative aspects based on moral and ethical values in the scuba diving tourism system. Therefore, by depicting the theoretical linkage between the scuba diving tourism system and given theories, the theoretical framework was constructed in line with the normative aspects. Moreover, the theoretical framework influenced the ontology of this study during active participation in the field of the study. Concordantly, the main research question of this thesis is defined as:

- 'To what extent do the normative aspects of the scuba diving tourism system address principles of sustainability?'

This study also includes five sub-research questions each of which address to theoretical framework given in Chapter 4. The five sub-research questions are:

i. How do stakeholders understand principles of sustainability in the scuba diving tourism system?

ii. How do stakeholders prepare operational plans and provide regulations to manage the system with control activities for the sustainable use of scuba dive sites?

iii. How do stakeholders address the triple bottom line of sustainability while interacting with the marine environment within the scuba diving tourism system?

iv. How do stakeholders accommodate personal knowledge about principles of sustainability and their skills in the scuba diving tourism system?

v. How do stakeholders recognise the philosophical, theoretical, and managerial cores as the normative aspects of the scuba diving tourism system?

The method of this study is adjusted and planned according to the research proposal to address these questions. A case study was carried out in Malta because of scuba diving 
opportunities in a range of natural and alternative dive sites. In line with this, the following sections are provided for establishing the fundamental Information for the reason for conducting this study in line with the research proposal and philosophy of this thesis.

\subsubsection{Ontology}

Ontology is the study of being, answering the question of what is real and what is the nature of reality. The ontological assumptions are subjective and grounded on interpretivism to conduct the research. Because real-life settings like physical phenomena that are shaped from the social world and interactions between subjects or socially constructed (social constructivism) are hard to be understood by the positivist paradigm (Saunders et al., 2019). In a general sense, social constructivism explains realities derived from subjects` interactions and interpretations of the existing phenomena (Saunders et al., 2019) that reflect the subjective interpretation. A subjective ontology seeks the facts to create a wider understanding of the current phenomena that are culturally and historically situated within the real world based on variable behaviours, attitudes, experiences, and interpretations (O'Gorman \& MacIntosh, 2015). In this connection, the ontology for this study is to understand the current phenomenon of knowledge regarding principles of sustainability and its practices in real-life settings, moral and ethical values, and practices of stakeholders in the realm of the scuba diving tourism system. Moreover, with an empathetic stance, this study focuses on stakeholders' lived experience that is the interpretations of meaning-making (Collins, 2010) of moral and ethical values to better understand their social world and point of view (Saunders et al., 2019).

The ontology also defines why the study is important to conduct as a research paradigm. In this study, it is expected that principles of sustainability in the scuba diving tourism system shape the understanding of stakeholders or participants relations and their experience with the underwater world. According to The National Oceanic and Atmospheric Administration (NOAA, 2020), underwater environments in oceans and seas is important due to producing the air that we breathe and absorbs 50 times more carbon dioxide; regulating and controlling the climate; providing worldwide transportation; promoting recreational activities such as tourism, sports, and scuba diving; creating \$282 billion worth of economic incentives for three million people; and food and medicine. More explicitly, with regards to sustainable practices and current phenomena, UNESCO (2020) shows that how important, but vulnerable and under threat the marine environment is. The ocean constitutes over 90 per cent of the habitable space 
on the planet, however, about 35 per cent of the critical marine ecosystem has been destroyed to a global extent and 60 per cent of the remaining has been used unsustainably and struggles with marine pollution because of unregulated agricultural practices; adverse industrial purposes; and intensive tourism activities. There are around 500 'dead zones` which cover more than $245,000 \mathrm{~km}^{2}$ of surface globally, equivalent to the size of the United Kingdom. In contrast, approximately 12 per cent of the land area is protected around the world, compared to roughly 1 per cent of the world ocean and seas. Overall, by the year 2100 , it is estimated that more than half of the world's marine species may stand to become extinct because of global warming and unsustainable practices.

In terms of touristic incentives, as IOC/UNESCO, IMO, FAO, UNDP (2011, p. 20) states: "tourism is one of the most important forms of revenue for coastal communities and much of this tourism derives from coastal amenities, which require healthy marine ecosystems, such as boating, scuba diving, fishing and swimming. Therefore, principles of sustainability become crucial to be able to use these sources to generate economic revenue and create touristic incentives for everyone. For example, many island nations rely extremely heavily on tourism for income, and any threat to the long-term viability of the tourism sector would have a massive effect on their economies". In this connection, this study focuses on how stakeholders understand the importance of oceans and seas and more importantly put sustainability into practice within the scuba diving tourism system. This study also discusses how the scuba diving tourism system can contribute to the protection of these sources or cause a detrimental effect on the underwater environment. Because tourism can become a tool for increasing awareness towards the marine environment (Lucrezi et al., 2013; Domínguez-Gómez \& GonzálezGómez, 2017). For instance, as documented in this study, certain scuba diving implementations such as underwater photography, unskilled buoyancy controls and certain scuba diving practices in caves or during the night, which all are intensive in practice, cause some problems for the marine environment. To have a better understanding of outcomes of unsustainable practices, this study tries to identify the current gaps regarding challenges the scuba diving tourism industry/market faces today, as well as precautions and implementations which are applied in the scuba diving tourism system by stakeholders in different aspects. To protect the fragile marine environment, maintain the economic incentives, and improve the life quality for local communities this study examines normative aspects based on the moral and ethical values according to principles of sustainability that can be applied for scuba diving tourism. 


\subsubsection{Epistemology}

Epistemology is the study of knowledge about how to know or what is the relationship between subject, object, participant, or researcher (Jennings, 2010; Seidman, 2013; Korstjens $\&$ Moser, 2017). In the sense of epistemological positioning of this study, the interpretive paradigm in the sense of constructive subjectivism and phenomenology are chosen to proceed with the research to comprehend the lived experience constructed through the social interactions (Mackenzie \& Knipe, 2006; Saunders et al., 2019). The epistemology of this study is to understand the relationship between the scuba diving tourism system and principles of sustainability and its practices in the real-life within the scope of stakeholders subjective perceptions which represent their understanding, experience, moral and ethical values. More precisely, this study shows how stakeholders put their knowledge derived from principles of sustainability and moral and ethical values in scuba diving tourism into practice in the destination in terms of problem-solving and decision-making processes under certain circumstances. In this sense, this study tries to find out whether the source of sustainability knowledge differs from ecologically, economically, and socially promoted normative aspects according to principles of sustainability. For this reason, the current literature is reviewed to build the fundamental knowledge for the research, and interviews took place with the stakeholders as a real-life reflection of the knowledge and practices in this study. In other respects, scuba diving tourism activities have an effect on underwater surroundings. This effect comes into existence by the interaction between scuba divers and scuba diving tourism which is associated with other stakeholders as is well documented in the current literature. Because of the increasing demand for scuba diving all over the world and the popularity of this activity, this research undertakes to comprehend sustainable development implications and question the current knowledge of stakeholders towards sustainability in the scuba diving tourism system.

In the sense of epistemological assumptions, the meanings of statements are aimed to be discovered through the narratives (Van der Walt, 2020) of stakeholders. Compared to other methodological approaches like positivist paradigm and statistical data interpretation, the matter of principles of sustainability in scuba diving tourism needs to be understood by lived experiences of stakeholders who are involved in this activity. This research focuses on an understanding of the current issues in relation to subjective knowledge (Saunders et al., 2019) of stakeholders and practices according to principles of sustainability in the scuba diving tourism system within the interpretivism paradigm. The case study was conducted in Malta due 
to the popularity and wide range of opportunities for scuba diving tourism. The reason the field study was chosen as the main research methodology in practice was to reveal non-theoretical knowledge and practices according to principles of sustainability derived from the participants, stakeholders, or subjects' experiences in the existing scuba diving tourism system. The current phenomenon in Malta is examined not only between scuba divers, scuba diving centres and the researcher but also for the stakeholders who are employees, decision-makers, authorities, and related scholars. Rather than having objective perceptions, subjective perceptions of participants were considered essential to understanding the current phenomenon. In accordance with this purpose, the interpretive paradigm can have an important role in acquiring the current phenomenon or actual situation that is affected by the subject's experiences and the way of interpretation of the sustainable practices in the scuba diving tourism system. As indicated in the next section, the interpretive paradigm provides the researcher with an empathic way of describing subjects` perceptions.

\subsubsection{Interpretive Paradigm}

The qualitative research design, which is subjective based rather than being objective, is a process of assumptions of inquiries that are the point of departure of a study. Moreover, researcher/s` own perception and understanding are the important constituents of running qualitative research (Creswell \& Poth, 2007). In this connection, empathetic understanding comprises the basis for the interpretive paradigm (based on the work of Max Weber in the late 1970s) (Jennings, 2010). As Weber (1978) states "empathic or appreciative accuracy is attained through sympathetic participation ... in which the action took place" (p. 5). Therefore, in the scuba diving tourism system context, subjectivism exposes individual perceptions and opinions about principles of sustainability, which rely on different backgrounds and diverse demographics. This research uses a qualitative research method, the semi-structured interview with the data collected from interviewees` (stakeholders) perceptions. The research is examined the issues that occurred in reality rather than employing experimental study.

The interpretive paradigm considers multiple realities in order to enhance statements of the phenomena (Jennings, 2010) as an ontological basis. According to the epistemological basis, to be involved in the social life where the phenomena come into view is a fundamental point to conduct research. That creates a relationship between the subject and the researcher. From the point of the methodological basis of the interpretive paradigm, this study is to perform 
semi-structured interviews with the intention of seeking an 'emic perspective` (Fetterman, 1989, p. 31). When it comes to method, memos, coding, and thematic analysis (as used in this study) give better results to identify the phenomenon. Besides ontology, epistemology, and methodology, within the scope of axiological or ethic basis, the phenomenon is complicated and worthy of note. The researcher and the subject link to social change (Guba \& Lincoln, 2005) and both should maintain independence to be involved in the process of knowledge exchange. Within this context, the interpretive paradigm is used in this research to define normative aspects (stakeholders` moral and ethical values) according to principles of sustainability in the scuba diving tourism system to bring the real-world setting of social action`s knowledge into view (Jennings, 2010). By doing so, this study is aimed to examine the scuba diving tourism system by working through the subject, existing knowledge in the real setting and lived experiences of stakeholders in Malta. The study is based on a phenomenological approach as a qualitative research method (phenomenology), which is indicated in the next section.

\subsubsection{Phenomenology}

Phenomenology is the study of the subject's experience and how to experience it. Phenomenology is used when the research questions ask for the real meaning of the experience as the knowledge that emerged in certain times and events through describing and interpreting the meaning of the individual experience. Phenomenology seeks observed experience by putting it in the centre of the first-hand derived point of view (Moser \& Korstjens, 2018; Moran, 2019). This is an approach to understand and indicate the experience within a certain living context (Crotty, 1996, 1998; Hayllar \& Griffin, 2005). Merleau-Ponty (1962) states "phenomenology tries to give a direct description of our experience as it is, without taking account of its psychological origin and the causal explanations" (p. 7). Phenomenology is considered as one of the influential and widespread philosophical methods and approaches in the sense of social relations, empathy, cultural tradition, and embodiment (Moran, 2018), therefore it is inductive qualitative research. Established in the $20^{\text {th }}$ century by Edmund Husserl (1859-1938), a German mathematician, in 'descriptive' norms and reinterpreted by Martin Heidegger as in 'interpretive' norms. In Husserl's phenomenological foundation, the individual`s experience is a conscious action and people rely on its meaning (Creswell, 1994) which is a "universal a priori of correlation between experienced object and manners of givenness" (Husserl, 1970, p. 166). However, as Moran (2018) addresses, experiences are 
impressed by past meaningful experiences (also named as the 'harmoniousness' by Husserl) which is determinative motivates of expectations of continuity.

People are aware and conscious while experiencing an object or event, in their daily lives, the ordinary, every day, the pre-scientific world (Moran, 2019), by having knowledge, thought, memory, imagination and emotion. In addition to these, as Howitt (2019) addressed, people`s attitudes, values and beliefs are also included in individuals`experience perceptions, as well as free will, time-consciousness (Husserl, 1928), justification, clear-thinking, symbolic meaning, awareness, subconscious drives, and desires (Moran, 2013). The main themes of the phenomenological study are empathy; intersubjectivity; intentionality; historicity; perception; embodiment; intuition; eidetic insight; sociality; and the lifeworld (Gallagher \& Zahavi, 2012; Moran, 2018). The first-hand approach is to extend knowledge across experience itself and self-evaluation. With this design, the primary research questions to find out the implicit or actual meaning of the experience are:

a. What do people know as a person? (Reiners, 2012)

b. How do people think about their experiences? (Howitt, 2019).

c. What is the nature of perception? (Husserl, 1928).

d. How are objects experienced in perception? (Moran, 2019).

e. What is the experience like? (Husserl, 1928).

f. What is the meaning of the experience? (Husserl, 1928).

g. How does the lived world present itself? (Finlay, 2009).

Phenomenology is the "study of human experience and the way in which things are perceived as they appear to consciousness" (Langdridge, 2007, p. 10). Therefore, people develop knowledge by experiencing and this shapes people`s understanding. Fundamentally it is a wilful description that tries to achieve overall meaning from all types of interaction that relate to the subject (Moran, 2019). Phenomenology, during the research, practices some principles to expose the experience (Howitt, 2019) as:

a. People have experience when they are conscious of what they do.

b. Phenomenology can describe a specific individual`s concerns.

c. Description of the experience based on its meaning and how people understand what is experienced which means observable occurrence. 
Phenomenology studies are interested in the way of human interaction between itself and the world of phenomena. These phenomena can be an action; an activity; a relationship; an empirical object (Zeegers \& Barron, 2015); or knowledge itself. Giving a meaning towards the experienced object or subject explains the lived phenomena. "There is an essential doublesidedness-often called 'correlation` to phenomenological intuition. There is, on the one hand, the object meant or intended and, on the other hand, the act of meaning or intending it" (Moran, 2019, p. 206). However, the experience is not an easy phenomenon to have knowledge on, because beliefs, biases, assumptions, presuppositions, attitudes, and opinions vary from person to person (Howitt, 2019). As a researcher, they should not be separated while interpreting the individual`s perception. Moreover, the time limit and a certain time when the experience occurred also become a significant matter to explain the participant`s understanding. In this sense, "the expression phenomenology signifies primarily a methodological conception ... this expression does not characterize the what of the objects of philosophical research as subject matter, but rather the how of that research" (Heidegger 1962, p. 50).

In phenomenological study methods, researchers should be bias-free and put their freethinking (unfilled) brackets to understand and describe the phenomenon (Idczak, 2007; Reiners, 2012) through the subject`s/sample`s eyes and their point of view. As Zeegers and Barron (2015) state, the researcher should piece together a person`s reflection and the existing knowledge which will be transformed into the experience through interviews, diaries, and personal statements. In this connection, the study aims to piece together the understanding of stakeholders and current issues through semi-structured interviews in the scuba diving tourism system in Malta. Because this study tried to address “... how people describe things and experience them through their senses" (Patton, 2003, p. 105), phenomenology was used to expose individual perceptions and opinions through stakeholders` experiences. In a sense, the qualitative approach is used for understanding the knowledge of stakeholders. Although there are different qualitative research methodologies such as grounded theory, ethnography, or heuristic research, this study is grounded on phenomenology which provided the researcher with a better understanding and flexible research design during the data collection and analysis process through interpretive paradigm. 


\subsection{Research Strategy}

\subsubsection{Personal Interest and Development Background in Research}

I had dived in summer 2009 for the first time in Side - Turkey. Since then, this unique and memorable experience led me to be interested in scuba diving and the underwater world both as a scuba diver to gain advanced experience and practice, and as a researcher to discover the hidden area of this captivating world from the tourism perspective. In January 2010, I started my master`s degree programme and wrote my master thesis about the alternative implementations of tourism products in scuba diving tourism. Because of my constant interest in scuba diving tourism, I wanted to continue to study this subject also in my $\mathrm{PhD}$ degree. Over the past 6 years, gradually, I have given importance to principles of sustainability. I realised that the underwater environment is the most vulnerable place and affected by irresponsible human activity, including stakeholders of scuba diving tourism. When I started my $\mathrm{PhD}$ degree, I planned to work on the framework of sustainability-based scuba diving tourism. After a while, this plan has evolved into seeking normative aspects according to principles of sustainability in the scuba diving tourism system. The research includes my own scuba diving experiences as a diver and as a researcher and personal observations under the water in which I witnessed the threats to marine life over the course of time. Studying in Malta, because of my heritage identity and bonding with the Mediterranean, where I was born and had scuba diving experience for the first time, studying about the scuba diving tourism system in a Mediterranean destination, the Maltese archipelago, matched with my interests. The Mediterranean is a special and important sea on account of endemic aquatic species; has rich marine life; and abounds with marine species both fish and vegetation. However, the Mediterranean, unfortunately, is under a massive threat. My lifetime knowledge, my own scuba diving history, and my field of interest directed me to study in this region to understand better the scuba diving tourism system in a comprehensive way and contribute to the understanding of protection with principles of sustainability and its practices as I can. The proposed study aims to contribute both literature and sustainable scuba diving tourism development goals by defining the normative aspects according to principles of sustainability for creating an effective scuba diving tourism system.

\subsubsection{Method}

The methodology is the process of collecting data and getting knowledge, undertaking a strategy to find an answer for how to conduct research (Jennings, 2010; Taylor et al., 2016; 
Moser \& Korstjens, 2018). A method is a tool for data collection that leads to interpretation, or analysis. In this research, the main data collection process was divided into three phases: the literature review (secondary data); the semi-structured interviews (primary data); and active participation with in-situ observation (supportive knowledge for primary data) - to be able to interpret the explained phenomenon with real-time practices and the researcher`s experience in the activity as a researcher. The literature review generated and designed the core framework of this study. For this purpose, the current literature of scuba diving, tourism system, scuba diving tourism system, sustainability, sustainable development (in general, in tourism and scuba diving tourism) principles, including implications and practices are examined. For the theoretical background, the Stakeholder Theory (Freeman, 1984; Donaldson \& Preston, 1995) approach is integrated into this research to explain the foundation of the scuba diving tourism system. The General System Theory (von Bertalanffy, 1949) and Living System Theory (Miller, 1978) are included to identify what a system is.

The normative theory (Jeager \& Sekznick, 1964) is also introduced in this study to discover knowledge and values as the fundamental source of the scuba diving tourism system. Along with establishing the theoretical background, the literature review helped to generate questions for the interviews. Interviews were carried out with authorities, decision-makers, scuba diving centre owners and managers, representer of The Professional Diving Schools Association of Malta, Gozo \& Comino (PDSA), scuba diving instructors and interns, scholars in tourism, marine biology (as marine biologists) and marine archaeology (as marine archaeologists) and scuba divers to gain comprehensive knowledge of sustainability practices in scuba diving tourism system. In addition to that, an in-situ observation process was carried out to better understand the reality of the current issue and statements given by stakeholders as scuba divers and scuba diving centres and to support the results derived from the field study through phenomenology. The overall method strategy of this study can be seen in Figure 5.2. 

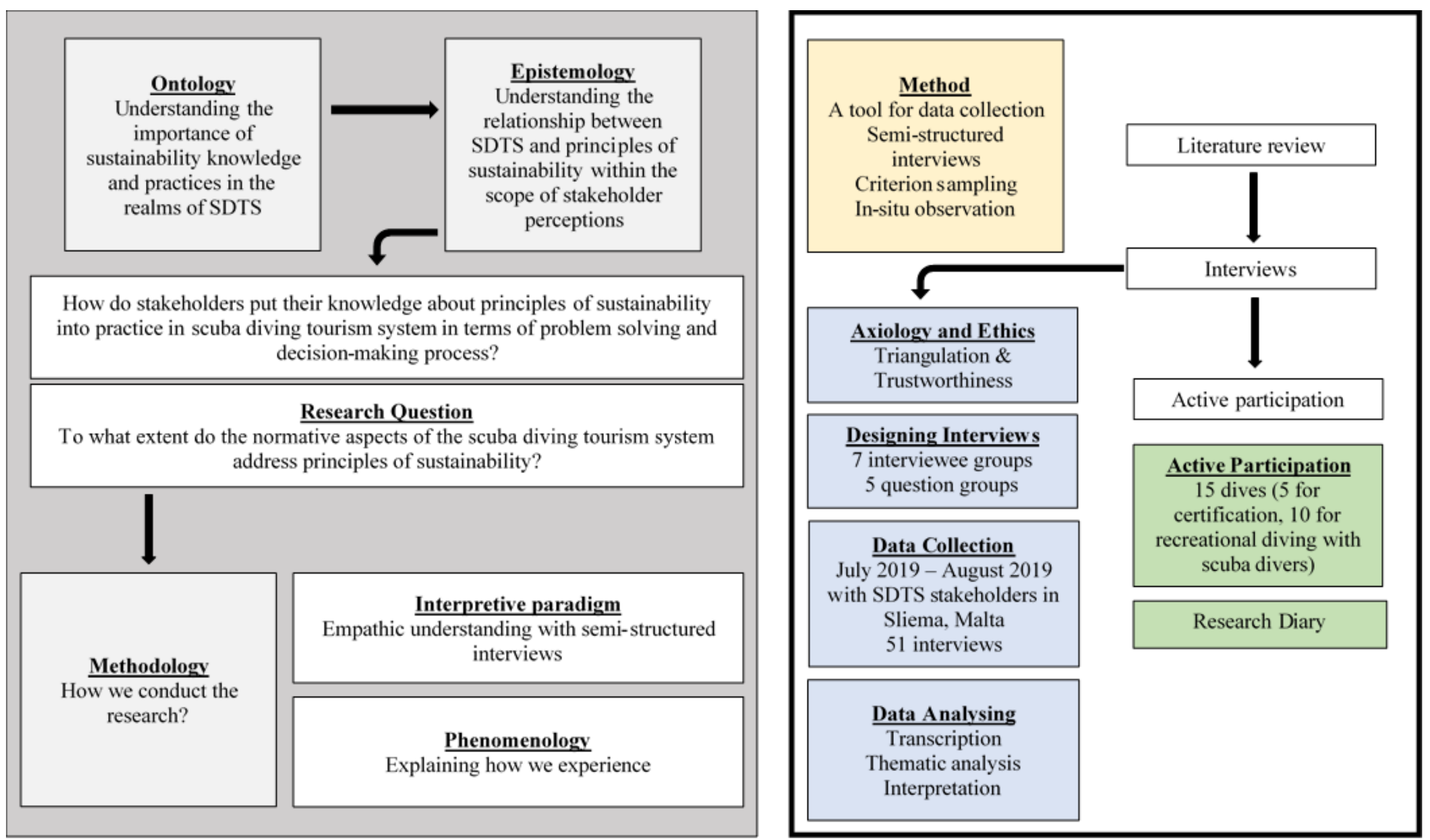

Figure 5.2. Overall Methodology and Method of This Study 


\subsubsection{Interviews in Qualitative Methodology}

The purpose of qualitative methodology is to provide a wide sense of descriptive data derived from people's own experiences. It is a way of having knowledge about the empirical world (Taylor et al., 2016). As Corbin and Strauss (2008) address, qualitative research aims to identify people from the outlook of observed reality as they experience it and to understand how those people see things in daily life, through strong or weak mutual interactions in a natural and unnoticeable manner (Rossman \& Rallis, 2012). However, "the challenge was to enter the social world of our research subjects and understand their world from their point of view" (Saunders et al., 2009, p. 116). To overcome this problem, interviews, as a qualitative research method, help the researcher to become involved in these social surroundings within a particular 'limited time and resource. Through this, a researcher can have participant's thoughts, perceptions, feelings, and experiences; and provide opportunities for a better understanding of the meaning of what people say (Moser \& Korstjens, 2018) and "... the meaning they make of that experience" (Seidman, 2013, p. 9) with a broad perspective and empathetic approach.

The qualitative interview is exploratory and dynamic (Brinkmann \& Kvale, 2014), so in order to reveal participants' perceptions through their (observed) experience, semistructured interviews were carried out in this research. The semi-structured interview is a (broad) thinking research form for both parties (researcher and interviewees) which has some characteristics and advantages for researching (Howitt, 2019), "regarding attitudes, opinions and values" (Jennings, 2010, p. 175) within the research and analysis process. The reason a qualitative interview method has been chosen is to extend the exploratory knowledge. The qualitative interview can provide advantages to the researcher such as (1) Researcher/s can have a list of areas to explore and understand by questioning. (2) Researcher/s can try to encourage the interviewee to provide open answers. (3) The qualitative interview can provide researchers with expanding and creating new questions to have better knowledge about the current phenomenon. (4) From a wider perspective, different strategies can be used during the interview/s. (5) There is always a chance to rephrase the questions and ask again. (6) Getting responses can be quick and controlled in the sense of the quality of the interview/s (Jennings, 2010). Thus, the qualitative interview gives advantages to the researcher to have the ability to control the research process while collecting the primary data. 
The interviews are one of the oldest and widest used qualitative methodology tools which link to a mutual or individual conversation between the subject and researcher/s. The parts are "merely one of the many ways in which two people talk to each other" (Benney \& Hughes, 1970, p. 176; see in Jennings, 2010, p. 171). While conducting research, there are a few essential features for getting an optimal benefit from the field study that researcher/s need to imply or address in qualitative interviews such as (1) Rich and wide knowledge replies are desirable. (2) The recording is advisable. (3) The reliability, validity and trustworthiness of the qualitative interview/s need to be well implied. (4) To be a good listener is essential. (4) The qualitative interview seeks to explore the thinking of the interviewee. (5) The qualitative interview depends on a flexible research design (Marshall \& Rossman, 2011). In this way, researcher/s can provide a desirable outcome from the qualitative interviews` which overlap with research aims. The result obtained from the qualitative interview is based on the expressions of lived experiences that emerge from the perception of the individual and reflect their subjective world. Therefore, the prerequisites address the real-life experience before and during the interviews in the process of preparing and actualising the interviews in the field study. In this sense, since interviews are the 'favoured digging tool for social researchers (Brinkmann \& Kvale, 2014); are suggested for use in tourism studies (Jennings, 2010). In this connection, questions of qualitative interviews with stakeholders and the research plan were designed according to these prerequisites. The following section provides the background knowledge for the interviews and phrasing of questions which were taken place during the research period.

\subsubsection{Designing the Interview}

Interviews are designed according to the theoretical framework for the under study to understand (Jennings, 2010; Korstjens \& Moser, 2017; Howitt, 2019) the stakeholders` perception of the normative aspects in scuba diving tourism system within the frame of principles of sustainability. While designing the interview, the abovementioned interview characteristics and question rules are employed throughout the process. Thus, the information gathering process, through questions used during the interviews, is structured to be able to explain the research phenomenon. Within this perspective, as can be seen in Table 5.1, the semi-structured questions are used to answer the research subjects. Semi-structured questions are designed regarding employed theories and categorised with due regard to the field of area 
and research question. Thus, it is aimed to provide desirable outcomes from the qualitative interviews which overlap with research aims.

Table 5.1. Concepts of Interview Questions

\begin{tabular}{|l|}
\hline Within the scope of ... \\
\hline Sustainability, Implications and Practices (Principles of Sustainability and Normative Theory) \\
\hline Scuba Diving Destination Image (Systems Theory and Normative Theory) \\
\hline Scuba Diving Experience and Motivation (Normative Theory) \\
\hline Local People and Local Economy (Stakeholders Theory and Normative Theory) \\
\hline $\begin{array}{l}\text { Scuba Diving Investment / Infrastructure and Carrying Capacity } \\
\text { (Principles of Sustainability in the sense of Systems Theory and Stakeholders Theory) }\end{array}$ \\
\hline
\end{tabular}

Within this scope, authorities, owners, managers, employees as instructors and interns, scuba divers and scholars in related fields (such as tourism, marine archaeology and marine biology) made up the characteristics of interview subjects. All in all, the interview questions were categorised into five perspectives, within the scope of (1) sustainability, implications and practices (Principles of Sustainability and Normative Theory); (2) scuba diving destination image (Systems Theory and Normative Theory); (3) scuba diving experience and motivation (Normative Theory); (4) local people and local economy (Stakeholders Theory and Normative Theory); and (5) scuba diving investment and scuba diving infrastructure and carrying capacity (Principles of Sustainability in the sense of Systems Theory and Stakeholders Theory).

\subsubsection{Sampling Method}

To reveal the subjects`experience and understand the individual point of view (Moran, 2019; Howitt, 2019), predefined criteria (Moser \& Korstjens, 2018) can be used to meet the objectives of the research in phenomenology. In this connection, criterion sampling is chosen according to designed interview questions and the purpose of this study which is one of the recommended methods for conducting qualitative interviews. Compared to purposive sampling, which is used for researchers' judgement, the advantage of criterion sampling is to reach a variety of characteristics in the perception of different stakeholders. Criterion sampling can provide researcher/s having enriched information about the phenomenon under study; interpreting the findings meaningfully (Creswell, 2013; Creswell \& Poth, 2016; Moser \& Korstjens, 2018); and ensuring the objective approach. In general, the criterion sampling method (predefined criteria) overlaps with the purpose of the qualitative interviews to reveal the best knowledge to address theoretical background (Moser \& Korstjens, 2018). Within this 
research agenda, the criterion sampling method was implemented in this study based on the availability of the participants and the size of the population that represents the research sample (Jeaheng \& Han, 2020).

\subsection{Data Collection}

The research was conducted in English and people were interviewed who have English speaking skills. Conducting research in English provided the researcher with advantages to research in more detail with a diversity of participants. Moreover, research in English gave flexibility within the process to control and follow the research guideline as planned. Within this scope, the research was conducted in the period from July 2019 to August 2019, which is considered the high season for scuba diving tourism in Malta (details regarding field study area are given in section 5.8). The main research location for scuba diving centres, employees and scuba divers were around Sliema, as can be seen in Figure 5.3 ${ }^{9-10}$ : (A: Location of Malta in the Mediterranean Sea; B: The Maltese Archipelago; C: Location of Sliema). The reason Sliema was chosen is that scuba diving tourism become a very dynamic activity in the area during the season. In addition to that, appointments with scuba divers were unsuitable for sampling due to the limited length of stay and different diving timeslots. Also, scuba diving spots are spread over the islands and archipelagos of Malta. As to reduce risks, the location of Sliema and the number of scuba diving centres available in the area provided an advantage to interview scuba divers and owners and managers. In total 4 scuba diving centres (the biggest in accordance with the number of employees and tourists in daily and yearly operation capacities) were visited during the research period. The owners, managers and employees of the scuba diving centres and scuba divers were interviewed at these scuba diving centres. The other stakeholders such as scholars at the university, authorities in Malta Tourism Authority (MTA) were interviewed in different locations across the main island of Malta. 


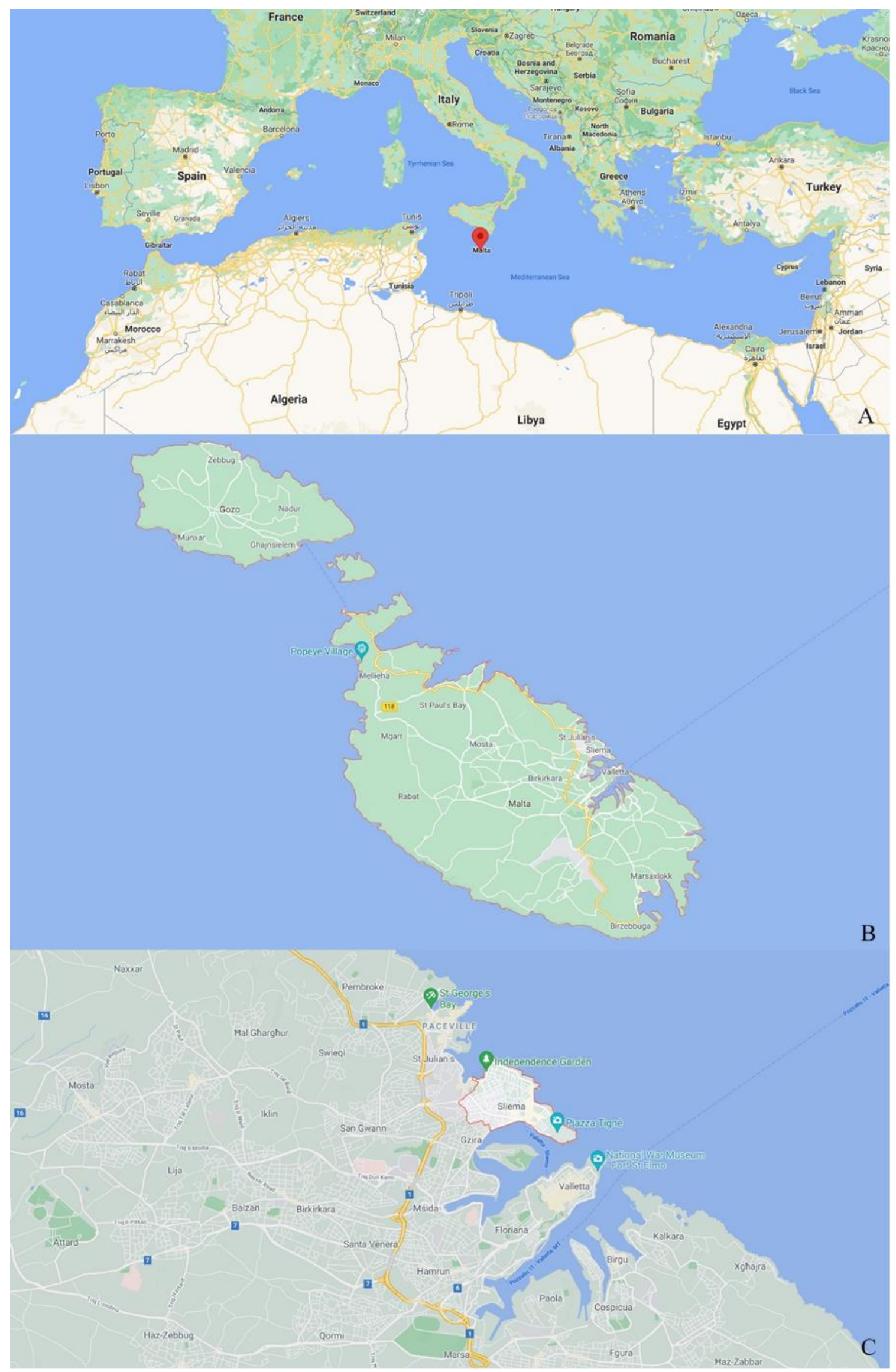

Figure 5.3. Maps of Malta and Sliema (Google Maps, 2021) 
According to the research scheme and timeline, in total 66 participants from 7 stakeholder groups were interviewed. However, 15 participants` data files were eliminated from further analysis according to the poor quality (mostly sound quality) of recordings and transcription; repeating statements; less information about sustainability which is the main theme of this study. Therefore, 51 interviews have been included in the final primary data set. Within the scope of research, 3 scuba diving centres' owners (with 1 representative from PDSA) and 2 managers; 3 local authorities; 22 scuba divers; scuba diving centre`s employees as 9 scuba diving instructors and 3 scuba diving interns; 4 marine biologists; 2 marine archaeologists; and 3 tourism scholars were interviewed during the research period. The total number of questions for each group of participants can be seen in Table 5.2. As a note, the highest number of questions were asked (53 items) to marine biologists (MBI) because of their broad knowledge of the research area. All participants were asked to be interviewed on a voluntary basis and were informed before the study about the purpose of the research and oral consent has been taken as part of the laws on privacy (Lucrezi, et al., 2019). The interviews were voice recorded on a digital platform after having consent to record and were kept in an encrypted personal laptop. Moreover, a research diary as self-reflective notetaking, which is a valuable and helpful tool to prompt insights (Nadin \& Cassell, 2006), was used to keep the researcher own ideas and thoughts, observations, and memos to be used in the data analysis stage. Interviews were transcribed individually by the researcher and final documents for each participant were kept in digital files as same as recordings, in encrypted personal laptop.

Table 5.2. The Number of Interview Questions

\begin{tabular}{|l|c|c|c|c|c|c|c|}
\hline Participants & MTA & OWN & DIV & INS/INT & MBI & MAR & TUR \\
\hline $\begin{array}{l}\text { Wustainability, Implications and the scope of ... } \\
\text { Practices }\end{array}$ & 8 & 21 & 12 & $14 / 8$ & 27 & 11 & 15 \\
\hline Scuba Diving Destination Image & 3 & 2 & 6 & $2 / 1$ & N/A & 4 & 1 \\
\hline $\begin{array}{l}\text { Scuba Diving Experience and } \\
\text { Motivation }\end{array}$ & 2 & 4 & 15 & $5 / 3$ & N/A & N/A & 1 \\
\hline Local People and Local Economy & 5 & 8 & 3 & $4 / 3$ & 13 & 9 & 5 \\
\hline $\begin{array}{l}\text { Scuba Diving Investment / } \\
\text { Infrastructure and Carrying Capacity }\end{array}$ & 2 & 9 & 1 & $2 / 1$ & 13 & 5 & 6 \\
\hline Total Number of Questions & $\mathbf{2 0}$ & $\mathbf{4 4}$ & $\mathbf{3 7}$ & $\mathbf{2 7 / 1 6}$ & $\mathbf{5 3}$ & $\mathbf{2 9}$ & $\mathbf{2 8}$ \\
\hline
\end{tabular}




\subsubsection{Interviewing Stakeholders}

Providing consistency and trustworthiness of this study, before starting to examine the research subject, to identify each individual participant demographic questions were asked to interviewees such as gender and age; occupation; education level; diving certification; the number of diving; nationality; motivations; and preferences for alternative dive sites (if any due to characteristics of the destination, Malta), and documented in the individual interview form (see Appendix 1). This provided for the researcher a rich and reliable data source (Silverman \& Patterson, 2015; Korstjens \& Moser, 2018) for descriptive analysis of the interviewees. Interview questions regarding the researched subject were prepared and asked according to current issues and phenomena under the study of the scuba diving tourism system within the context of sustainability practices (for initial plan and questions see Appendix 2). The interviews started with asking questions related to the understanding of sustainability in the general sense based on the theoretical background of this thesis. For this reason, the first question for each interviewee was 'What does sustainability mean for you?'. The following interview questions were ordered, specified, or redefined according to a narrative of personal experience; personal statements; point of interest; and area of expertise within the scope of research themes. Individual knowledge of stakeholders in sustainability and their perceptions were sought to reveal actual intelligence in the current phenomenon, which this research aimed to investigate. The interview process for authorities (MTA - see Appendix 3) was considered from a decision-maker perspective. This group were also responsible for the marketing of scuba diving tourism and therefore considered as media authorities, as well. Thereafter, scuba diving centres`owners and managers (OWN - see Appendix 4) were interviewed from the scuba diving tourism point of view to reveal the current knowledge, values, implications, and practices. One of the scuba diving centre owners was also representing the PDSA.

Scuba diving instructors (INS - see Appendix 5) were approached to reveal both an employee and practitioners` point of view in scuba diving tourism. The interns (INT - see Appendix 6) were also included in this category because of their active role in the industry as future's instructions who will educate visitors to behave sustainably. Tourism scholars (TUR - see Appendix 7) were approached because of their tourism knowledge based on the field study area and point of view on practices. Marine biologists (MBI - see Appendix 8) were interviewed as they had specialist knowledge about marine biology in the area. Current issues 
and practices including possible implications and precautions in the marine environment in Malta with regards to threats and protection of the marine surroundings were examined during the interviews with this group. During the interviews, the research questions linked to the themes of scuba diving destination image, scuba diving experience, and motivation perspectives were excluded because these are out of their point of interest. Instead, the interviews were dominated by the perspective of sustainability, implications, and practices. Marine archaeologists (MAR - see Appendix 9) were also recruited for their perceptions on marine archaeology, underwater cultural heritage and protection practices in the scuba diving tourism system and the role of alternative dive sites in Malta. Compared to the marine biologists (MBI), only the scuba diving destination image perspective was excluded from the interview according to their lack of expertise. Scuba divers (DIV - see Appendix 10) themselves were included in the study to reveal their practical experience point of view in implications related to principles of sustainability. The scuba divers are the important study group of this research, for the reason of being important for the scuba diving tourism system and cannot be separated from the pool of stakeholder participants. Compared to other interview groups, scuba diving experience and motivation perspectives were tried to be comprehensively explored with this group of stakeholders during this study.

For scuba diving centres`owners, managers and the PDSA, the interviews were conducted by appointment. The same appointment system was implemented for scholars from Malta University in Tourism, Marine Biology and Marine Archaeology departments and authorities in Malta Tourism Authority (MTA). In regard to scuba diving instructors and interns, who work in the same scuba diving centres with owners and managers, they were interviewed according to their availability and willingness to participate in this research. Interviews with scuba divers, scuba diving instructors and interns were practised after the actual scuba diving activity to find out the latest subaqueous experience of scuba diving. Overall, the saturation of data when the participants' expressions began to repeat (Glaser \& Strauss, 1967; Patton, 2002; Corbin \& Holt, 2005; Jennings, 2010; Moser \& Korstjens, 2018) was a cue to stop the data collection process.

\subsubsection{Active Participation and In-Situ Observation}

As a researcher in qualitative interpretive tourism studies, being enunciative (indicating and verbalising) of personal experience gained during the field study is important to ensure the 
reliability and trustworthiness of the research. Unless pursuing ethnography, observation studies, symbolic interaction or specified case studies, it has been suggested that there should be limited personal interference as a researcher during the analysis (Swain, 1995). However, to "get behind the statistical shapes and patterns and explore at first hand the wide variety of adaptive responses" (Pryce, 1979, p. 279) are essential for qualitative research. In this sense, the experiences or knowledge and statements of the participants alone are not sufficient to explain current practices and phenomena. Therefore, the researcher's own experience may have an important place in order for the research to have sufficient information about the research background. Because especially qualitative interpretive analysis is based on finding expressions and experiences that are hidden in terms of the meaning of the implications.

In this connection, to have a better understanding of the real situation behind the given statements and to observe in detail and analyse different circumstances and situations from particular settings (Moser \& Korstjens, 2018), active participation is involved in the research process. Because "as we understand something we are involved and as we are involved, we understand" (Welch, 1999, p. 242). For this purpose, 15 scuba dives were taken part in during the research period, 5 scuba dives for certification, and 10 recreational scuba dives. To strengthen the meaning of statements, in the active participant category, interviews were held with some scuba divers, scuba diving instructors and interns right after participating in the scuba diving activity together. The active participation and in-situ descriptive observation provided a better understanding of sustainable practices in scuba diving tourism in this study. In line with normative aspects, the active participation contributed to the knowledge of this thesis by questioning whether sustainable practices are implemented or not by scuba diving centres and where and when the practical actions and self-regulations of scuba divers were practised. This phenomenon, in question, was documented with photographs taken by the researcher; and outcomes of active participation were used during the data analysis to interpret better the results in this study.

\subsection{Data Analysis}

In phenomenology studies, researchers seek for a meaning of the experience and individual perceptions (Moser \& Korstjens, 2018) derived from the field study, therefore, interpretation of the data is an essential analysis process. In line with this, qualitative research can provide fundamental assessment tools as creating in-depth narratives using an enriched 
interpretation process to better understand how people perceive and assess reality within their perspective and subjective experience (Polit \& Beck, 2017; Moser \& Korstjens, 2017; Korstjens \& Moser, 2017). In this sense, thematic analysis helps to reveal these experiences and perspectives by using systematic patterns of establishing knowledge, reasoning (as analysis) and presenting (Braun \& Clarke, 2006; Vaismoradi et al., 2013).

Qualitative data analysis is an interpretive approach employing thematic analysis, which involves considerable amounts of data and takes a long time (Harding \& Whitehead, 2013), for processing, creating initial categories and finalising the themes (Moser \& Korstjens, 2018). Thematic analysis is an interpretive approach for qualitative data analysis by developing narratives that “... it is the search among data to identify content” (Marshall \& Rossman, 2014, p. 150). Examination of the data is related to coding the text inductively which leads to "essence-capturing" with "consolidated meaning" (Saldaña, 2021, p. 13) to create "narrative memories" (Saldaña, 2021, p. 20) as themes. The result of thematic analysis is dependent on the validation of the data; processing the data with a proper template; modifying the findings according to the epistemological foundation; and creating a saturated and meaningful set of themes (Neuendorf, 2019). It is expected that the themes found as a result of the analysis have a link between one another in terms of meaning as "internally consistent" (Marshall \& Rossman 2014, p. 154) but individually distinguish from each other. In this connection, the process of thematic analysis has six phases: (1) Familiarising with data; (2) generating initial codes; (3) searching for themes; (4) reviewing themes; (5) defining and naming themes; and (6) producing a report (Braun \& Clarke, 2006; Braun et al., 2015, pp. 188-189; Neuendorf, 2019, p. 213). In line with the six phases, engaging in data was the first process for thematic analysis to identify potential descriptive themes (1) in this study. Following, establishing initial coding, and assessing the correspondence of data according to these codes was proposed to be done by a systematic approach (2). The next step of thematic analysis was the categorization of data and code allocation according to the created themes (3). Once previous analysis phases were done, the themes and related allocations were reviewed in regard to internal consistency (4). Making the decision on marking out and identifying the themes was the stage next to the last to start writing the story of the narratives of the data (5). The final step was reporting the data in accordance with the related literature and objectives of the research to the understanding of phenomena under study (6) as can be seen in Appendix 11. 
With regards to the thematic analysis, the primary data analysis process of this research, as aforementioned, included transcribing the collected data from the field study. Interviews were collected at different times and dates within the period of the research. Once in-field research was completed, the research journals were reviewed, and voice recordings of interviewees were transcribed by using an AI software (called temi.com) and checked manually. To picture the storyline of the narrative, which is a fundamental step for analytical analysis (Elliott, 2018), so-called `meta-narrative` (Stuckey, 2015) or `meta-code` (Punch, 2014), data were coded. The storyline of the data is directly related to the emergent coding strategy based on the meaning and concepts of the data. In this sense, Miles et al. (2014) suggest refining the data until becoming more meaningful regarding the research topic. In this connection, to clarify the data set into a more meaningful structure, the whole data set was refined and subcategorised into about 25 codes. The redundant codes were eliminated and reduced to 18 codes (see Appendix 12). These 18 codes were then categorised further into 15 themes under 5 subthemes that became the main headings of the findings. The name of each theme was inspired by the narratives. Following this, the findings were adapted to the theme framework which will be indicated in the result section (Chapter 6). For example, effects resulting from scuba diving activities have been categorised under the theme of Stress, while external influences have been collected under the theme of Strain. This strategy provided the thematic framework more consistency in order to explain current issues and future implications and data became more manageable in terms of analysing and communicating with the reader.

In regard to participants, each data file of interviewees was categorised, named with a unique code, and regulated within the specific cluster they belong. Rather than having a pseudonym name for participants, a systematic three-unit numeric etiquette model was chosen to identify participants in order to simplification the procedure of the data analysis. For this purpose, DIV was used for scuba divers. In addition to this, INS for scuba diving instructors, INT for scuba diving interns, MAR for scholars in marine archaeologists, MBI for scholars in marine biologists, MTA for Malta Tourism Authority (authorities and media stakeholders), OWN for scuba diving centre owners, managers and the PDSA, and TUR for scholars in tourism studies were used and denominated as the data etiquettes of the individual subject. Moreover, following to three-unit etiquette numeric code, to distinguish the participants' numeric etiquette (from 1 to 22 ) was added to the etiquette scheme, respectively, in subject identity, which will be called from now on, as subject ID. In transcription file, 22 scuba divers 
- DIV (total 36,461 words with 06.20.38 hours recording); 9 scuba diving instructors - INS (total 22,562 words with 03.22.51 hours recording) and 3 scuba diving interns - INT (total 4,798 words with 00.36.04 hours recording); 2 marine archaeologists - MAR (total 5,870 words with 00.58.40 hours recording); 4 marine biologists - MBI (total 20,598 words with 03.01.09 hours recording); 3 authorities - MTA (total 8,428 words with 02.05.41 hours recording); 5 owners, managers and on behalf of the PDSA - OWN (total 21,318 with 03.52.18 hours recording); and 3 tourism scholars - TUR (total 11,645 words with 03.52.49 hours recording). In total, 131,683 words with 24.10 .10 hours of recording study data were analysed in this research.

To summarise, as can be seen in Figure 5.4 in connection with the data analysis process, within the scope of this study, the data analysis process was divided into four parts. The first part was dedicated to the description of the research. In general, the literature review created a fundamental frame for research aims. Research questions were identified through the critical literature review. Sampling was determined as a criterion sampling strategy according to field study and research was started with interviews. In the second part, the inference was related to understanding the data and extraction process from unstructured documents in terms of thematic analysis. To address the aim of the study and research, several steps (from familiarising with data to reviewing themes), regarding Braun and Clarke (2006); Braun et al. (2015) and Neuendorf (2019)'s suggestions, were taken as guidelines to ensure the link between data and theoretical background. The third part referred to the validation of the data. During the field study, interviews were recorded with a digital voice recorder, which established the main research data source of this study; and was kept in an encrypted personal laptop. Reliability and trustworthiness are explained in detail in the following section/s. In the last part, an appropriate analysis was applied to preliminary themes and named into a systematic and numeric model, which constituted the main analysis result of this study and the research. Results of the research were written according to the data evaluation process and in this regard, the researcher`s interpretation and discussion are involved in the analysis process. The researcher's observations derived from the active participation were also added to better understand the current and ongoing issues and evaluate the given statements. 


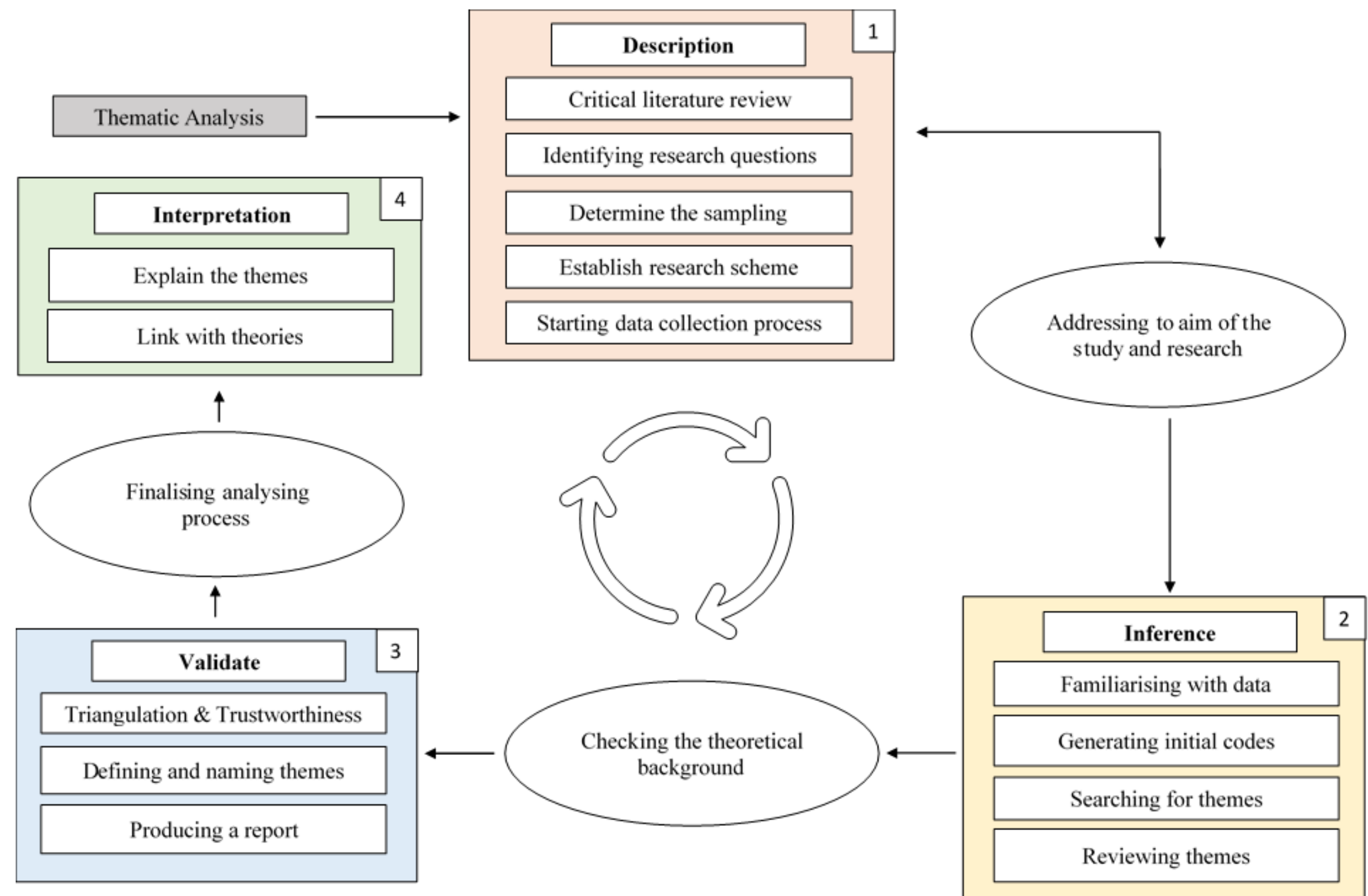

Figure 5.4. Overall Data Analysis Process 


\subsubsection{Reliability and Validity}

To ensure the reliability and validity of this study, several methods were used within the whole structure of this thesis. In the beginning, the literature review determined the main point of this study, which was establishing the sustainability in scuba diving tourism system. Unnecessary and out of date data sources were eliminated from the study. During the interview, as far as possible, there was no personal intervention or no personal questions were asked in the interview process (Lucrezi et al., 2019). In addition to that, no questions were asked out of the context of the research or discussed any extraneous topic outside the main research point. The raw data was transcribed as obtained from the interviews without any changes. In other words, data was transcribed the same as bare facts and a coding scheme was applied. Coding errors are expected in the results of the nature of qualitative analysis (Marshall \& Rossman, 2011). Therefore, a cross-check system was implemented to minimize the risk of unreliable and invalid data and clarify statements for their similarity or necessity (Dedeoglu et al., 2020). For this, the re-coding process was applied for the same data, by the researcher of this study and, in addition, independently by three external researchers in the same academic field. All process was taken placed independently and controlled systemically. Next, to provide interrater reliability between coders, the percentage agreement method was used. Percentage agreement is a process of calculating the ratio of items on which the coders agree to the total number of items rated and can simply be calculated by kappa statistic by using the formulation in Excel. In detail, all initial coding processes were compared, and a coding agreement was conducted to confirm consistency (Viera and Garret, 2005). According to the result, the reliability rate of the ratio of the coding agreement was $\% 93$ within the degree of almost perfect agreement. Therefore, the coding scheme which was derived from each coder was transformed into preliminary statements for the initial theme framework.

Once the qualitative data is initially examined, a question is emerged regarding not whether the data can be proved statistically, but whether the data can be trusted in qualitative data analysis. It can be expected that evaluating raw data derived from interviews according to the quantitative method regarding the validity and reliability, may not be rigour academically. Because optimal credibility of the qualitative data may not be reached due to the unclarity between the data and the researcher`s error (Sandelowski \& Barroso, 2003). Therefore, before starting analysing the qualitative data five-phased trustworthiness (Lincoln \& Guba, 1985) 
examination is recommended to ensure the data accuracy derived from the findings and results (Creswell, 2013; Creswell \& Poth, 2016; Korstjens \& Moser, 2018). These are Credibility (the internal validity); Transferability (the external validity); Dependability (qualitative reliability); Confirmability (objectivity); and Reflexivity. Besides, Authenticity (Polit \& Beck, 2012) can also be used for the trustworthiness of the data. Furthermore, as Denzin (2009) stated, fourphased triangulation based on data processing (from planning, preparing, organising to analysing and reporting) can also enrich the generalizability of the research (Decrop, 1999) and validity of the study, which are triangulations of data; method; investigator; and theory. In a general sense, triangulation and trustworthiness depend on the well-saturated, organised, and enriched data collection process (Elo et al., 2014); analysing; and reporting of findings. Within the scope of the triangulation and the trustworthiness, analysis of data is given in the following sections in detail based on ethical concerns and assumptions in qualitative research.

\subsubsection{Triangulation}

The main purpose of the four-phased triangulations is to reduce or eliminate the researcher`s prejudices and biases in the research process. As Decrop (1999) notes that data triangulation is related to the source of the data. Enriched qualitative data foundation, such as prolonged engagement, a variety of interviewee's characteristics from different stakeholders, can increase the reliability. Method triangulation refers to using more than one method, such as semi-structured interviews, recordings, and field notes, to reduce the researcher bias and subjectivity. Investigator triangulation suggests having more than one researcher while collecting and analysing the data. Theory triangulation proposes using more than one theoretical background from different disciplines or approaches to analyse the qualitative data.

In this study, data triangulation was provided by having real person`s statements, and the data was collected from a diverse range of participants`characteristics with prolonged engagement. The main method required for qualitative data used in this study to collect was semi-structured interviews. Mintzberg (1979) notes that "no matter how small our sample or what our interest, we have always tried to go into organizations with a well-defined focus-to collect specific kinds of data systematically" (p. 585). In this sense, semi-structured interviews provided an in-depth insight into the researched phenomenon. Moreover, notetaking was applied during the data collection process. The in-situ observation was also used in this research to ensure the credibility of this research. Therefore, three independents but interrelated methods 
were used in this study to enrich the method triangulation. With regards to investigator triangulation, Eisenhardt \& Bourgeois (1988) suggests conducting an interview "with one researcher handling the interview questions, while the other records note and observations. The interviewer has the perspective of personal interaction with the informant, while the notetaker retains a different, more distant view" (Eisenhardt, 1989, p. 538). In this sense, interviews were conducted by a two-person team; the researcher of the thesis and an independent researcher was invited to the field study for assisting with notetaking. As part of theoretical triangulation, multiple perspectives were involved while interpreting the data. As can be seen in Chapter 4, three independent but interrelated bodies of theories from different angles (biology, social sciences, management sciences etc.) were used. Moreover, phenomenology; interpretive paradigm; and active participation were also employed as theoretical implications. During the data analysis process, sources from the critical literature review integrated into the theoretical background; and these constructed the contributions, as presented in the discussion and conclusion chapters.

\subsection{Research Ethics and Trustworthiness}

\subsubsection{Axiology and Ethics}

Axiology and ethics are the studies of finding out the right and the wrong with asking how we should act and what is the value of knowing. From this point of view, this study firstly followed scientific principles as fundamental to research. All steps have been considered

carefully and conducted based on general, individual, and institutional ethical principles. For example, the research was implemented based on the guideline of Swansea University School of Management as the Postgraduate Research Code of Ethics - approved on 10/06/2019 - with the University`s Research Integrity Framework (P1415-956). Other axiology and ethics values that were used during the research are listed as below:

a. Interviews were recorded according to the participants' permission.

b. All interviewees attended the research voluntarily from beginning to end.

c. The best interview location was provided to the participant and offered alternative places where if they were not happy.

d. During the interview, there were not asked questions to reveal the participants identity and personal questions were kept limited to only learning their experiences. 
e. Interviewers were told data were to be used only for scientific research purposes, and not be shared with third parties for commercial uses.

f. During the interviews, sensitive or very personal topics were not discussed.

g. Damage to the environment was limited to the greatest extent possible.

h. During the interviews, safety issues were carefully considered.

i. During the in-situ observation, all safety requirements had been taken and implemented according to global safety standards and guidelines of Swansea University School of Management as the Postgraduate Research Code of Ethics in regard to participating in scuba diving by the researcher and partners to make sure other participants and researcher`s safety underwater and the diving site.

j. During the in-situ observation, the dive plan, other scuba divers, or scuba diving instructor before, during, and after the scuba diving activity were not intervened by the researcher/s in any way.

k. The cultural norms, traditions, and values of the community in the place of field study were well respected.

1. Personal critics and judgements were not used at any time.

m. Personal thoughts of the researcher were not added to participants' data.

n. Data derived from the interviews were kept in an encrypted personal use laptop.

o. Data is collected confidentially and protected from third-party access.

p. Data was transcribed faithfully.

q. No data was published or shared with a third party.

r. No discrimination was applied against personal attributes e.g., gender.

\subsubsection{Trustworthiness}

\subsubsection{Credibility}

Credibility can be defined as the truthfulness of qualitative findings derived from the field study, which is the confidence that can be placed in the truth of the research findings. Credibility establishes whether the research findings represent plausible information drawn from the participants' original data and is a correct interpretation of the participants' original views. As internal validity, credibility represents having true and original interpretive qualitative data for analysing. For example, prolonged engagement and persistent observation are considered some of the important factors for the credibility of the qualitative data. 
Prolonged engagement represents having enough time to spend in the field until reaching an intended variety of characteristics. Persistent observation is related to data analysis "until the final theory provided the intended depth of insight" (Korstjens \& Moser, 2018, p. 122).

In this study, to ensure credibility, a field study was concluded until reaching enough data and interviewing with a variety of participants in the sense of prolonged engagement. Each interview question was answered by an associated stakeholder according to context and related content under the study. In any stage of data collection and data analysis processes researcher`s interference was not involved. Therefore, the collection of the original data was ensured optimally and analysed throughout the research. With regards to persistent observation, raw data was analysed to achieve the best insight.

\subsubsection{Transferability}

Transferability, as external validity, explains to what extent qualitative data can become applicable to other settings, and the extent to which data can be transferred to other contexts or settings with other participants. Transferability provides meaningful insight to the reader for describing the findings or results within another context with their perception in specific settings. The researcher facilitates the transferability judgment by a potential user; therefore, reader/s is/are the contributor/s to transferability.

In this study, the research topic was related to the scuba diving tourism system. Therefore, the qualitative data (raw and transcribed forms) derived from the field study addressed this purpose, which can be transferred to similar contexts or research settings that are related to scuba diving. Obtained data from the field study represents an overall insight into the research topic and can also be transferred in another tourism context related to the stakeholder approach. For instance, research findings can be used as examples of real-life stakeholder phenomena in similar studies such as adventure tourism, sustainable tourism, or water sports. The obtained data represent lived experiences of interviewees, and these can be useful to understand the current issues in the research setting under study. In addition to that, the result of the study supports previous research findings, therefore, the outcome of this study can be generalised in similar contexts along with the existing studies. The data and results can be a practical point of departure for further studies. Moreover, the knowledge of the theoretical background of this study which is principles of sustainability is applicable for other contexts. 


\subsubsection{Dependability}

Dependability questions how stable the qualitative data is over time. Moreover, as qualitative reliability, dependability seeks the consistency and reproducibility of the results. Dependability involves participants' evaluation of the findings, interpretation, and recommendations of the study that all are supported by the data as received from participants of the study. Dependability of the qualitative data includes the whole process of data analysis from findings to reporting. Therefore, dependability is an overall evaluation.

In this study, the data of this study was not related to specific settings at a certain time. First, the data was collected with prolonged engagement, therefore, qualitative data derived from the field study included a diverse range of points of view of stakeholders. In this connection, data represented the variety of perspectives in a particular setting. Moreover, the data was linked with general arguments within the researched phenomenon. For this reason, the qualitative data of this research derived from the field study represented broad consistency and reproducibility. Therefore, obtained data and can represent the overall researched subject during the data analysis and data is consistent with the overall research aim based on theoretical and methodological assumptions, in the sense of dependability.

\subsubsection{Confirmability}

Confirmability refers to the degree of objectivity and how neutrally data was given or explained without the researcher's prejudices and bias. Confirmability questions the degree to which the findings of the research could be confirmed by other researchers. In this sense, the main concern of confirmability is whether it is possible to be confirmed data by other researchers or not. On the one hand, for example, presenting representative or direct quotations (Graneheim \& Lundman, 2004) increases the confirmability if given "from as many participants as possible" (Elo et al., 2014, p. 7). Confirmability seeks and tries to confirm by establishing that data and interpretations of the findings are not figments of the inquirer's imagination but derived from real-time data. On the other hand, the higher number of quotations may weaken the quality of the analysis (Graneheim \& Lundman, 2004) and may cause unclearness in the result if not written or analysed systematically. Confirmability also refers to methodological consistency of the study which includes evaluation of a set of knowledge about research materials, sampling, initial actions, interest, and research process. 
In this study, all recordings were documented for each participant with timestamps of each statement to provide the raw data source, thus, statements can be cross-checked in transcribed forms and voice recordings. Raw data was used to proceed with the data analysis. The result chapter was written and evaluated by direct quotations from the interviewee`s statements. During this process, correction or paraphrasing that may change the meaning of statements were not applied to the data source, and it was transcribed as original as possible. The whole recordings were listened to, and the data source was also checked by an independent researcher before proceeding with the analysis process and confirmability of the data was achieved. As methodological consistency, from sampling to analysis processes were given in detail throughout the methodology chapter.

\subsubsection{Reflexivity and Authenticity}

Haynes (2012) states that "we should try to be aware of how our ontological, social and political positioning affects the work that we do by informing the choices we make about research topics, questions, approaches, methodologies and outcomes" (p. 78). Therefore, reflexivity explains the researcher`s positionality between the methodology and theoretical foundations of this study within the ontological orientations and epistemological assumptions. The main questions regarding reflexivity are 'Where do researcher ideas on the reflexivity fit? Are any of these approaches [and questions] appropriate for the research/or how can researchers find their own approach?`(Corlett \& Mavin, 2018, p. 396). In qualitative research, reflexivity is fundamentally related to data collection and in-situ assessments. Reflexivity explicates the degree of coherence between research questions asked by the researcher and given statements by participants. It is a methodological tool engaged in reality (Haynes, 2012; Corlett \& Mavin, 2018) and nested in the nature of knowledge (Alvesson et al., 2008; Corlett \& Mavin, 2018; Subramani, 2019) while unveiling the ways of doing the research (Hibbert et al., 2010) (see page 104-105).

The reflexivity of this study is based on semi-structured interviews and my in-situ observation with active participation conducted during the period July 2019 to August 2019 in Sliema, Malta. Reflecting on the lived experiences encouraged me to be aware of the factors that affect the research. The reflexive approach during the research (data collection and data analysis) I was influenced by the moral and theoretical concepts employed in this study which intertwined relationships of context, phenomenology, and methodology. Practising reflexivity 
had an impact on the process of ethical choice of the words/questions employed in this study and my epistemological and methodological positions during the knowledge construction (Etherington, 2004). In practice, in this research, as Lucrezi et al. (2017) employed in their study, one of the common tools to enrich the reflexivity of the qualitative data is to use reflexive notetaking while I was interviewing the participants. Reflexive notes can describe the relationship between the subject of the interview and the researcher during field study and the setting in which they are involved. For example, my research questions were found difficult to understand by some interviewees. I paraphrased the questions during the interview but kept the source on the interview form and research journal. As part of the process of critical selfreflection about me (own biases, preferences, preconceptions), and the research relationship (relationship to the respondent, and how the relationship affects participant's answers to questions), I realised that academic language does not represent the reality of research nature and the way of communication between stakeholders. Therefore, without changing the subject and meaning of the topic that I researched, paraphrasing the questions provided me advantages to research while reflecting on the real-life phenomena. And this process made me understand that the actual research during field study should be adjustable according to participants understanding and level of knowledge. In this sense, during the transcription process, the journal helped me to track the questions and analyse the research findings derived from stakeholders` answers/statements given to paraphrased research questions. As some researchers illustrated in their studies (Hillmer-Pegram, 2017; Lucrezi et al. 2017; Lucrezi et al., 2019) in a similar context, I revisited and used data obtained from the notetaking/research journal for confirmation of the transcribed data during the first phase of data analysis. Before proceeding with the analysis, I checked and examined/reviewed research findings with the second researcher who took the notes to ensure consistency of the retrieved data.

However, ensuring reflexivity may encourage the researcher to share private information publicly (Crossley, 2021). Due to the data privacy policy based on the ethical guidelines and participants` unwillingness to share their identity, photos with interviewees or photos taken during the interview process have not been included in this research. However, to ensure reflexivity, before starting the interviews, oral consent has been taken (Lucrezi, et al., 2019) while filling up the participant`s `Individual Interview Form` (Appendix 1). As used in the study of Gerungan and Chia (2020), during the research period, each interview was recorded (audio records) digitally from beginning to end via a voice recording app. Therefore, 
during the data analysis process, transcriptions were also represented as the whole source of interviewed arguments between the subjects and researcher. The initial research plan was conducted, and each research question was answered during the field study. The whole qualitative data source obtained from varied methods represented the research topic under study. In this connection, during the field study process, notetaking along with voice recordings applied critical self-reflection. In addition to reflexivity, authenticity can narrate the degree of how close to reality data is (Polit \& Beck, 2012), and the originality of the study within the ontological orientations and epistemological assumptions. In this study, each research question was answered by a stakeholder (involved in the research based on criterion sampling method) who was related to the research phenomenon. In this sense, the authenticity of this study was achieved by deriving contemporary examples and real person`s statements with lived experiences obtained from the field study in Malta.

\subsection{Methodological Limitations}

This study has several methodological limitations before and during conducting this study. Theoretical limitations are covered in the conclusion. This study was self-funded research; therefore, the research budget was limited. In line with this, the research was planned in accordance with the limitations of time due to both the planned budget and the seasonality of the destination. The research was conducted within the period from July 2019 to August 2019. For example, because of time limits, the number of interviewees remained at a certain number. However, research was ended when responses become saturated, and an eligible qualified number of participants was achieved. Moreover, while conducting the field study, interviews with the local people remained relatively limited due to their less active interaction with the scuba diving tourism activities. Nevertheless, the majority of scuba diving centres owners and scholars, and all interviewees from authorities were local and they represented local perspectives regarding the understanding of the current issues and phenomena under study. In addition to this, the research was conducted in the high season for the destination. Therefore, the research period was relatively costly in terms of participating in scuba diving activities and accommodation for both scuba divers and researchers. One of the most problematic issues was finding proper accommodation across the research period. Because the best time for conducting field study was to go to Malta in high season, and due to the high demand for accommodations, I was struggling to find a place close to my research area. 
As a researcher, finding a nearby and alternative budget-friendly place (where I intended to get interviews from scuba diving centres, authorities, and universities) to stay was the hardest thing to overcome. Even with reservations in advance, due to an undeveloped peerto-peer accommodation system and fully reserved hotels, reservations had been cancelled and that made me stay places far away from the research area. Moreover, because of my lack of knowledge about Malta and scuba diving activities there, I made extensive research about the field and tried to get some appointments through e-mails with potential interviewees according to criterion sampling strategy who is in Malta. Due to non-response e-mails, I arrived in Malta to start my research without any confirmed appointment. To create a participant/interviewee pool, I contacted key people from universities and authorities face to face to get an appointment within the purpose of the criterion sampling method. During the research period, I travelled to distinct locations to meet key stakeholders and sometimes this was time-consuming as a consequence of unexpected events. For example, especially during the in-situ observations process, I spent a typical field research day from 6 am to midnight. I had to also spend a long time reaching the research area due to the unreliable public transportation system. However, with two different accommodation options in different areas, relatively close to the observation area and Sliema, I could manage to reach the participants on time and finished my research as I planned before coming to Malta within the initial research budget and time planning.

During the research period in practice, the other issue that I struggled most with was the lack of knowledge about the meaning of sustainability, especially during the interviews with scuba divers. To conduct research, their comprehensive understanding of sustainability was the key and important point of departure to go further in the interviews. For example, for the French-speaking participants, I had to redefine my first question and explain them many times for each participant. The reason laid behind the difficulty in their understanding of the meaning of sustainability which translated as 'durabilité' in French as a form of longevity or lifespan. In time, we found a middle ground with scuba divers and achieved to continue the research. However, a few data files derived from interviews have been excluded from analysis due to a lack of quality information regarding knowledge of sustainability. Another problem was to get an appointment and meet on time with scuba diving centre owners, managers, and some authorities for local scuba diving associations. In view of scuba diving being a very dynamic sector, especially during the summer season, this was more acceptable but hard to carry out foreordained meetings. Nevertheless, all meetings took place even if delayed a few 
days apart. I also did some participant observation to get a picture of the actual scuba diving activity. For this purpose, I made 15 dives in 8 days and most of the day I had to make a few concessions from my interviews on the day of active participation, especially with scuba divers, scuba diving instructors and interns. This was beyond my intention and research plan. To get a better chance and number of interviewees, some days I made over 5 interviews in a day to finish the research on time. Overall, in spite of all challenges and misadventures, on my own behalf, I completed all prerequisites and detailed schedule of this research on the basis of the determined timeline. Last but not least, even though all triangulation and trustworthiness have been carefully considered by me, as part of the nature of qualitative research, there may always be some issues that remain, meaning that what is presented can only ever be a partial truth.

\subsection{Field Study Area}

\subsubsection{The Mediterranean Sea}

The field study area is chosen as Malta which is an archipelago in the Mediterranean. The Mediterranean is a dynamic region of human societies, cultural practices, and activities and home of exchange of ideas, customs, culture, beliefs, and trade of goods, both historically and in contemporary times. According to Blondel (2006), this region has been a place for powerful civilizations who affected the ecosystem and reshaped the land-use practices besides containing the rich ethnographic characteristics and national and ethnic identities. The name of the Mediterranean Sea comes from the Latin word 'Mediterraneus' which means, 'in the middle of the earth` or `surrounded by land`. The Romans commonly called it Mare Nostrum in Latin `Our Sea` or Mare Internum `Inner Sea`. The Mediterranean is located between $30^{\circ}$ and $46^{\circ}$ north latitude, $9^{\circ}$ west and $38^{\circ}$ east longitude. It stretches over a length of $3800 \mathrm{~km}$ from the extreme east to the extreme west point and the largest width is approximately 1600 $\mathrm{km}$. It covers an area of about 2.5 million $\mathrm{km}^{2}$. The average depth of the Mediterranean Sea is about $1500 \mathrm{~m}$. The deepest point is around $5300 \mathrm{~m}$ and is located in the Ionian Sea near the coast of Peloponnese in Greece. The total length of the coastline is roughly $46,000 \mathrm{~km}$ (Bethencourt et al., 2018); with four regions: Western Mediterranean; Adriatic Sea; the Ionian Sea and Central Mediterranean; Aegean Sea-Levantine Sea (UNEP-MAP RAC/SPA, 2010). 


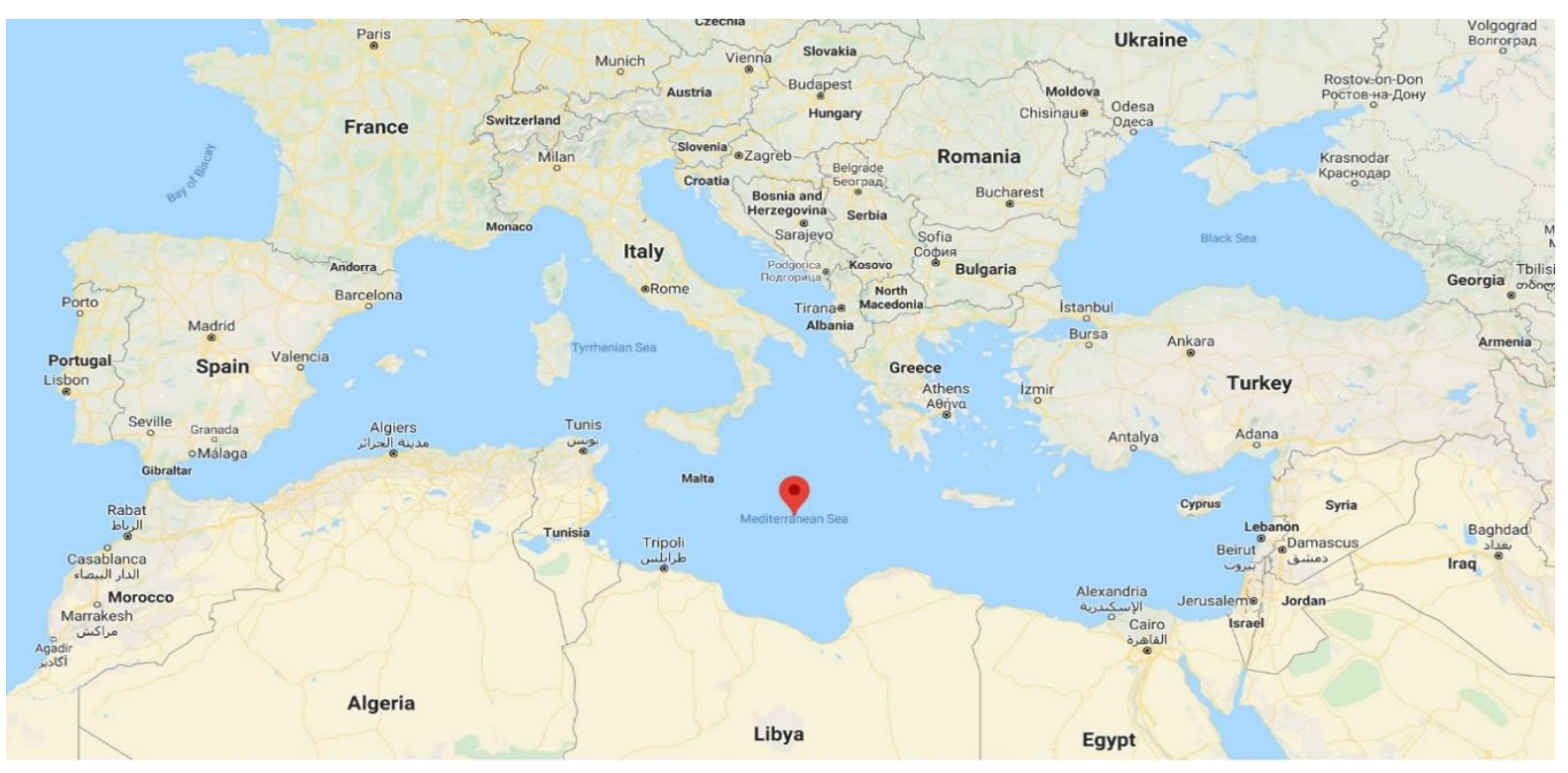

Figure 5.5. The Mediterranean Sea (Google Maps, 2021)

As can be seen in Figure 5.5 $5^{11}$, The Mediterranean is a semi-enclosed sea bordered by coasts of 22 countries and territories (Turkey, Greece, Albania, Montenegro, Bosnia and Herzegovina, Croatia, Slovenia, Italy, Malta, France, Spain, Morocco, Algeria, Tunisia, Libya, Egypt, Israel, Palestine, Lebanon, Syria, Cyprus, and Northern Cyprus). "The Mediterranean Sea connects through the Strait of Gibraltar to the Atlantic Ocean in the west and through the Dardanelles to the Sea of Marmara and the Black Sea in the northeast. In the southeast, the Suez Canal links the Mediterranean to the Red Sea and the Indian Ocean" (Coll et al., 2010, p. 2). The Mediterranean Sea has rich biodiversity (MedPAN, 2020), and approximately 17,000 marine species consider it as their home, of which constitutes 7.5 per cent fauna and 18 per cent flora of the world marine population (Bianchi \& Morri, 2000). Moreover, the Mediterranean region hosts more than four hundred fifty million people 40 per cent of whom live on the coast. However, as MedPAN (2020) states, the marine ecosystem in the Mediterranean is under threat which links to biodiversity loss (degradation of seagrass meadows); diminishes the well-being of coastal populations (accidental or deliberate marine pollution and the production of solid wastes and sewage); and reduction of food production. For example, according to recent evaluations made within the framework of the General Fisheries Commission for the Mediterranean (GFCM), 90 per cent of the assessed fish stocks were overexploited. Over the last few years, urbanisation and coastal development become one of the main reasons to intensify the above-mentioned risks. In addition to that, unregulated activities such as any scale of fishing, transportation and industries put additional pressure. 
Besides, the Mediterranean region is one of the world's most popular tourism destinations, attracting more than 300 million tourists; this figure represents about 30 per cent of international arrivals (Fosse \& Tellier, 2017; MedPAN, 2020) and these have been creating adverse effects on this area. Therefore, it becomes the most important question while taking into consideration the vulnerability of Mediterranean coastal and marine ecosystems and finding a balance between generating socio-economic benefits for stakeholders and sustainable practices in terms of using marine resources.

\subsubsection{The Maltese Archipelago as Malta}

The Maltese archipelago lies virtually at the centre of the Mediterranean. The archipelago consists of three islands: Malta, Gozo and Comino with a total population of over 443,000 (for reference see Table 5.3 below) inhabitants occupying an area of 316 square kilometres (Visit Malta, 2020a). With this area, the Maltese Archipelago is one of the smallest in the world but is strategically important (Britannica, 2020). Malta is the largest of the three islands and is still the cultural, commercial, and administrative centre. Gozo is the secondlargest island and more rural; it is known for its more abundant countryside and open spaces. Comino, while largely uninhabited, is a popular destination for day-trippers, including scuba diving, and hikers. Visitors to the Islands are often attracted to the archetypal, Mediterranean climate, which is typified by hot summers and mild winters (Malta Government, 2020).

Table 5.3. Facts and Figures About Malta

\begin{tabular}{|c|c|}
\hline Definition & Status \\
\hline Capital City: & Valletta (gov.mt) \\
\hline Islands: & Malta - Gozo - Comino (gov.mt) \\
\hline Population: & $443,174^{13}$ (worldometers.info) \\
\hline Size: & $316 \mathrm{~km}^{2}$ (gov.mt) \\
\hline Territorial Waters: & Approximately $10,762 \mathrm{~km}^{2}$ (msp-platform.eu) \\
\hline Official Language: & Maltese and English (gov.mt) \\
\hline Religion: & Roman Catholic (gov.mt) \\
\hline Currency: & Euro (gov.mt) \\
\hline Country Code: & +356 (gov.mt) \\
\hline Time Zone: & GMT +1 (gov.mt) \\
\hline Government: & Republic of Malta (gov.mt) \\
\hline GDP (2019) & EUR 13,208.5 millions (mta.com.mt) \\
\hline GDP per capita (2019) & EUR 26,352 (mta.com.mt) \\
\hline Total tourist expenditure (2019) & EUR 2.2 billion \\
\hline Tourist expenditure per capita (2019) & EUR 807 \\
\hline
\end{tabular}


Malta is also seen as a popular destination by tourists. As an illustration, in 2019, Malta received a total of 2.753 million (2.056 million first time / 697k repeat visitors) international arrivals, indicating a 5.9 per cent growth compared to the previous year (MTA, 2020b). The average length of stay per tourist was about 7 days which generated 19.338 million overnights stays (including Gozo and Comino) (MTA, 2020b). According to World Economic Forum (WEF, 2019), as shown in The Travel \& Tourism Competitiveness Report 2019, due to the high prioritisation of the tourism market, Malta has become the world's most tourismdependent country. Most of the tourists arrive at Luqa International Airport (98.1 per cent), as it is in close proximity to Valletta. 1.9 per cent of all international arrivals travel by sea using the Port of Valletta as an entry point, in 2019. Although the numbers based on statistics are considerable, Malta's tourism segmentation is highly seasonal. Most tourist arrivals are usually recorded in July and August.

\subsubsection{Scuba Diving Tourism in Malta}

The Maltese Islands' clear blue the Mediterranean Sea is ideal for scuba diving. All three Islands offer some scuba diving experiences with an abundance of marine landscapes, caves, and alternative dive sites like artificial wrecks. The calmness and clarity of the sea make for good visibility, down to around 30 metres, whilst the risk of encountering dangerous fish is extremely low, which creates suitable conditions for first-time scuba divers and beginners. For the more experienced scuba divers (excluding technical scuba divers), there is plenty of depth and scuba diving variety, from 12 to 50 metres (Visit Malta, 2020b). Moreover, Malta is famous for some of the best-known scuba dive sites ranging from labyrinthine caves to landscape and wartime wrecks, including artificial wrecks, all types of scuba dive sites* displayed in Figure $5.6^{12}$. In total, there are 219 scuba dive sites listed on maltadives.com and 45 are considered popular scuba dive sites areas, as can be seen in Appendix $13^{14}$. A number of conservation areas have been established around submerged wrecks located in Maltese waters. 


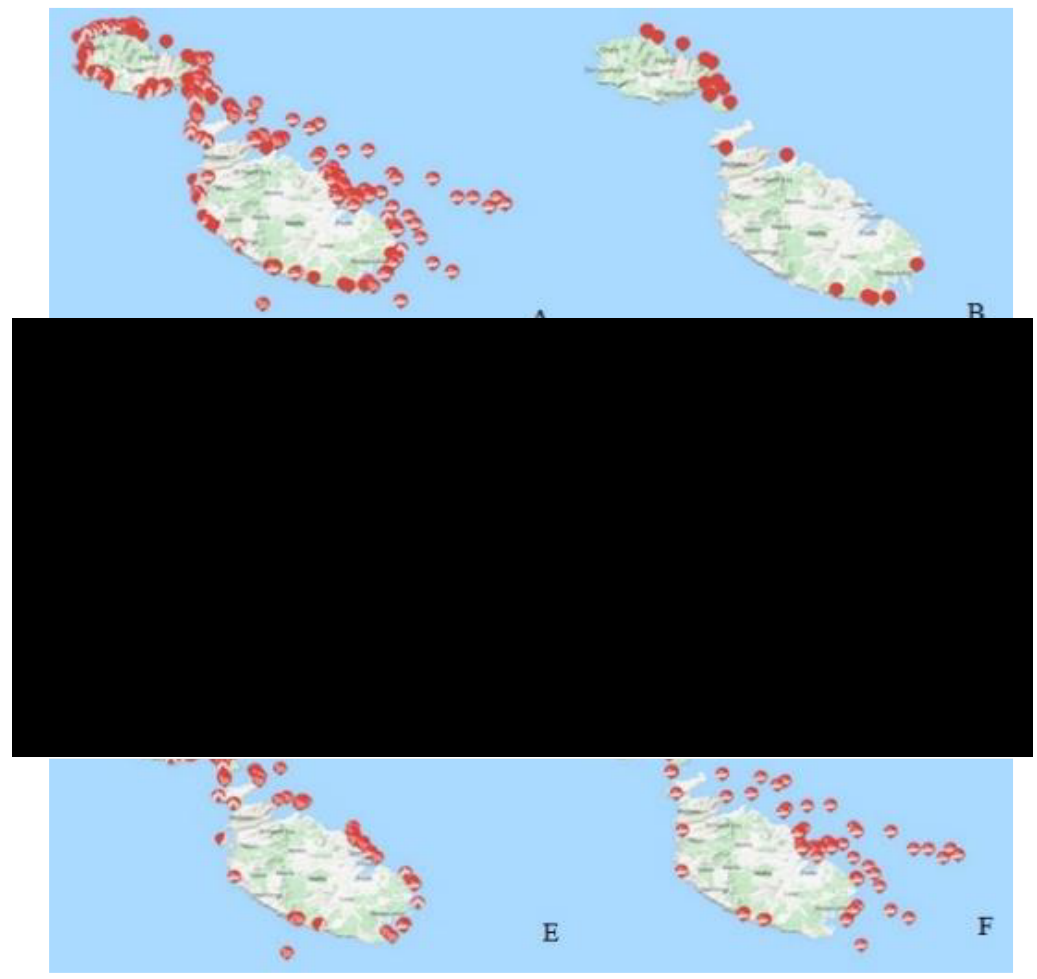

*A stands for all types of scuba diving areas, B for unnamed; C for caves; D for walls; $\mathrm{E}$ for reefs; and $\mathrm{F}$ for wrecks. The popular alternative (deliberately sunk) dive sites in Malta are (Visit Malta, 2020c): The Um El Faroud in Wied Iż-Żurrieq; MV Xlendi, Cominoland, Karwela off Xatt 1-Aћmar; Tug St. Michael, Tug 10 in Marsaskala; The Imperial Eagle off Qawra Point; Rożi, P29 off Cirkewwa. In terms of historical wrecks there are Blenheim Bomber off Xrobb 1-Ghagin; and Bristol Beaufighter off Exiles Point.

Figure 5.6. Malta, Gozo and Comino Popular Dive Sites (Malta Dives, 2021)

Table 5.4. Malta Scuba Diving Facts and Figures

\begin{tabular}{|c|c|c|c|c|c|c|}
\hline $\begin{array}{c}\text { Typology } \\
\begin{array}{c}\text { Total Inbound } \\
\text { Tourists }\end{array}\end{array}$ & $\mathbf{2 0 1 0}$ & $\mathbf{2 0 1 5}$ & $\mathbf{2 0 1 6}$ & $\mathbf{2 0 1 7}$ & $\mathbf{2 0 1 8}$ & $\mathbf{2 0 1 9}$ \\
\hline $\begin{array}{c}\text { Motivated by Scuba } \\
\text { Diving }\end{array}$ & N/A & N/A & 101,700 & 117,300 & 127,350 & 131,382 \\
\hline $\begin{array}{c}\text { Number of Scuba } \\
\text { Divers }\end{array}$ & 64,300 & 113,322 & 142,800 & 155,344 & 169,850 & 177,645 \\
\hline Malta & N/A & N/A & N/A & 105,720 & 114,270 & 127,632 \\
\hline Gozo & N/A & N/A & N/A & 29,898 & 29,344 & 22,406 \\
\hline Comino & N/A & N/A & N/A & 1,849 & 1,036 & N/A \\
\hline Malta \& Gozo & N/A & N/A & N/A & 17,877 & 25,200 & 26,407 \\
\hline $\begin{array}{c}\text { Average PP } \\
\text { Expenditure }\end{array}$ & N/A & N/A & N/A & $€ 442.70$ & $€ 445.91$ & $€ 476.44$ \\
\hline Total Expenditure & N/A & N/A & N/A & $€ 182,916,000$ & $€ 189,355,500$ & $€ 222,056,250$ \\
\hline The UK & N/A & N/A & N/A & 15.1 per cent & 16.0 per cent & 15.5 per cent \\
\hline Italy & N/A & N/A & N/A & 16.0 per cent & 12.5 per cent & 14.7 per cent \\
\hline Germany & N/A & N/A & N/A & 11.8 per cent & 11.4 per cent & 12.1 per cent \\
\hline France & N/A & N/A & N/A & 10.5 per cent & 9.5 per cent & 11.7 per cent \\
\hline
\end{tabular}

The popularity of scuba diving in Malta tripled from 2010 to 2019. According to Malta Tourism Authority (MTA, 2020a), today more than 177.000 tourists practice scuba diving in Malta annually, while over 131.000 of them are motivated by scuba diving specifically. Within this figure, approximately 6.5 per cent of total inbound tourists attended scuba diving activities in 2019. As can be seen in Table $5.4^{15}$, scuba diving contributes significantly to the Malta 
tourism based economic revenues, which is about $€ 222$ million total expenditure of tourists engaging in scuba diving activity. Over half of tourists visited Malta for scuba diving in July, August, and September. Most scuba divers came from the UK about 27.500 with 15.5 per cent, while Italy was second with 14.7 per cent, third as Germany 12.1 per cent and France as fourth with 11.7 per cent of the scuba diving market. As a result, all these figures and statistics make Malta a suitable field study area. 


\section{CHAPTER 6: RESULTS}

\begin{tabular}{|c|c|c|c|c|c|}
\hline $\begin{array}{c}\text { Chapter } 1 \\
\text { Introduction }\end{array}$ & & $\begin{array}{c}\begin{array}{c}\text { Overview } \\
\text { and } \\
\text { Introduction }\end{array} \\
\end{array}$ & $\begin{array}{l}\text { Research } \\
\text { Outline }\end{array}$ & $\begin{array}{l}\text { Chapter } \\
\text { Reviews }\end{array}$ & \\
\hline $\begin{array}{c}\text { Chapter } 2 \\
\text { Scuba Diving Tourism }\end{array}$ & \begin{tabular}{|c|}
$\begin{array}{c}\text { Discovering } \\
\text { the } \\
\text { Underwater }\end{array}$ \\
\end{tabular} & $\begin{array}{c}\text { Scuba } \\
\text { Diving } \\
\text { Economy }\end{array}$ & $\begin{array}{c}\text { Scuba } \\
\text { Diving } \\
\text { Experience }\end{array}$ & $\begin{array}{l}\text { Current } \\
\text { Issues }\end{array}$ & \\
\hline $\begin{array}{c}\text { Chapter } 3 \\
\text { Sustainability }\end{array}$ & $\begin{array}{c}\text { Sustainable } \\
\text { Tourism } \\
\text { Development }\end{array}$ & $\begin{array}{l}\text { Division } \\
\text { and } \\
\text { Concept }\end{array}$ & \begin{tabular}{|l} 
Current \\
Practices in \\
Scuba \\
Diving \\
\end{tabular} & $\begin{array}{l}\text { MPAs and } \\
\text { Alternative } \\
\text { Dive Sites }\end{array}$ & \\
\hline $\begin{array}{l}\text { Chapter } 4 \\
\text { Theoretical Foundation }\end{array}$ & $\begin{array}{l}\text { Normative } \\
\text { Theory }\end{array}$ & $\begin{array}{l}\text { System } \\
\text { Theories }\end{array}$ & $\begin{array}{l}\text { Stakeholder } \\
\text { Theory }\end{array}$ & SDTS & $\begin{array}{l}\text { Identifying } \\
\text { the Gap }\end{array}$ \\
\hline $\begin{array}{c}\text { Chapter } 5 \\
\text { Methodology }\end{array}$ & $\begin{array}{l}\text { Research } \\
\text { Framework }\end{array}$ & $\begin{array}{l}\text { Research } \\
\text { Strategy }\end{array}$ & $\begin{array}{l}\text { Research } \\
\text { Ethics }\end{array}$ & $\begin{array}{c}\begin{array}{c}\text { Limitations } \\
\text { in } \\
\text { Methodology }\end{array} \\
\end{array}$ & $\begin{array}{c}\text { Field Study } \\
\text { Area }\end{array}$ \\
\hline $\begin{array}{c}\text { Chapter } 6 \\
\text { Results }\end{array}$ & Strain & Stress & Sustain & Supervision & Support \\
\hline $\begin{array}{l}\text { Chapter } 7 \\
\text { Discussion }\end{array}$ & & $\begin{array}{l}\text { Inferences } \\
\text { and Links }\end{array}$ & $\begin{array}{c}\text { Constituents } \\
\text { and } \\
\text { Foundations }\end{array}$ & $\begin{array}{c}\text { Revised } \\
\text { Sustainability } \\
\text { Criteria }\end{array}$ & $\begin{array}{c}\text { S-SDTS } \\
\text { Model }\end{array}$ \\
\hline $\begin{array}{c}\text { Chapter } 8 \\
\text { Conclusion }\end{array}$ & & $\begin{array}{l}\text { Ans wers to } \\
\text { Research } \\
\text { Questions }\end{array}$ & Implications & Reflection & Limitations \\
\hline
\end{tabular}

Figure 6.1. The Structure of Chapter 6

\subsection{Introduction to Chapter 6}

Chapter 6 represents the overall results and findings of this study which derived from the answer to the question of 'to what extent do the normative aspects of the scuba diving tourism system address principles of sustainability?' Moreover, sub-questions enrich the findings and support the theoretical framework during the study. These are related to how stakeholders understand sustainability or sustainable development in the SDTS; prepare operational plans and provide regulations to manage the system; address the triple bottom line of sustainability while interacting with the marine environment; accommodate personal knowledge about sustainability and their skills in SDTS; and recognise the philosophical, theoretical, and managerial cores as the normative aspects of SDTS. First of all, information regarding the demographics of the interviewees was given. Knowledge of sustainability was 
considered as the fundamental ground of this study. Therefore, before starting to examine the main themed findings of this study, the knowledge of sustainability was analysed. As can be seen in Figure 6.1, five themes were presented in the order of a systematic sustainable scuba diving tourism development approach. The results relate to issues about current and future problems in Malta specifically.

\subsection{Demographics of the Interviewees in This Study}

Within the research period between July 2019 and August 2019, 2 managers and 3 scuba diving centres' owners (one of the owners also represents PDSA), 3 authorities from the tourism department, 22 scuba divers, 9 scuba diving instructors, 3 scuba diving interns, 4 marine biologists, 2 marine archaeologists and 3 tourism scholars were interviewed to understand better the characteristics of the interviewees, demographic features of the participants, their motivations and preferences for alternative dive sites (according to main scuba diving offers of Malta, artificial wrecks) were asked, as can be seen in Appendix 14. With regards to the frame of this study, gender, age, occupation, educational background, level of scuba diving certification, number of scuba diving, nationality, scuba diving motivations (in terms of touristic perspectives) and preferences of scuba diving types including alternative dive sites for scuba diving were explored.

As indicated earlier, the SDTS involves different backgrounds and diverse demographics. For this reason, demographic questions were asked to the interviewees to provide a rich and reliable data source (Silverman \& Patterson, 2015; Korstjens \& Moser, 2018) and identify the stakeholders related or associated with SDTS. In this connection, in total, 29 out of 51 interviewees were male while 22 of them were female (indicated as $\mathrm{M}$ and F respectively in Appendix 14). Specifically, in terms of each group, the gender-related results were as 12 female and 10 male scuba divers; 6 female and 3 male scuba diving instructors; 1 female and 2 male scuba diving interns; 2 male marine archaeologists; 1 female 3 male marine biologists; 1 female and 2 male authorities; 1 female and 4 male owners (including 2 managers; 1 female and 1 male, and one of the owners represents the PDSA); and 3 male tourism scholars. The average age of the interviewees was 37 within the range of 17 to 65 . The highest number of scuba dives among participants was over 10000 while some of the interviewees have participated in scuba diving for the first time just before having the interview. According to educational background results, among participants 14 of them had a bachelor's degree, 12 
masters, 12 colleges, $7 \mathrm{PhD}, 4$ high schools, and $1 \mathrm{MBA}$. 21 of interviewees were Dive Master while 7 of them had no certificate for scuba diving. The majority of the participants were Maltese, and the others were as follows: 10 British 4 German, 4 Belgian, and 4 French. The more common motivation is wreck diving, which was stated twenty-five times by participants, and is Malta's strongest offering. Furthermore, 7 out of 22 scuba divers were specifically motivated by wreck scuba diving. The other results based on motivations are the variety; good visibility; marine life. The most preferred alternative sites were related history; surroundings; depth; and going inside the wreck, respectively.

\subsection{The Knowledge of Sustainability}

The knowledge of sustainability on a basis of the scuba diving tourism system has an important normative role which is the key figure for this study is revealing the understanding of the stakeholders. This holds a set of normative standards of justification and evaluation by creating acts and beliefs (Smithies, 2012). For this reason, the interviews started for each participant with the question of 'What does sustainability mean and what do you know about sustainability?'. The revealed knowledge derived from individual interviewees is provided in Appendix 15. According to the results, each interviewee has knowledge about sustainability or sustainable development, to some extent. Protection of the environment constituted the most important issue according to their knowledge. In general, the source of knowledge of sustainability comes predominantly from film documentaries for recreative scuba diver participants. For example:

- "I remember watching documentaries about". DIV - 2

- "I watch like the blue planet maybe see documentaries about how, you know, things like”. DIV - 4

- "Basically, from time to time I watch some documentaries”. DIV - 18

It is revealed that recreational scuba divers tend to watch documentaries rather than having specific education or further education regarding sustainability. However, the data shows that there was no systematic education or getting informed about how important sustainability is in the marine environment or how the marine ecosystem can be sustained according to principles of sustainability. Therefore, it can be said that, as the literature supports, 
there is still limited knowledge about sustainability and its outcomes for people who participate in scuba diving tourism for recreational purposes.

However, the source of knowledge was not indicated by stakeholders. Therefore, the degree of credibility of the knowledge addressed to the triple bottom line was observed to be low level. Through the knowledge of participants about sustainability, it can be said that the general outcome is related to doing something and taking care of the environment for future generations while obtaining economic benefit at the same time. However, active involvement with environmental focus is not satisfactory level in practice for some reasons. Therefore, the effectiveness of the knowledge regarding sustainable development in marine environments remains limited. To facilitate the data analysis (McNaught \& Lam 2010; Cater et al., 2019) Word Cloud as a visual interpretation tool (Figure 6.2) was used to clarify a large amount of data (generated from the interviewee`statements see Appendix 15). This word cloud illustrates the perception that sustainability is a concept with the need to take action, and that environment is still the most significant core of the idea, despite more recent attempts to present a more holistic understanding.

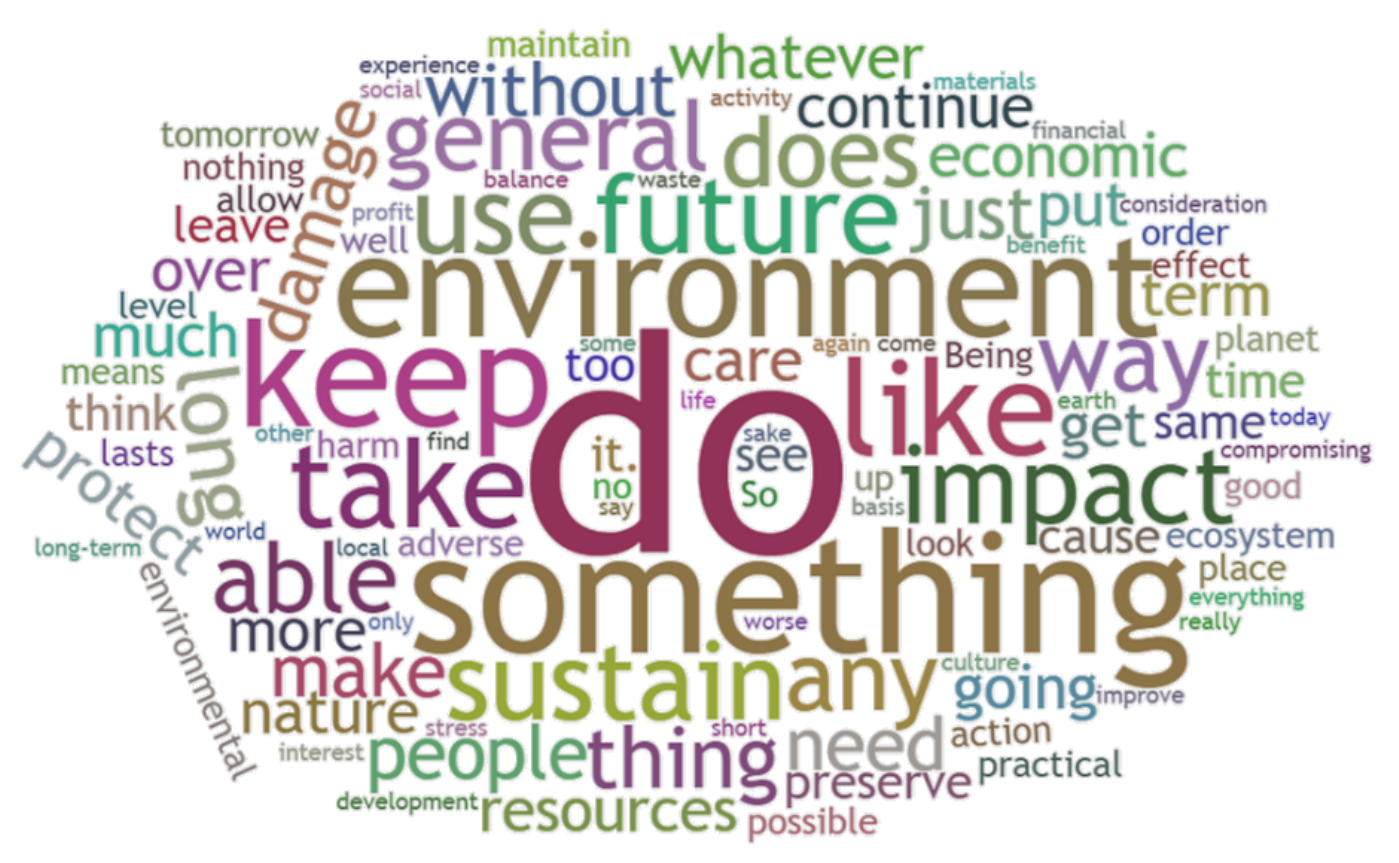

Figure 6.2. Word Cloud of Overall Meaning of Sustainability for Respondents

Indeed, maintaining what scuba divers like doing was mentioned by interviews primarily in the sense of ecological integrity. To have economic benefits through long-term 
environmentally friendly practices were also a point of sustainability in their understanding within the interviews to evaluate and understand the meaning of sustainability in scuba diving tourism. Moreover, what causes damage to the marine environment and how people can eliminate impacts that put stress on the future were also questioned as a matter of the knowledge of sustainability. Some examples regarding interviewees`statements of each stakeholder group are given below.

- "Do not harm the natural resources or the environment, to cause damage or waste just to take care of the environment". DIV - 7

- “Like not leaving any footprints, not damaging, not stressing”. INS - 4

- "Any action that you do does not put any excessive strain on what you are doing, which will allow you to continue doing it ... So, your actions must not impact what you do tomorrow and what tomorrow will bring”. OWN - 2

- "The harmony between the protection ... as much as practical and at the same time where practical and where possible the sharing”. MAR - 2

- "Not the economics or anything like that, that the ecosystem is stable in the long term except for natural ... or natural succession or something like that”. MBI - 4

- "Taking what you need without compromising the needs of future generations". MTA $-2$

- "Trying to think ahead. Not going forward, shortcuts and not putting today's financial interests before the interest of tomorrow”. TUR - 1

According to these statements, scuba diving practices can contribute to the conservation of the marine environment (Mota, 2016) and people are likely to evaluate destinations from a sustainability perspective overall (Iniesta-Bonillo et al, 2016). Because, from a tourism perspective, sustainability should mean to keep the act of experience to be alive in the future by showing respect to other living creatures and the environment by learning but not depleting it. In this respect, all participants emphasised sustainability in terms of environmental protection or responsible resource usage. In general, it was observed that each interviewee tended to explain sustainability according to their position. For instance, while the marine 
archaeologists explained sustainability from heritage and protection perspectives, the marine biologists and the scuba diving centres defined the term sustainability with their understanding of the protection of the marine environment. Tourism scholars interpreted sustainability from the gaze of destination and local livelihood perspectives which highly exist in their focus. However, only a few interviewees provided more detailed knowledge about sustainability which refer to the triple bottom line from the point of view of local perspective and future generations' needs and underlined its long-term effectiveness characteristic. As a result, sustainability in scuba diving tourism is not only about the novel experience but also about awareness of the detrimental effect on the marine environment according to interviewees.

\subsection{S Thematic Framework of Sustainability (5S Themes)}

Scuba diving tourism, as a sector, is faced with momentous changes due to innovations (Lazoc \& Lut, 2013) and selective touristic demands. This demand is the primary indicator of the scuba diving tourism system and creates the value of the destination, as well as businesses by integrating all contributors (Fletcher et al., 2018). The SDTS has emerged from product and service demand and supply, which will be turned into an experience for the visitor. From this point of view, the main purpose of the SDTS is to provide a framework for uniting supply and demand together in the destination where the activities take place (Hall \& Butler, 1995). Hence, to govern the system becomes an important execution. However, the different drivers arising from different demand attributes with the various source of supply and components of the stakeholders make this system complex. Therefore, effective, and efficient management of the system can be derived from a systematic approach blended with planning, analysis and identifying the development tools (Manente \& Minghetti, 2006). In this proposal, stakeholders have responsibilities to improve the system and enhance the destination attributes, which are demand conditions; strategy, and organisation of the system (Porter, 1998); the environment; the competitiveness; main and supporting resources (such as infrastructure, transport, and access); and policy, planning, management and development of the destination (Ritchie \& Crouch, 2005). As all destinations are featured differently in terms of size, location, market, rapidly changing technology, therefore, policies should be adopted systematically; reshaped according to the structure of destinations; reconfigured in the manner of needs of the organisations (Fletcher et al., 2018); and re-embodied in relation to the essentials of the system which depends on common interests of stakeholders in scuba diving tourism. 
In this connection, the research framework was established by thematic analysis of the stakeholders` perspectives and results derived from individual perceptions of interviewees towards sustainability, sustainable development, and the scuba diving tourism system. As the main data source, statements and knowledge given by participants of this study were transcribed, analysed, coded, and thematised, respectively. The final themes were classified and denominated into the ` $5 \mathrm{~S}$ of Sustainability in Scuba Diving Tourism System`, in short, `5S Themes`. As a result, the 5S Themes was matched to the literature review and the theoretical framework of this study. Classification of the results was applied to the concept of this study. Results explain the current and investigated phenomenon of sustainability in the scuba diving tourism system. The results of the field study data were combined and demonstrated the interrelationship between the 5 dimensions of the sustainability in scuba diving tourism system model. This represents the steps for achieving sustainable development in the destination through understanding constituents of current issues, threat appraisal, management, requirement, and improvement.

The final themes were structured in the $5 \mathrm{~S}$ Themes as can be seen in Table 6.1. The proposed 5S Themes emerged from the data of the field study and are employed as the conceptual framework of the results. Themes explain the current issues, threats, and the investigated phenomenon of sustainability in the scuba diving tourism system. Constituents of this themed structure include five dimensions and five sub-categories of sustainability in scuba diving tourism and stands for the steps to achieve sustainable development in the destination with a systems approach. The main dimensions are `Strain`, 'Stress`, 'Sustain`, 'Supervision` and 'Support'. First, the dimension of strain explains the current issues which stand for general negative issues that affect scuba diving tourism and the destination due to external factors. Strain is constituted by controversial threats such as uncontrolled fishing activities, lack of marine life and marine pollution. Second, the stress dimension is clarified by threat appraisal which assesses issues by the scuba diving tourism industry which explains negative influences caused by actual scuba diving activity. In general, threats originated from scuba divers and the scuba diving tourism industry. Carrying capacity and impacts of the sea cave and night diving, scuba diving congestion as a form of `jacuzzi diving` phenomenon and lack of knowledge about the marine ecosystem are included in this dimension to better understand the most frequently faced matters. 
Third, sustain is established by the management subtitle, which represents the actions in different aspects that need to be taken to control and manage through alternative and adopted decisions. They are scuba divinvesment (the combination of dive and investment) and divinfrastructure (the combination of dive and infrastructure), awareness and education, and Marine non-Protected Areas (MnPAs). Fourth, the supervision is demonstrated by the requirement of sustainable practices for scuba diving centres, power of pre-diving briefings, and safety of scuba diving and alternative dive sites which explains the need for effectively managed requirements. The last dimension is the support that addresses the improvement and the success of sustainable scuba diving tourism development which gives an opportunity to think about the improvements and prosperity within the systems approach. The feature of alternative dive sites, behaviour for protection, and the questioning of the future of the scuba diving tourism system also become significant constituents of this theme.

Table 6.1. 5S Thematic Framework of Sustainability in Scuba Diving Tourism System (5S Themes)

\begin{tabular}{|c|c|c|c|c|}
\hline Strain & Stress & Sustain & Supervision & Support \\
\hline Current Issues & Threat Appraisal & Management & Requirement & Improvement \\
\hline $\begin{array}{c}\text { Controversial } \\
\text { Threats as } \\
\begin{array}{c}\text { Uncontrolled } \\
\text { Fishing Activities }\end{array}\end{array}$ & $\begin{array}{c}\text { Carrying Capacity } \\
\text { and Impacts of } \\
\text { Sea Cave and } \\
\text { Night Diving }\end{array}$ & $\begin{array}{c}\text { Scuba } \\
\text { Divinvestment / } \\
\text { Divinfrastructure }\end{array}$ & $\begin{array}{c}\text { Sustainable } \\
\text { Practices for } \\
\text { Scuba Diving } \\
\text { Centres }\end{array}$ & $\begin{array}{c}\text { The Feature of } \\
\text { Alternative Dive } \\
\text { Sites }\end{array}$ \\
\hline $\begin{array}{c}\text { Lack of Marine } \\
\text { Life }\end{array}$ & $\begin{array}{c}\text { Scuba Diving } \\
\text { Congestion as } \\
\text { Jacuzzi Diving }\end{array}$ & $\begin{array}{c}\text { Awareness and } \\
\text { Education }\end{array}$ & $\begin{array}{c}\text { Power of Pre- } \\
\text { Diving Briefings }\end{array}$ & $\begin{array}{c}\text { Behaviour for } \\
\text { Protection }\end{array}$ \\
\hline Marine Pollution & $\begin{array}{c}\text { Lack of } \\
\text { Knowledge About } \\
\text { the Marine } \\
\text { Ecosystem }\end{array}$ & $\begin{array}{c}\text { Marine non- } \\
\text { Protected Areas } \\
\text { (MnPAs) }\end{array}$ & $\begin{array}{c}\text { Safety of Scuba } \\
\text { Diving and } \\
\text { Alternative Dive } \\
\text { Sites }\end{array}$ & $\begin{array}{c}\text { The Future of } \\
\text { Scuba Diving } \\
\text { Tourism System }\end{array}$ \\
\hline
\end{tabular}

The 5S Themes was starting point to report the results. Each constituent was categorised and indicated in systematic order. The reason to give this thematic framework in advance was to put themes in systematic interpretation order. Overall, the $5 \mathrm{~S}$ Thematic Framework of Sustainability in Scuba Diving Tourism System includes 15 themes within 5 categories and 5 implication factors that represent the way of achieving a sustainable scuba diving tourism system. Although, sustain remains the fundamental structure of this model for both directions, all factors are interrelated, interdimensional and mutually complementary. The progress of prior, current and post scuba diving activity influences sustainable development in the destination within the systems approach. On the one hand, strain and stress can be 
comprehensively evaluated before attempting to consider sustain, supervision and support. On the other hand, supervision and support depend on the success of sustainable principles. As can be seen in the constituents, sustain covers the important role to carry out the supervision and support goals with requirement and improvement processes. All themes are presented below according to the order of the Table and in such a manner to create a story within the individual subject.

\subsection{Strain $(1 / 5 S)$}

The dimension of strain stands for the issues that need to be considered as external threats (as cause-effect relation) to the scuba diving tourism system with limited direct control. According to interview recordings, participants identified current issues with three subcategories. They are controversial threats such as overfishing or commercial fishing, recreational fishing, and spearfishing; a lack of marine life, which is the most appeared in interviews; and the effect of direct marine pollution. Overall, strain explains current environmental issues that the scuba diving tourism system was adversely affected because of many encountered circumstances and external factors and results in detrimental consequences. These issues were revealed by asking the question of 'What is the most important threat for scuba diving tourism in Malta?' This question was asked to all participants except tourists because for scuba divers, threats were not in view in the first place when they come to their destination especially for the first time. However, there were some certain cues like lack of marine life which was mentioned by a few scuba divers as well, as an outcome of their current scuba diving experience. Several numbers of scuba divers complained about the scarcity of marine life in Malta (caused by fishing activities according to other stakeholders`statements) while expecting to see more. In line with this result, Kraus and Diekmann (2017) have found out that fishery activities target more than a single species underwater and fish stocks can only be maintained in a healthy marine ecosystem. In this sub-theme, three fishing types are related to the controversial threat to marine life. Among other countries where fishing takes place, the marine environment in Malta has been affected negatively because of intense and unregulated fishing activities. Related results were given in the subcategories as below: 


\subsubsection{Controversial Threats}

\section{a) Overfishing or Commercial Fishing Activities}

"Fishing, that's a big problem, I would say". MBI - 1

Malta is facing declining fish abundance in both fish stocks and aesthetically, therefore this creates important threats for the marine environment, which also negatively affects scuba diving tourism. This threat has been pointed out many times by the interviewees as overfishing had a negative effect on their scuba diving experience and cumulatively influences marine life. For example:

- “... they come with a trawler and then just destroy everything. I think that's more of a problem”. INS - 3

- "So, by catching everything ... that is not sustainable ... what the fishery at the moment is a free for all, go and catch whatever you want”. OWN - 2

The most important issue was the lack of control over commercial overfishing. As interviewees claimed that there were no regulations and enforcement for commercial fishing in Malta.

- "From the fishing point of view, it a mess here. It's uncontrolled, it's disaster. There is not really enforcement. It's very big problem; the fishing is the worst thing”. OWN - 5

- "The fishery is totally unregulated. I mean, it's not managed at all, basically. There is a management plan in theory, but in practice, it hasn't really achieved anything ... The fishing is really emptying the seas". MBI - 1

The unregulated commercial fishing practices create destructive impacts for both benthic ecosystems (Kraus \& Diekmann, 2017), and offshore and coastal marine life due to unsustainable practices which result in degradation of the marine population with a long-term effect, at the same time as it happens in Malta. As a result, overfishing and commercial fishing become one of the most threatening controversial issues for the scuba diving tourism system in the sense of loss of marine life in the sea and resulting in negative impacts on scuba divers` experience in return in the sense of aesthetical value. 


\section{b) Spearfishing Activities}

All scuba diving centres in Sliema / Malta, which were interviewed during the field study period, offer shore diving opportunities for all levels of scuba divers, either in front of their scuba diving centres or other scuba dive sites around the Maltese archipelago. Shore diving is one of the biggest competitive advantages for the scuba diving tourism market of Malta. It provides price competitiveness for this country in terms of geographical situation including easy access and low transportation costs. However, shores not only attract scuba divers but also people who are enthusiastic about spearfishing practices due to ease of access. Therefore, this attractiveness damages marine life in related areas and affects the scuba diving experience in a negative way. For example:

- "The worst thing is that they are actually fishing within the first 15 to 20 meters, and they are getting the smaller grouper'. TUR - 2

- “... six groupers that made their home over there were murdered straight away within a year ... and there's hardly anything now”. OWN - 2

According to the respondents, a certification and enrolment were required for participating in spearfishing. However, this qualification was withdrawn from the legislative regulations recently, and registrations or skills are no longer needed:

- “... about four or five years ago, people needed to have a license to own a spear gun, because it was considered a weapon ... Now it's no longer required”. MBI - 2

The success of scuba diving tourism in Malta relies on improved or enhanced shore diving opportunities with rich marine life, however, unrestrained spearfishing activities has negative effects on the scuba diving practices on the shore and scuba diving tourism. The abundance of marine life is the most significant constituent of scuba diving tourism. Moreover, this may not only cause a declining range of fish, but also safety issues.

- "We have a lot of spearfishermen, especially in the swimming areas ... But this spearfishing in swimming areas for areas where we are diving, so it's not just unsustainable, it's dangerous, really dangerous”. INS - 9 
However, even if spearfishing caused a threat to both environment and scuba diving practices, opposing views were stated by active participants both scuba divers and instructors. For example, "I have no problem with constant spearfishing as long as you only spearfish a number of fish with the naturally replenish themselves, you don't damage the population" (DIV - 21). Or "spearfishing ... it's a really hard-core sport. And if you actually even managed to shoot some fish, that's impressive. I'm actually impressed by the skills because I won't be able to do it" (INS - 3). Therefore, whether spearfishing is a controversial threat for Malta or not remains open to discussion.

\section{c) Recreational Fishing Activities}

The other controversial threat as the fishing type was recreational fishing, which was common and had a cumulative effect on marine life directly and indirectly. One of these adverse effects was (indirectly) a safety issue including the increasing boat traffic around the shore and (directly) fishing activities around the sites, where the scuba diving activities take place. In addition to that fishing on alternative dive sites, especially wreck dive sites, was the other problem in this threat risk cycle. As with being Fish Aggregation Devices (FAD) (Rountree, 1989; Schneider et al., 2021; Vivier et al., 2021), popular alternative dive sites attract these recreational fishing fanatics and stakeholders tend to blame them as the main reason for decreasing fish population.

- "Amateur fishing, for example, it's increased so many of the image of fishermen, everyone buying a small boat and go on fishing. That has an impact, and they catch the small juveniles, and they take them home and they feed them to the cat”. MBI - 3

- "The unfortunate thing with artificial reefs is that it does congregate fish in a particular place, but then that makes it easier for someone with a fishing boat to come around and fish right on those reefs". TUR - 2

- "You find fishermen all the time fishing”. OWN - 4

Most dive sites are facing fish stock decline due to various fishing activities. Among these, recreational fishing is affecting coastal areas more than the others and this influence scuba diving tourism and turns return as a negative impact on aesthetic pleasure. Therefore, the following question becomes the fundamental issue that needs to be answered. 
- "Why are we letting a few hobbyists ruin a whole ecosystem?” OWN - 5

\subsubsection{Lack of Marine Life}

Lack of marine life is a consequence of uncontrollable circumstances and unsustainable activities. This may have happened because of not only as aforementioned various fishingrelated causes but also climate change, undiscovered events in the marine ecosystem or different human-driven factors outside of the control of stakeholders of scuba diving tourism in Malta. However, even if the negative outcomes of the lack of marine life are well documented in this study, there was no comprehensive explanation for the cause of this event from any stakeholders. Lack of marine life appeared as an issue by active stakeholders in the scuba diving tourism system and was experienced by many scuba divers. For example, as an outcome of recent scuba diving experience:

- “There's not a lot of like as much fish and stuff”. DIV - 2

- "Especially around Malta, it's always a bit empty here and it gets emptier every year. Here is just like when you're lucky you find an octopus". DIV - 3

Even if there are other alternative scuba diving attractions like topography, artificial wrecks and caves that draw attention, the lack of marine life was still considered by scuba divers as a negative experience from their perspective.

- "For me is the topography makes it very interesting. Marine life is very small". DIV 10

- "The topography is great; there are lots of artificial wrecks. The marine life is clearly almost decimated. This place is decimated. The professionalism in diving industry makes a very good job in the very poor environment. Water visibility is fantastic, and the topography is epic because of limestone. The actual marine life is very small and marine life is toast, is nothing, is nothing here, is all gone”. DIV - 21

From the perspective of everyday scuba divers like instructors and scuba diving centre owners, the situation was becoming more apparent, with the combination of garbage. For instance, the storied statements below can draw a picture of the current situation about marine life in Malta: 
- "In Malta no have marine life a lot" (INS - 8). "It was a lot better years ago" (INS 9). "Unfortunately, ... doing reef dives here, a lot of them gets a bit boring." (OWN 1). "A lot of people we take diving, they exit the water and say there wasn't many fish and there wasn't much life” (OWN - 4). "Beautiful typography; the wrecks are really nice; you have very clear visibility; you have a variety of dive sites. But where is the marine life? Where is it?" (OWN - 2).

From the academic and local administrative perspectives, this threat was emerging as a more significant issue compared to the past and other scuba diving tourism destinations.

- "I think in shallow waters there's very little life left nowadays ...”. MBI - 1

- "I remember some dive sites in Malta full of fish". TUR - 3

- “... the marine life is the one missing ingredients". MTA - 2

Moreover, investing in alternative dive sites like artificial wrecks may be the reason trying to improve the scuba diving experience and enhance marine life, however, most of the present ones are only available to advanced scuba divers and fishing enthusiasts.

- "There is a lot of marine life, and for advanced divers, there are nice shipwrecks ... If you look, for example, Zurrieq ... to see the abundance of marine life on that shipwreck, that's fantastic to see". OWN - 3

Marine life in Malta is under threat due to many human-driven causes. Setting up effective planning for managing these areas can help to eliminate these risks, however, marine surroundings in Malta are also threatened by land reclamation in the future. Land reclamation has not only become one of the biggest threats but also has an impact on the future of scuba diving tourism in Malta. This is because, all construction waste will end up in the sea due to lack of land area and the process of digging or filling the sea will also affect the surroundings, as it happened in the past. As a result, land reclamation will negatively influence the marine surroundings, as also becoming a source of marine pollution in Malta, and the potential adverse effects will continue to affect for a long time.

- "The most dangerous threat for the marine environment in Malta ... in the foreseeable 
future ... is going to be land reclamation. Because the island is overpopulated, the construction industry is a very, very, very active as you have seen. And there is a problem of disposal of construction of waste” (MBI - 2). "The government, they're just interested in construction, not the construction waste ... once they start doing land reclamation, they will ruin it”. (OWN - 2).

\subsubsection{Marine Pollution}

This constituent tries to explain problematic issues in Malta for scuba diving tourism and its system. To reveal this issue, the question was 'What is the most important threat for scuba diving tourism in Malta?'. Pollution was the most encountered issue around the scuba dive sites. Although shore diving gives a lot of advantages for scuba diving centres and scuba divers in terms of easy access, the scuba diving experience can be easily affected negatively due to plastic pollution coming from near facilities to scuba dive sites, which concerns a longterm threat. For example (see Figure 6.3):

- "We dived, and I saw some like plastic and stuff". DIV - 9

- "I saw some plastic or some paper". DIV - 11

According to the data, such issues of plastic and cigarette butts as the source of marine pollution were viewed as a local problem by some respondents. For example:

- "The general population in Malta, I think they have got very low awareness any environmental impact ... Leave rubbish like around everywhere ... People are always throwing the cigarette butts on the floor. I think people are not collecting the cigarette butts, they just throwing on the ground end up washed into the ocean”. DIV - 12 

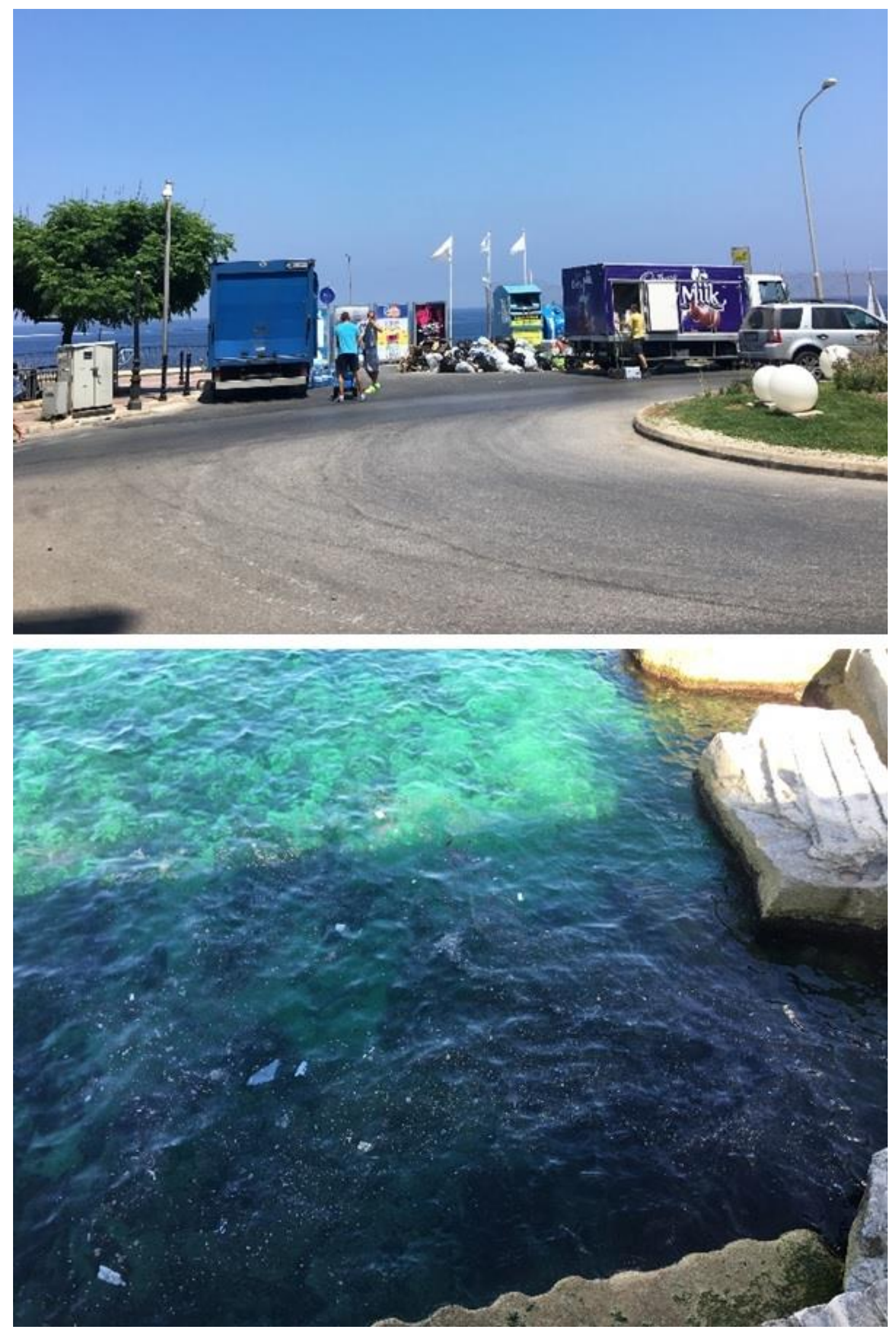

Figure 6.3. The Garbage Dumps and Marine Pollution in Sliema (Photos were taken by the researcher) 
However, plastic pollution or rubbish was not constantly observed by scuba divers.

- 'I was impressed that there was no garbage in the bottom of the sea. I didn't see much plastic at all, and I thought I would see a lot more”. DIV - 16

Nevertheless, the problem of marine pollution, like plastic bottles or cigarette butts, was a continuous threat to the scuba diving tourism experience which was produced not only by locals and land-based landfills.

- "Rubbish and litter ... You know, out by the beaches they've had picnics and barbecues. Sometimes we see like plastic chairs in the sea and like lots of plastic cups and cigarette butts". INS - 6

... But also, by a consequence of natural events.

- "If you go diving after a big rainstorm, you will really, really notice how much detrimental that is. I went, diving once in December after a very big rainstorm and it was like a meter of pure floating garbage”. INT - 2

However, opposite to the above-mentioned statements, although scuba diving instructors were complaining about cigarette butts and litter, it was noted that every empty corner just in front of scuba diving centres was used by employees and customers as an ashtray or bin, as can be seen in Figure 6.4.
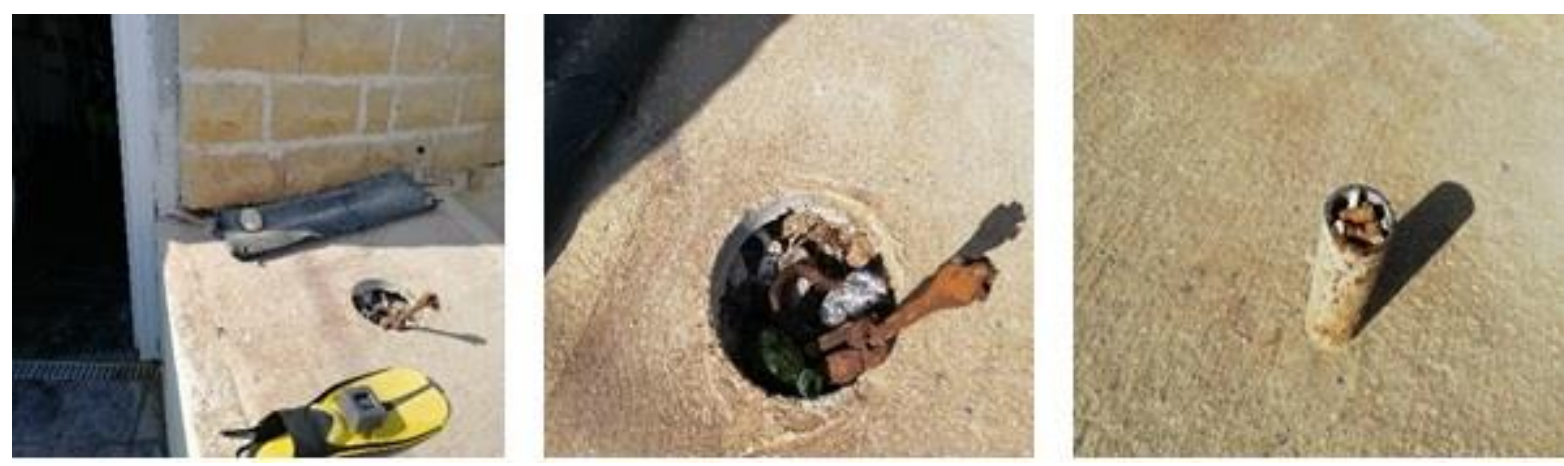

Figure 6.4. Recreational Ashtray at the Front of Scuba Diving Centre (Photos were taken by the researcher)

From the owners` perspectives, overpopulation and stray animals are two reasons for the garbage which end up in the sea and create marine pollution. 
- "All you see is garbage ... how can that be sustainable? ... We are twice the population we were 40 years ago, so there's double the strain and no enforcement, so it's a recipe for disaster". OWN - 2

- “... you put your rubbish on the sidewalk ... the dogs or the cats bite open or the rats, the litter go is everywhere. The wind blows it into the sea, and this is it". OWN - 4

The research findings of this study showed that among local stakeholders, litter and overcrowding were the most important concerns and sources of marine pollution. However, locals` lack of awareness and knowledge about the marine ecosystem or limited ocean literacy were the other considerable reasons which caused the marine pollution. Because, if people are unaware of their negative impacts on the environment, they do not tend to act or behave in an environmentally friendly manner (Passafaro, 2020) or people are usually unaware of the consequence of unsustainable behaviours (Juvan \& Dolnicar, 2014) on the environment.

\subsubsection{Summary for the Theme of Strain}

The first theme of the $5 \mathrm{~S}$ Themes of sustainable scuba diving tourism system aimed to explain directly observable impacts which put a strain on the marine environment such as controversial fishing problems, lack of marine life, and marine pollution. Overall, unsustainable commercial, recreational, and spearfishing activities are the most important threats and have a significant negative impact on marine life in Malta. However, spearfishing and recreational fishing are not part of the enforcement subject focus by authorities. "Someone who is fishing in an MPA as a nuisance, it's not a big crime. So, it's not a priority" (MTA 3). Moreover, in the sense of the local perspective, marine pollution was a problematic issue for marine life and, therefore, for the scuba diving tourism system among all participants. This issue brings a constant challenge for keeping the sea healthy and clean every day. As a result, establishing a sustainable scuba diving tourism system and reducing adverse effects on marine surroundings, there is a need for comprehensive and effective awareness among associated stakeholders which can be ensured by knowledge, monitoring, management plans, proper implementation, and enforcement implications. 


\subsection{Stress $(2 / 5 S)$}

The stress dimension signifies how scuba diving activities threaten marine environments in Malta. This theme explains the current challenges that are caused by scuba divers and the scuba diving tourism industry, rather than focusing on external threats discussed in the strain theme. In this theme, there are three sub-categories which are carrying capacity and impacts of the sea cave and night diving activities; scuba diving congestion as (novel) jacuzzi diving phenomenon; and lack of knowledge about the marine ecosystem. Interview questions that identified these themes were 'What is the most important threat for scuba diving tourism in Malta?'; 'What can be done to be more sustainable in scuba diving tourism?'; 'Last year eight per cent of overall tourists were motivated by scuba diving, do you think this puts stress on carrying capacity in Malta?', which revealed constituents of stress and gave an opportunity to evaluate the measures. Overall, the stress is about practical issues as a result of unsustainable scuba diving tourism practices which become a threat appraisal. Therefore, this theme seeks to better understand the current threats and reveal potential measures depending on personal background and experience which was created by statements of active and supporting stakeholders of the scuba diving tourism system. In general, this theme represents overuse, negative impacts, congestion, protection of the marine ecosystem, and provides a better understanding of direct threats derived from directly scuba diving tourism stakeholders.

\subsubsection{Carrying Capacity and Impacts of Sea Cave and Night Diving}

\section{a) Carrying Capacity}

In parallel with the increased popularity of scuba diving tourism in Malta, carrying capacity is an issue among stakeholders interviewed, even though there is no scientific or statistical evidence for this. Because scuba diving is an intense nature-oriented activity, environmental and local carrying capacities have significant implications to both protect the surroundings and ensure the best scuba diving experience for scuba divers. From the operational point of view, as interviewees claimed that achieving optimal carrying capacity relies on scuba divers` skills and the number of scuba divers, which needs to be regulated from different perspectives, but this is done informally in Malta. For example, according to statements, restricting or allowing limited space for experienced or advanced scuba divers to certain dive sites may provide effective site management. If the maximum capacity is exceeded, scuba diving tourism may change negatively. However, there was one argument that the 
carrying capacity of Malta is higher than other destinations, especially in terms of daily scuba diving operations, because of the relative resilience of the benthic organisms. To manage the dive sites in the scuba diving tourism system sustainably, the operational capacities become the limit to control the number of daily scuba divers. For example:

- "In the Malta maximum capacity limited to truck, maximum five people, six people have experience ... It's absolutely normal for guiding, absolutely easy to manage everything in the frame standards ... it suggests one truck, one instructor at a maximum five people. It's really easy". INS - 8

When it comes to discussing the total number of tourists, in terms of scuba diving centre owners` perspectives not only the current infrastructure but also the number of scuba diving centres are the main issues in Malta. It was claimed that if scuba diving centres aimed to provide more quality services rather than focusing on quantity this can be a better solution to achieve the ideal carrying capacity. For instance:

- "In my opinion, we over-saturated now ... From that point of view, I am a bit worried ... I don't think it can handle much more ... We have a lot of seas, but the infrastructure cannot take much more. So, what we are trying to do is rather than more numbers, trying put the quality of our product and then increase price”. OWN - 5 “... But you cannot only have one or two dive sites. The whole infrastructure has to change. Personally, it would be better if there were less diving centres". OWN - 2

In this sense, the way of doing business that remained limited by the infrastructure can be improved by investing in alternative dive sites like artificial wrecks and extending the seasonality which may become a solution to spread the crowding and ensure optimal carrying capacity in Malta.

- "Open up more dive sites to spread divers to different dive sites instead of putting all stress on the same five dive sites, every single day". INS - 5

- "It would be nicer if the number of diving tourists was spread more evenly across the twelve-month period rather than as having a huge, spike in summer and then very quiet in winter". OWN - 4 
On the other hand, from the academic point of view, scuba diving tourism with this infrastructure cannot handle the current number of tourists regarding ecological capacity. In addition to this, overcapacity also puts stress on the marine ecosystem of Malta in many ways and maybe giving a break from scuba diving tourism can be an answer. For example:

- "Ideally there would be a break when you could have a few months off, you know, everything to just recuperate”. MBI - 1

In this perspective, a solution in the long-term management of the dive sites may be as suggested by OWN - 4, extending the season with some break offs as highlighted MBI - 1 . The other suggestion was planning and opening more alternative dive sites and managing the area. However, there are other questions which need to be discussed and issues for carrying capacity for these alternative dive sites, such as if it is an artificial wreck, in what purpose wrecks and where they will be scuttled; who will be targeted; what relation is it going to have with the marine environment; how is it going to attract and protect the new wildlife on wrecks; how many wrecks can be supported; and more importantly what is the limit going to be for this alternative dive site? However, it is worth noting the following statement regarding the current issue that scuba diving tourism faces.

- "I honestly, I think the limit is being reached and the limit is imposed by the environment ... it's not possible to have many more wrecks in areas that are suitable from an environmental point of view”. MBI - 2

Moreover, exceeding alternative dive sites`capacity may cause a safety issue for scuba divers in the future, rather than maintaining the current number and looking after their conditions to enrich the experience from a broad angle.

- 'I think that Malta has enough wrecks. I think that it's better to keep an eye on maintain them. There are problems, for example, that is the Um El Faroud, which is a very popular wreck, the places called with Zurrieg. So, Um El Faroud is slowly breaking up. So, I mean, it's not going to happen in five years' time, perhaps. Maybe in 10, 15 years it's going to be a problem, I think. It will end up; some structures collapse and sometimes it becomes a danger for the divers' themselves". MBI - 3 
Determining the number of alternative dive sites was getting more confusing from the authority point of view whether putting significant wrecks to increase the popularity of scuba diving tourism or opening more scuba dive sites to achieve the carrying capacity. Therefore, carrying capacity is still under discussion regarding what is the optimal rate and how it emerged in Malta or affected the marine environment from a different point of view. For instance:

- 'I think that we don't need to scuttle anymore ships unless there's something really impressive like a big ship or something that is significant ...

+ Don't forget we have a limited space ...

+ Listen, we need more dive sites to be able to cope with the numbers". MTA - 3

\section{b) Sea Cave Diving}

Sea cave diving is considered one of the most exciting types of activity by many scuba divers in Malta. As I experienced during my active participation, I can say the same thing. It was the relatively most memorable scuba diving experience for me. However, during the field study, several stakeholders who were interviewed, stated that cave diving was one of the most threatening activities for the marine ecosystem in Malta. This is because, even if it is not noticeable by scuba divers, each cave accommodates a unique biota in the whole marine ecosystem (Gerovasileiou \& Voultsiadou, 2012) and scuba diving activities adversely affect this fragile marine environment. One of the most visible effects was to hit the organisms by inexperienced finning or scuba diving technique. For example, as stated by marine biologists:

- "Because scuba divers in caves, unless they are experienced, they can very easily hit against the walls. There's attached organisms like corals, bryozoans which are very fragile”. MBI - 2

The other reason was producing air pockets in the cave`s ceiling which starts to kill off marine organisms (see also Edney et al., 2021b for other recent findings) (see Figure 6.5).

- "I think that for example, something like cave diving is a threat. You the problem with the bubbles; creating a pocket on the ceiling ... And the bryozoans just die and then they fall and the bottom of the cave full of this thickness, full of bryozoans, all over the base. So, I am sure that with this cave diving, there is an adverse effect". MBI - 3 

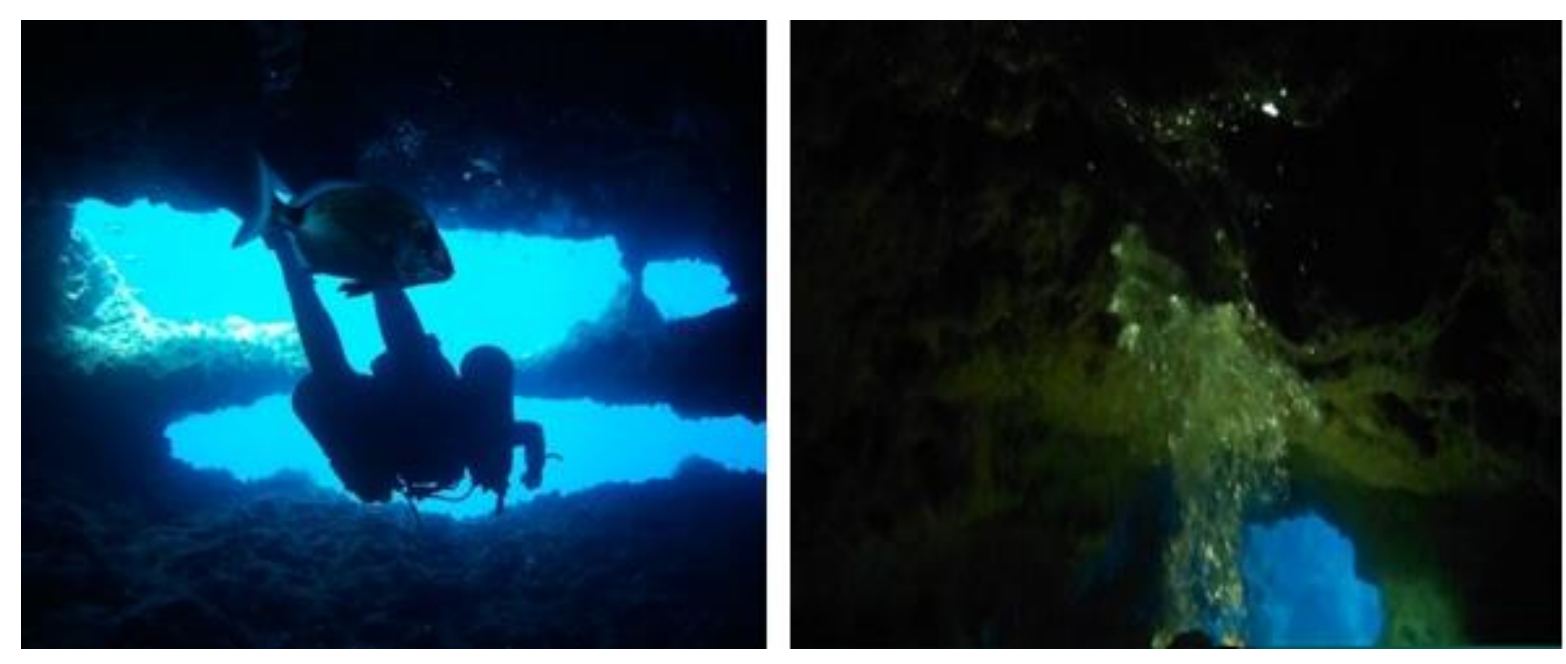

Figure 6.5. Air pockets Caused by Scuba Divers in Caves (Photos were taken by the researcher)

In terms of ecological integrity and economic efficiency, the solution seems to implement restrictions by considering the carrying capacity for each cave, instead of prohibiting the whole activity. For example:

- 'I don't think it should be banned. I think it needs to be regulated better. I think there should be a study made and the carrying capacity also, it will depend on the habitat". MBI - 1

- "There might be some caves which are already very popular; already up to now heavily impacted then those caves can remain open today. I think some other caves which are still pristine, they are still in good condition. They there can be controls". MBI - 2

In conclusion, sea cave diving activity causes damage because of the constant recreative scuba diving trends however, it also drives an important economic incentive. For this reason, existing damaged caves may be used for limited numbers of scuba divers, while the pristine caves remain protected. In addition to this, investing in more alternative dive sites around this area or promoting artificial wrecks will be the other effective solution to redirect scuba divers` attention from these fragile areas and protect the ecosystem while providing economic benefits.

\section{c) Night Diving}

The night diving issue is the least mentioned threat among the other controversial cases. However, as Barker and Roberts (2004) point, night dives cause a double effect on marine life 
compared to daylight diving because of reduced visibility. Therefore, in this study, this was one of the issues which need to be considered. Night diving is usually different from daylight diving due to the opportunity to see the abundance of marine life which stimulates unique and memorable experiences. On the one hand, scuba divers carry a torch, and these torches with strong lights disturb marine life. On the other hand, because of darkness, the ability to see the surrounding area and focusing on seeing marine creatures closely, scuba divers may damage the marine environment, as can be seen in Figure 6.6. For example:

- "Light, I think personally it's less consideration during the day. Then during the night, because at night you really annoying them with the light”. DIV - 3
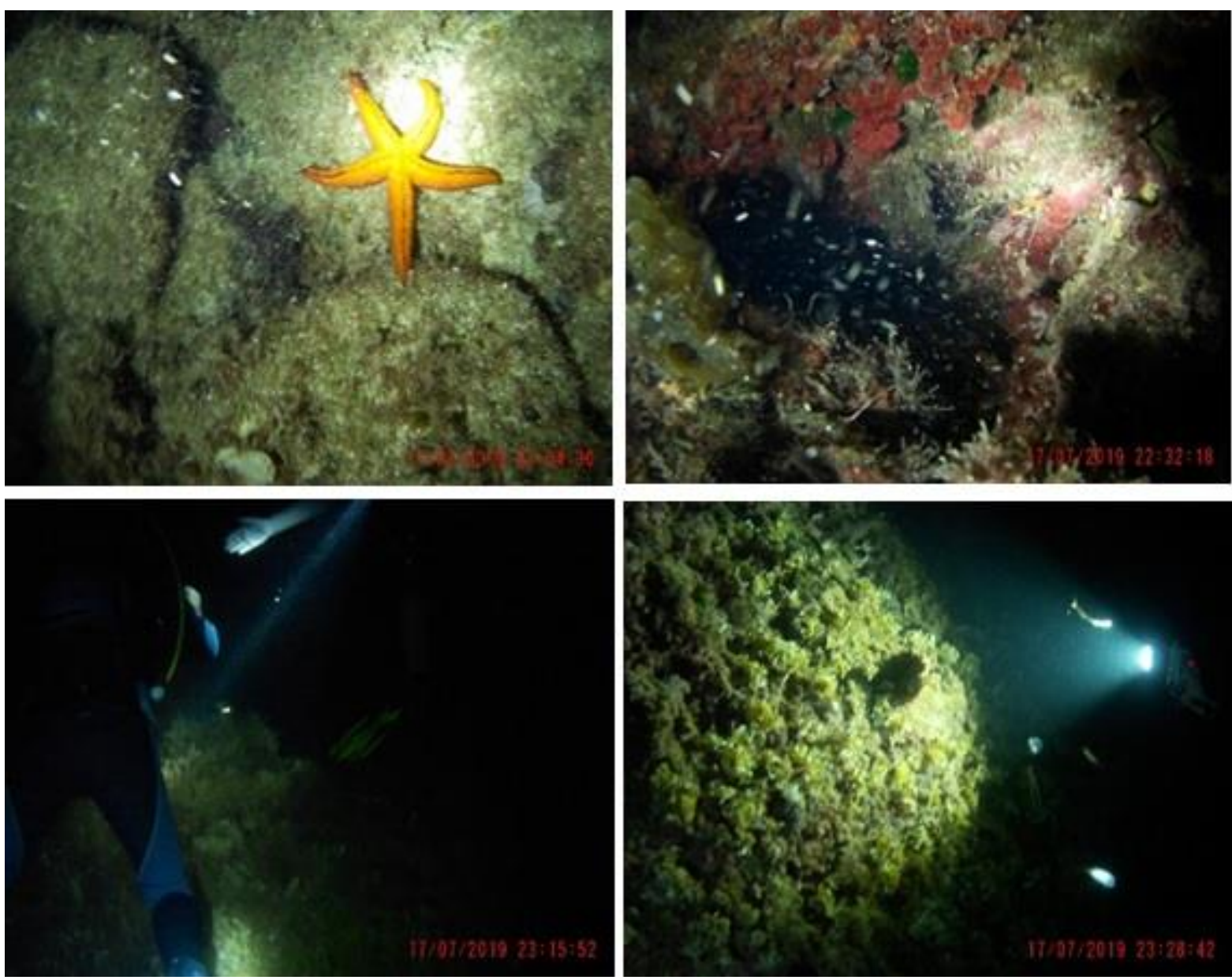

Figure 6.6. Night Diving Issue and Disturbance of the Marine Life (Photos were taken by the researcher) 


\subsubsection{Scuba Diving Congestion as Jacuzzi Diving}

Scuba diving congestion was a major issue in Malta. This is because, this situation directly affected the scuba diving experience negatively and scuba divers were complaining about the crowding, which was an important indicator of this issue and their experience. This problem is not only caused by individual scuba diving centres but also the whole activity. For example, on the one hand, if the weather is windy, all diving centres prefer to go to certain scuba dive sites. Therefore, popular sites, especially alternative dive sites, attract a large number of scuba divers during certain time slots. As a result, the scuba diving experience sometimes is affected by the concentration of scuba divers in one place. This issue was named by an instructor as the phenomenon of scuba diving in a jacuzzi. More specifically, all the bubbles caused by scuba divers turn the sea into a jacuzzi and the experience is affected by less visibility during the activity. Besides, paying attention to other scuba divers in the dive sites rather than focusing on the environment negatively affects the actual scuba diving experience.

- "Ecologically, again, like if you have so many divers on the dive site and you can 't see the fish anymore, that's obviously getting I think too much ... We are getting there. It's probably like it's getting on the max capacity. But I think it's reaching its capacity that people can really enjoy, not to be in a crowd ... Sometimes it's like jacuzzi like you can't see the dive site anything anymore because you see divers everywhere”. INS - 3

The experience was negatively influenced due to crowding and queueing such as “busy” DIV - 2; “we went like a group of 30 people”. DIV - 11. The issue was revealed by asking scuba divers as 'How do you describe your scuba diving experience?'. For other participants, interview questions were 'How do you describe scuba divers` experience?'; 'What is the most important threat to scuba diving tourism in Malta?'. One of the most complained issues from scuba divers was diving with too many other scuba divers under the sea (for reference see Figure 6.7). 

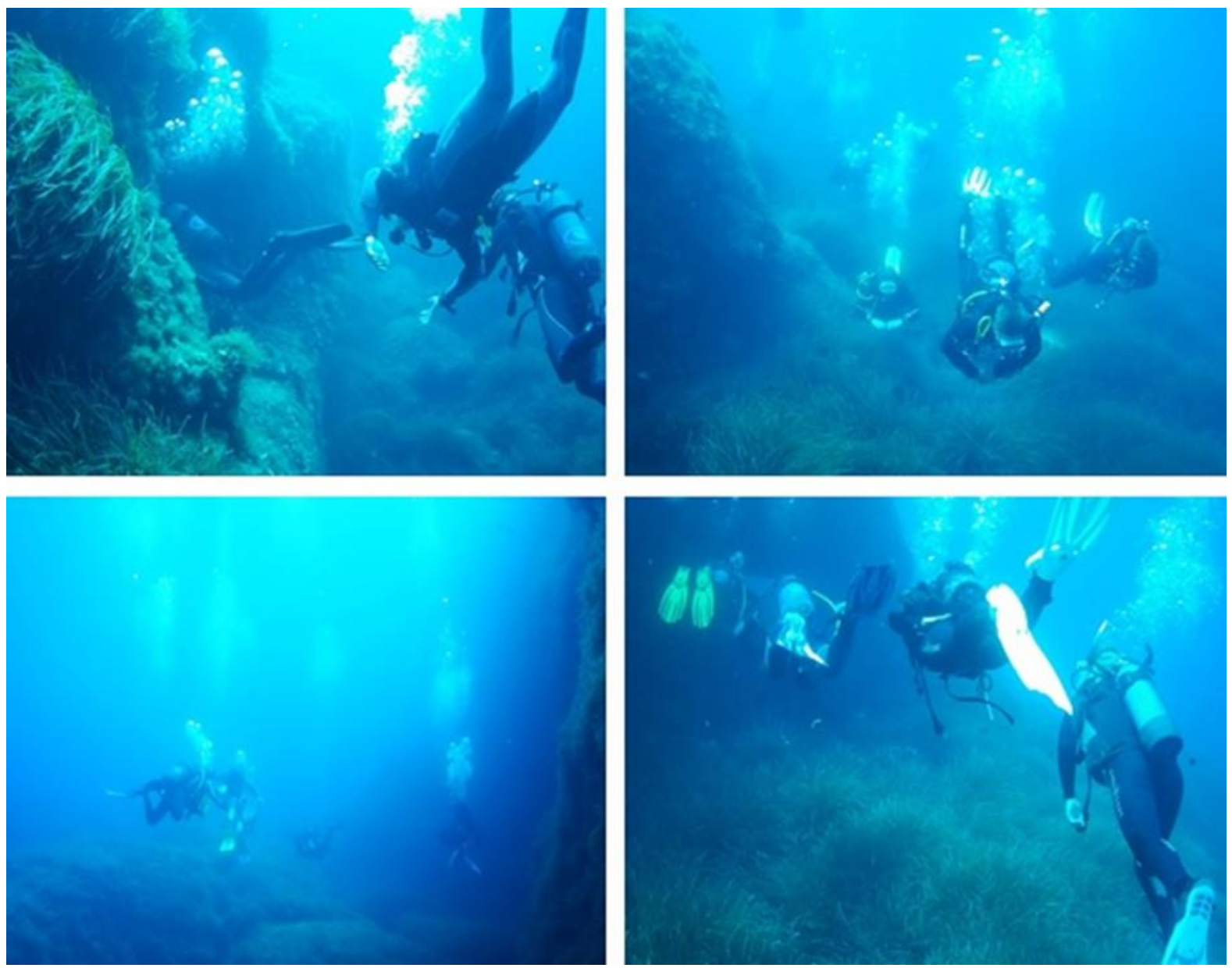

Figure 6.7. Scuba Diving Congestion as Jacuzzi Diving (Photos were taken by the researcher)

- Have a busy season and then you have full-stack. You've got a hundred people every day bombing those spots, swamping”. DIV - 14

- "I think that seems kind of a lottery more than the other things with which dive site you're picking on that day. And if you got unlucky, it can be other people that have chosen the same destination". DIV - 15

In the academic frame of reference, scuba diving congestion as jacuzzi diving seems like a threat to the scuba diving tourism system and causes a safety problem. Even though one of the advantages of scuba diving tourism in Malta is to have available scuba diving spots in different weather conditions during the season, this can cause a dilemma.

- $\quad$ "So, the biggest threat, at the moment, I think for the scuba diving industry in Malta is congestion. I've seen the growth of the industry over the years and congestion is a major problem. So, I thought shore dives are very, very, very problematic”. TUR - 2 
This may also affect the natural behaviour in marine surroundings and cause a negative scuba diving experience.

- "I don't know if more people than fish on the water". MBI - 1

- "It's all, it's like a jamboree, you know, people and obviously fish swim away and so on”. MBI - 4

According to the administrative perspective, alternative diving sides can play a significant role in distributing the scuba diving congestion and ensuring safety.

- “(Artificial) Reefs are placed strategically to create new dive sites so that you don't have concentrations that minimise the diving experience because most divers want an element of the pleasure of diving ... not being there with 300 people, which could also become a bit of a danger issue if you have too many people at once. So, the idea is to complement the product by providing alternatives, so that you avoid crowding and you give repeat visitors a new experience”. MTA - 2

\subsubsection{Lack of Knowledge About the Marine Ecosystem}

Lack of knowledge about the marine ecosystem caused unsustainable behaviour among scuba divers and scuba diving instructors, which affected the marine surroundings in the first place. The lack of knowledge could be limited ocean literacy -according to Cava et al. (2005), this is defined as how we understand the ocean in the sense of people's influences and ocean`s effects on people- about cave ecosystem, fish chasing, the impact of touching or on marine organisms and formations. On the one hand, as indicated previously, each cave has a unique ecosystem that scuba divers were not aware that air pockets might pose a threat to this marine ecosystem. However, a lack of knowledge about this fragile marine environment may cause a detrimental effect through generating poor scuba diver behaviour.

- "The caves that we went through today or completely see the rocks because they were so swell. There's nothing on them that's completely thin rocks. For me like, well, it doesn't matter. It's just rock. And there's nothing on them anyway. Nothing growing on it. So, I wouldn't worry about it.” DIV - 4 
On the other hand, if scuba divers see the activity as entertainment, it may also cause a negative impact on the marine environment by disturbing it because people are unaware of negative impacts on the environment caused by their unsustainable behaviours (Higham \& Lück, 2007; Garrod, 2008; Juvan \& Dolnicar, 2014; Passafaro, 2020) without realizing it.

- "I caught myself sometimes grabbing for not grabbing of course, but I was trying to touch fish”. DIV - 8

- 'So, I haven't really thought about ... I think if there's a cave that's just a few meters in from the air site ... I can't really see that it would change that much based on just a few divers". DIV - 15

- "I like to swim with the fish sometimes I like to try and touch the fish. Yes. I've wondered, but I'm not aware of the extent to which can cause damage”. DIV - 16

Sometimes, just the presence of scuba divers who do not know the how marine ecosystem works or inexperienced scuba divers who lose their control may cause significant damage to the marine surroundings.

- "More bubbles underwater mean less fish because of its noise. Less divers underwater, definitely less damage ... Scuba divers produce damage ... They go right into the Posidonia, they lose their buoyancy, and they get themselves tangled in the Posidonia. Look how many times they go on the sand, and they kick up. God knows how many eggs sacs there will be these like pouches... There will be pouches of egg sacs and starfish, just the centimetre under the sand and different filaments and things that need to grow, and the divers go and smack everything and kill everything”. OWN - 2

The other reason which significantly affects marine surroundings is underwater photography. As indicated in the literature review, underwater photography has negative effects on marine surroundings and most damage has been caused by scuba divers who are keen on taking photography (Rouphael \& Inglis, 2001; Barker \& Roberts, 2004; Krieger \& Chadwick, 2013), as documented below: 
- “... when I am taking pictures, I don't focus as much, actively focus as much anymore on my buoyancy. So sometimes, I drift off or sink a bit to the bottom and my fins to get into sand ... I need to be more aware not to get anything delicate”. DIV - 19

According to instructors, lack of knowledge caused also changed the behaviour of fish due to some scuba divers` inappropriate and unsustainable behaviours. Besides, in some cases, to some extent, the consequences of their actions need to be explained well to increase their knowledge about the marine ecosystem or it is assumed that scuba divers are expected.

- "We see some unnatural behaviours or fish coming towards divers. So, it just indicates that they have been being fed, which I don't agree with ... my divers, if they ask me, well, can I take a bit of bread, I say for me, no, it's not a natural behaviour. So, I try and, but I try to explain why as well. I do not just say no, that is it. I try and say, explain because of this reason". INS - 1

\subsubsection{Summary for the Theme of Stress}

The theme of stress described the direct negative effects on the marine environment, which are caused by activities related to scuba diving tourism and lack of knowledge. Revealed problems put additional stress on the marine environment in Malta and affect the scuba diving tourism system and scuba divers`experience, adversely. For example, according to the data claimed by interviewed stakeholders, carrying capacity is exceeded in Malta. Both short-term and long-term negative impacts can be observed as a consequence of lack of carrying capacity such as seen less fish population in popular dive sites or intense scuba diving activities in particular dive sites. A measurement system for improving carrying capacity is needed for each dive site. The other issue is the scuba diving congestion or in other words 'jacuzzi diving' phenomenon. Crowding has negative effects on scuba divers`experience such as reducing underwater visibility and limiting the moving ability. At the same time, this may cause a safety issue if it is not managed properly or carefully handled during the activity. Lack of knowledge about the marine ecosystem or lack of experience in scuba diving may stand as the reason for not acting sustainably during active participation. To cope with these kinds of problems education can be used as an effective tool. Moreover, a proper pre-diving briefing may help to ensure safe scuba diving for the marine environment. From an academic point of view, the best solution to improve the experience starts with education and depends on a long-term plan for 
achieving sustainable development in the scuba diving tourism system, however, this remains still a big question to solve.

- "By educating them. What else? Yes. I think it 's. I think it's the only thing you can do". MBI - 3

- "So, the best answer is education". MAR - 2

\subsection{Sustain $(3 / 5 S)$}

The constituent of sustain is the core theme in this framework of the sustainable scuba diving tourism system which seeks applications of practical normative management perspectives. Sustain also tries to provide a better understanding of improvement tools for the scuba diving tourism system. The main question for this theme was 'What can be done to be more sustainable for scuba diving tourism?'. The given statements were explained by investment in infrastructure for scuba diving, creating more awareness through promoting environmentally friendly underwater behaviour, improving self-regulation and knowledge, encouraging responsible scuba diving, enhancing scuba diving education and implementing policies on MPAs, effectively. This theme can be demonstrated better by management as all factors address the theoretical and practical narratives to achieve sustainable scuba diving tourism development and enrich the experience for all stakeholders. Opening new dive sites, focusing on education, raising awareness, revising current practices, reassessing the present situation about MPAs can be effective management strategies to put into practice for a longterm solution and achieve more sustainable development in dive sites and the destination.

\subsubsection{Scuba Divinvestment / Divinfrastructure}

This theme is the other renamed (novel) phenomenon in this study. Scuba divinvestment (short for scuba diving investment) stands for opening new sites, while scuba divinfrastructure (short for scuba diving infrastructure) refers to infrastructural investment such as parking, touristic facilities, or other environment-related investments. This sub-theme was derived from the administrative and operational points of view. However, scuba divers as the active participants were experiencing the outcomes and facing every day challenges due to lack of investment and infrastructure in scuba dive sites. For example, parking was one of the important concerning issues for access to the sites: 
- "With Zurrieq in particular the accessibility to the shoreline, especially the parking facilities is a huge headache. ("Like when you go to the dive site to see there is no parking left". INS - 3). If you don't get there early in the morning, there is no way that you find a parking spot ... So, the problem is access". TUR - 2

Managing the dive sites, improving access to the sea and out of the sea, restrooms, and ladders were other issues under the discussion for the scuba diving tourism system in Malta.

- "Because we've got thousands of people per day diving in Malta. I think that would be a nice operation. Especially, there was a few dive sites where you do have bins that do get cleaned. You do have restrooms, so people don't have to go behind the bush and things like that because those happened ... Some of the dive sites, it's easy to come out of the water. The biggest thing that I get from people this in some locations is very difficult to exit and enter the water... So that's the thing that for tourists' comfort is very important". OWN - 3

- "We're talking about ladders which are broken for many months at dive sites. No toilet facilities at dive sites. Yes, there are some dive sites with, but not all”. OWN - 4

To improve the capacity, conducting research for possible investments seems an effective solution. For instance:

- "Do a bit of a study on the big sites and see how many people go there and see whether we can want improve spaces. So, ... improve access to exiting and entering from the dive site". TUR - 3

Limited facilities were significant issues that need to be managed effectively to ensure protecting the environment and not only providing better service quality but also ensuring the safety of all active participants. Moreover, one of the practical solutions may be charging a small fee or fines and using that money to improve all facilities in scuba dive sites.

- "What needs to be done is a having sign up and reminding people not to litter and especially having fines and laws against it”. INT - 3

- "I mean you pay, what it's, 50 cents per day tourist tax, when you go to a hotel, no 
questions asked. If you do the same with dive centres, no questions as this is to make sure that you see nice things in the water, pay for that". OWN - 3

However, the lack of effective management and enforcement standards in the system and non-designated dive sites have remained the main obstacles to increasing the operational capacity for the abovementioned issues.

- "The problem is managing it. For the simple reason that when we dive in Malta, we can do a lot of shore diving. But the dive sites have not been designated yet officially". OWN - 5

- "If there's more investment, you know and more enforcement, I think we will have a better season in better conditions". OWN - 1

As indicated earlier in the sub-theme of carrying capacity under the stress dimension, the other solution is opening new alternative dive sites like artificial wrecks to improve the operational capacity. However, while this seems like a short-term solution, again, management can become a problem for such sites. Existing dive sites have some structural shortcomings and opening new alternative dive sites will create more problems to solve unless planned properly. Before opening, a proper management plan can be prepared according to the needs of the site, natural and marine surroundings, and structure, in water and on the surface. Otherwise, shortcomings may continue to damage the marine environment, for example:

- "If you don't have a well-managed entry-exit point, you might have people climbing over the rocks and damaging the habitats near the wreck. So, you have damage coming from that". MBI - 1

\subsubsection{Awareness and Education}

In this dimension, there are two independent but interrelated factors such as awareness about environmental issues related to marine surroundings and having knowledge for selfregulation and education which can be taken into consideration before and during scuba diving activities. If they are not managed properly, that puts additional stress on the marine environment and the system may become more conflicted. 


\section{a) Awareness}

This sub-theme, as a part of sustain, tries to explain how scuba divers can take care of the marine environment with their knowledge and how they may apply this knowledge in practice while participating in the scuba diving activity. Constituting this sub-theme, questions were that 'Are you aware of the importance of the marine ecosystem?' and 'Do you have any self-regulation during the scuba diving?'. Revealed statements are given below in terms of changing or controlling behaviour or improving eco-friendly scuba diving experiences in the marine environment, as the main purpose of a sustainable scuba diving tourism system. A few scuba divers are aware of their behaviour, for example:

- 'Didn't touch the floor. Try not to move too much my fins so that it does not push away the sand or the algae. I have never dived with gloves. If I did, I wouldn't touch them and it can happen by accidents, but I try not to touch anything, purposely”. DIV - 1

- "I know that when we are diving, we are invading the environment, which is not ours. So, I try to minimise the effect as much as I can ... In general, I don't touch unless there is something very strange that happens". DIV - 18

In addition to self-precautions, lack of knowledge may encourage people positively to stay away from organisms or be aware of potential danger. For instance:

- 'If my buoyancy isn't right and I hit the ground, I really don't like it because I know that I'm damaging. So, my buoyancy, I always try and keep up and keep away from everything. And I also am scared of touching things because I don't know what if it's going to have in my hands. I don't know much about it”. DIV - 2

Trying not to touch and buoyancy control seem preferable and practical self-regulation techniques during scuba diving activity among scuba divers to prevent distracting marine life and safety issues while taking care of the environment itself. It can be said that, in general, experienced scuba divers are theoretically aware of the potential consequence of their action, and have a marine-friendly mindset:

- 'I really try to touch the bottom as little as I can. I don't touch the fish. I don't want to and especially in wrecks, you just like try to touch as little as it can ... I don't like 
annoying octopus". DIV - 3

- $\quad$ "I would like to think I am a very friendly diver, environmentally and in all aspects... I am very careful not to affect to what is down there ... I wanted that when I came out the water everything should be the same as when I went into". DIV - 10

A few scuba divers participated in the activity with a lack of knowledge of how to be sustainable during scuba diving. This might be a reason to not develop some skills or start thinking about becoming a more sustainable and eco-friendlier scuba diver and raise awareness.

- I actually have never really thought about sustainability in diving before and it's obviously that there are some issues ... I never thought about the detriment that divers have”. DIV - 5

- "I think there is a sort of lack of education ... and not knowing that you're obviously damaging environments. I hadn't really thought too much about it”. DIV - 15

Moreover, as can be seen in Figure 6.8, problematic issues of unsustainable finning techniques and touching the ground in practice were observed in-situ during the active participation. Due to self-distraction, unattached equipment, poor buoyancy and lack of experience, some scuba divers had contact with underwater structures like artificial wrecks and seabed which might cause adverse effects on their surroundings. As a result, if awareness, knowledge, education, and self-regulation did not address this, it may cause more damage than benefit. For example:

- 'There is some awareness, but I don't know what impact that person has had. Maybe that person has hit something and caused damage, it should take 50 years to for the coral colony to recover. So, the potential for damage is quite high, I think”. MBI - 2

The awareness and knowledge of detrimental effects on marine life are important to participate in the activity with sustainable principles. If the knowledge allows scuba divers to improve their surface and underwater skills during the activity and contribute to the marine environment, it may affect their scuba diving experience positively while engaging marine surrounding with constructive changes in scuba diving tourism. In other words, as indicated in 
this study, the experience can be a transformative experience at the same time. However, sometimes for scuba divers, it may not as easy as it is to say or be aware all the time.

- 'I don't know how to really be sustainable diving ... Like I wouldn't, I'm just not aware of any other ways that, or me being like not touching the actual wildlife and I am knocking ... It's really hard to be aware constantly. If you're panicked or you distracted, you can't be aware”. DIV - 7 

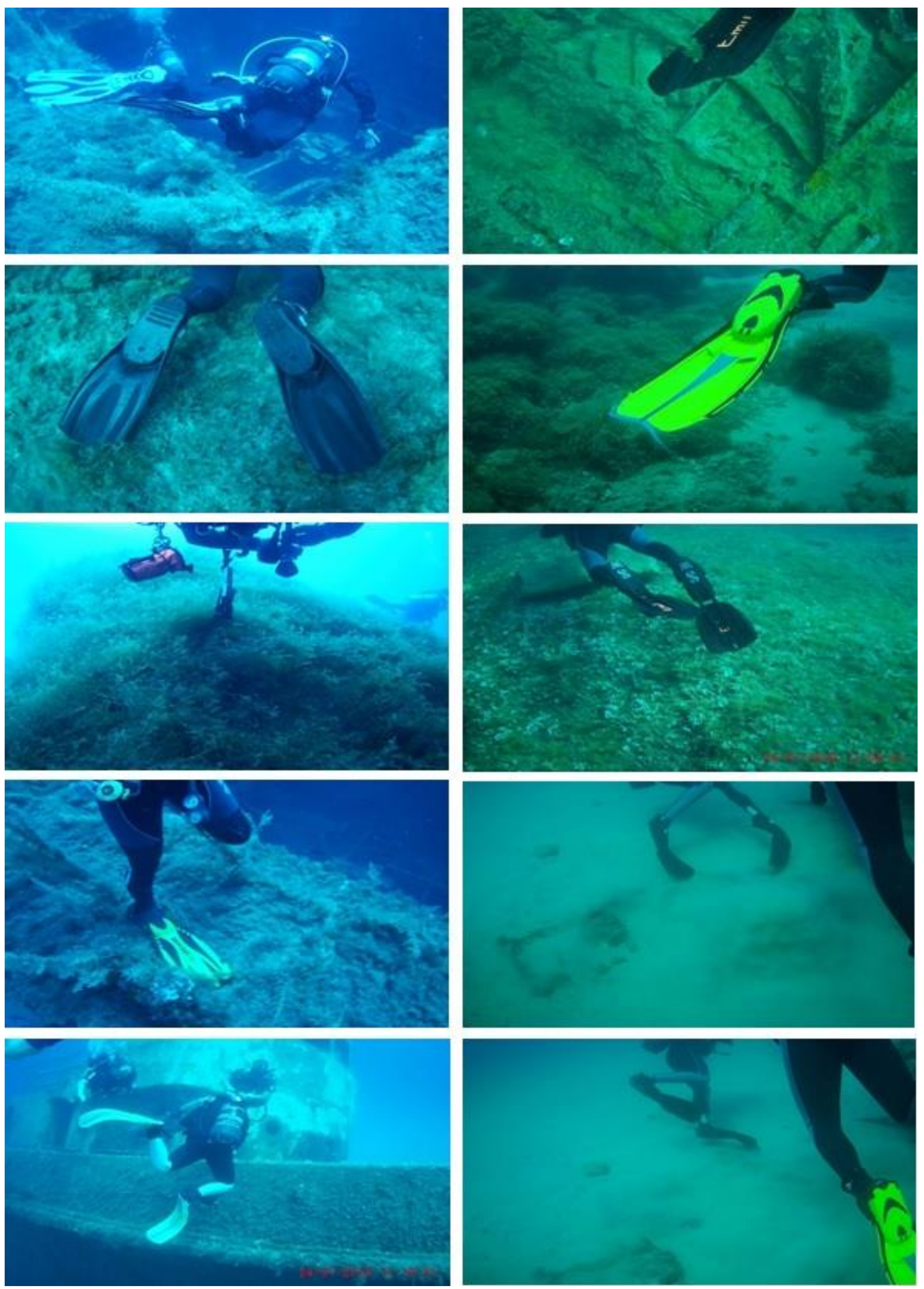

Figure 6.8. Inappropriate Underwater Behaviours (Photos were taken by the researcher) 


\section{b) Education}

It is agreed by all stakeholders in the scuba diving tourism system that education for scuba diving is one of the most efficient ways to control the detrimental behaviours caused by active participants during the activity, in a manner of achieving sustainable development standards. For this reason, education is a core element for this theme and the overall framework. This is not only about reducing negative impacts on the marine environment but also developing skills and continuing to do scuba diving activities in the future. At the same time, more education or skilled education means causing less damage to marine surroundings through developing sustainable underwater behaviour and having knowledge about it more specifically. Such an education can help to improve underwater behaviour to become more sustainable. For example:

- "I feel like if I had more experience and I saw rubbish in the sea and gloves, I would pick it out and take it home with me. But I don't feel comfortable doing that because I don't know, you know, especially this glass and stuff. Education I think is the best bet really is educating people”. DIV - 2

Education can be through educational material, pre-diving briefings or self-interest. No matter what education is taken for developing or increasing knowledge (of behaviour or current issues); practical training such as buoyancy control or raising awareness that provides a lot of benefits for scuba divers and scuba diving tourism system, in return, contribute advantages to the marine environment and sustainable tourism development principles, as well. Moreover, having a specialised or advanced education regarding skill development may provide more information and awareness about the marine environment and enhance the memorable scuba diving experience which becomes an important part of the sustainable scuba diving tourism system.

- 'I recognize that for beginners it's not so easy because you do not have balance. So, if you see something, something cool, I'm like, and then you breathe and you go up and you're, you don't know it until you are like, bam your head". DIV - 11

- 'I wouldn't ever try to pick something up. I do worry that if I haven't got my buoyancy right on the bottom, then maybe I am messing up". DIV - 12 
For some participants in the research, it can be said that education was more about the skill development process, while other scuba divers are interested in more about the content of the official education provided by PADI scuba diving certification programmes in Malta. Therefore, the content of educational material is needed to be discussed and reviewed in more detail. For instance:

- "I guess as I started to learn more about the qualifications within PADI, I am hoping that the teaching continues and they're together". DIV - 15

However, the most widely used educational material, provided by PADI, does not address sustainability or the importance of the marine environment comprehensively, especially at the advanced certification level. I agree with the following statements because I participated in an advanced certification programme (advanced open water) during my active participation and apart from Project AWARE highlights, there was scarce information about marine life, compared to advanced skill development tips in the educational material provided.

- $\quad$ "None. There is almost nothing. There is almost nothing in the courses that teach you. Doesn't matter that zero of the courses have touched on sustainability or, you know, good practices to preserve marine biology or marine ecosystems. I don't think the PADI certificate cares much about ecosystems. No”. DIV - 16

- "I find what PADI does very well. Always say take care of the sea life, don't touch, don't grab, you don't want to disturb the sea life, you don't want to damage things, stay away from reefs so you don't break anything. That means it's a good concept. Because that means you can still have many divers come but they don't disturb things too much. Okay, there is not much written about protecting the sea life, this is true. I am adding this on my own would I think would be good”. DIV - 22

On the one hand, it must be noted that PADI provides also specialised courses, and they cover different content including environmental issues, for example:

- "I think you can have really good conversations when you're doing different courses, like the advanced calls, when you do fish ID and underwater naturalist, they lend themselves really nicely to you then be able to talk about some of the bigger issues. It's 
just a natural part of the conversation, I think when you're doing it”. INS - 6

On the other hand, individual scuba diving centres may fill this gap with local-based education specialisation. For example:

- "We've been organising marine biology courses. I don't know if there is another dive centre that actually organises marine biology courses with the university. They do the classes there and then we do the fieldwork. I mean we are very passionate about the marine environment. So, we put a lot into it”. OWN - 2

But these educations are mostly about skill development within a limited time and resources. For example:

- 'Unfortunately, we don't have much to speak about. Because you can speak a lot and then they have seen that thing and they say why did you spend 10 minutes, then we have sometimes we see. That is stress we in". OWN - 5

As a result, proper verbal education becomes essential to support skill development by emphasising reducing detrimental effects and respecting the environment while improving the scuba diving experience.

- “... of course, we stress it more because they are going to be certified. They are going to be diving hopefully for the rest of their lives. So, it's something that we tried to stress in our briefings and our education”. INS - 2

- " "It does change completely their mindset as long as you are open about it to discuss it, and nothing is black and white ... it's just education and awareness raising. You trigger a lot of change, I think”. INS - 5

\subsubsection{Marine non-Protected Areas (MnPAs)}

"Marine reserves, that's the only thing that will sustain the diving industry”. OWN - 2

Marine Protected Areas (MPAs) was the most concerning issue for administrative, operational, and academic stakeholders. The reason is that although some certain marine areas have been declared as MPAs in Malta, which means that there are designated areas, 
management of these areas is limited, which transforms MPAs into Marine non-Protected Areas (MnPAs). Therefore, MnPAs is another new phenomenon identified in this study. Although these areas are existing on paper for years, the sustainability policies which includes acts like protection, management, and enforcement have not been sufficiently implemented according to interviewees' statements. To set an example, the territorial waters areas of the Maltese Archipelago ${ }^{16}$ are about $11,500 \mathrm{~km}^{2}$. Within the three nautical mile zone of these islands demonstrates the best practices to ensure the protection of the marine environment is divided into specific marine zones like coastal activities sites such as scuba dive sites, swimming areas; conservation zones; aquaculture areas; trawling zones; sewage outfall; spoil dump points; shipping zones; bunkering zones; and fishing zones or artisanal fishing areas within and around designated MPAs (Said et al., 2017). However, in terms of implementation of MPAs around the Maltese Archipelago, the only area enforced was around Comino Island as safeguarding the Posidonia Beds / Meadows, according to findings derived from stakeholders`interviews results and outcomes.

By mid-2020, according to Malta Environment \& Resources Authority (ERA, 2020), 8 MPAs were designated in 2018, three inshore and five offshore areas. The three new inshore areas are extensions to the area covered by existing coastal MPAs. Two of the offshore areas are new sites, while the other three are extensions of the existing MPAs, previously declared in 2016. Overall, 35.5 per cent of territorial waters $\left(4,138 \mathrm{~km}^{2}\right)$ have been designated as MPAs.

In line with this knowledge, a few scuba divers were aware of the importance of MPAs and suggested the need to preserve marine life and limit the fishing to protect fish abundance for scuba diving experience in Malta. For example:

- "Marine reserves I think do work. They really work. There is no thought given to protecting parts of the ocean. We have a few marine reserves, but this is really globally, tiny, tiny areas set side”. DIV - 10

- "You got have marine reserves and just stop fishing and just monitoring on fishing". DIV - 21 
From the first-hand operational point of view, instead of investing in more alternative dive sites, MPAs can become a priority to establish a protected area or emerge these areas with designated MPAs.

- “Wrecks, it's very minimal. It's feasible. It's probably cheaper. It's probably more shortterm return on investment if you do wrecks ... More marine parks would be good, protected zone for no fishing, fish nurseries, no diving in MPAs ... of course, good enforcement". INS - 5

Similarly, from a management perspective, there was the toughest discussion about the debate of MPAs`situation. Scuba diving centres`owners stated that they would like to have MPAs to protect dive sites of which can improve the scuba diving experience and is essential for the scuba diving tourism system.

- "We have been trying for 30 years with every government lobbying and lobbying for a reserve and marine reserve, no-take zones. That does not only benefit diving tourism, but it benefits efficiently to use as well ... A real MPA, not the five protected areas that we have at the moment. They are what I call, jokes. They want to make us laugh so they protected five huge areas under the Natura 2000 directive for the Posidonia ... Now is the Posidonia protected in those five areas? No. Where are the protected areas for the fish? Where are the protected areas for marine life in general?". OWN - 2

- "Now, we still suffer because we haven 't implemented a marine reserve. We are one of the only countries in Europe that do not have a marine reserve ... There are MPAs on paper to get EU funds. Which are mainly they are at level one, safeguarding the Posidonia Beds which is the good thing itself. But the management plans have not being implemented, it's being going on for 7 years. No management plans ... It 's absurd what the Mediterranean looked like before. It's beautiful when it's really taken care of. You find funding for aquariums through Government, but you don't find funding for artificial reefs and marine reserves, it 's beyond belief”. OWN - 5 and Chairman of the PDSA

On the contrary, MTA claims that the idea behind the national aquarium, built in 2014 was to create awareness. 
- "We create awareness. We did the project of the aquarium and within the project of the aquarium there's obvious awareness and there are certain projects to save the sea". MTA - 3

However, from scuba diving centres` perspective, lack of management plans and enforcement is still the case for marine life in Malta according to their following opinions after years of works and waiting. More needs to be done to designate the areas with the ability of implementation and enforcement in these areas, even if they are declared MPAs by the authority. For example:

- "We've been trying and fighting for marine reserves and the bit of enforcement, but the meeting of the meeting I truly quit phones on deaf ears ... I think most of this enforcement they would just something which our country really lacks ... Enforcement here doesn't really exist, unfortunately". OWN - 1

- "But another reason undoubtedly, I mean the nature didn't give us much in terms of marine life, the little there was overfishing, overexploited through commercial fishing, hobby fishing, fishing for restaurant and the sort of thing ... On the negative side ... we are making the reefs and the fish are breeding, but there is nothing stopping fishermen from going over these reefs and throwing nets and getting everything that they can. So, it 's very easy to declare areas as marine areas, and whatever ... Unfortunately, a lot of life which is being created is also being harvested immediately, because there is no control and no interest in stopping these boats, these fishermen from going out with nets and collecting everything". MTA - 2

Similarly, from the reference frames of marine biologists, exploitation of the MPAs is the major issue regarding managing these areas, especially in busy seasons due to both recreational and commercial misuses.

- "In the summer months, it gets extremely busy. And so, depending on the side of the island and you have a lot of recreation, boat traffic, a lot of the anchor because there aren't more buoys available. It creates a lot of litter, a lot of small oil spills. There are bunkering sites ... that overlap with MPAs, which aren't really particularly well managed either ... I would start by enforcing existing laws. Because we have a lot of 
laws on paper but then in practice, they're not enforced.". MBI - 1

- $\quad$ "So, you can take your speargun and go and fish in an MPA, no one will stop you. You can take your diving kit, going the most lovely pristine cave and just do whatever you want, destroy it, no one stops you.” MBI - 2

As a result, from a tourism point of view, the same problems can be observable, and lack of management and enforcement are the most problematic issues which create a long-term detrimental effect on marine life.

- "So makes no difference whether that is on paper or not as an MPA. Because people still go there and do whatever they like and they're far away enough to be able, there's no surveillance on the place so nothing happens in this case ... then we still have these ships coming around dropping anchors and creating huge problems". TUR - 2

\subsubsection{Summary for the Theme of Sustain}

The theme of sustain explained managerial challenges in terms of providing an improved operational capacity of sustainability in the scuba diving tourism system. However, there are some difficulties to ensure sustainable development in scuba diving tourism. As indicated in this section, scuba divinvestment and scuba divinfrastructure need to be built up to secure entry and exit points for scuba divers and upgrade daily operational facilities such as restrooms, parking, and waste management. In the sense of knowledge and self-regulation, there are still things to be done to raise awareness for understanding better the importance of the marine ecosystem. Responsible scuba diving was also mentioned by stakeholders to create a sustainable scuba diving experience for the scuba diving tourism system, in terms of having awareness or putting their knowledge in practice and transforming their behaviour into a constructive way. However, if it is not internalised with developed skills or enriched scuba diving experience, it will only contribute to a temporarily positive impact. With regards to education for certification and developing sustainable behaviour, materials and verbal instructions can be more effective and promote sustainability constantly for both instructors and scuba divers. However:

- "The question is whether it's being pushed enough. I mean, you're trying to a course in three days which is like the typical, if you are aware of PADI open water course, its 
max, it can be done in four days and sometimes even in three. The question is, if we are really giving enough time, whether it's to teach all about sustainability or simply teach or how to dive properly... If you are surviving in scuba diving also means respect the environment". TUR - 3

Furthermore, behaviour for protection relies on education and role modelling, however, it is hard to measure the effects in terms of environmental issues, whether protection is going to turn into a positive contribution in the long-term relationship with scuba divers and scuba diving centres or become destructive consequences. When it comes to MPAs, the lack of enforcement causes more strain and stress on the marine surroundings and these areas turn into MnPAs. As specified in this fragment of the 5S Themes, MPAs can be designated and actively managed under certain criteria, such as no-take zone, buffering zone, fishing spots, dive sites or even associating with alternative dive sites like artificial wrecks and heritage areas. However, designation and implementation rely on many factors and more importantly, conflicts of interest, which needs to be regulated and enforced in return:

- " "The way that I see it's that if you at least have designated areas where you can fish or you can dive or you can do both, then it draws the problem to at least a circumscribed area. And that would leave other areas free of problems ... At the moment, you can go and fish everywhere as long as you're within regulations and you know, kind of method you use and so on, and you can go and dive everywhere. So, there is no restriction at all ... So, you've got this conflict of interest”. MBI - 4

- "I think it's a matter of resources and priorities ... No one else seems to be interested. I think it's not a problem of collaboration. It's the question of priorities and resources". MTA - 3

\subsection{Supervision $(4 / 5 S)$}

Supervision addresses the idea of implementation issues. In this constituent, three different sub-themes are able to explain the structure of the scuba diving tourism system. Two of them are related to scuba diving centres, while the other represents the safety concerns of scuba diving and alternative dive sites. Supervision stands for situations or circumstances that are a requirement including establishing sustainable practices for scuba diving centres activities such as clean-up and regulations. Sustainable practices employed in the system can 
ensure sustainable behaviour of scuba divers by offering more responsible scuba diving activity with effective pre-diving briefings and understanding and maintaining the safety standards in the current scuba dive sites. Fundamentally, this theme tries to examine how the scuba diving tourism system can be in the achievement of sustainability and clarifies the requirements for this. The main research questions of this theme were 'How do you evaluate the scuba diving opportunities in Malta?' and 'How do you designate Malta in terms of scuba diving tourism?'. These questions were asked to all stakeholders who were interviewed in this study. From the administrative perspective, there was an additional interview question which was, 'Are you happy about the development of alternative dive sites in Malta?'

\subsubsection{Sustainable Practices for Scuba Diving Centres}

Sustainable practices identify operational and organisational capacities of scuba diving centres in terms of activities and actions. This explains how images related to scuba diving tourism are perceived in the sense of sustainable value by scuba diving centres. In general, sustainable practices emerge from an understanding of instructors or centres`actions, such as recycling, reducing plastic use or trying to not generate plastic waste, rather than an overall evaluation such as certification or quality of the service. For this issue, the main question was 'What do you do in your business to be more sustainable?' (See Figure 6.9 for reference).

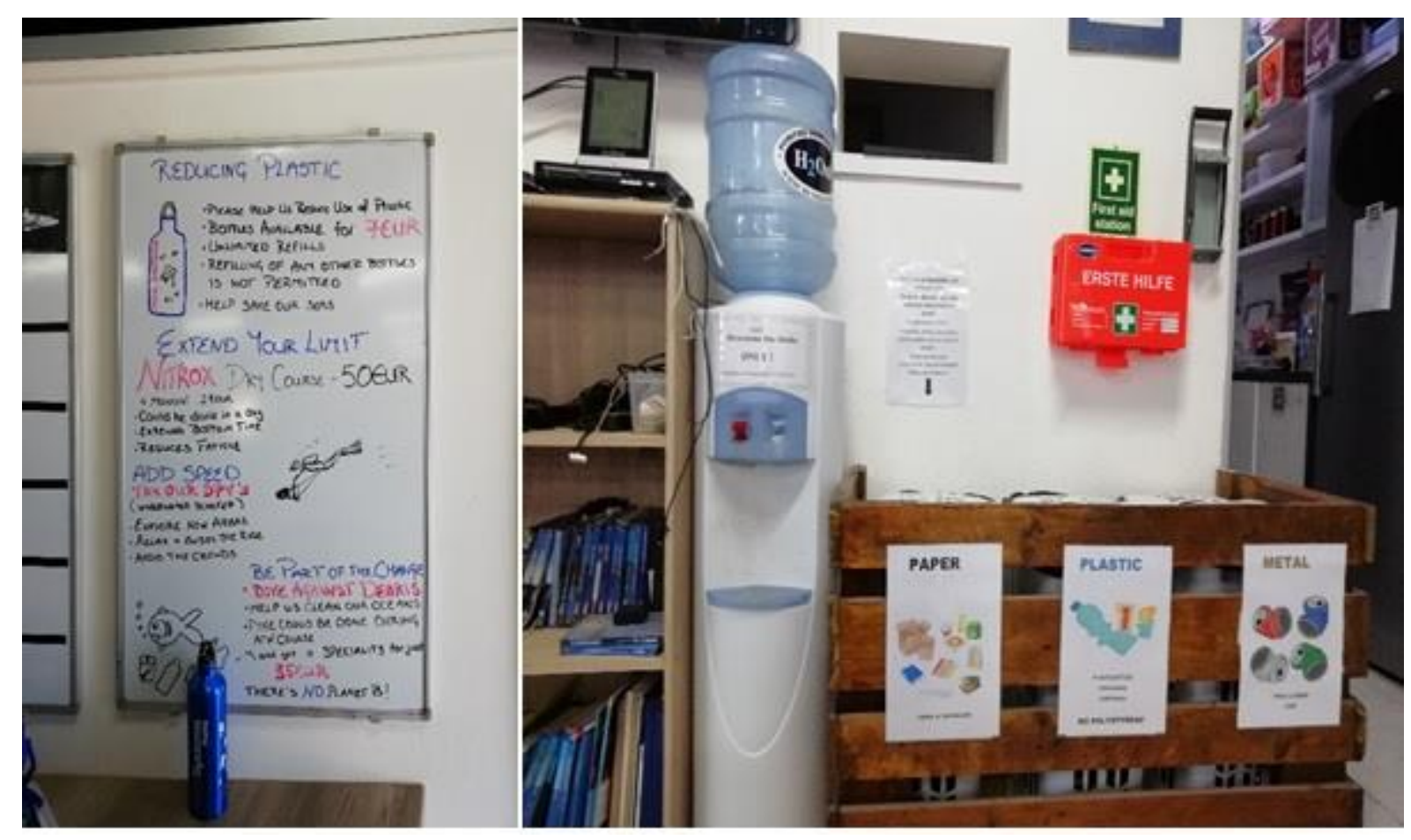

Figure 6.9. Example of Sustainable Practices in Scuba Diving Centre (Photos were taken by the researcher) 
In a sense, "a lot of dive centres are using tiny plastic bottles for their clients, which is ridiculous. We use the fountain, which is a big difference ... You're not a cafe. You're a dive centre. You should be promoting no single-use plastic and these sorts of things" (INS - 2). "We reduced plastic bottles, for example, two years ago ... The dive centre can try and reducing plastic and being a bit more environmental to fit. But it's, it's not as easy as it sounds ... We split our waste as well, you know, with plastic, metal, paper; we split our waste. What else do we do as a dive centre? I don't know” (OWN - 1). However, "all diving equipment has plastic in it. Do you want to totally go no plastic? Close the diving centre. Because you have a lot of plastic from fin clips to regulators, everything is plastic. It's whether recyclable or not and do you recycle or not?" (OWN - 2). Therefore, "I think that would be the biggest thing, new equipment packaging is the biggest thing for our waste on plastics in general" (OWN - 4).

Moreover, clean-up events as an alternative indicator of sustainable practices for scuba diving centres are an important sustainable activity. These are conducted by a collaboration of individual scuba diving centres and global associations. A few scuba divers stated that it is an opportunity to act sustainably. For example:

- "If I would have had the opportunity to go for like the plastic or the garbage-collecting dive, yeah, I would do it”. DIV - 9

The total number of debris collected from the sea in Malta can be seen Dive Against Debris database which shows the number of debris were taken out from the water, part of Project AWARE / PADI, as in Figure 6.10 ${ }^{17}$. However, debris can still be seen underwater in popular dive sites even if clean-up events took place as specified in the database. Clean-up events may provide benefits for scuba diving centres, in return as reputation, or a brand image in the sense of sustainability. Therefore, the impacts of the clean-up can be evaluated more broadly by the scuba diving centres and destination managers. For instance:

- "It would play a positive impact. Personally, and for this business, it's done more because it's in support of the dive industries, the marine life, the conservation of what we all love as supposed to the business aspect of it. Yeah, it could certainly be seen as something positive for the business". OWN - 4 

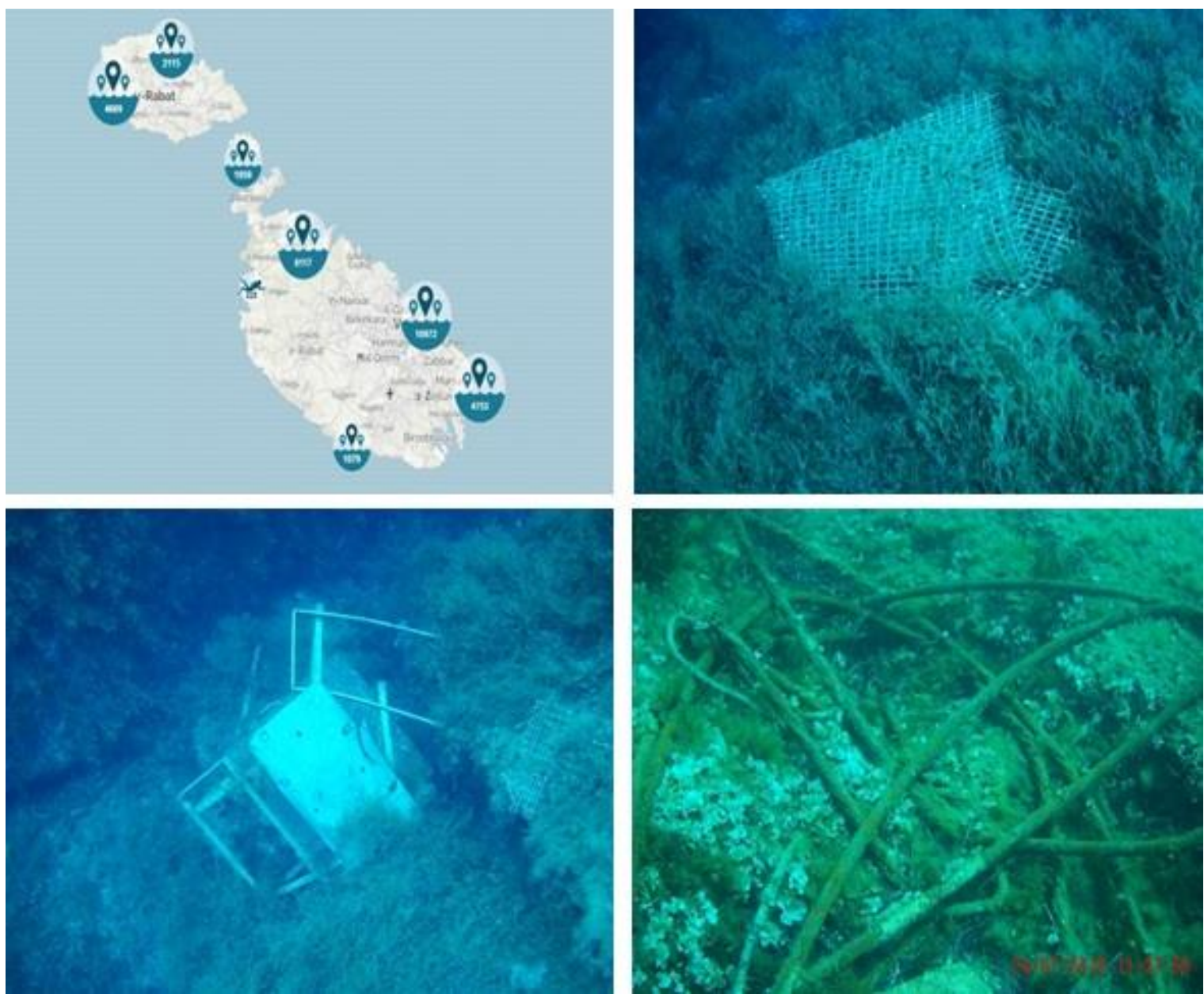

Figure 6.10. Dive Against Debris Map \& Debris Around Malta (Photos were taken by the researcher)

However, compared to owners of scuba diving centres' point of view, in the administrative and academic lens, they identified different views about the way of doing sustainable business, although there were some concerns about 'greenwashing'. For instance:

- "Generally speaking, the diving community is very sustainability-minded. They are very pro-environment, they are very vociferous, they act by example, they do a lot of ocean-bottom clean-up, bringing up rubbish and bottles and tyres whatever because for them it's their workplace, they want to preserve it, they are very sensitive and want to preserve it". MTA - 2

- "For me, it looks a bit cosmetic. I mean, if I'm taking eight people down in the sea, they're basically to save an instructor dragging the half of them across the seabed and with all due respect, then, I will tell them to refill your bottle ... does not sustainability. It does just pretend to be sustainable”. TUR - 3 
In this regard, to eliminate the concerns of merely cosmetic initiatives, dissemination of the results of clean-up events may become useful to create a positive image and impactful to promote sustainable practices while increasing awareness among related and non-related stakeholders. For example:

- "For example, that we had last week is we intentionally went to a location where there are so many young people sitting on the beach. So, there are hundreds of kids sitting there, and you could see the shocking faces when they see all the shit coming out of the sea and they join into helping ... Most of what we do is to show our underwater cleanup, the results. I think that's it basically we don't do much more”. OWN - 3

However, as stated, these events remained limited impact due to the lack of collaborative efforts and limited dissemination capacity among stakeholders. For instance:

- 'You'll see dive centre is doing clean-up at the local dive site, no one in which area they are using the most. So, it could be seen as I suppose quite selfish ... Um, but it tends to be the sites which are closest to the dive centres and less organised especially ... I think if all dive centres got on-board and each and every single one did a clean-up at a beach or the dive site combined with all of their rubbish, so removed it, put it in the trucks and put it all in one place, I think the shock factor will have more of an impact. So that would be good for them to work together. I think it needs to be done on size and volume to make the impact. Uh, I don't see a pile of rubbish on this beach making an impact and the word spreading enough. If you got 50 dive centres to collect 50 trucks of rubbish, drive into the Valletta and offload it in the main square, then that would have an impact”. OWN - 4

\subsubsection{Power of Pre-Diving Briefings}

Power of pre-diving briefings is a follow-up of the awareness and education sub-theme. This is because, pre-diving briefings create supportive and instrumental knowledge through education which turns into awareness and a positive contribution to the marine environment with regards to scuba divers` behaviour, especially before and during the scuba diving activity. To some extent, scuba divers are aware of the importance of marine life and tend to have selfregulation and take care of their surroundings. However, even advanced scuba divers often do 
not have comprehensive knowledge about the consequences of their misbehaviour or are unaware of the outcomes of their actions. Therefore, one of the effective solutions is to emphasise pre-diving briefings.

- "So, you have to take part of the like the sustainable education and our responsibility, any type of diving centre to make sure that ethics on taught and followed by divers. So, it's kind of something that has to be". DIV - 14

Inexperienced scuba divers need more information and skills to take sustainable action before and during participating in underwater activities. For this reason, pre-diving briefings may become effective and powerful tools to control unsustainable behaviours and convert such behaviours into a more sustainable way. Furthermore, there is a clear appetite for pre-dive briefings from divers. For example:

- 'I think somebody told me there was a cave and there's lots of marine life and you don't want to go because you are disturbing too, okay, well I won't go there”. DIV - 4

- $\quad$ "Like if someone tells me some interesting facts or interesting ways to be more aware, I'd be interested in hearing". DIV - 7

- 'I'm certainly very aware and if somebody for example says to me that it's not good to feed the fish, it changes their behaviour and please don't feed fish; I would change that in a second and be more careful". DIV - 15

According to given statements by scuba divers, it can be said that, in general, scuba divers are waiting to be told to get more information which able to explain the reason for taking an action or the precaution. Therefore, this sub-theme becomes an important constituent of supervision. Because, both pre-diving briefings and principles need to be enriched and customised for each scuba diving at any level, without any exception and implemented properly. This responsibility, from an operational perspective, belongs to scuba diving centres and instructors. To reveal that issue, a question was asked as 'Do you provide education for scuba divers before going underwater?'. For instance:

- "We teach our students and other divers to respect the environment and to practice environmentally friendly techniques for scuba diving ... So, we remind people before 
getting in the water that all the creatures and life form and coral not to be touched and nothing is to be taken out of the ocean, especially the first ones with the little or no experience then that comes first. With certified divers most of the time it goes without saying that you shouldn't do that. But we still remind everyone because even among certified divers that can be a responsible people who need to be reminded". INT - 3

However, during my active participation, I participated in 15 scuba diving activities with six different instructors on different days and scuba dive sites and types. Although, I had interviews with all of them, and they stated that they always remind and teach people before doing scuba diving about being responsible; not to touch and take care of the marine environment, none of the instructors told the group about sustainable behaviour before scuba diving. Therefore, there is a disconnect between intention and action in terms of the instructors. In this case, pre-diving briefings need to be prepared as a checklist for instructors and scuba divers, perhaps in line with scuba safety checks. Overall, this also needs to be managed through further education and awareness from the diver leaders, for example:

- "So, if these people, the dive leaders are knowledgeable and are told what they should and shouldn't do, they will pass on that information ... The more informed the dive leaders are, the more informed the tourists". MBI - 4

\subsubsection{Safety of Scuba Diving and Alternative Dive Sites}

Safety is one of the most considered issues among scuba divers and other stakeholders. For this reason, with the cooperation of all stakeholders, safety requirements need to be become a fundamental requirement to ensure safety in the scuba diving experience for each participant. Safety measurements are important to reduce the fatality rate. To set an example, according to DAN (Divers Alert Network), the number of scuba diving fatalities in Malta was 3 in 2018; while 5 fatalities in 2017; 4 fatalities in 2016 (Denoble, 2019); and 5 fatalities in 2015; with injuries of 10,320 scuba divers, since 2013 (Buzzacott \& Denoble, 2018). Therefore, safety measurements and precautions for scuba divers become an important issue for the scuba diving tourism system in Malta. This is because:

- “A few years ago, regulations were changed largely by pressure from PDSA ... So nowadays a diver can come in walking along the shopfront for example and say, Oh, 
it's scuba diving, I think I'll do that. And they will just sign a form saying I am fit to scuba diving. Very often they don't even know that they are not fit to scuba diving”. TUR - 2

To avoid certain negative possibilities, some divinvestment such as hyperbaric chambers (there are currently two hyperbaric chambers; one on the main island and one in Gozo according to MTA - 2) may reduce the risks if occurred despite all precautions taken place during the scuba diving activity. Besides general precautions, due to the fact that artificial wrecks diving is the most popular scuba diving activity in Malta, safety measures need to be taken comprehensively for active participants (see Figure 6.11 for reference). These measures are not only about the structure but also about access and using skills. For example:

- "The wreck itself I thought was just dangerous ... I don't feel very comfortable on a wreck dive”. DIV - 16

- "When you go on the wreck, you should be careful about, sharp things and not to get, not to touch anything, not to get hurt”. DIV - 1

Safety concerns also affect the attractiveness of scuba dive sites. According to scuba diving instructors, access, appearance, and general situation of the sites are important indicators for this attractiveness. From the perspective of scuba diving centres, certification level can be used as the moderator to determine the safety measures, especially for environmental sustainability.

- " A lot of people want to see one particular thing, but if you're not sure if they are okay to do that, I think, for your own safety, for that person's safety and for the sake of keeping the location alive, it's quite important. I don't want to put the wrong people ... Because we've got a fantastic reef just here. If we put a thousand people on it this year and everybody's walking on, next year, I won't have that beautiful". OWN - 3 

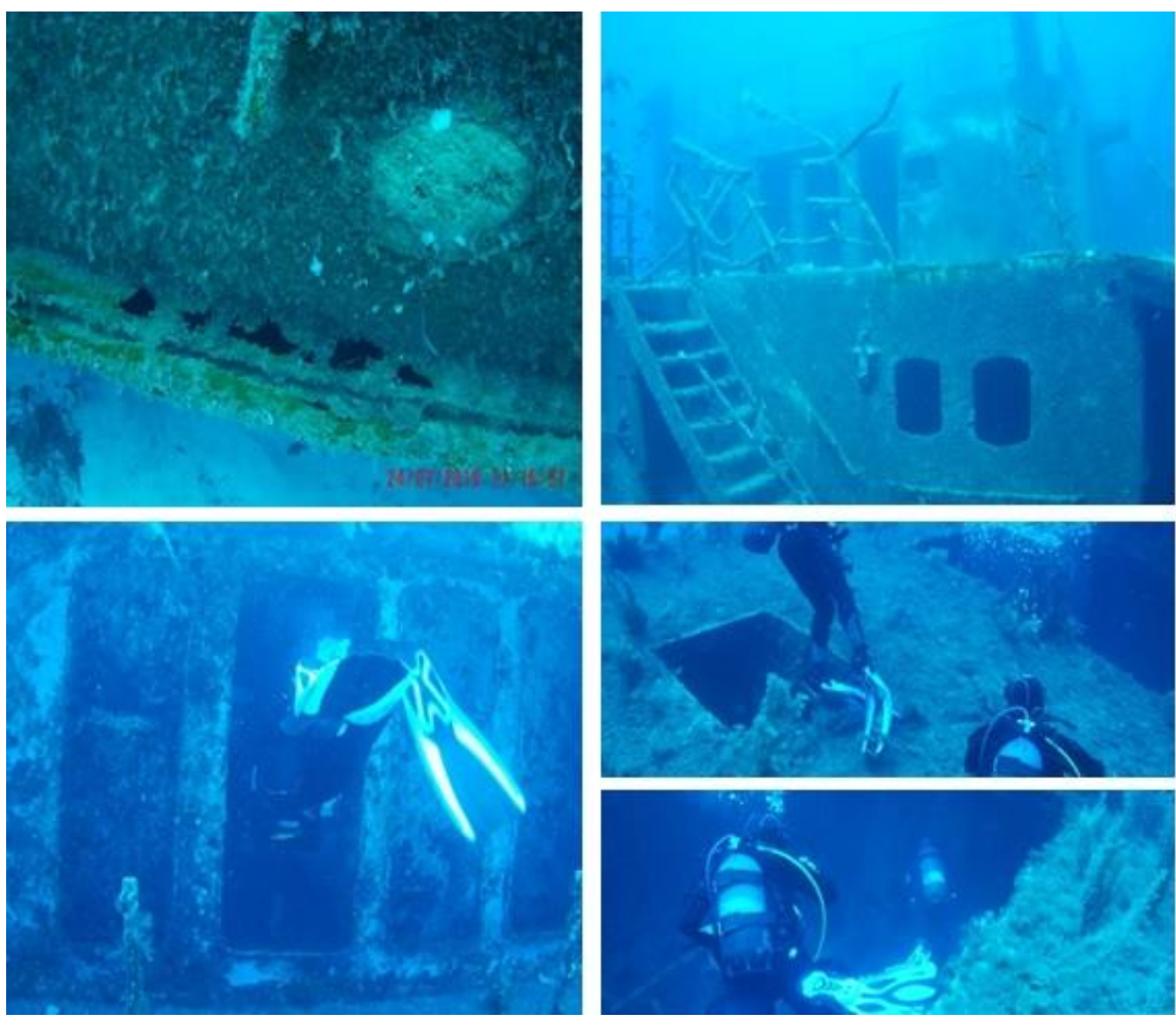

Figure 6.11. Example of Safety Issues About Wreck Diving (Photos were taken by the researcher)

Moreover, it is claimed that boat traffic around the dive sites may cause severe safety issues around specific dive sites in Malta (see Figure 6.12 for reference). For example:

- $\quad$ "Boat traffic. People dropping anchors on the dive groups even with floats up and flags up". OWN - 4

- "Everyone can have a boat, a bigger boat, and marinas everywhere. It's incredible, areas which would before were just naturally, or swimming areas have been taken up by Marinas". TUR - 1

As a result, the safety in both natural and alternative scuba dive sites rely on not only the current situation of the die site itself but also on planning the surroundings by addressing all stakeholders`interests with a collaborative effort from all angles. 

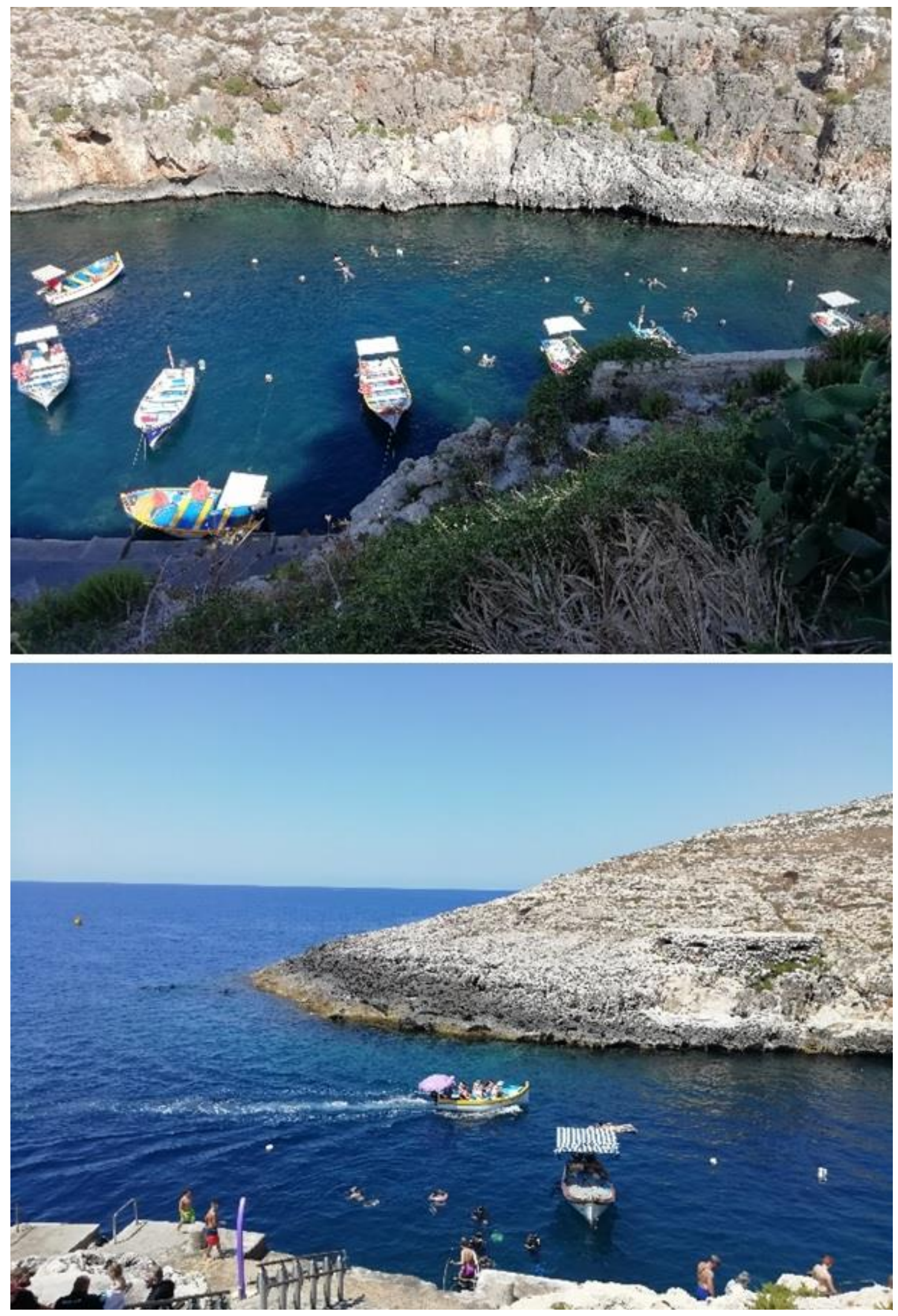

Figure 6.12. Boat Traffic Around Scuba Diver's Entry and Exit Points (Photos were taken by the researcher) 


\subsubsection{Summary for the Theme of Supervision}

Overall, the relationship between sustainability in the scuba diving tourism system and the supervision of the operations comes to light with a lot of conflicts and views among different but interdependent stakeholders. For example, on the one hand, scuba diving centres understand the way of becoming sustainable as recycling or preventing single-use plastic or encouraging scuba divers to buy refillable and durable flasks with the intention of making an additional profit. However, scholars thought that there is not enough interest and action taken by scuba diving centres. Moreover, authorities have not interested in the clean-up process. However, despite all these efforts in terms of marketing, it can be said that scuba diving tourism in Malta is not fully sustainable due to ineffective supervision.

Sustainability comes with requirements and regulations. In a general sense, the scuba diving tourism system relies on these regulations which need to be managed and enforced constantly and comprehensively to ensure the best scuba diving experience for scuba divers. Furthermore, identifying and taking all precautions for safety can eliminate unintended consequences. For example (for reference see Figure 6.12):

- "In order for a boat to take tourists to the blue grotto, they should have at least a prop guard on the propellers of the outboards ... so that the propeller will not actually injure someone and cut them into pieces. I mean because of propeller turning around even for swimmers". TUR - 2

However, it is believed that economic efficiency as an incentive is far more important than ecological integrity, social equity, and safety.

- "It's an industry. So, the operators are allowed to make a profit. So, they lobby the authorities to do things that suit them. But they are not particularly worried about the environment. They are worried that because of what they do, the environment suffers and therefore the industry will suffer. But they are not really worried about the threats to the environment for the environment's sake”. MBI - 4

In addition to sustainable practices, one of the most important daily practices can be giving a comprehensive pre-diving briefing for each level of scuba diving activity. This is because, whether scuba divers are experienced or not, each dive site has a unique ecosystem 
and structure, and such briefings may address the protection of surroundings and about preventing any potential harm, effectively. Therefore, for each activity, pre-diving briefings should be specialised, localised, and implemented properly.

\subsection{Support $(5 / 5 S)$}

Support is the last constituent of this framework and discusses the future of the scuba diving tourism system. This constituent asks how the scuba diving tourism system can be sustainable while promoting alternative dive sites with their feature. The findings were given in three sub-themes, which are the features of alternative dive sites, behaviour for protection and the future of the scuba diving tourism system. Improvement is the key factor of this theme. Even if there are well-managed regulations and enforcement for the scuba diving tourism system, without the normative understanding of present conditions of existing scuba dive sites and effective future implications, there will not be a long-term solution to achieve sustainable scuba diving tourism development in Malta. In this theme, the feature of alternative dive sites as the main scuba diving attractions plays a leading role in the future of scuba diving tourism. Moreover, the role of alternative dive sites is also questioned whether attracting and protecting marine life or as a threat to marine surroundings. In addition to that, this theme also seeks an answer to whether artificial dive sites were used only for the attraction of scuba diving tourism or contributed to the destination and its system in the sense of sustainable scuba diving tourism development practices. In conclusion, the future of the scuba diving tourism system depends on effective and well-planned improvements which contribute positively to the marine environment through constructive contributions. Overall, this dimension examines how stakeholders create value-adding for scuba divers while securing the future of scuba diving tourism in Malta. The main question of this theme was 'What can be done to be more sustainable for scuba diving tourism in Malta?'

\subsubsection{The Feature of Alternative Dive Sites}

Alternative dive sites represent a strong side and competitive advantage of scuba diving tourism in Malta. This sub-theme relates to the main questions of the support theme which were evaluation of the scuba diving tourism system and designation of Malta in terms of its marketing position. However, alternative dive sites and their surroundings need to be managed effectively to ensure safety for scuba divers and regarding environmental sustainability. 
Unplanned and unmanaged scuba diving development in terms of setting up alternative dive sites may bring many problems which negatively affect the scuba diving tourism system. This sub-theme also tries to reveal the alternative dive site preference among scuba divers (see Appendix 14 for details). Therefore, the knowledge regarding preferences may help to draw a picture of how scuba divers would like to see the destination. Overall, statements derived from scuba divers showed that variety is an important element for scuba diving tourism. For instance:

- "There are lots of opportunities, in Malta. There is something for anyone. One to just dive very shallow and look at the fish. Or if you want to challenge yourself, go to the wrecks or even deeper and do the technical”. DIV - 12

- " "I think, the diving is quite interesting and fascinating here enough. And there are many sites, there is much to see". DIV - 22

Malta offers a variety of scuba diving opportunities that attract scuba divers, and they are suitable for each type of experience level, such as shore diving, deep diving, cave diving, reef diving, and technical diving. Among these alternatives, wreck diving has the advantage of easy access and appeal. However, the location of the wrecks causes major concerns from scuba divers which means that dive time is sometimes limited. For example:

- "I wish could have stayed longer underneath, but this one, in particular, was quite far out, so we had to swim out quite a lot. I kind of expected to sort of surface swim and then drop down." DIV - 2

- "I would have like a longer dive or a bit more ... The deeper you go is the more difficult it's to see, at least for our certification ... if it's like 60 meters, we cannot really enjoy with the wreck”. DIV - 13

- "I like to penetrate the wrecks to see what's inside. I mean if it's a nice wreck in 10 meters it's perfect. I don't need to go 30 meters just to see wrecks". DIV - 18

- "So, the deeper you go, the more air you use. So, if I don't go too deep to visit a wreck, I have more time to observe it and swim around and go into". DIV - 20 
The variety of wrecks is not only about offering different things to see underwater for scuba divers but also this keeps scuba diving instructors' interests alive.

- "So, I'm never bored because every day is something new and people are looking for something different”. INS - 2

Compared to these different types of scuba diving opportunities, the limited marine life is still a negative issue in Malta as identified in the strain theme. For this reason, dive sites need to be well planned to ensure having the best experience, in the sense of suitability, attraction and safety. Therefore, the following questions were asked to extend the knowledge regarding the phenomenon under study and understand better the future practices which have been planned by associated stakeholders: 'To what extent can variety keep scuba diving tourism be kept economically and socially sustainable without an abundance of marine life?' or 'Can artificial and technical diving speciality become an opportunity for the future of scuba diving tourism in Malta?'

- "At the moment, the technical diving industry is taking a very good push forward because if you have a lack of marine life, what is you have to offer? Now you have opened the way for technical diving. People who want to go down to 80, 90 meters and see, a novel swordfish plane or an aircraft carrier or something like that, or possibly even an old Phoenician wreck with amphorae and stuff like that. But still, when you get down there, you are not going to see the abundance of marine life. You are diving technically for these deep wrecks and that is what Malta is becoming famous for". OWN - 2

The feature of alternative dive sites is the most noted issue especially from the academic point of view. The reason for this is that Malta promotes such diving opportunities in different stages, and it is believed that they attract marine life. However, the designation of a scuba diving destination brings more questions to understand better the role and structure of alternative dive sites, such as 'Are alternative dive sites a long-term solution to sustain marine life and enhance the scuba diving experience in Malta?' and 'Can Malta continue to invest in alternative dive sites for recreational use, as well as distribute the scuba diving congestion?' or 'Can Malta start thinking about investing in novel and ecological alternative dive sites like artificial reefs instead of artificial wrecks to attract marine life and create a tourism attraction?' 
Nevertheless, for scuba divers, the area of wrecks is not only a good place to see marine life but also become an attraction. For example:

- "For me, it's all about the wildlife. I think it's quite a nice thing that sinking that they are putting new wrecks out there. It may take a long time but in time, they will provide habitat for more fish and marine life around the island ... it's very valuable for the marine life”. DIV - 10

- "Whereas this is something that man built, but now it's part of the nature because it's been inhabited by fish spaces. I think that's why it's interesting”. DIV - 13

From the scuba diving centres` point of view, the current wrecks need good management to ensure their ecological contributions and maintain marine life around the wrecks and their different features.

- If you don't protect your wrecks diving industry will suffer. Because there's no marine life anymore if no more wrecks". INS - 5

- "Eventually these wrecks 30-40 years might crumble down and not remain as interesting as it was. But it will be still an artificial reef. So, sustainability from an ecosystem point of view, it's okay. From a tourism point of view, depending on the care we give the wreck". OWN - 5 and Chairman of the PDSA

Moreover, in the aspect of history, artificial wrecks may provide additional value for scuba diving tourism in Malta. Besides the ecological contribution, cultural and historical attractiveness can be included for the future of scuba diving tourism. For example:

- "With the shipwrecks, it's something different. And then it's always interesting like you know, the story of the wreck. Why is it there? Even if it's artificial, there's every shipwreck, every ship has a story. So, I like to involve that fun because it makes the dive more interesting”. INS - 3

- "They will one day, they will have a historical value as part of the history of diving in Malta. But with regard to the historical value of the site itself, I don't know only time will tell”. MAR - 2 
From the frame of marine biology reference, artificial wrecks are in a long debate as can be seen below. For example, in the long-term, whether artificial wrecks are environmentally friendly and safe for marine life or not; whether artificial wrecks are considered as artificial reefs or not; can artificial wrecks be used for attracting marine life'; or whether they have more than solely a touristic value are still questioned within this group of stakeholders. Therefore, proper monitoring and management become the key issue for a better understanding and ensuring the sustainability of scuba diving tourism in Malta.

- "I have a bit of a love-hate relationship with wrecks because, on the one hand, I see them as rubbish. It's kind of a useful way to dispose of something, you don't know what else to do with it... I do think it can be useful, because it creates popular dive spots and after a while, they have their own ecosystem, so they get covered ... I think probably the wreck does increase productivity and so it's beneficial for fish life, also, it gives a habitat. But I think it also attracts some fish from nearby habitats". MBI - 1

- "Large enough that it's stable over a long time ... It's stable, it will get colonized by organisms. So, to me, it's an artificial reef ... But the area of direct compared to the area of the natural habitat is small. So, the contribution of the wreck to increasing biodiversity, increasing fish numbers and so on. I think is rather small ... I think the contribution is so low that the potential of having a positive environmental impact is not worth the risks. So, if we're talking locally, in my mind, if you are scuttling a wreck, it 's fundamentally in order to attract an economic activity”. MBI - 2

- "Because divers like wrecks. They like swimming on wrecks. They like the look of the ship on the seabed. It fascinates them, it excites them. That is why divers want wrecks. But there is a demand, there's a huge demand for wrecks ... So, the government said ok, we just start lowering the wrecks. When they started lowering a wreck, it's true the divers increased". MBI - 3

Overall, artificial wrecks have many benefits for scuba diving tourism in terms of attracting marine life, controlling crowdedness, and redirecting scuba divers`attention from pristine or fragile sensitive areas.

- "It safeguards the marine life ... So, the availability of the wreck is good because ... 
you are creating a distraction, somehow. You are moving people away from more sensitive areas". TUR - 2

In addition, artificial wrecks may become an effective tool for marketing strategies:

- "I think a little bit novelty helps". TUR - 3

\subsubsection{Behaviour for Protection}

"Conservation of the ocean really starts and ends with the people going into the ocean. That includes all the divers in it ... Every little bit counts”. INT - 2

Behaviour for protection is related to how sustainability can be created in the scuba diving tourism system and how scuba divers can become more marine friendly in terms of their behaviours which rely on knowledge about protection. In this connection, scuba diving can promote protection because it allows people to see the real situation. According to the data, if scuba divers saw an instructor or other scuba divers pick up a pile of rubbish during the activity, they will be more likely to copy this behaviour and try to start thinking and acting picking up rubbish. Moreover, scuba divers tend to show behavioural changes towards actively protecting the marine environment; they might motivate their peers as their experience or training increased. As interviewees stated they are likely to copy the positive manner behaviour presented by scuba diving instructors and their buddies. For this reason, the scuba diving instructor can try to become a role model for responsible scuba diving experience. If instructors show a protection behaviour, scuba divers who dived with them, probably behave more constructively. Therefore, how scuba divers become more sustainable is answered by role modelling in the reference of guiding. This theme was questioned by 'Do you identify yourself as an eco-friendly or marine-friendly scuba diver?' and 'What can be done to be more sustainable in scuba diving tourism?'. The responses are related to being concerned about the likelihood that if they knew about the real situation. In general, behaviour for protection emerges by information and explanation, in terms of becoming an eco-friendly or marinefriendly scuba diver. For example:

- "As an instructor, I try and dive as a good role model. If I see a bit of plastic or something, I pick it up. I make sure that my clients do not tease, touch, harass marine 
life. I would not do that myself, so I do not expect them to do it”. INS - 1

- "I do pick up litter by showing that already that you pick up other divers, we'll do the same. Or even your students, yeah, we'll copy that behaviour. So much as doing it. You already inspired that". INS - 5

However, behaviour for protection still depends on constant education and enhanced practices and more importantly the knowledge of themselves not only for scuba divers but also scuba diving instructors to ensure the safe and sustainable scuba diving experience within the systems approach. When it comes to the conservation of alternative dive sites like artificial or historical wrecks, scuba diving tourism can also contribute to the behaviour of protection and increase public awareness towards the marine environment. Scuba diving centres tend to protect their main products, which Malta is famous for, by taking care of them or selfenforcement. Moreover, as scuba diving tourism is getting more popular, public awareness towards protection arises, at the same time, which adds value to the destination.

- "The dive centres that are taking people on these wrecks are very careful. Because it's our bread and butter. But we cannot control the ones who are not going with us. What we do is when we see bad behaviour, sometimes we record it, and we try to approach the person and explain and if just being is still bad we get the police or something into it. We make sure the take protection seriously”. OWN - 5

- "They (scuba diving centres) do the information, they do the protection part of it, and they take them there and at the same time as they are making profit, they are protecting the site". MAR - 1

As a result, behaviour for protection in scuba diving tourism is one of the effective practical measurements to minimise the detrimental effect caused by active participants. If awareness, knowledge, education, and self-regulation are combined with responsible and sustainable scuba diving tourism practices, scuba divers may contribute positive incentives to the marine environment, rather than a negative influence. Moreover, encouraging scuba divers into having environment-friendly behaviour may enhance the scuba diving experience in a sense of transformative and positive contribution. For instance: 
- "I have a week to dive on it, but they say we have a clean-up ... I go for the cleaner because that's new and that's actually helping us. So, I will do that. That also is part of how the ethics they taught me here and also my own personal morals and example. So, I'm definitely, I will go for the clean-up”. DIV - 14

- "So, preserve for the world before going diving spot ... We also have kind of shot that we agreed that we should team out to garbage we get from ... So, there is something very common we do". DIV - 17

The means of supporting behaviour for protection in scuba diving tourism relies upon the performance of how scuba diving instructors guide and their passion, at the same time. If they start to employ information and facts in every scuba dive as a part of pre-diving briefings and in-situ experience, this may change the whole scuba diving experience at the active sites. For example:

- "That's how I think that's the best way to educate them about the sustainability of the ocean. That's how I learned, before I started diving, I didn't know what it was underneath. I didn't really care so much. Now that I know and I see it, it's like, oh, we really need to look after this. So, to encourage somebody to dive in my opinion is to encourage them to start looking after the environment". INS - 9

- "I believe that there is a huge difference between actually seeing it happen and hearing what is happening. So, it's really a great wake up call, if you've actually gone down to the water and seen all the trash ... it would come as a shock to many people”. INT - 2

\subsubsection{The Future of Scuba Diving Tourism System}

The last sub-theme of this theme identifies aspects for the future of scuba diving tourism. The theme represents the stakeholders understanding and existing knowledge regarding sustainability in Malta. In the sense of the triple bottom line of sustainability, the theme questions whether stakeholders have mutual interest and shared knowledge about ensuring environmental, societal and economic sustainability in the scuba diving activity. For example, scuba diving tourism contributes not only to ecological integrity but also economic efficiency in the destination. 
- "We bring to the economy around 8 to 10 per cent of all incoming of tourism ... usually people who spend more, who bring their family, who generally are spending money on diving, on accommodation but these people still go out to the restaurant, they still to do tourist stuff. They are quite value-added tourists". OWN - 5

Therefore, the prosperity of sustainable scuba diving tourism and maintaining the economic benefits depend on supporting current and future implications, practices and protecting the marine environment within a systems approach. For example, according to the data, encouraging more people to dive, informing and improve their skills can become effective solutions to reveal the individual perspectives towards the understanding of current issues and practices that can be implemented at present and in the future.

- "If more people dive it helps raise the awareness ... that makes you aware of what you see that you have to take care of the environment underneath or in the water. I think more people should dive and see what's there and what is worthwhile being preserved". DIV - 8

From a different perspective, the debate of either presenting more artificial wrecks or an enriched experience is an important point to address. The future of the scuba diving experience in Malta depends on alternative dive sites like artificial wreck investments or focusing on enhanced scuba diving experience. However, without primarily improving marine life, it is unlikely possible to secure sustainable scuba diving tourism in Malta, as these comments from the owners of dive operations note.

- "The future of diving is that with very good promotions and spending hundreds of thousands of euros in promotions, you can still trick people into coming to Malta. So, you're still going to get those first-time divers who still, you know, see a photo, which is really well-balanced photoshop and go wow, this wreck. Wow, this cave. I want to do it ... Yes, you are still going to get that tourism, but ... there is nothing to see here. I mean ... if you want to go scuba diving, you want to scuba dive primarily for the marine life ... You don't go down underwater and potentially risk your life just to see rocks for sand. Maybe a cave ... So, the future of diving in Malta, I have a lot of people that don't come back. I have a lot of people that do back ... But the real diver, for ones to dive for fish, doesn't come back... The people are really nice, it's cheap, but where's 
the marine life? You know, let's spend more next time and go to the red sea or the Maldives or somewhere else”. OWN - 2

- " When there is nothing to see, there is no reason to go in the water". OWN - 3

However, the improvement and prosperity of sustainable scuba diving tourism development now depend on diversity in Malta. Today, along with a variety of wrecks, Malta is becoming famous for technical diving beyond the recreational depth limit. Experiencing and specialising in advanced deep diving or technical diving for Malta could bring an advantage in the future. For instance, on one level in terms of availability:

- "The business for shallow recreational wrecks is much bigger because the number of people who dive on recreational wrecks, down to 35 meters is much bigger than people who dive down to 100 meters. So, there is much, much more people who come for the scuttled wrecks. But this is now, maybe in 10 years diving to 100 meters will be the same as diving to 40 meters today, so we have to be ready”. MAR - 2

Or, in terms of ecological perspective:

- "We were filming a depth of about 50, 60, 70 meters near the shore ... And at that depth, I saw the life that they used to be in shallower waters 15, 20 years ago. So, I think everything is kind of hiding, you know, further down”. MBI - 1

When considered from these points of view, technical diving or deep diving can be an advantage in the future if planned properly for scuba diving tourism in Malta. But, today, under standard conditions, the role of human activity itself is an ongoing issue to provide sustainability although artificial wrecks help to create new aquatic life underwater. Therefore, this situation raises a fundamental question to be asked that 'Are artificial wrecks able to secure the future of scuba diving tourism, without compromising the principles of sustainable scuba diving tourism system and experience?'

- "I think that it will create a new ecosystem, which will have more varied wildlife on this case ... Over the years I've seen several things going on the Um El Faroud, for example, I documented for about three years a Gorgonian growing on the side of the ship, actually in one of those galleries by the side of the ship ... And it had grown for 
some time until one day I got there, and I found that some diver had actually knocked it down by the flippers. ("That's something took 50 years to grow and all little things like that". TUR - 3). It's good to have an artificial reef, but at the same time you would expect that the divers will eventually create problems to some extent”. TUR - 2

Linked with the above-mentioned points of artificial wrecks' contributing role towards sustainability in scuba diving tourism, some other issues were raised. For example, if there is a risk of damage by scuba divers on artificial wrecks, the limitation in the number of scuba divers according to certification level can be a solution to control the detrimental effects on existing dive sites and can be also an effective way to enhance the scuba diving experience. However, this limitation arises two normative views that challenge the system, as the economic concern and the mentality of the scuba diving tourism system's stakeholders.

- 'If you are not suitably qualified or you don't have the experience, then you should be limited to where to go. But then, unfortunately, the economy comes into it. I paid for a holiday; I want to see that place because there is ... I think for diving centres to be more sustainable, there needs to be a bit of a change in mentality. We cannot keep on going for like a more mass-production type of even with teaching or courses". TUR - 3

Therefore, although the value-adding for scuba diving may be difficult to manage, having certain measures, providing the knowledge and efficient enforcement can balance this dilemma. Moreover, establishing standards or codes of conduct related to ethical orientation and required permission to do the activity (Garrod \& Fennell, 2004) can also be a useful tool to ensure the sustainability in scuba diving tourism within the systems approach in Malta.

\subsubsection{Summary of the Theme of Support}

The theme of support is related to the future of the scuba diving tourism system. The feature of alternative dive sites is the most important issue in this theme, which need to be wellmonitored, managed and enforced to achieve success in sustainable scuba diving tourism development. In addition to this, behaviour for protection for scuba diving tourism, in the sense of ecological integrity and economic efficiency, is one of the most important indicators for achieving sustainability in scuba diving tourism and enhancing the experience more uniquely. Responsible scuba diving, skill development, raising awareness, giving information, and 
controlling the number of scuba divers may become essential strategies or implications to create the value of scuba diving tourism. For example, there is a need for specialised pre-diving briefings for each scuba diving type and level of scuba divers. However, if it is not internalised as a part of scuba diving skills, inappropriate behaviours may continue until learnt otherwise.

\subsection{Summary for Chapter 6}

Malta offers a variety of scuba diving opportunities, and each site requires a different specialisation in terms of area use and management. The variety of opportunities also requires the varied levels of certification for scuba divers that encourage them to have a new course and extend their skills. In other words, this seems an opportunity to economically sustain scuba diving tourism in the long term. Within this diversity, artificial wrecks are the most important scuba diving products among recreational scuba divers. Even if it is still under discussion whether artificial wrecks are a good way to support marine life in Malta, it is believed that they concentrate on aquatic life and offer an enriched scuba diving experience. In the long-term, they may need to be reconsidered and managed effectively for safety and environmental impacts according to the obtained data. Therefore, unless current issues and future implications are managed holistically by involving all stakeholders, the scuba diving tourism sector may not have a constructive influence on SDTS in Malta. Otherwise, metaphorically:

- "The more flat surfaces you build, the less you are interacting and cleaning and managing your environments. The more boats you allow around your coast, the more problems you're creating to your ecosystem and dredging up the seafloor ... It's like you have a problem with being obese, getting fatter and fatter and you don't think that your problem is with that you should get thinner. Do you think solution is that you think about this making your clothes bigger? Somehow Malta thinks that way ... Keep going and keep going” TUR - 1.

This chapter aimed to draw an overall picture of the current issues of scuba diving tourism and the normative values present in the SDTS in Malta. For doing this, results investigated how scuba divers understand sustainability and the scuba diving experience. Moreover, the chapter also questioned how stakeholder understands the implications of STDS and involve in sustainable practices in Malta. Following this, current issues and practices and possible future applications were presented in the 5S Thematic Framework of Sustainability in 
the Scuba Diving Tourism System. These themes discussed the external issues as indicated in the strain dimension, and internal factors caused directly by the scuba diving industry as addressed in the stress theme that negatively influences the marine environment and the SDTS in Malta. The theme of sustain explained the management gaps, while the theme of supervision emphasised the requirements for sustainability achievement for the scuba diving tourism system. Lastly, the theme of support discussed and questioned how the scuba diving tourism system could be improved based on principles of sustainability. The chapter illustrated the overall issues that Malta face today. The potential consequences that may occur in the future are also emphasised by given statements. As a result, Malta faces several challenges in terms of managerial limitations and providing sustainability implications. The data state that the challenges need a proper management plan with an optimal enforcement capacity while taking care of the current issues. The detailed discussion will be indicated in the following chapter. 


\section{CHAPTER 7: DISCUSSION}

\subsection{Introduction to Chapter 7}

\begin{tabular}{|c|c|c|c|c|c|}
\hline $\begin{array}{l}\text { Chapter } 1 \\
\text { Introduction }\end{array}$ & & $\begin{array}{l}\text { Overview } \\
\text { and } \\
\text { Introduction }\end{array}$ & $\begin{array}{l}\text { Research } \\
\text { Outline }\end{array}$ & $\begin{array}{l}\text { Chapter } \\
\text { Reviews }\end{array}$ & \\
\hline $\begin{array}{c}\text { Chapter } 2 \\
\text { Scuba Diving Tourism }\end{array}$ & $\begin{array}{c}\text { Discovering } \\
\text { the } \\
\text { Underwater }\end{array}$ & $\begin{array}{l}\text { Scuba } \\
\text { Diving } \\
\text { Economy }\end{array}$ & $\begin{array}{l}\text { Scuba } \\
\text { Diving } \\
\text { Experience }\end{array}$ & $\begin{array}{l}\text { Current } \\
\text { Issues }\end{array}$ & \\
\hline $\begin{array}{c}\text { Chapter } 3 \\
\text { Sustainability }\end{array}$ & $\begin{array}{l}\text { Sustainable } \\
\text { Tourism } \\
\text { Development }\end{array}$ & $\begin{array}{l}\text { Division } \\
\text { and } \\
\text { Concept }\end{array}$ & $\begin{array}{c}\text { Current } \\
\text { Practices in } \\
\text { Scuba } \\
\text { Diving }\end{array}$ & $\begin{array}{l}\text { MPAs and } \\
\text { Alternative } \\
\text { Dive Sites }\end{array}$ & \\
\hline $\begin{array}{l}\text { Chapter } 4 \\
\text { Theoretical Foundation }\end{array}$ & $\begin{array}{c}\text { Normative } \\
\text { Theory }\end{array}$ & $\begin{array}{l}\text { System } \\
\text { Theories }\end{array}$ & $\begin{array}{c}\text { Stakeholder } \\
\text { Theory }\end{array}$ & SDTS & $\begin{array}{l}\text { Identifying } \\
\text { the Gap }\end{array}$ \\
\hline $\begin{array}{l}\text { Chapter } 5 \\
\text { Methodology }\end{array}$ & $\begin{array}{l}\text { Research } \\
\text { Framework }\end{array}$ & $\begin{array}{l}\text { Research } \\
\text { Strategy }\end{array}$ & $\begin{array}{l}\text { Research } \\
\text { Ethics }\end{array}$ & $\begin{array}{l}\text { Limitations } \\
\text { in } \\
\text { Methodology }\end{array}$ & $\begin{array}{c}\text { Field Study } \\
\text { Area }\end{array}$ \\
\hline $\begin{array}{l}\text { Chapter } 6 \\
\text { Results }\end{array}$ & Strain & Stress & Sustain & Supervision & Support \\
\hline $\begin{array}{l}\text { Chapter } 7 \\
\text { Discussion }\end{array}$ & & $\begin{array}{l}\text { Inferences } \\
\text { and Links }\end{array}$ & $\begin{array}{l}\text { Constituents } \\
\text { and } \\
\text { Foundations }\end{array}$ & $\begin{array}{l}\text { Revised } \\
\text { Sustainability } \\
\text { Criteria }\end{array}$ & $\begin{array}{c}\text { S-SDTS } \\
\text { Model }\end{array}$ \\
\hline $\begin{array}{l}\text { Chapter } 8 \\
\text { Conclusion }\end{array}$ & & $\begin{array}{l}\text { Ans wers to } \\
\text { Research } \\
\text { Questions }\end{array}$ & Implications & Reflection & Limitations \\
\hline
\end{tabular}

Figure 7.1. The Structure of Chapter 7

Chapter 7 presents the overall discussion derived from the literature review and findings of this study (as can be seen in Figure 7.1). The chapter covers the main issues that are emphasised throughout this thesis. In general, the discussion chapter is divided into five parts. Following the initial overview, the second section continues with a discussion of the results derived from the $5 \mathrm{~S}$ Themes and links to the literature. The chapter outlines the themes and main findings regarding the SDTS in Malta. Third, the literature review regarding constituents and foundations of SDTS is revisited to improve the systems approach presented earlier. Next, the chapter presents new criteria in association with three grounds of stakeholder theory based on sustainable scuba diving tourism development principles which signpost the normative aspects that need to be employed in the system. Last, a new model as Sustainable Scuba Diving Tourism System (S-SDTS) is introduced as the main contribution of this thesis. 


\subsection{General Inferences of Research Findings}

The main purpose of this study is to redesign the scuba diving tourism system according to principles of sustainability by embodying normative theory, system theories and stakeholder theory. Normative aspects stand for the fundamental moral and ethical values that are present or can exist in the system. Even though values may differ based on destinations or mutual interests of the group of stakeholders, these values come into existence in scuba diving tourism through individual knowledge and experience, the degree of relationship/interactions between associated stakeholders and the marine environment. In this sense, this study reveals the current phenomenon within the systems approach based on stakeholders' perceptions which included scuba divers, scuba diving centres`owners, managers, employees (instructors and interns), authorities, marine biologists, marine archaeologists, and tourism scholars. For this purpose, the study examined, first, the issues regarding sustainable and unsustainable practices in scuba diving tourism and the influences behind the negative consequences through the literature review. Following, for gathering the knowledge of sustainability and understanding of stakeholders, semi-structured interviews were conducted in Malta within a phenomenological approach to better understand the present knowledge which exists in practice. Moreover, insitu observation via active participation and visual documentation was provided for getting broad intelligence about practical implementations which were turned out to be scarce and need to be improved by both scuba divers and other active stakeholders associated with the SDTS. Lastly, all these steps led to a narrative for redesigning the scuba diving tourism system according to principles of sustainability through defining the normative aspects.

It can be noted that because of the diverse relations and different phenomena existing in practice, it is difficult to define any system in certain characteristics (Goeldner \& Ritchie, 2009). As to the scuba diving tourism system (SDTS), destinations are comprised of complex, independent but interrelated and interdependent relations with various internal and external elements (Baggio, 2008). Each constituent, whether a person or an organisation, has a distinct capacity that affects the efficiency and effectiveness of the SDTS. Therefore, identifying the mutual grounds and normative aspects of the SDTS becomes an important practise to ensure optimal sustainability in scuba diving tourism as the key positions differ in each destination. In this regard, a well-designed systems approach for scuba diving tourism can provide the micro and macro level of social and economic linkages and integrated relationships to address the 
common values and problem-solving skills for associated stakeholders. In this sense, constituents of the system as stakeholders are expected to be fully involved in the system as indicated in stakeholder theory (Phillips \& Reichart, 2000; Orts \& Strudler, 2002). On this point, it is expected to enrich the collaborative efforts (Lucrezi et al., 2017), define values, and establish relations among associated and indirectly related stakeholders in the competitive environment for better understanding the current and future issues on the account of principles of sustainability, in a scuba diving tourism system.

However, the existing scuba diving tourism system (SDTS) model does not emphasise sufficiently (Dimmock \& Musa, 2015) the normative aspects for relationship building between the marine environment and all stakeholders or the degree of knowledge of principles of sustainability that is essential to understand. Clarifying ongoing issues and reinterpreting the SDTS on the basis of the normative aspects as moral and ethical values derived from principles of sustainability can improve the phenomenon by suggesting an effective course of action in the current system. Combining these elements and finding a balance between heterogeneous groups and interrelated relations with the marine environment can improve the system. Thus, managing the system in the sense of formulation of the policies; providing information sources; and reinforcing strategic development (Goeldner \& Ritchie, 2009) can be provided in association with the triple bottom line of sustainability. Besides, stakeholders can position themselves more effectively into the system while trying to find the best sustainable practices; seek economic interests; improve the social benefits; and enrich the scuba diving experience.

Although the role of the environment and nature have been considered as an essential part of the managerial approach (Boons, 2013), stakeholders interaction or interrelation with the marine ecosystem are not recognised as to cause a direct effect. Rather the participation of stakeholders is perceived as conceptual constructs (entry into a system, but not becoming a part of the marine environment) regarding their role in the system. As a result, the marine ecosystem (the main component of the system) becomes vulnerable to misuse and is adversely affected by human-driven pollution, disruptions, misuse and exceeding the capacity, at the same time. Hence, by maintaining the achievement and enhancing mutual actions towards replenishing the marine environment, it is expected that stakeholders update and adapt themselves according to economic and social requirements (Schaltegger \& Lüdeke-Freund, 2012) differ from traditional tourism/business and its unusual surrounding in the SDTS. In this regard, setting up 
normative aspects for the standards and regulations can create mechanisms of rewarding or providing incentives that help stakeholders to achieve sustainable development goals in the SDTS. Based on this inference, the results of this study are used to be able to redesign the SDTS in terms of defining the normative aspects according to principles of sustainability.

\subsection{Summary of Emergent Themes and Links to Literature}

As a result of the aforementioned discussions, normative aspects as moral and ethical values of the SDTS refer to identifying the interest of stakeholders. These values can be recognised as better understanding the marine environments in terms of stakeholders interference and effects and determining economic incentives on the basis of positive social impacts within ethical consideration. Moreover, providing a unique experience for scuba divers also relies on the effectiveness of these values. Besides, creating normative aspects in line with stakeholder theory can be employed in the SDTS to have a better understanding of the meaning, function, and purpose of the system. Because without well-defined normative aspects, stakeholders may not develop the optimal knowledge required in the system in order to establish fundamental moral and ethical values; structure what the system is for; and deal with challenges that exist within the SDTS. For example, as also documented in this study, the main reason for damaging the natural marine assets is due to lack of skill and insufficient understanding of the importance of the marine environment (Rouphael \& Inglis, 1995; Allison, 1996; Hawkins \& Roberts, 1997; Medio et al., 1997). In this sense, reducing unsustainable practices and inappropriate behaviours derived from scuba divers or certain stakeholders depends on having adequate knowledge about the marine environment, such as increasing the understanding of ocean literacy (Fauville et al., 2019; Garcia \& Cater, 2020). Therefore, providing knowledge for or sharing the information between stakeholders about the marine environment in the SDTS can stimulate moral and ethical values for the stakeholders and create an effective strategy to manage and protect the scuba dive sites. The knowledge can also bring more sensitiveness towards environmental concern (Hines et al., 1987; Lyons \& Breakwell, 1994); responsibility for environmental protection (Huang \& Shih, 2009); and willingness to take an action (Sivek \& Hungerford, 1990; Cheng \& Wu, 2015). In this connection, normative aspects in the sense of knowledge based on moral and ethical values become the key instrument to reduce adverse effects (Huang \& Yore, 2005; Steg \& Vlek, 2009; Chao \& Lam, 2011) on the marine environment where scuba diving activities take place. 
Developing responsible practices regarding surface or underwater skills by having an interest in learning and feeling concern (Chawla, 1998) towards marine environment-related issues are suggested as beneficial precautions in the current literature. Moreover, starting to take care of the environment and developing protection sense (Fryxell \& Lo, 2003) with an empathetic perspective (Hungerford \& Volk, 1990; Halpenny, 2010) are also considered as effective strategies to protect the marine environment and maintain the SDTS. Because the sense of protection with empathy can encourage stakeholders to advance their skills and use these skills to decrease the detrimental impact of activities (Amyx et al., 1994; Huang \& Shih, 2009). Moreover, these stakeholders can improve the personal and management capacity regarding implementations according to principles of sustainability in the SDTS. In accordance with the purpose of this study, the 5S Themes was created through reflective notetaking, semistructured interviews, in-situ observations via active participation with stakeholders who were actively involved in and had some degree of influence on the SDTS in Malta. The 5S thematic framework of sustainability in the SDTS seeks an explanation of external threats and the present situation (1/5S); pressures that come from scuba diving activities on the grounds of a dearth of the normative intelligence of the marine environment (knowledge, information and ocean literacy) (2/5S); challenges due to lack of effective management capacity (3/5S); unintended possible and existing consequences because of addressing limited requirements (4/5S); and questions regarding the future of the SDTS based on principles of sustainability (5/5S). On this point, each constituent of the $5 \mathrm{~S}$ Themes covers normative aspects according to principles of sustainability in the SDTS and links to the existing literature, as detailed below.

\section{a) In reference to Strain $(1 / 5 S)$}

Scuba diving is intensely marine-oriented with supporting elements, touristic services, scuba diving centres, various stakeholders, employees and more importantly scuba divers (Bideci \& Cater, 2019b). As documented in this study, scuba diving is becoming more popular both for scuba divers and destinations (Garrod \& Gössling, 2008; Spalding et al., 2017; Tynyakov et al., 2017). This trend introduces millions of tourists' movement, globally; billions of economic revenues for the destinations; and a novel subaqueous experience for the scuba divers. However, external factors (Klint et al., 2012; IUCN, 2021; Lucrezi et al., 2020) negatively affect the marine surroundings on which scuba diving tourism relies on. For example, first, uncontrolled, and unregulated commercial or unsustainable artisanal fishing 
practices have adverse effects on underwater surroundings in reducing the fish population and threatening the species which are famous and important for scuba diving tourism in Malta, such as groupers and octopus. Fish variety is one of the competitive advantages among scuba diving tourism destinations (Stolk et al., 2005; Uyarra et al., 2009). Therefore, the declining fish population reduces the popularity of scuba diving in Malta. Moreover, from an ecological perspective, the marine environment may become desert-like rock and sand and limit the attractiveness of the destination for scuba divers.

Second, the lack of marine life is the most important issue in the SDTS in Malta. Although there are certain reasons, such as overfishing and other human-driven activities (marine transportation, dumping construction waste) as indicated in this theme, marine life in Malta has declined in recent years for other unfavourable actions and reasons. The lack of marine life was the most noticeable consequence from the perspective of all stakeholders, especially for scuba divers. Last, in Malta, marine pollution due to various reasons such as lack of infrastructure, unenforced regulations, ignorance, unrestrained marine-related activities, and unsustainable plans such as land reclamation cause threats for natural resources, people, and the future. As an island community, Malta relies on the healthy condition of the marine environment. In the same direction, to gain economic and social benefits from scuba diving tourism depends on well-preserved and rich underwater surroundings (Bideci \& Bideci, 2021). Therefore, a better understanding of external factors and their effects in the SDTS (Lucrezi et al., 2017) can give the advantage to overcome controversial issues; manage the scuba dive sites and the destination; and eliminate negative consequences on the marine environment and underwater surroundings.

\section{b) On the Basis of Stress (2/5S)}

The marine environment is not only under pressure due to external factors but is also affected negatively by the direct effects of unfavourable and unsustainable scuba diving tourism practices and activities (e.g., Rouphael \& Inglis, 2001; Thapa et al., 2006; Danovaro et al., 2008; Worachananant et al., 2008; Catlin \& Jones, 2010; Camp \& Fraser, 2012; Lucrezi et al., 2013; Su \& Swanson, 2017; Edney et al., 2021a). The same effect can also be seen in Malta according to the data of this study. For example, exceeding the carrying capacity (Davis $\&$ Tisdell, 1995) of scuba dive sites puts stress on these unique surroundings. In this sense, optimal carrying capacity is a contemporary issue and lack of measurements causes crowding 
in the underwater surroundings that negatively influences the scuba diving experience, as well as creating some safety issues in Malta. Disregarding the carrying capacity assessments increase the number of people underwater but decrease the quality of the scuba diving experience by creating a phenomenon like diving in a jacuzzi. Besides, some scuba diving types like night and cave diving affect marine life more intensely in terms of damaging the surrounding by killing the organism; disturbing the wildlife (Lucrezi et al., 2017); and interfering with the natural cycle. In addition to this, the reason for showing unsustainable underwater behaviour (Chung et al., 2013; Lucrezi et al., 2020; Edney et al., 2021b) by active participants (scuba divers, scuba diving instructors and interns) is due to a lack of knowledge about the marine environment and its ecosystem (Garcia \& Cater, 2020). Because limited or inadequate knowledge causes additional stress on the marine environment because of the negative actions and practices which are unintentional or without the understanding of the consequences. Therefore, a comprehensive understanding of adverse consequences derived directly from scuba diving activities can provide stakeholders with better management strategies within the SDTS.

To set an example, during the interviews, some scuba divers stated that they undertook some self-regulation during scuba diving such as buoyancy control or proper fining techniques. However, it was observed that during the active participation, self-regulation underwater by the scuba divers who have different certification levels was practised differently and insufficiently. In practice, unsustainable finning techniques were observed and photographed for the record and presented as research findings in this thesis (see Figure 6.8 on page 153 and Figure 6.11 on page 169 for reference). In addition to this, scuba diving instructors said that they always give a pre-diving briefing for acting sustainably underwater, such as not touching, not to chase or not feeding fish. During the in-situ observations via active participation in 15 dives with 8 different scuba diving instructors, only once brief information about being or acting sustainably in the underwater was given by a scuba diving instructor to a group of scuba divers. During the in-situ observation period, no pre-diving briefing according to sustainable diving practices or acting sustainable underwater was given by the scuba diving instructors beyond the scuba diving location, and dive plan.

Another example is, during my active participation and part of education for advanced scuba diver certification issued by PADI, I participated in night diving. The marine life was 
spectacular and was different from the scuba diving which carried in during the daylight. At the same time, we as scuba divers were following the instructor by carrying torches. We tried to swim and see the newly encountered marine creature, where the instructor pointed out. Even though, the group was comprised of advanced diving skilled people, touching the ground or surroundings and hitting something by fins were always ignored due to limited time underwater and ensuring the most creatures to be seen. Approaching the organisms closely also caused high content of sediment due to scuba divers' movements, as well. However, from a business perspective, the focus was "you like, I make sure for you, show must go on" INS - 8, which keeps the scuba divers entertained; but not thinking anything about the damage to the marine environment. In the sense of sustainability, there may be some precautions that can be implemented for night diving. Such as limiting the number and providing carefully guiding for inexperienced or experienced scuba divers through giving a proper pre-diving briefing specialised to diving type.

Furthermore, the characteristics of scuba divers are usually associated with the number of dives or time spent underwater, which may result in ambiguity or misunderstanding for scuba divers' perception and their role in the SDTS. Because the experience in scuba diving is not only measured by counting the number of dives but also it is a learning process about natural resources and experiencing environments (Harriott et al., 1997; Dimmock, 2009; Musa \& Dimmock, 2012). Moreover, scuba divers`expectations, level of certifications and skills, motivation or underwater behaviour also become important indicators to identify the characteristics of scuba divers, in the contemporary era. In this connection, it is advocated that scuba divers should be evaluated from multiple levels in the SDTS depending on different outputs with their unique individual dimensions in Malta or a particular destination. Therefore, a better understanding of the degree of individual influences and characteristic features of scuba divers can provide an advantage to set normative aspects for stakeholders to put their moral and ethical values into practice regarding diminishing the adverse effects on the marine environment according to sustainable scuba diving tourism development principles.

\section{c) With Regards to Sustain $(3 / 5 \mathrm{~S})$}

A sustainable scuba diving tourism system development depends on multi-directional administrative, operational, enforcement, monitoring and in-situ implications (HillmerPegram, 2014; Lucrezi et al., 2017; Scholtz \& Saayman, 2018). These are to maintain the 
balance between economic benefit with social equity and protection of the marine environment while ensuring scuba divers have a unique experience. However, according to data, several participants stated that there is no demand for sustainability if there is no economic incentive or claimed that economic benefits lead to sustainability in Malta. In other words, the sustainability-based practices only come with economic revenue or only relate to income generation. However, without healthy and sustainable resources scuba diving tourism cannot sustain the economic benefits and incentives. Therefore, in terms of sustainability-oriented knowledge building for SDTS and the involvement of the stakeholders in the system, five core values, fairness, efficiency, knowledge, wisdom, and stability (Susskind \& Cruikshank 1987; Nicodemus 2004; Byrd, 2007) can be adopted into stakeholders' interests and share benefits (Parmar et al., 2010). In this sense, fairness in income generation; the efficiency of the system`s function; knowledge of principles of sustainability; wisdom in the balance between social equity and protection of the marine environment; and stability in management capacity can be acknowledged as the fundamentals of the normative aspects as moral and ethical values according to principles of sustainability.

In terms of practices in dive sites, there are in-situ approaches and suggested global management implications with codes of conduct to improve the quality of touristic scuba diving services such as developing the investment and infrastructure for the industry; creating awareness via increasing the quality of education regarding the efficient use of sources (Bennett et al., 2017); and designation of MPAs. As indicated in this study, divinvestment and divinfrastructure are related to improving the quality of scuba diving operations. The lack of developments was one of the major points of concern related to scuba dive sites as stated by scuba diving centres in Malta. For example, fundamental operational tools like improving parking facilities, setting up ladders for entry and exit points, and other facilities related to sustainable development such as providing recycling, restrooms, and environmentally friendly dive sites management were inadequate. In this sense, while popularity is increasing, at the same time, inadequacies are becoming a problem related to scuba dive sites. Another issue that came to light in Malta was the lack of awareness and education. For example, according to the data, if scuba divers have had been well educated, they would have become more aware of the marine ecosystem and most of the adverse effects caused by active participants could have been eliminated. The knowledge, as the normative aspect of the system, related to the marine 
environment based on principles of sustainability can encourage stakeholders to develop their skills and use these skills to decrease the detrimental impact of activities in the SDTS.

Managing dive sites has been seen as a difficult phenomenon in Malta. In line with the above-mentioned points, according to Malta National Tourism Policy, covering the years between 2015 and 2020, marine conservation and scuba diving activities can have the act of improving the reefs which "... need to be populated by fish species" (NTP, 2015, p. 53). However, rather than fundamental principles of sustainability, national tourism policy focuses on infrastructure and regulations. For example, the published version of diving master plans in 2012 and 2013 for Malta \& Gozo, which is not available to find officially, was not linked to current policymaking. For this reason, even if it is indicated as the subject of the national tourism policy, there was not any up to date (by the time this study is conducted) official master plan to manage and sustain natural and alternative scuba diving areas along with the triple bottom line of sustainability in terms of planning of artificial wreck structures; protected areas and attitudes towards them; and to eliminate negative effects of other current issues such as regulating commercial marine routes, bird migration, designation of special areas, preparing to scuba diving industry for climate change, and dealing with marine pollution in Malta.

Regarding policymaking, one of the most controversial issues was the status of Marine Protected Areas (MPAs) in Malta. MPAs can provide economic and social benefits. To be more precise, if MPAs are well-designed, effectively managed, properly enforced, and continuously monitored, they may become more beneficial, returning around 1.4 and 2.7 times higher than their costs (Brander et al., 2020). For example, MPAs in Spain, France, and Italy generate income derived from recreational activities 2.3 times higher than MPA management costs (Sala \& Giakoumi, 2018). Moreover, in these MPAs, fish abundance in marine reserves is about 670 per cent higher than in unprotected areas and 343 per cent higher than in partially protected MPAs. Another MPA in the Medes Islands in Spain, which is a fully protected area less than 1 $\mathrm{km}^{2}$, generates revenues of about 10 million euros annually and around 85 per cent of this revenue comes from scuba diving activities and glass-bottom boat attractions (Lubchenco et al., 2016 for PISCO, 2016). However, in Malta, although there are about ten designated MPAs, by 2019, around the archipelago, only one is implemented and actively protected for Posidonia beds with a lot of misuse issues as revealed in statements of stakeholders. Besides, there was no certain data about the economic benefit generated from the MPA, in question. Therefore, 
MPAs are becoming MnPAs (Marine non-Protected Areas) which means that they exist, but they have neither been protected nor fully implemented. As a consequence, marine life with more abundant and diverse species attracts more scuba divers to visit a place. Addressing points of principles of sustainability, increasing the degree of sustainable practices, identifying the codes of conduct in management and enterprises aspects can enable a broad understanding. Moreover, monitoring and enforcement can be included in both eradicating the illegal diving operations and designating the marine protected areas in terms of access to the diving areas with basic facilities and improved access to water. With this regard, improving management capacity for meeting local people and future generations` needs can also enhance positive scuba diving experience and help to raise awareness towards underwater surroundings among active participants and other stakeholders in the SDTS in Malta.

\section{d) At the Heart of Supervision (4/5S)}

Sustainable practices are essential operational tools for scuba diving centres in-situ and in-business activities in Malta. However, these practices were about increasing the business image rather than only contributing to the marine environment for the sake of itself. From the point of view of scuba diving centres, sustainable in-business practices were meant mainly as recycling and not using or not encouraging single-use plastics. All scuba diving centres which were interviewed carry out or apply for these sustainable practices. However, according to data, to what extent these practices contribute or are related to the protection of the marine environment are still questionable. Moreover, they are unlikely to contribute more substantial environmental measures (Dearden \& Manopawitr, 2011; Augustine et al., 2016; Lenzen et al., 2018; Jensen et al., 2020) such as reducing carbon footprint and environmentally friendly material use during the execution of the activity and underwater. It is worth noting that, in terms of scuba divers, the quality and capacity of the scuba diving centres are a more important consideration to participate in scuba diving activity. Therefore, scuba diving centres environmental concerns are not the matter of preference for scuba divers or they are not sufficiently aware of these sustainable practices taken by a scuba diving centre itself. Compared to these in-business practices, scuba diving centres stated that they participate in or organise clean-up events to clean the underwater surroundings in-situ. These events contribute to the marine environment in many ways such as helping to reduce the level of existing sources of marine pollution; increase the quality of the water; and creating awareness among people to 
some extent and scuba divers towards environmental issues (Lucrezi et al., 2017; Lucrezi et al., 2020). According to data, even though it is not sufficiently studied scientifically, it is believed that participating in clean-up diving can enhance the scuba diving experience for those who attended as recreational scuba divers. Therefore, these practices may become more visible for scuba divers to increase the level of sustainable practices rather than in-business practices. However, there are discussions among stakeholders in academia about whether clean-up events are contributing to the environment or just being a cosmetic for scuba diving centres. Nevertheless, these practices are getting more popular among active in-water participants in Malta. As a result, revising or improving the sustainability practices for the scuba diving centres themselves can be effective tools as normative aspects to have positive impacts on their businesses that can increase the value of the scuba diving tourism system.

In Malta, for example, according to the data, one of the most controversial issues regarding the sustainability of scuba diving tourism was the lack of enforcement capacity due to the conflict of interests. A figure can be seen in Appendix 16, which illustrates the governance for enforcement in Malta according to derived from interviewees`statements and narrative of stakeholders and created by the researcher. According to research findings, lack of communication, ineffective planning, and political obstacles are the primary reasons for insufficient implementations in terms of achieving sustainable scuba diving tourism development strategies. Moreover, as interviewees, both the Malta Tourism Authority and tourism scholars, state that enforcement is undertaken by different authorities which causes a conflict in the jurisdiction of developing sustainability for the scuba diving tourism system. This also creates complexity about who is responsible for scuba diving tourism in terms of regulations and enforcement policies. For example, each stakeholder relies on a different enforcement department for having the best results under the authority of different interests. For this reason, enforcement in the field addresses only specific issues rather than holistic enforcement for scuba diving tourism. If there is an issue such as in regard to heritage protection; a problem with boat traffic; or operating unauthorized scuba diving centres the enforcement is undertaken by specific authorities. However, if there is a problem of marine pollution; illegal commercial or artisanal fishing; unsustainable practices of scuba diving centres; inappropriate behaviours of scuba divers; or lack of infrastructure upgrade, there is no enforcement capacity for these issues, which are vital and necessary for achieving sustainable development in scuba diving tourism. Although they have smaller effects individually, together 
they can become significant issues, and may cause devastating influence that has already been seen over time according to stakeholders` statements in Malta. Therefore, redesigning the authority of enforcement in the instrumental ground and creating codes of conduct within the descriptive and management cores according to the needs of the marine environment can be beneficial for the scuba diving tourism system in Malta.

Appropriate knowledge plays a key role to reduce negative impacts (Lindsay et al., 2008) and controlling or changing scuba divers` unsustainable behaviours (Cottrell \& Graefe, 1997; Townsend, 2003; Thapa et al., 2005). This is because, the more educated and informed scuba divers about the marine environment is the more likely to tend to be careful while interacting with the underwater surroundings (Cheng \& Wu, 2015) in terms of taking selfregulation or sustainable underwater precautions (Wurzinger \& Johansson, 2006). In this sense, the $(3 / 5 \mathrm{~S})$ theme of supervision showed that instead of providing one-sentence information (Barker \& Roberts, 2004), well-developed, enriched and enough emphasised pre-diving briefings (Medio et al., 1997; Krieger et al., 2013) become one of the most important requirements which can work as a tool diminishing the adverse effects in the SDTS which come from active participation. Although none of the stakeholders mentioned standard prediving knowledge regarding principles of sustainability, adequate pre-diving briefing along with self or intense education and localised knowledge can have a positive contribution to the scuba diving experience, as indicated in the (2/5S) stress theme.

In addition to comprehensive pre-diving briefings and skill development or setting up sustainable development practices in Malta, the other solution mentioned was to promote alternative dive sites. Alternative dive sites can be varied and offer a diverse range of underwater scenery. However, a limited number of alternative structures like artificial wrecks (particular ships or planes) have gained recognition in Malta and promoted and invested as scuba diving attractions. In such a manner they provide a controlled marine environment, accessibility, and attractiveness that is preferred by both certified and novice scuba divers (Kirkbride-Smith et al., 2013; Tynyakov et al., 2017; Edney et al., 2021). Thus, from the viewpoint of tourism and touristic purposes, artificial wrecks have significant social and economic benefits (Bideci \& Bideci, 2021). According to findings, they also offer wellprotected marine biodiversity with an abundance of fish and other marine creatures in the sense of environmental contribution in Malta. While increasing the ecological integrity, these sites 
can stimulate economic benefit by offering novel and 'magic' atmospheres (Bideci \& Cater, 2019a) with mystery, historic and beauty (Edney \& Boyd, 2020) at the same time. However, using artificial wrecks as a scuba diving attraction has some safety risks which need to be carefully considered before sinking or opening to scuba divers such as accessibility, entry and exit points, sharp materials, availability going inside and deployed position. These concerns not only the structure itself but also it is required to regulate the scuba dive sites and their underwater and above water surroundings. For example, intense boat traffic around the dive sites (see Figure 6.12 on page 170) causes a threat to scuba diving safety around such alternative dive sites in Malta. Therefore, a proper operation plan is an essential requirement for managing these scuba dive sites with collaborative work and effort among stakeholders. To mitigate these risks, instead of using wrecks or vessels, well-planned and environmentally friendly created or manufactured artificial reefs can be a good alternative for using as scuba diving attraction (Bideci \& Bideci, 2021). In addition to this, by means of promoting alternative dive sites, stakeholders can develop their learning capacity through the observational or experimental processes and can provide marine-oriented management skills for the SDTS through the ethical and theoretical foundation (Freeman, 1994; Freeman et al., 2004) which also represents the principles of sustainability (Bideci \& Cater, 2019b; Bideci \& Bideci, 2021). All in all, sustainability in SDTS relies on effective management strategies (Needham \& Szuster, 2011; Anderson \& Loomis, 2012) in terms of regulating scuba dive sites and better understanding the underwater behaviours of scuba divers.

\section{e) On the Grounds of Support (5/5S)}

Along with the alternative offerings, scuba diving tourism can contribute substantially to the conservation of marine ecosystems and raise awareness in the protection of the underwater environment through establishing codes of conduct (Bennett et al., 2017). Regarding principles of sustainability for the SDTS while reducing detrimental effects on natural habitat and artificially created/manufactured resources, codes of conduct can ensure economic benefits (Hillmer-Pegram, 2014) for stakeholders; improve the quality of social life for locals; and grant quite a unique experience for scuba divers. However, without adequate management and enforcement capability of audits and outcomes of the administrative zone, the SDTS may become unwieldy (Lucrezi et al., 2017). In this connection, the theme of support questioned the future of the scuba diving tourism system in Malta. The theme examines how 
scuba diving tourism can maintain the current position and enhance the future potential in a manner of the joint effort to have a better systems approach.

A proper SDTS approach requires collaborative work with all involved parties by means of independent and comprehensive efforts and achieving sustainability goals for a competitive advantage. However, in practice, it is revealed that sustainability in scuba diving tourism has not been emphasised sufficiently. Through providing a better understanding of current issues and future implications, the scuba diving tourism system in Malta, from scuba divers to stakeholders; from responsible scuba diving practices to codes of conduct; or from managing scuba dive sites to implementing safety measures can be well addressed and discussed within the system. Therefore, the question of how scuba diving tourism facilitated desirable sustainable development standards within the system in Malta has remained the main ongoing discussion. In a broad sense, current issues show that there is much that needs to be done to achieve the best possible sustainable development standards in Malta regarding the SDTS by addressing the interests of stakeholders (Scholtz \& Saayman, 2018) and more importantly the marine surroundings. In this sense, raising awareness can provide a better understanding of the importance of sustainability and protection of the marine environment whilst providing economic benefits and ensuring the life quality for locals (Hillmer-Pegram, 2014). Even though there is a rising awareness of environmental issues (Juvan \& Dolnicar, 2014; Passafaro, 2020; Garcia \& Cater, 2020), social and economic dimensions remain lacking. The future of this tourism depends on many factors such as marketing position, collaborations, variety, and safety of alternative dive sites, deep or technical diving specialisation, regulations, education, and more importantly proper enforcement within the long-term plan. Therefore, a proper systems approach based on normative aspects as moral and ethical values according to principles of sustainability among stakeholders can be established by revising the current SDTS approach in order to optimal sustainable development standards.

For example, in terms of active participation, if alternative dive sites are well planned and well managed (Edney et al., 2021a), scuba diving tourism in Malta can sustain its destination features by diversifying the alternative dive sites in terms of accessibility, type, and location; protecting the current underwater developments; and enriching the experience of scuba divers (Dimmock \& Musa, 2015). One of the environmentally friendly strategies is to encourage scuba divers to act for protection, which contributes positively to scuba divers 
experience and reduces the adverse effects caused by active participants. Scuba divers are willing to participate in clean-up events in Malta. Therefore, promoting a responsible and environmentally friendly scuba diving experience can change the 'ordinary' scuba diving experience into a transformative one. By doing so, the SDTS can become more meaningful for stakeholders in Malta. The future of the SDTS depends on looking beyond current capacities and creating a proper working systems approach (Musa \& Dimmock, 2013; Dimmock \& Musa, 2015 ) that adopts normative aspects in association with the triple bottom line.

\subsection{Constituents and Foundations of the Scuba Diving Tourism System}

Managing scuba dive sites requires a comprehensive process to ensure sustainable development standards, which becomes complicated (Musa \& Dimmock, 2013; HillmerPegram, 2014; Dimmock \& Musa, 2015; Lucrezi et al., 2017; Scholtz \& Saayman, 2018) due to a variety of external factors. Moreover, each destination has a different type of organisation, different relations with associated stakeholder groups (Baggio, 2008; Baggio et al., 2012) and offers different scuba diving opportunities. Therefore, addressing the principles of sustainability foundations (Lucrezi et al., 2017) in SDTS as a first outset can provide a better understanding of the functions of principles and their impacts on actions. With this design, the constituents and foundations of the SDTS are revisited within a broad approach based on principles of sustainability to reach constructive outcomes in the SDTS (as can be seen in Figure 7.2) compared to Musa \& Dimmock`s (2013) and Dimmock \& Musa`s (2015) SDTS approaches. The scheme of constituents and foundations provide theoretical and practical insights that categorised each constituent as stakeholders according to their associated role. Fundamentally, there are four main constituents that affect the system and its function, which are marine environment and its surroundings (as the main resource/s); scuba divers (as users); stakeholders (as implementers); and governance and institutions (as regulators and partners). 


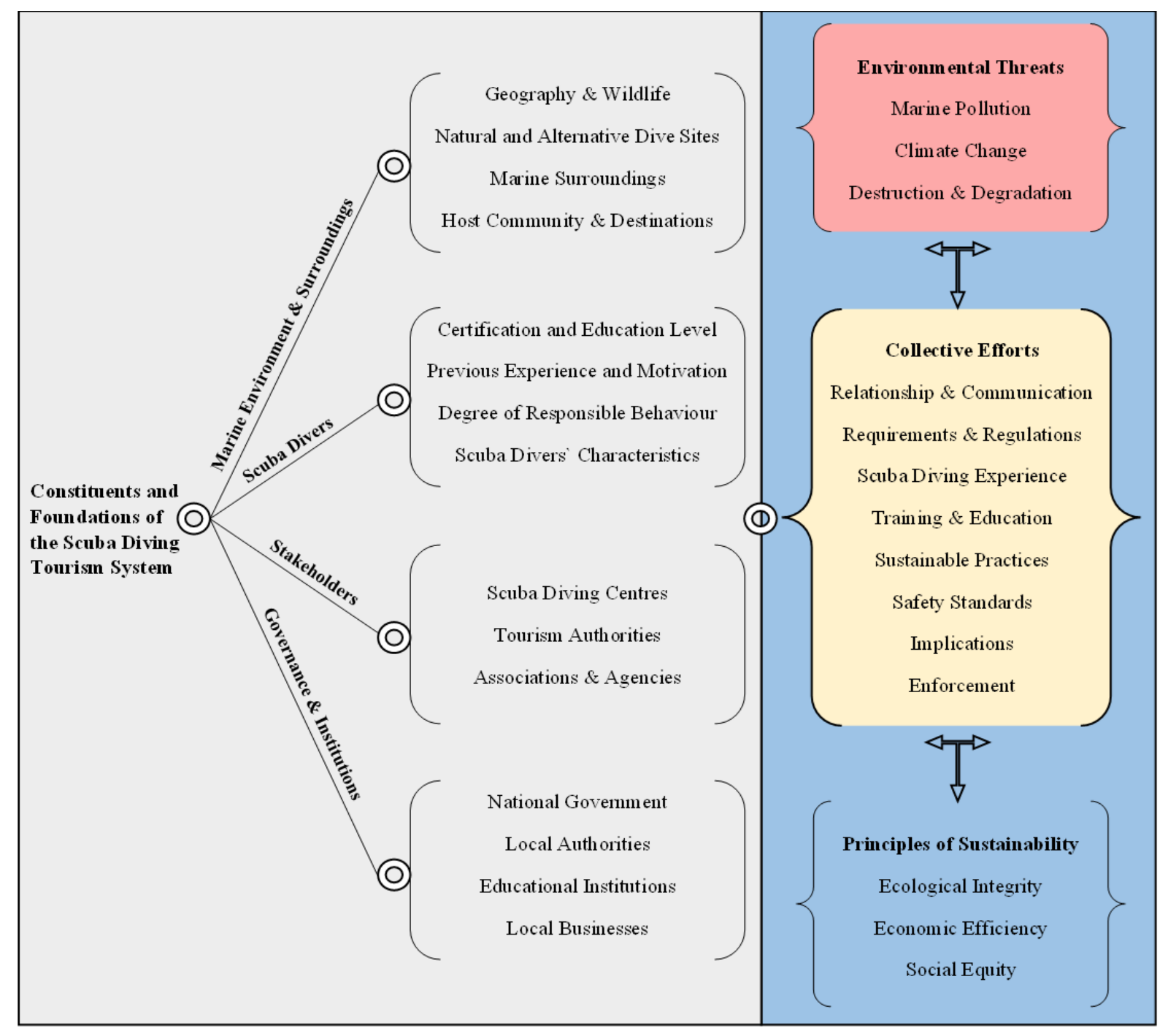

Figure 7.2. Constituents and Foundations of the Scuba Diving Tourism System

The first constituent is the marine environment which is the most important element in the SDTS, and all stakeholders depend on it for sustainable scuba diving tourism development. Associated or related stakeholders influence the marine environment with their knowledge, strategies and practical implications which cannot be considered only from a recreational perspective. In ecological base, it contains every part of the aquatic living being such as the reef ecosystem, Posidonia, cave ecosystem and different wildlife, for example. Both natural and alternative dive sites become constituents for the SDTS. Along with other marine-related beings, the local community can also be taken into consideration as part of the marine environment due to being an important constituent that shapes the destination. Moreover, they are also essential parts of delivering the tourist experience. 
Since scuba diving tourism has a demand-based structure (Fletcher et al., 2018), scuba divers are substantial contributors who rely on different outputs and unique individual dimensions in terms of economic and social benefits for the foundation of the SDTS. However, scuba diving experience, unless well managed and based on principles of sustainability, may negatively impact the marine environment. For this reason, a better understanding of characteristics of scuba divers in the sense of certification and education level; previous experience and motivation; and the degree of responsible behaviours can help to design a sustainable scuba diving experience as well as achieve sustainable achievements. Besides, their attitude will be indicative of whether sustainable practices work or fail, hence, this is a key feature to keep scuba divers`attention alive or understand the reason for demand changes (increase or decrease) in the short-term and long-term periods. With this regard, scuba divers experience can help to create an evaluation criterion for a better understanding of the current situation and future decisions in terms of sustainable scuba diving tourism development standards. Because at the end of the lived scuba diving activity, positive or negative experiences would rise to the surface from beneath the water.

The third constituent as stakeholders includes scuba diving centres as the main contributor and operator, tourism authorities (including media management) as policymakers and controllers are part of the SDTS primarily as being implementers of the applications and standards in the destination. In addition, associations, and agencies (PADI - CMAS - DAN SSI - NAUI - BSAC), and other education and training providers are also significant constituents in the SDTS. Local scuba diving associations (like PDSA for Malta) also have a position in the SDTS as they can become an important contributor as localised education and information provider. Even though, scuba diving centres or schools operate the active scuba diving activity, standards and sustainable practices need a collective effort to ensure a sustainable SDTS development. It is advocated that these stakeholders play a part to regulate activities through collaboration and accommodate moral and ethical values as normative aspects according to principles of sustainability into the SDTS.

The fourth constituent of the SDTS includes national (or regional) governments that can take a leading role in regulating and reassuring sustainability for every stakeholder. Educational Institutions (such as research offices and universities -based on the destination structure) can have a crucial role in providing information and education for better planning 
and management. Local authorities can have responsibilities for implementation and enforcement while having a partnership with scuba diving centres, associations, and agencies for ensuring the best standards on the basis of principles of sustainability. The success of SDTS relies on executing sustainable standards and its positive outcomes. Because, poor quality, unsustainable actions or illegally operating a scuba diving centre can affect the scuba diving experience and the destination image negatively. Therefore, governments and institutions can have the responsibility to address or employ normative aspects according to principles of sustainability into the SDTS.

In regard to findings, the foundations of the SDTS address also environmental threats for the marine surroundings which become reality in different ways. Marine pollution is a widespread impact that can be easily seen by stakeholders and scuba divers in the first place in Malta. Marine pollution has negative effects on the scuba diving experience and wildlife surroundings, due to insufficient waste management (Thapa et al., 2005; Su \& Swanson, 2017) and inadequate education (Passafaro, 2020) among active participants who associated with scuba diving tourism and the host community. Destruction and degradation are also caused by unsustainable scuba diving practices. As documented in this thesis, these can be night and cave diving activities, caused by inappropriate underwater behaviours (Barker \& Roberts, 2004; Di Franco et al., 2009; Anderson \& Loomis, 2011; Chung et al., 2013; Lucrezi et al., 2020; Edney et al., 2021b), and unsustainable fishing practices. Besides, uncontrollable factors such as climate change or an increase in water temperature (Dearden \& Manopawitr, 2011; Klint et al., 2012; IUCN, 2021) can affect seasonality, appropriate conditions for scuba diving activity and may reduce wildlife population noticeably. Elimination of negative influences needs a collective effort and requirements, or regulations can be handled according to the needs of the surroundings and according to stakeholders` interests and authorities`capacities. All parts can take an action to contribute to the process of creating standards and principles of sustainability in practice. As a result, sustainability can be taken as the fundamental point of departure and that become an inseparable part for all stakeholders in the SDTS.

\subsection{Revisiting Sustainability Criteria in the SDTS}

As indicated in this research, the degree of background knowledge for sustainability among current stakeholders is still inadequate (Higham \& Lück, 2007; Garrod, 2008; Passafaro, 2020). Although people claimed that they have an environmentally friendly attitude, 
they did not act as supposed to (Juvan \& Dolnicar, 2014), due to a lack of knowledge or understanding of environmental impacts as a consequence of their acts (Passafaro, 2020). Therefore, criteria based on normative aspects with moral and ethical values in terms of managing and protecting within the context of principles of sustainability can be the key factors for the SDTS in the sense of the stakeholder approach along with the present developments. In this regard, existing criteria related to the early version of SDTS, designed by Musa and Dimmock (2013), introduced the function of the system based on descriptive cores. A year later, the second version (Hillmer-Pegram, 2014) was developed on the instrumental core on the basis of resilience theory. The updated system approach (Dimmock \& Musa, 2015) highlighted the perspective of doing business from descriptive cores. The recent version (Lucrezi et al., 2017; Scholtz \& Saayman, 2018) has focused on principally relationship building with instrumental grounds. As can be seen in Table 7.1, descriptive, instrumental, and normative sustainability criteria related to the current literature (for reference of the existing items in grey font coloured shown earlier in Table 4.1 on page 63) are categorised to present a structured sense of grounded values of SDTS which are both independently important and interrelated with each other. To create the body of knowledge regarding the three grounds of stakeholder theory, a two-step classification process was determined. The existing items (light grey font) were derived from the literature review and related to the present SDTS approaches were put in order as the first-order process. In the second order, the data retrieved from the field study of this thesis were examined and added 19 new sustainability criteria into categories as descriptive, instrumental, and normative aspects (bold font). The literature review and field study-oriented items were aggregated to define the current dimensions of SDTS in the sense of stakeholder theory according to principles of sustainability. 
Table 7.1. Revised Sustainability Criteria in SDTS According to Stakeholder Theory` Dimensions

\begin{tabular}{|c|c|}
\hline Descriptive Grounds of SDTS & Instrumental Grounds of SDTS \\
\hline 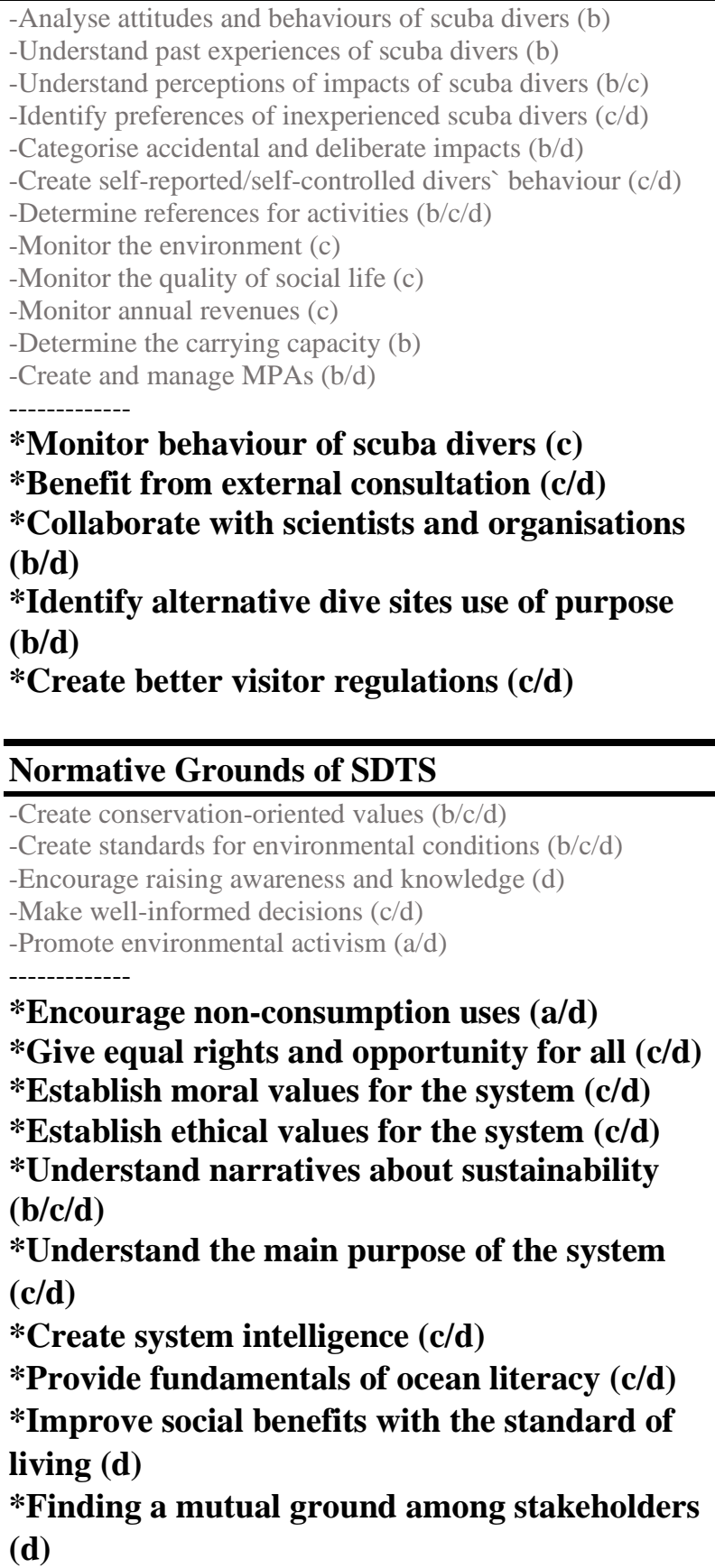 & $\begin{array}{l}\text {-Reward sustainable business performances (a/d) } \\
\text {-Measure conservation tools (b/c/d) } \\
\text {-Systematically analyse scuba diving tourism (b/c) } \\
\text {-Develop relationships among stakeholders (d) } \\
\text {-Sponsor and fund new scuba diving areas (a/c/d) } \\
\text {-Provide training for stakeholders (d) } \\
\text {-Self-advocacy and representativeness of all } \\
\text { stakeholders (c/d) } \\
\text {-Form compensation or negotiation at the local level } \\
\text { (d) } \\
\text {-Minimise the negative impacts caused by scuba divers } \\
\text { (d) } \\
\text {-Limit access to marine areas as if required (b/c/d) } \\
\text {-Restrict intensive fishing practices in scuba diving } \\
\text { areas (d) } \\
\text {-Promote scuba diving (a) } \\
\text {-Adopt marketing tools to local capacities (a) } \\
\text {-Generate market diversification (a) } \\
\text {-Exploit new marketing channels (a) } \\
\text {-Ensure the service quality on a local basis (a/b/c/d) } \\
\text {-Stimulate artificial reef and wrecks areas (a/b/c/d) } \\
\text {-Establish product diversifications (a) } \\
\text {-Agreement in planning and management (c/d) } \\
\text {-Adjust regulations and restrictions (b/c/d) } \\
\text {-Plan long-term management plans and strategies } \\
\text { (b/c/d) } \\
\text {-Promote scientific reports and master plans (b/c/d) } \\
\text {-Address scuba diving specialization (c/d) } \\
\text {-Guide underwater behaviours of scuba divers (c/d) } \\
\text {-Cooperate between stakeholders and residents (c/d) } \\
\text {-Transparency with respect to revenue (c/d) } \\
\text {-Put together tourism services (c/d) } \\
\text {-Make effective pre-dive briefings (c/d) } \\
\text {-Govern and/or self-regulation, actively (d) } \\
\text {-Create socially responsible programs (a/d) } \\
\text {-Reduce economic leakages (d) } \\
\text {---------- } \\
\text { *Exhibit sustainable practices (a/d) } \\
\text { * Give priority to local qualified employees } \\
\text { (c/d) } \\
\text { *Protect local culture (d) } \\
\text { *Supervise local customs and traditions } \\
\text { (d) }\end{array}$ \\
\hline
\end{tabular}


Herewith, 48 key sustainability criteria were extracted from the current literature review related to SDTS with 12 descriptive grounds, 5 normative aspects and 31 instrumental grounds (as can be seen in Table 4.1 and Table 7.1). It is evident that normative aspects are the least emphasised sustainability criteria within the current SDTS approaches. On the contrary, instrumental grounds are the main subject of existing SDTS while descriptive cores were relatively well indicated. To have a better insight, four categories, which are inspired by $5 \mathrm{~S}$ Themes, have been created that identify the context and function of the sustainability criteria in the SDTS. These are (a) Marketing; (b) Analysing; (c) Planning (with monitoring); and (d) Protecting (by managing), in short MAP+P. The MAP+P refers to 5S Themes in order to better understand the current issues and potentials $(\mathrm{M})$ in general, strain and stress factors (A), sustain and supervise $(\mathrm{P})$ and support $(\mathrm{P})$. For example, promoting scuba diving tourism in the destination is instrumental and is related to marketing (a); analysing attitudes and behaviours of scuba divers are analysing (b) and descriptive; promoting scientific reports and master plans to planning (c) is instrumental while monitoring the environment as descriptive in the same category; agreement in planning and management is protecting (d) and instrumental with creating and regulating conservation-oriented norms in the normative ground. In each category, all items were addressed according to their impact and operational capability in the SDTS.

In detail, the marketing dimension constitutes promotional elements that can help the advertisement. Having a well-balanced management tool can create marketing strategies that help to achieve the ideal planning and organisation. The criterion of marketing has an important role in rewarding the implications (for example clean-up events) and giving importance to them (having healthy sea conditions), which can raise awareness among stakeholders and encourage them to act. Analysing is an important dimension that demonstrates the impacts of each element according to operational capacity which relates to an understanding of impacts to some extent of knowledge. Analysing can help to create more comprehensive managerial implications before employing precautions and final decisions by having measurement tools to eliminate unpredicted negative impacts. Planning ensures effective management tools and is being formed by constituents which need to be taken into consideration to ensure the implementation of principles of sustainability in the destination. Planning can have long-term management principles to ensure marginal benefits in economic efficiency and social equity while protecting the marine environment. Creating better visitor regulations and consulting, in collaboration with external organisations and scientists, are important acts of the planning process. The last 
dimension, which is essential for the scuba diving tourism system overall, protecting, helps to secure present and future values by having good management tools in the SDTS. Strategies related to protecting can also help to create well-established organisational enforcement capacities in the destination and the subdivisions of managerial implications. To be able to manage the scuba dive sites and the destination, sustainability criteria regarding protecting can become important methods for three grounds of stakeholder theory.

As a consequence, establishing a proper SDTS in sense of sustainability criteria of which are adeptly monitored, skilfully supported, expertly planned and adequately analysed rely on employing effective descriptive, instrumental and normative grounds. In this sense, 5 descriptive grounds, 10 normative aspects and 4 instrumental grounds (in total 19 new items) have been added by the researcher which originated from narratives of stakeholders related to the research topic. These criteria provide a rich insight into sustainability in the scuba diving tourism system development dependent on normative aspects. Each item represents different but integrated dimensions that needed to be evaluated independently but interrelatedly. For instance, establishing moral and ethical values for the SDTS and understanding narratives about the principles of sustainability can enrich the main purpose of the system based on normative foundations among stakeholders. Besides, encouraging responsible underwater behaviours and being a role model to others can be considered as generating the values of protecting. In this way, the whole SDTS can achieve sustainable development aims. Besides, recently Edney et al. (2021) found that scuba divers touch objects/artefacts (mostly) intentionally during the wreck diving; therefore, monitoring the scuba diver and understanding such unsustainable behaviours can help to have better management in scuba dive sites. Hereby, on the grounds of normative aspects, sustainability criteria can be assessed comprehensively with regards to the source of knowledge; moral and ethical values; collaborative efforts in functional planning; implementation of fundamentals; effective management; recovery; and enforcement procedures within the SDTS which are subject to the sustainable scuba diving tourism development principles. If the SDTS is regulated comprehensively and effectively according to principles of sustainable development standards based on distinguishing features of the destination, to the greatest extent possible, it can be transformed from threats into a positive -transformative- contribution which increases awareness; educate stakeholders from scuba divers to the local community; and can provide optimal social and economic benefits. 


\subsection{The Sustainable Scuba Diving Tourism System (S-SDTS)}

Given the current state of SDTS, the system may need a new structure that is redesigned to address contemporary issues and ensure the benefits for all stakeholders. It is expected that an effective systems model for scuba diving tourism promotes socio-economic benefits while providing a unique scuba diving experience (Wongthong \& Harvey, 2014) whilst protecting the marine environment. For achieving optimal sustainability in scuba diving tourism, a new model for the SDTS includes the relationships among the constituents and values derived from sustainable scuba diving tourism development principles. Therefore, the normative aspects can become important constituents of ensuring optimal sustainability in the SDTS. In this respect, normative aspects can provide stakeholders with principles and space that they can use their knowledge and skills to create effective strategies (Freeman \& McVea, 2001) for sustainable scuba diving tourism development goals within the SDTS. The normative aspects can help stakeholders identify the value and purpose of the system (Freeman, 1999) in accordance with the management and enforcement capabilities. Furthermore, the moral and ethical values of organisations within the system can be embodied through identifying the normative aspects according to principles of sustainability comprehensively according to fair practices which can represent the interests of stakeholders (Evan \& Freeman, 1988; Friedman \& Miles, 2006). For example, through data of this study, basic information sources (such as localised pre-diving briefings) can be created about the consequences of strain (1/5S) or stress $(2 / 5 \mathrm{~S})$ effects on the system as well as raising awareness about the current state of the marine environment through the ethical and theoretical foundation (Freeman, 1994; Freeman et al., 2004). Moreover, normative aspects can develop organisational capacity about practical implications which can be accommodated by stakeholders into descriptive and instrumental value to create optimal sustainability within the system.

Although there is no ideally characterised value for the system (Baggio, 2008; Hall, 2008), normative aspects can establish and formulate the fundamental values related to the source of knowledge and interests in the SDTS which can be reckoned by all stakeholders who seek to get benefits from scuba diving tourism. In a broad sense, having certain results as a result of certain actions depend on well-recognised moral and ethical values which emerge from the normative base of stakeholder theory (Freeman, 1994; Donaldson \& Preston 1995; Freeman, 1999; Freeman \& McVea, 2001; Freeman et al., 2004; Friedman \& Miles, 2006) that 
explain the stakeholders' behaviour and their acts (Theodoulidis et al., 2017). When these actions come together and start affecting the SDTS, problems emerge, therefore, solutions to address these problems require collaborative efforts of the associated stakeholders. All stakeholders can act to meet common interests according to their capacity, role, position, and power and establish a successful sustainable scuba diving tourism development by taking responsibility. In these regards, the above-mentioned constituents and foundations integrate the fundamental sets of elements; explain the function of the system; help to create the contemporary systems approach regarding the current issues and future implications; and build moral and ethical values between the constituents and the environment (Hall, 2008) which are interconnected, interdependent and interacting (Laszlo \& Krippner, 1998) with each other constantly. Furthermore, the SDTS can be dependent on well-planned comprehensive and contemporary collaborative management initiatives (Giglio et al., 2020) including regular and long-term communications (Lucrezi et al., 2017; Scholtz \& Saayman, 2018); continuous monitoring (Sterling et al., 2017); activity plan and guidelines (Trave et al., 2017); and a platform for sharing responsibility (Sharma-Wallace et al., 2018) in establishing education and enforcement standards in the destination.

This study presents a new model for the SDTS and from now on will be denominated as `Sustainable Scuba Diving Tourism System`, in short S-SDTS. The meaning of the system; formulation of the values; implementation of the system; evaluation of both environmental and socio-economic impacts derived from decisions; and actions based on sustainability (Starik \& Kanashiro, 2013) become the main functions and purpose of the S-SDTS. For this purpose, Goeldner and Ritchie (2009)'s subdivisions of tourism system creation are employed to define the meaning and the value of the S-SDTS. In this connection, (1) the definition of the S-SDTS is to understand the meaning of principles of sustainability in scuba diving tourism. (2) Philosophy of the S-SDTS refers to achieving the best sustainable development goals in scuba diving tourism with a collaborative effort. (3) Vision of the S-SDTS stands for creating sustainable scuba diving tourism development based on the local specifications with contemporary approaches and solutions. (4) Positioning and branding strategies represent how stakeholders can value the S-SDTS according to shared interests. (5) Development of the SSDTS provides a better planning capacity for stakeholders. (6) Competitive and collaborative analyses of the S-SDTS ensure a systematic approach to evaluate the current situations of the issues and future implications indicated in the 5S Themes. (7) Monitoring and evaluation of 
the S-SDTS help stakeholders to improve the system while addressing the normative aspects according to principles of sustainability sufficiently. (8) Destination audit of the S-SDTS identifies the destination future to maintain the value of scuba diving tourism. The S-SDTS is established on the normative aspects according to principles of sustainability as the core elements of the system and depend on attributes, capacities and interests of stakeholders and shared moral and ethical values which are the key determinants to shape this system.

The S-SDTS model is created based on the three independent but interrelated groups of theories, Stakeholder Theory (Freeman, 1984) with three grounds (Donaldson \& Preston 1995); General Systems Theory (von Bertalanffy, 1947, 1955, 1972), and Living Systems Theory (Miller, 1978); and Normative Theory (Jeager \& Sekznick, 1964). Overall, the Stakeholder Theory explains and clarifies the constituents of the S-SDTS; the role of the stakeholders within the S-SDTS; the degree of the stakeholders`capacity in terms of the impacts and contributions of which stakeholders can be influenced negatively or affect the system constructively. However, the main critique of stakeholder theory, which S-SDTS fundamentally relies on, is that this theory only focuses on managerial aspects and suggests if managers follow the laws and regulations stakeholders can have a better understanding of the system (Donaldson \& Preston 1995; Freeman et al., 2004; Friedman \& Miles, 2006). Therefore, to increase the insight of the S-SDTS, the Systems Theory is used to identify the meaning of the S-SDTS; the purpose of the S-SDTS; and the functions of the S-SDTS. Following, the Normative Theory describes the values that depend on the triple bottom line of sustainability principles which are acknowledged by stakeholders in the S-SDTS as moral and ethical values. With this design based on theoretical and philosophical foundations, the S-SDTS model is redesigned by addressing centrality; contextual; design; goal; information; operational; and viability (Adams, 2012, p. 220). In this sense, the centrality of the S-SDTS relies on principles of sustainability as the main value, because it is the point of departure for conveying the message and creating communication. The context of S-SDTS is to improve the current capacity and ensure the future of scuba diving tourism concerning moral and ethical values derived from principles of sustainability. The narratives create sustainability criteria based on three grounds of stakeholder theory and this set of knowledge for the system is to use to improve the S-SDTS at present and in the future. The goal of the S-SDTS stands for achieving the optimal result with marginal benefit and improving the performance of scuba diving tourism according to principles of sustainability. Besides, the goal explains the aim of the 
system for associated groups, brings them together and encourages them to act. The information of the S-SDTS is established on providing the knowledge which is required to execute the system. Moreover, information provides values, possessing the meaning of the system, transferring knowledge, and modifying the practices according to the goal of the SSDTS. The operational capacity of the S-SDTS guides associated stakeholders to how can manage the system in-situ and improve the achievement. The viability of the S-SDTS addresses a better design that includes the process, existing circumstances, and future implications to ensure a working and operational system in which stakeholders can contribute and involve in.

The S-SDTS model increases the cognitive awareness in the sense of normative aspects (Goodpaster, 1991; Goodpaster \& Holloran, 1994; Boatright, 1994; Clarkson, 1995; Quinn \& Jones, 1995) and the capacity of narrative interpretation regarding moral and ethical behaviours of stakeholders (Jeager \& Sekznick, 1964; Jones \& Wicks, 1999). These behaviours rely on knowledge; collective effort and full participation by sharing common interests; and understanding the importance of the marine environment according to principles of sustainability. In this respect, the sustainability criteria related to $\mathrm{MAP}+\mathrm{P}$ based on three grounds of stakeholder theory can help stakeholders to develop or improve their behaviour in accordance with the purpose of the S-SDTS. Because the MAP+P addresses the principles and standards which are influenced by the attitude of associated groups; enhancing scientific thoughts through knowledge; and making practices more meaningful. Within this context, as inspired by Wheeler and Sillanpää (1997) the new model for S-SDTS (as can be seen in Figure 7.3) is designed to reflect the degree of influences of the associated stakeholders; literature review; results of this thesis derived from the field study; revisited constituents and foundations of the SDTS; and existing and newly generated sustainability criteria -MAP+P. For this purpose, the system cluster is divided into three levels of stakeholder scheme in five stages. Thus, redesigning the current SDTS and transforming the fundamentals into the S-SDTS model through defining normative aspects according to principles of sustainability provides a better understanding of moral and ethical values. In this way, it is aimed to present a more meaningful and functional systems approach by expanding the constituents of the S-SDTS according to the roles determined in the system and the individual capacities of the stakeholders. 


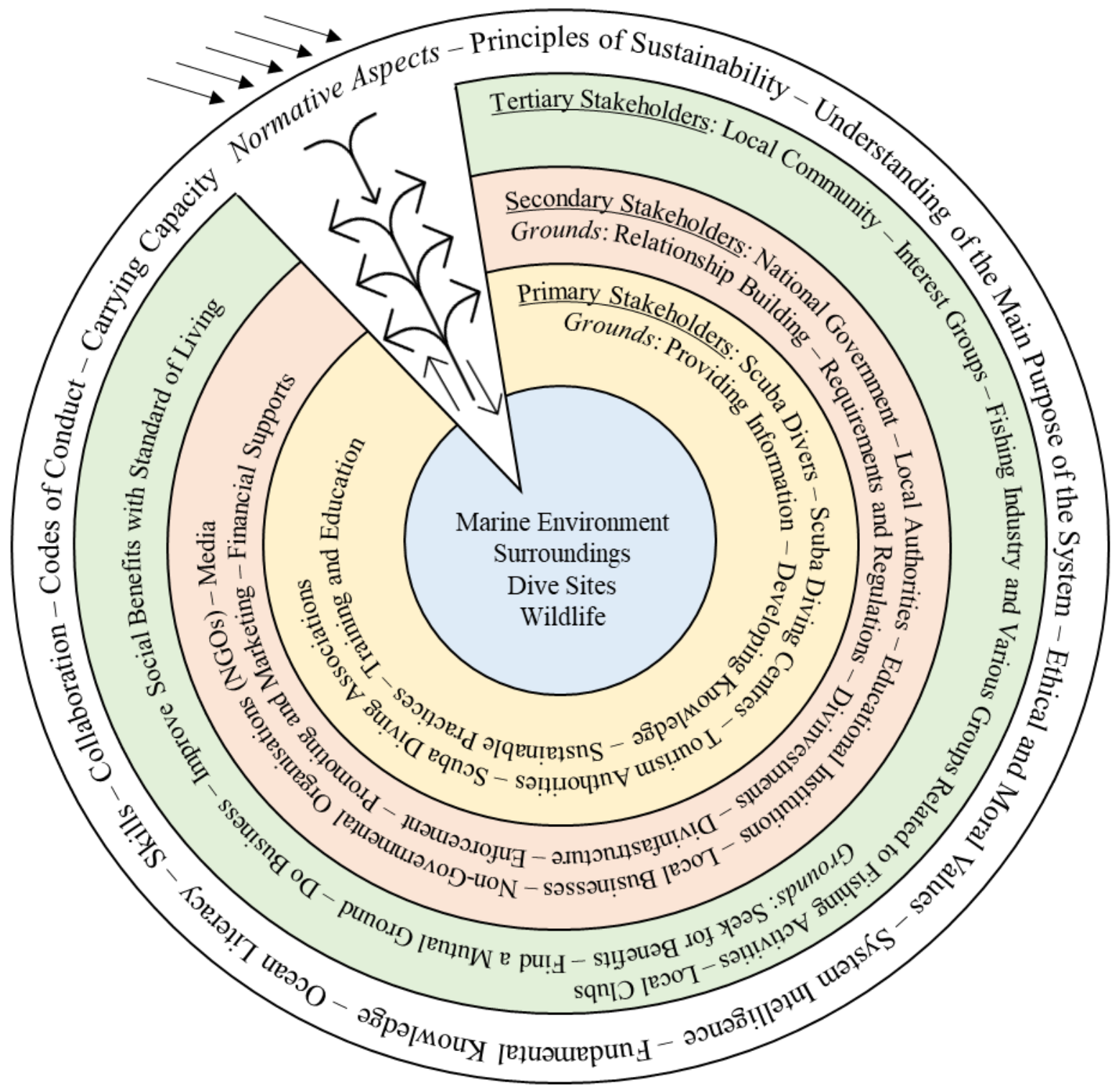

Figure 7.3. Sustainable Scuba Diving Tourism System (S-SDTS) 
In the S-SDTS model, the first group of stakeholders situate as primary stakeholders including scuba divers, scuba diving centres, tourism authorities and scuba diving associations, which are directly related to scuba diving tourism practices. They are either influenced or affect the system first-hand. In this category, local or international scuba divers; scuba diving centres owners, managers and employees as instructors and interns; authorities related to scuba diving tourism as administrator and policymaker; local and international scuba diving associations and agencies as education, knowledge, standards, and codes of conduct providers are the fundamental constituents of S-SDTS model. The normative aspects of primary stakeholders are providing information, developing knowledge, implementing sustainable practices, and regulating training and education processes to ensure a sustainable and proper in-water operation in the system.

Developing policies that fitted with the interests of stakeholders (Byrd, 2007) or increasing the body of knowledge (Yuksel et al., 1999) become effective solutions that can strengthen the meaning of the organisation and improve the normative analysis capacity within the system. For this reason, the secondary group of stakeholders in the S-SDTS is comprised of the national government as the main policymaker and decision-maker; local authorities who are localised and specialised policy implementers along with the enforcement authority; educational institutions (universities and research offices, whichever is appropriate according to the destination structure) which are knowledge providers and organise research activities. Local businesses such as scuba diving gear and air suppliers, hotels, restaurants, airports, transport and related suppliers or foundations like banks, financial supporters, and other agencies; Non-Governmental Organisations (NGOs) as pressure groups like Green Fins initiatives as indicated earlier in this study; and media actors are involved in the S-SDTS as secondary stakeholders. They can be considered as agencies for promoting and marketing, publicity and raising awareness at both local and international levels. Stakeholders in the secondary group can have direct effects on the S-SDTS to some extent. As Garvare and Johansson (2010) emphasise, if their interests or expectations are dominating or unclear in the system, this ambiguity and contradiction may cause a destructive effect. On the contrary, the positive contributions of these stakeholders can enrich the quality and operational capability of the S-SDTS. Secondary stakeholders can have different responsibilities according to their realm of authority to keep the S-SDTS in an organised and well-managed structure and provide safety measures for each constituent. The normative aspects of this cluster can be ordered as 
relationship-building among related and associated stakeholders; addressing requirements and regulation-making and implementing; promoting divinvestments and divinfrastructure and increasing the enforcement capacity; and developing marketing strategies and financial supports for the system. Therefore, not only in-situ management but also on-water and outwater management practices can be provided by the group of secondary stakeholders.

The last group, as tertiary stakeholders, even though they are not considered to be involved directly in the S-SDTS, are individuals or groups, whose activities may affect the system. Nevertheless, the unfavourable activities within the system can affect their benefits, in this case, they may like to be part of future decisions or primary and secondary stakeholders in the S-SDTS may like to involve them in this process for some reasons. Tertiary stakeholders usually consist of the non-scuba diving related local community as hosts and local people; interest groups as organised or non-organised group of people like environmental activities; non-related businesses; fishing industry and various groups related to fishing activities such as commercial, artisanal, or spearfishing; and local clubs like a non-profit scuba diving club. However, for example, unsustainable daily or operational actions of tertiary groups may cause devastating consequences such as the degradation of the marine population or create marine pollution. For example, according to the data of this thesis, some activities such as unsustainable fishing and unregulated fisheries have the most adverse impact on the marine environment in Malta. In such a case, fishing activities decrease marine population, local communities related to fishing activities increase the level of marine pollution because of unsustainable practices and ignorance, consequently, environmental activists in collaboration with local scuba diving clubs or other stakeholders in primary and secondary clusters can take a role to protest or force the government to act. Every single stakeholder can be affected by the sustainable or unsustainable actions of other stakeholders, therefore, the whole ecosystem of the S-SDTS can be influenced constructively or drastically according to the consequence of certain action/s. The grounds of the tertiary group of stakeholders are to seek benefits from the S-SDTS; try to find mutual ground to collaborative action or the problem-solving process; extend their business operations and capacities; and improve social-economic benefits by enriching the standard of living.

The success of the S-SDTS is subject to building a proper and balanced relationship between stakeholders and the marine environment. A well-balanced relationship can provide a 
better understanding of their position and capacity. However, a system can become a complex phenomenon due to the lack of intersectoral and cross-department collaboration (Lucrezi et al., 2017; Scholtz \& Saayman, 2018; Garcia \& Cater, 2020). Therefore, the core constituents of the S-SDTS are the marine environment and its surroundings; MPAs or protected areas; natural or alternative dive sites; and healthy wildlife abundance (as non-human stakeholders). The core determines the fundamental relationship-building process all stakeholders depend on and represents the main value of the network in the S-SDTS. Therefore, the marine ecosystem must be well evaluated and, more importantly, treated in terms of reducing threats and increasing the optimal carrying capacity. Environmental threats which are directly or indirectly related to marine surroundings can be taken into consideration by all stakeholders in the S-SDTS as part of management initiatives. In addition to that, a better understanding of the outcomes of sustainable development practices in the marine environment can provide advantages to control both current issues and enrich the future implications to achieve the sustainable development goals in the destination. A better understanding of the outcomes can also encourage authorities to create well-designed planning; have successful marketing strategies; establish efficient monitoring; implement proper and powerful enforcement within the effective implementation of management; and increase protection capacities in-situ and out-water environments. Ensuring enforcement and constant monitoring in the marine environment can be one of the most effective ways to be able to implement normative aspects into the system while trying to enrich the scuba diving experience and addressing the stakeholders interests in the S-SDTS.

The foundation of the interactive relationship in the S-SDTS based on knowledge sets a working and proper system (Adams, 2012; Adams et al., 2014) for associated groups, practitioners, and the environment. However, scuba diving tourism has different micro and macro influences that affect the system (Fletcher et al., 2017). For example, in the marine setting, it is almost impossible to control the involvement of stakeholders and their influences. Stakeholders can enter or leave the system without notice and may influence it with a constructive or destructive effect. In a sense, exchanging knowledge (Miller, 1978) and the interaction between the parts and relationship (Laszlo \& Krippner, 1998) with the surroundings manifest as a system as open and self-organising. Therefore, the S-SDTS has been designed as an open system to diffuse normative values and principles into wider society. Moreover, it is advocated that if a stakeholder intended to enter the system, normative aspects of the S-SDTS should be internalised before seeking benefits or taking any advantages. 
Overall, providing an unusual and unique scuba diving experience relies on forming and developing the S-SDTS in terms of improving training and education quality for responsible scuba diving; taking essential health and safety measures; having proper implications for sustainable scuba diving tourism outcomes; better understanding current issues and future implications; determining the standards; and evaluating the impacts of stakeholders actions and uncontrollable events. Besides environmental threats such as climate change, unexpected events like the Covid-19 pandemic, economic crisis and political conflicts could be the area of interest of stakeholders in the S-SDTS from time to time. Therefore, collective efforts and constant communications between all stakeholders become one of the important matters in the S-SDTS to achieve sustainable tourism development goals and address the constituents interests. All stakeholders in the S-SDTS are dependent on certain relations with certain outcomes. With this regard, certain characteristics of the S-SDTS in the sense of normative aspects according to principles of sustainability are to be acknowledged as common purpose such as understanding of the main purpose of the system; identifying the strain and stress factors; establishing ethical and moral values; creating system intelligence; providing fundamental knowledge; increasing ocean literacy; developing skills; ensuring collaboration; defining codes of conduct; and measuring optimal carrying capacity. 
CHAPTER 8: CONCLUSION

\subsection{Introduction to Chapter 8}

\begin{tabular}{|c|c|c|c|c|c|}
\hline $\begin{array}{c}\text { Chapter } 1 \\
\text { Introduction }\end{array}$ & & \begin{tabular}{|c|c|c|}
$\begin{array}{c}\text { Overview } \\
\text { and } \\
\text { Introduction }\end{array}$ \\
\end{tabular} & $\begin{array}{l}\text { Research } \\
\text { Outline }\end{array}$ & $\begin{array}{l}\text { Chapter } \\
\text { Reviews }\end{array}$ & \\
\hline $\begin{array}{c}\text { Chapter } 2 \\
\text { Scuba Diving Tourism }\end{array}$ & $\begin{array}{l}\text { Discovering } \\
\text { the } \\
\text { Underwater }\end{array}$ & $\begin{array}{l}\text { Scuba } \\
\text { Diving } \\
\text { Economy }\end{array}$ & $\begin{array}{c}\text { Scuba } \\
\text { Diving } \\
\text { Experience }\end{array}$ & $\begin{array}{l}\text { Current } \\
\text { Issues }\end{array}$ & \\
\hline $\begin{array}{c}\text { Chapter } 3 \\
\text { Sustainability }\end{array}$ & $\begin{array}{c}\begin{array}{c}\text { Sustainable } \\
\text { Tourism } \\
\text { Development }\end{array} \\
\end{array}$ & $\begin{array}{c}\text { Division } \\
\text { and } \\
\text { Concept }\end{array}$ & \begin{tabular}{|l} 
Current \\
Practices in \\
Scuba \\
Diving \\
\end{tabular} & $\begin{array}{l}\text { MPAs and } \\
\text { Alternative } \\
\text { Dive Sites }\end{array}$ & \\
\hline $\begin{array}{l}\text { Chapter } 4 \\
\text { Theoretical Foundation }\end{array}$ & $\begin{array}{l}\text { Normative } \\
\text { Theory }\end{array}$ & $\begin{array}{l}\text { System } \\
\text { Theories }\end{array}$ & $\begin{array}{l}\text { Stakeholder } \\
\text { Theory }\end{array}$ & SDTS & $\begin{array}{l}\text { Identifying } \\
\text { the Gap }\end{array}$ \\
\hline $\begin{array}{c}\text { Chapter } 5 \\
\text { Methodology }\end{array}$ & $\begin{array}{l}\text { Research } \\
\text { Framework }\end{array}$ & $\begin{array}{l}\text { Research } \\
\text { Strategy }\end{array}$ & $\begin{array}{l}\text { Research } \\
\text { Ethics }\end{array}$ & $\begin{array}{c}\text { Limitations } \\
\text { in } \\
\text { Methodology }\end{array}$ & $\begin{array}{c}\text { Field Study } \\
\text { Area }\end{array}$ \\
\hline $\begin{array}{c}\text { Chapter } 6 \\
\text { Results }\end{array}$ & Strain & Stress & Sustain & Supervision & Support \\
\hline $\begin{array}{l}\text { Chapter } 7 \\
\text { Discussion }\end{array}$ & & $\begin{array}{l}\text { Inferences } \\
\text { and Links }\end{array}$ & $\begin{array}{l}\text { Constituents } \\
\text { and } \\
\text { Foundations }\end{array}$ & $\begin{array}{l}\text { Revised } \\
\text { Sustainability } \\
\text { Criteria }\end{array}$ & $\begin{array}{c}\text { S-SDTS } \\
\text { Model }\end{array}$ \\
\hline $\begin{array}{l}\text { Chapter } 8 \\
\text { Conclusion }\end{array}$ & & $\begin{array}{l}\text { Ans wers to } \\
\text { Research } \\
\text { Questions }\end{array}$ & Implications & Reflection & Limitations \\
\hline
\end{tabular}

Figure 8.1. The Structure of Chapter 8

This chapter covers the overall conclusion of the thesis (as can be seen in Figure 8.1). In the first instance, research questions are answered to reveal the results examined by this study. Next, philosophical, theoretical, managerial, and practical implications are given to have a better understanding of the contributions and outcomes of this thesis. A reflection of the journey of the researcher is also given in this chapter. Lastly, this chapter presents the overall limitations of this study and recommendations for future studies. In general, the study redesigned the present SDTS into S-SDTS by identifying sustainability criteria through defining normative aspects. This showed how sustainable scuba diving tourism development principles can help associated stakeholders in order to protect the marine environment; address their interests; improve their capacity and skills; find their responsibility within the system; 
meet local needs; and generate economic income while providing unique subaqueous scuba diving tourism experience to the scuba divers.

To give the main contributions of the results of this study, as theoretical implications, this study redesigned the present scuba diving tourism system to enhance the value of the system through defining the normative aspects based on the mutual moral and ethical values according to principles of sustainability. By doing this, the value of the system has been explained by the relationship between stakeholders and the marine environment. Employed theories helped to better understand the current phenomenon and characterised the meaning of the S-SDTS. Moreover, the 5S Themes provided a contemporary insight for the S-SDTS including both negative impacts on scuba diving tourism and the possible positive contributions. This study contributed to theories in terms of enhancing the narratives, identifying the responsibilities and fundamentals of the system`s function, and clarifying the roles of stakeholders in the scuba diving tourism context. For this, the scuba diving tourism system was redesigned with a theoretical approach that identifies the roles of associated stakeholders within the system. In addition, nineteen new sustainability criteria were added into the theoretical background of the scuba diving tourism system`s literature as a result of research findings to the current. The criteria model was named MAP+P that refers to Marketing, Analysis, Planning and Protecting the value of the S-SDTS. The MAP+P`s items were derived from the narratives of different stakeholder groups on the basis of normative aspects for the S-SDTS. Overall, in line with the moral and ethical values, the main purposes of this study were to provide a better understanding of the interests of (1) how to protect the marine environment while addressing stakeholders` interests and needs of the system; (2) how to generate sustainable economic revenue; (3) how to improve the quality of local life in the destination; and (4) how to maximise the unique subaqueous scuba diving tourism experience through defining the normative aspects of the S-SDTS according to principles of sustainability.

\subsection{Answers to Research Questions}

If planned and managed properly, scuba diving tourism can provide a unique experience to visitors with significant financial contributions to the local economy while interacting with the fragile marine ecosystem. For this, implementations regarding principles of sustainability are required to protect the marine environment to establish well-planned management strategies; and address the interests of associated stakeholders in scuba diving tourism within 
a contemporary systems approach. However, whether the value and meaning of principles of sustainability are properly understood or implemented is hard to evaluate. This thesis, therefore, highlighted the meaning and effectiveness of normative aspects in the sense of moral and ethical values within the scuba diving tourism system to improve the knowledge of the principles of sustainability and its implications. The main purpose of this approach was to redesign the scuba diving tourism system by reinterpreting ethical and moral values which are interrelated with sustainable scuba diving tourism development principles and its standards. By doing so, it was aimed to enhance the function of the SDTS while using the fragile marine environment for recreational purposes. The main research findings were based on a qualitative analysis of stakeholders' experience in response to the systems approach. Rather than only emphasising the descriptive and instrumental cores for the system as indicated in the previous versions of SDTS, this study redesigned the SDTS in the sense of a sustainability-based scuba diving tourism system through defining the normative aspects. The results indicated that the normative foundations of current SDTS in Malta constituted by the 5S Themes need to be revised by understanding the value of the system and its sustainability criteria. Therefore, the main research and sub-research questions of this study are answered as follows to have a better insight into the current phenomenon:

- To what extent do the normative aspects of the scuba diving tourism system address principles of sustainability?

This study showed that although there was some knowledge about sustainability among stakeholders, practices did not match how it is supposed to be in the current SDTS in the sense of the principles of sustainability in Malta. This result also shows similarity with the current literature discussion as documented in this study. This is because knowledge of sustainability is not internalised as the main ground of the SDTS. These negative effects can be reduced by collaborative effort within the SDTS and better implications regarding sustainability. Nevertheless, measures or precautions related to implications are taken into practice by stakeholders individually in Malta but remain insufficient. Therefore, normative aspects of SDTS are not addressed sufficiently with regards to optimal sustainable scuba diving tourism development goals. To improve the scuba diving tourism system according to principles of sustainability in the sense of moral and ethical values, this study introduces a new systems model for SDTS through defining the normative aspects. To develop a new system model, 
sustainability criteria related to SDTS were revised and reinterpreted according to the function and meaning of the new model which is the Sustainable Scuba Diving Tourism System (SSDTS). To better understand the phenomenon in question, the following five sub-questions extend the details about current issues which were employed and examined in this thesis.

(1) How do stakeholders understand principles of sustainability in the scuba diving tourism system?

The results clarified that understanding of the principles of sustainability its practices in the current SDTS in Malta was not adequate. Although, some in-business practices regarding sustainability such as recycling or reducing plastic use are taken by scuba diving centres as the main operational practices, major issues such as reducing carbon emissions or contributing to social equity and addressing future generations needs have not been emphasised sufficiently. Besides, scuba diving centres individually organise clean-up diving events as the implication of in-situ practices regarding sustainable practices. If these events were promoted in a broad perspective with a collective effort within the SDTS, this can increase awareness among directly associated or interested stakeholders and contribute to the sustainable scuba diving tourism development goals in Malta. Establishing or defining the normative aspects of S-SDTS according to the principles of sustainability and its sustainability criteria can help stakeholders to increase the value, function, and understanding of the purpose of the system. Therefore, the S-SDTS aims to fill this gap.

(2) How do stakeholders prepare operational plans and provide regulations to manage the system with control activities for the sustainable use of scuba dive sites?

According to the findings of this study, there was not a systematic approach, and each stakeholder acts in a manner of individual interests. During the field study, conflict of interest regarding regulations or limited decision makings capacity about managing the scuba dive sites emerged as the major problems among stakeholders of the current SDTS in Malta. Malta aims to increase the artificial dive sites capacities to have a competitive advantage among similar destinations. However, planning, submerging, and operating these sites are not taken with a systematic approach. Besides, improving or protecting the existing natural dive sites capacities are not in operational plans, therefore, implementation of principles of sustainability on these sites are not emphasised sufficiently. This resulted from a lack of operational and enforcement 
capacities and conflicts (see Appendix 16) according to the given statements. As a result, redesigning the S-SDTS through defining the normative aspects according to the triple bottom line of sustainability can help stakeholders to have a joint responsibility in the systems approach for preparing operational plans; managing the scuba dive sites; regulating carrying capacity; and increasing the enforcement capabilities. Moreover, sustainability criteria on the basis of normative aspects can provide better insight for stakeholders to act morally and ethically and have future decisions based on their interests and destination`s needs.

(3) How do stakeholders address the triple bottom line of sustainability while interacting with the marine environment within the scuba diving tourism system?

As indicated in this thesis, even though certain sustainable practices are taken by scuba diving centres or by scuba divers as individual self-regulation, these practices remain limited to eliminate the adverse effect on the marine environment in Malta. To be more precise, in reference to ecological integrity, scuba diving centres have certain but not joint and fully regulated practices such as clean-up events, recycling and encouraging both scuba divers and employees to use less plastic. In terms of scuba divers, they are likely to have self-regulation while interacting with underwater surroundings such as avoiding damage due to touching or interfering with the wildlife or increasing the skill of buoyancy. From the administrative point of view, sustainable implications regarding ecological integrity have not been emphasised sufficiently. Even though they have knowledge about current issues in Malta, implications are not practised adequately. For example, there are no regulations regarding overfishing or spearfishing which affect the fish population and variety in scuba dive sites and cause safety issues. In terms of social equity, there is a huge gap between the host community and the scuba diving industry in Malta. Except for a few owners of scuba diving centres in Malta, the host community are not involved directly in the scuba diving tourism industry in Malta. In addition, it is hard to evaluate the degree of benefits from scuba diving tourism that has been taken by local people. Moreover, there are almost no systematic implications regarding increasing the quality of social life or meeting the local needs. From the academic perspective, stakeholders are more aware of the negative consequences of unsustainable practices, however, due to a lack of communication, limited enforcement capacity and insufficient collaborative effort among stakeholders, no effective implementations are carried out presently to improve the social 
equity in Malta. Therefore, social equity remains one of the most controversial issues specifically to achieve sustainable scuba diving tourism development goals in Malta.

In the aspect of economic efficiency, even though the current situation of scuba diving tourism in Malta is getting improved regarding trends in revenue and the number of scuba divers, a lot of negative issues are mentioned by stakeholders. As to principles of sustainability, practices are only taken into consideration for the economic benefits for those who run a business in the scuba diving tourism industry in Malta. Therefore, there are poor linkages between scuba diving tourism and the triple bottom line of sustainability. These issues are likely to negatively affect the future of scuba diving tourism and the SDTS in Malta. Concerning the balance among, social equity, economic efficiency and ecological integrity, no strong link has been found in Malta, rather they intend to continue to have their economic revenue by practising little implications regarding sustainable scuba diving tourism development principles. For this reason, allocating the individual and group responsibilities with effective actions through redesigning the SDTS can guide stakeholders to have better practices. Moreover, emphasising sustainability criteria within the normative aspects can help stakeholders to have enhanced decision making to solve problems of current issues, and design future implications. In the sense of finding mutual ground based on the triple bottom line and solving the problems, the S-SDTS and its foundations with sustainability criteria can give advantages to stakeholders to have a better understanding of the current issues and employ sustainable scuba diving tourism development practices in Malta.

(4) How do stakeholders accommodate personal knowledge about principles of sustainability and their skills in the scuba diving tourism system?

This study pointed out that there is no systematic approach in Malta to accommodate personal knowledge about principles of sustainability into the SDTS. Therefore, limited knowledge does not bring sufficient evidence in the SDTS related to protecting the marine environment, improving social equity, and generating economic revenue. This is because normative aspects of the SDTS were not stressed enough for associated stakeholders. Therefore, revisiting the SDTS in accordance with normative aspects based on sustainable scuba diving tourism development principles can provide advantages for stakeholders to increase their management/operational capacity and have a better understanding of their skills in the SDTS. So, they can act according to their responsibility. To set an example, from a tourist 
perspective, the characteristics of scuba divers are not comprehended sufficiently. For example, it is considered that the important indicator related to scuba divers is about certification and education level that is constituted by skills, knowledge, taking courses and number of dives. However, the previous experience and motivation of the scuba divers in the sense of learning process; the reason and willingness to dive; and in-situ behaviours or interactions between scuba divers and the marine environment during the activity also have a significant effect on the scuba diving experience and their decision-making process. This expanded decisionmaking process includes various and multiple angles such as destination image, health condition, safety (country, region), perceived risk, effective marketing strategies, being present in social media, using interactive media tools, personal benefits, and limits. Besides, different indicators abovementioned constitute a varied range of moral and ethical values in many aspects which have an important influential role on scuba divers such as building more sustainable underwater behaviour. Therefore, each process and event may have unique characteristics and different evaluation criteria as part of providing the experience. Furthermore, ocean and sea health are the key factors for positive scuba diving experiences. For this reason, the marine environment as the core constituent in the S-SDTS becomes the most important factor while aiming to provide a unique scuba diving experience.

(5) How do stakeholders recognise the philosophical, theoretical, and managerial cores as the normative aspects of the scuba diving tourism system?

Overall, the results showed that there was a dearth of understanding of philosophical, theoretical, and managerial cores of the normative aspects in the existing SDTS in Malta among associated stakeholders. This resulted from a lack of knowledge about principles of sustainability and the purpose of the system based on normative aspects of the SDTS as moral and ethical values. Therefore, stakeholders have a limited comprehension of what they see and perceive different interests, experiences and skills, knowledge and symbolic meaning which conceptualise the reality and purpose of the SDTS. As a result, only by being involved as part of stakeholders in the SDTS (as scuba divers or other groups according to their role) does not contribute to the theoretical and managerial implications without having meaningful knowledge regarding current issues and purpose of the SDTS. Therefore, the main purpose of this study is to redesign the SDTS by emphasising the normative aspects according to principles 
of sustainability in scuba diving tourism by providing more meaningful values and encouraging stakeholders to be involved in contributing positively.

Based on answers given to the research questions, this study offered a new perspective of the scuba diving tourism system by employing the phenomenological approach and an interpretive paradigm in the sense of the qualitative method. In addition to this, to strengthen the results, in-situ observation via active participation was used to have a better insight into the scuba diving tourism system related to sustainability knowledge and its practices. Moreover, the understanding of sustainability in the SDTS was re-evaluated according to the impact of current practices with a systematic approach that depends on the General Systems Theory, Living Systems Theory, and the Stakeholder Theory on the basis of the Normative Theory. For this purpose, two different but interrelated research methods were applied to this research to make the experience and sustainability indicators more understandable. As a result, the SDTS has been redesigned as the Sustainable Scuba Diving Tourism System as S-SDTS which incorporated the triple bottom line of sustainability to have a more solid foundation in the sense of normative aspects through employed theories. The new model, S-SDTS, represents a broad approach to the meaning of the system; the purpose of the system; the function of the system; and the value of the system grounded in interrelated theoretical background. Therefore, there are several implications based on this conclusion presented in the following sections as philosophical, theoretical, managerial, and practical implications.

\subsection{Philosophical Implications}

The philosophical background of this study is derived from the question of how stakeholders in the SDTS understand, interpret, and implement principles of sustainability in the contemporary era. In this regard, normative aspects of the SDTS were re-defined according to principles of sustainability to better understand the existing phenomenon and current issues that face scuba diving tourism. This study created a new insight as to the Sustainable Scuba Diving Tourism System (S-SDTS) that sets up the foundation of the main purpose of the system; ethical and moral values; revised sustainability criteria; and fundamental knowledge of the implications for affiliated and associated stakeholders in this system. Rather than emphasising descriptive or instrumental grounds, this study focused on normative aspects, associated with the Stakeholder Theory, to increase awareness regarding the current actions, phenomena, and problems. As a result, as philosophical implications, this thesis provided a 
systematic approach to stimulate the primary meaning and the purpose of the S-SDTS along with the core narratives. Through analysis of narratives, the S-SDTS introduces a better understanding of the moral and ethical values which can enrich the function of the system among stakeholders. Overall, moral and ethical values based on interviewees`narratives are used to find the answer to what extent do the normative aspects of the scuba diving tourism system address principles of sustainability.

\subsection{Theoretical Implications}

This thesis provides some theoretical insights to add to the existing literature. Firstly, by evaluating the current form of the SDTS, this study addresses three independents but interrelated theoretical foundations in terms of the associated narratives of the newly developed S-SDTS model (see Figure 7.3 on page 212). First, Jaeger and Sekznick`s Normative Theory is employed to identify the ethical and moral values for the S-SDTS in the sense of criteria related to the triple bottom line of sustainability (see Table 7.1 on page 205). To be able to do this, literature reviews of scuba diving tourism (understanding the fundamentals of scuba diving tourism) and sustainable tourism development (principles of sustainability and practices in scuba diving tourism) were examined to have a better insight into the current phenomenon under study. Following, von Bertalanffy`s General Systems Theory and Millers`s Living Systems Theory are applied into the study to determine the components of the sustainable scuba diving tourism system (for overall research concept see Figure 4.3 on page 59 and for research framework see Figure 4.4 on page 65). Through introducing the S-SDTS model, the purpose of the system is explained, and each constituent of the system is described according to their role and responsibility as grounded in a systematic approach. Lastly, for creating a better framework, Freeman`s Stakeholder Theory with Donaldson and Preston's three grounds are involved in this study to distinguish the narratives related to ethical and moral values as normative grounds, descriptive and instrumental cores of the stakeholder theory and specify stakeholders` position within the S-SDTS.

Secondly, addressing normative aspects for the scuba diving tourism system, this thesis spans the broad remit of principles of sustainability beyond ecological protection in fragile marine environments. To achieve this, a critical interpretation is used to redesign the SDTS into the S-SDTS with a theoretical justification of knowledge and values through defining the normative aspects according to the triple bottom line of the principles of sustainability. Thirdly, 
this study provides a value for the newly developed systems approach by describing, accommodating, defining, and clarifying the meaning of the S-SDTS. In addition, this thesis provides a guideline by clarifying the implementation of descriptive and instrumental processes within the proposed model by re-defining and re-evaluating them. Fourth, this thesis introduces a critical interpretation of the knowledge and values of the S-SDTS with theoretical justifications. Fifth, this study proposes a body of knowledge and enriched sustainability criteria (MAP+P) for the S-SDTS (see Table 7.1 on page 205) by adapting the normative aspects according to the principles of sustainability with a contemporary perspective.

\subsection{Managerial and Practical Implications}

Achieving sustainability standards in scuba diving tourism development depends on a well-planned comprehensive systems approach that involves different constituents with varied interests. Therefore, an enriched understanding of normative aspects within the S-SDTS explained by the triple bottom line of sustainability helps authorities to manage both natural and alternative scuba dive sites more efficiently. As practical background, through $5 \mathrm{~S}$ Themes, stakeholders can have knowledge about negative issues from strain (external) and stress (internal) factors; enhance knowledge of the practices for S-SDTS via sustain theme; develop effective management and enforcement strategies with the theme of supervision; and ensure a sustainable future for scuba diving tourism through the theme of support. In this sense, how stakeholders can contribute to achieving the triple bottom line of sustainability in scuba diving tourism can be answered on two sides. These are, providing essential knowledge about normative aspects according to the principles of sustainability and creating regular and longterm meaningful communications between stakeholders. In this connection, this study pieces independent but interrelated dimensions which are knowledge and principles together to reinterpret how stakeholders can interact with the underwater world and solve the existing and potential problems with an effective involvement based on their capabilities. This provides mutual benefit both for stakeholders and the irreplaceable marine ecosystem. For example, scuba diving centres by having a broad knowledge about the marine ecosystem through ocean literacy can guide scuba divers into being more responsible in the underwater while actively participating in. Moreover, these attitudes create awareness among other directly and indirectly associated stakeholders and encourage them to act towards current concerns. 
In line with this objective, this study offers managerial and practical implications by explaining the basic components of the S-SDTS for stakeholders in the sense of ethical and moral values based on normative aspects according to the principles of sustainability. In addition, determining the role of the stakeholders and positioning themselves into their field of interest within the S-SDTS can give a suitable understanding of their responsibility for the stakeholders. For example, in the S-SDTS model stakeholders are divided into three categories as groups of primary, secondary, and tertiary stakeholders. Each constituent of the system has different narratives and normative aspects which are given regarding structured categories, therefore, defining these values provides stakeholders with a better understanding of the current issues and implications. By doing so, the system can work more appropriately according to the needs of the local and marine environment and addresses the interests of stakeholders based on their capabilities. In practice, S-SDTS identifies the stakeholders and enhance sustainable implications by building knowledge and normative values for the system, thus, stakeholders can contribute more constructively.

The existing SDTS model proposed by the researchers was well described with regards to descriptive and instrumental perspectives. As a consequence of that, SDTS explains current problems and suggested solutions such as improving communications; determining fundamental managerial practices; common interests and responsibilities. However, identifying the roles of stakeholders and the main values of the system have not been emphasised sufficiently. In this sense, in terms of the triple bottom line of sustainability, the SSDTS clarifies points of the meaning and purpose of the system. In practice, for example in Malta, there was no joint effort towards sustainable implications. Due to the lack of effectiveness of the meaning of the system, which is internalised and understood by stakeholders, outcomes of the practices are not ended up with desired improvements. This is because stakeholders only focus on their interests and individual benefits. With this regard, this study aims to guide stakeholders by suggesting employing the S-SDTS model in practice which enhances the value of the system. Herewith, the system managers, practitioners or executives can comprehend the fundamental functions of the system through sustainability criteria; control the implications and implementations; eliminate the misinterpretation of unsustainable practices; and classify the moral and ethical values between various interests of stakeholders.

Furthermore, the S-SDTS revisits existing sustainability criteria and adds new 19 items which are independently important and interrelated with each other based on three grounds of 
Stakeholder Theory. In terms of creating sustainable practices, the MAP+P criteria can help stakeholders to employ necessary elements, create codes of conduct, and embody the joint efforts to achieve optimal sustainability and its positive outcomes. Regarding planning, the outcomes can become more assessable for improving sustainable tourism practices; increasing service quality; and having better scuba diving area management. Besides, well-balanced sustainability criteria in the sense of management tools can be applied by both all stakeholders in scuba diving tourism and the destination managers as subdivisions of managerial and enforcement implications. Each existing and suggested item represents specific tools that refer to Marketing, Analysing, Planning, and Protecting (MAP+P) which provide broad insight into the actions and guide how each criterion is addressed to improve the S-SDTS. Each category of sustainability criteria addresses the actions according to impact factors and operational capability in the sense of normative, descriptive, and instrumental grounds. For example, the S-SDTS can help destination marketers to create an effective brand image for the destination based on sustainable development standards by encouraging clean-up events and enriched alternative dive sites in terms of variety and the capacity management of the area. In this sense, sustainable business performances can be increased by promoting awareness on protection and $\mathrm{MAP}+\mathrm{P}$ can give advantages for having a better decision-making process by developing a relationship via communication among stakeholders. The sustainability criteria in $\mathrm{MAP}+\mathrm{P}$ can also be used as evaluation indicators for having comprehensive managerial tools in accordance with improving functional planning; implementing the fundamentals; creating applicable management strategies; and enriching effective recovery and enforcement procedures.

Enhancing environmentally responsible behaviours among the active participants in terms of increasing sustainable practices, the S-SDTS can provide a guideline for sustainable implications which address all interests of stakeholders and constituents of the destination. For example, in terms of improving the scuba divers underwater behaviour in a sense of sustainable in-situ practices, it is recommended to stakeholders and specifically scuba diving centres to employ the S-SDTS and adopt for having better regulation. This can be actualised by introducing solutions and implications during the pre-diving briefings and developing knowledge regarding ocean literacy and the importance of the marine ecosystem. Besides, prediving briefings can be customised in accordance with diverse scuba divers` profiles (e.g., junior scuba divers) and local needs or requirements regarding accessibility and sensitivity of the dive sites. For instance, in Malta, according to the data, the carrying capacity of the present 
scuba dive sites is not analysed sufficiently. Therefore, the S-SDTS provides sustainability criteria on how to assess the carrying capacity in practice like avoiding the jacuzzi diving phenomenon identified in the interviews through increasing communication with other scuba diving centres and stakeholders. In addition to that, the lack of divinvestment and divinfrastructure in Malta erodes the quality of scuba diving operations. In this sense, the SSDTS can provide a guideline for stakeholders to improve the process of investment and infrastructure in scuba dive sites through the sustainability criteria and grounds specified for each group of stakeholders. For example, the future of scuba diving tourism in Malta relies on investment in artificial dive sites. Accordingly, through the sustainability criteria, the S-SDTS can guide stakeholders on how artificial dive sites can be managed according to principles of sustainability. Through the S-SDTS, PDSA and/or scuba diving centres can have more responsibility based on the role and capacity emphasised and described in the new system. The S-SDTS can guide the tourism authorities in Malta to have well-regulated, planned, and managed new alternative dive sites or improve the capacity of the existing ones, rather than expecting action from Malta Tourism Authority (MTA). All these actions can also be implemented in other destinations by employing the S-SDTS.

Moreover, the MnPAs are one of the controversial issues in Malta highlighted during the interviews. By employing the S-SDTS in the destination, stakeholders can understand the benefit of MPAs; disseminate their value by providing visualised and documented materials among stakeholders; develop their capacities to manage or participate in these sites; and understand the importance of the MPAs through emphasising moral and ethical values and more importantly with scientific insight. Via the S-SDTS, administrative stakeholders can employ a localised star-rating system based on the triple bottom line of sustainability that emphasises the moral and ethical values according to the local and destination`s needs and interests of stakeholders in accordance with global initiatives (Green Fins or PADI). By doing this, the destination image can be improved through sustainable practices more appropriately. In this sense, the S-SDTS can make the governance of the scuba diving tourism sector more functional by identifying the degree of stakeholders`responsibility in the destination. Overall, the S-SDTS explains the meaning, function, and purpose of the system for associated and interested stakeholders which helps to create well-established managerial implications based on adaptively monitored scuba dive sites; skilfully supported sustainable implications; adequately analysed outcomes; and expertly planned future decisions. 


\subsection{Reflection of My Journey}

Many researchers in tourism studies have limited interests regarding reflexivity either with a or two sentences, preferring to give in-depth discussions in methodological aspects (Schick, 2002; Feighery, 2006; Cohen, 2013; Crossley, 2021). However, explaining researchers` positionality in the research is an important practice that shapes the research and identifies the relational, cultural, and structural establishments between researchers and respondents during the knowledge production. Moreover, reflexivity allows researchers to address risks of ethical dilemmas; contribute to research ethics during the entire research process (Comstock, 2012); and mitigate controversial issues by ensuring transparency during explaining methodology and doing data analysis (Tubaro et al., 2021). One of the best ways to do this is to put researchers themselves as an active participants in the research while providing honesty about the research process with limitations and positive contributions (Ryan et al., 2014; Ryan, 2021). Thus, careful relationship building between researcher and respondents (interviewees) can strengthen the reflexivity and transparency along with a strong data privacy policy that accounts for data protection (Tubaro et al., 2021) within the researcher`s own perspective, which is already detailed in the methodology (5.4.2.5. Reflexivity and Authenticity).

In addition to the methodological reflexivity, it is also expected that the research should reflect the researcher' point of view and observations with descriptive assumptions that are put into practice during the journey of the research and contributed by the researcher. Therefore, this thesis reflects my overview regarding the phenomenon under study. In a sense, the journey of this thesis has influenced me in some ways. First, the study expanded my horizon about how to see the world, how to understand and interpret the phenomenon. This study provided me with a comprehensive understanding of what sustainability is and a set of knowledge about the systems approach on the basis of normative grounds in terms of theoretical and practical implications. Employing three different but interrelated groups of theories in this study allowed me to see the current issues from a broad perspective to comprehend the meaning of the researched phenomenon. Regarding enhancing the research quality, interrelating the employed theories provided me with more comprehensive ontological thinking and an outlook from a different angle. More importantly, the knowledge of theoretical background in the sense of the relationship between the knowledge and putting them into practice required a considerable number of steps. Therefore, by doing this research, I have had a chance to gather theoretical 
background with extensive knowledge to understand the current issues by finding the gaps and trying to fill these gaps to improve the solutions on an ontological base and practical implications within the epistemological approach. In addition to gaining knowledge during the field study, I encountered many challenges and dealt with them by finding solutions that increased my organisational capacity in terms of research planning and problem-solving skills such as finding links between lived experience and literature or ensuring the reflexivity as a researcher, as described in detail in methodology Chapter 5, sections 5.4.2.5. and 5.5. For example, the method led me to develop a more flexible interview structure and gave advantages to proceed with the research despite unexpected challenges during the active field study period. Moreover, the research encouraged me to make comparisons between the literature and current issues in real-life to better comprehend different organisational cultures and destination management contexts based on a systems approach. Besides, some secondary data sources were not produced for scientific purposes (Merriam\& Tisdell, 2015), therefore, interpreting these data sources into a scientific foundation was one of the main challenges. Overall, this study provided me confidence for my future career as developing a better balance between theory and practice in my future research planning.

\subsection{Limitations of the Thesis and Recommendation for Future Studies}

The main purpose of the study was to redesign the scuba diving tourism system according to principles of sustainability which are embodied in moral and ethical values as normative aspects. Although the study conducted a thorough certain methodological framework and has a theoretical background, there were certain limitations while exploring the phenomenon under study. However, the researcher of this thesis acknowledges the limitations while conducting this research. It is expected that the limitations of the thesis will help researchers to avoid facing the same issues and shortcomings in future studies. For example, as mentioned in the phenomenology section, limitations of this thesis can help future researchers to design better research structures and have a better understanding of conscious experience, specific individual's concerns and the meaning of experience and how people understand what is experienced which means observable occurrence (Howitt, 2019). This can help to design a more comprehensive systems approach in different destination features and social interactions (Mackenzie \& Knipe, 2006) through exploring outcomes of both individual and collective actions of a group of stakeholders "regarding attitudes, opinions and values" (Jennings, 2010, p. 175). It can be argued that interpretation of the data with the interaction of 
lived experiences has the limitation that obtained data may only be interpreted individually based on the researcher`s intuition (Atkins \& Wallace, 2012) or affected by casual relationships between the researcher and participants (Theofanidis \& Fountouki, 2018) during the data collection and analysis process. Therefore, during the production of knowledge, the way of interpreting the data may not represent the theoretical approach or may not provide results for the conceptional framework (Merriam\& Tisdell, 2015) of the research, but the researcher's understanding. However, to overcome challenges and minimise the philosophical conflicts in this study, the interpretation process was systematic while taking into consideration of reflexivity, triangulations and trustworthiness in the best possible way according to theoretical assumptions and research paradigm.

This thesis followed an interpretive paradigm in the sense of qualitative analysis. Therewithal, this study analysed limited findings derived from a certain number of interviews. Apart from Malta, the newly suggested S-SDTS model and its implications have not been tested in different settings. Indeed, there is always a trade-off with any model, as a simplification of reality, between fidelity and complexity, and in this, the S-SDTS is no different. Arguably by making the SDTS more complex and including the previously missing sustainability factors, this study has reduced its application to some degree. For this reason, it can be recognised that the impact of this thesis remained as a suggestion or in the representation of a particular setting. Therefore, in future studies, it is suggested that scholars repeat the research in destinations with no seasonality limitations and with different sample populations from a much larger local group or choose more than one institution for the collection of data. Since the sample populations were mainly determined according to criterion sampling method in this study from scuba divers, scuba diving centres and associated tertiary institutes, research was held with a limited period due to limited seasonality. In addition to that, the transferability of this study was not established on the overall facts of the scuba diving tourism system in the world. Besides, the introduced S-SDTS model does not include local differences. However, due to the fact that the S-SDTS model can be adapted to other destinations and their local needs. Moreover, it was found from the study that the current findings show similarities regarding localised un/sustainable practices with the findings of previous studies. This may be from the fact that the studies conducted previously were based on a mainly limited number of samples on the basis of systems approach. Therefore, there may be the same factors that lead to the same limitations while extending the research to different destinations. It must be accepted by 
research scholars that there may not exist a perfect working system in reality because of different influences over the period. For this reason, it is suggested that researchers employ the S-SDTS for further studies to improve and update the meaning of the system.

Despite all these limitations, researchers and practitioners can consider extending the normative aspects of S-SDTS in different destinations where coral reefs and the marine environment exist and are under severe threat. In this sense, to some extent, the S-SDTS and its normative aspects can be considered as the point of departure to lead and guide further studies by presenting the most updated version of the scuba diving tourism system based on contemporary principles of sustainability. To extend the knowledge of the current issues in question, it is recommended to use a mixed-method study with a broader perspective while examining the scuba diving tourism system in different settings. Therefore, in the future, employing the S-SDTS in different destinations with varied methodological backgrounds will show the effectiveness and other limitations of the system that exist in the real life. To avoid similar results in further research, it is also suggested that the researchers must consider the factors that can be found from different destinations and reassess results via a comparative study to find the factors and how they differ. This experience will help to improve the suggested systems approach more comprehensively. To better understand the implications of these results and achieve optimal sustainable development goals in scuba diving tourism, future studies could address stakeholders' interests in terms of advanced network analysis to identify unexplored actors of this system such as host or local communities who have a crucial role (Lee \& Jan, 2019; Yolal et al., 2021) in the destination and management initiatives. Last but not least, in this study, compared to similar studies, climate change and its indicators did not yet emerge as a primary issue of concern among stakeholders and their statements. Therefore, further research is also needed to determine the causes of environmental degradations based on climate change and its effects on stakeholders` practices; understandings of local communities` perspectives and attitudes; and the relationship between stakeholders and the marine environment in different scenarios. For that, a collaborative study, including both marine experts, professional institutional bodies and sector representatives, is recommended to practice the normative aspects as moral and ethical values with the descriptive and instrumental cores of the newly developed S-SDTS model. 


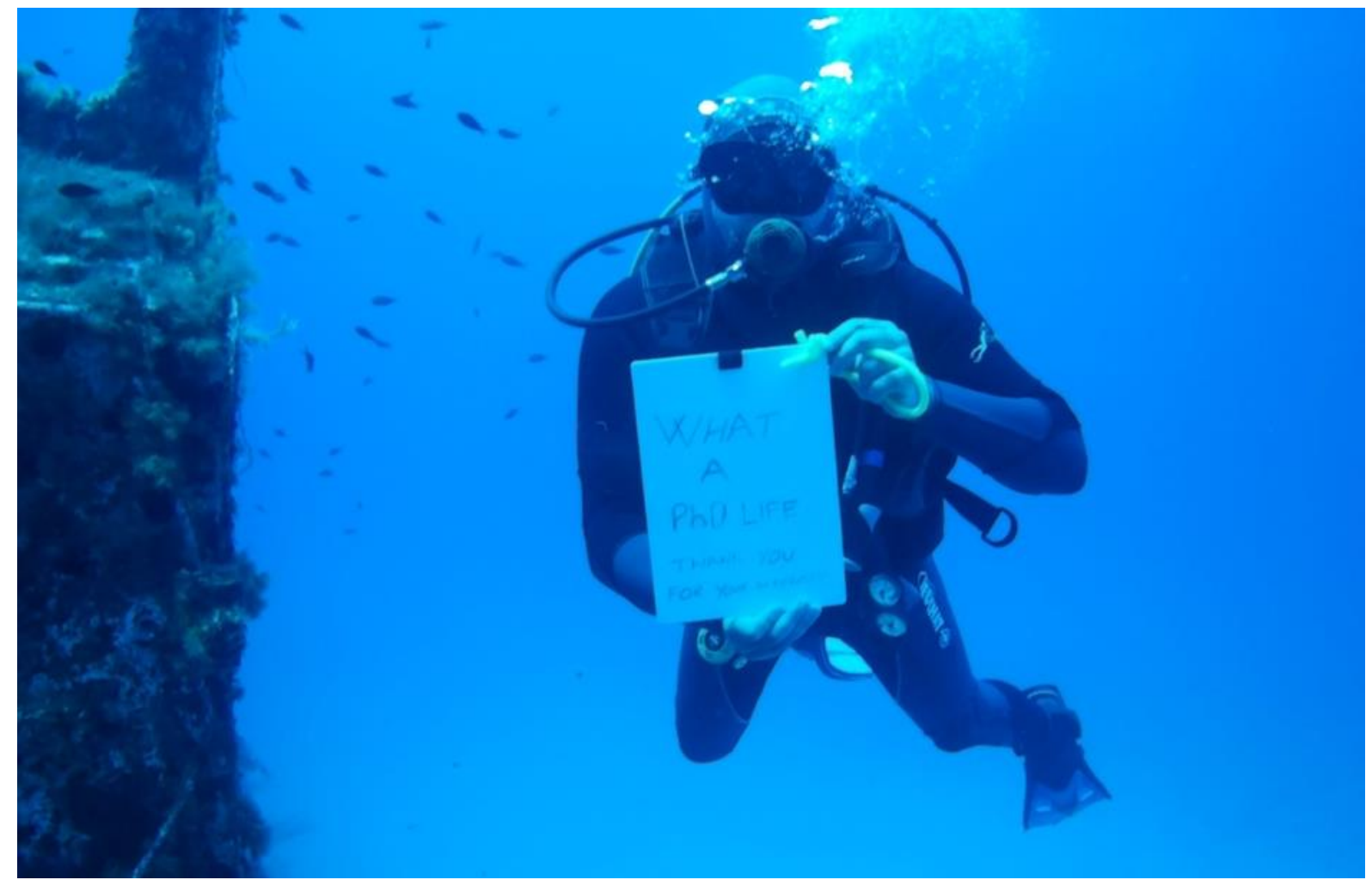

Figure 8.2. The End (Patrol Boat P29 -Boltenhagen- in Cirkewwa, Malta) 


\section{APPENDICES}

Appendix 1. Individual Interview Form

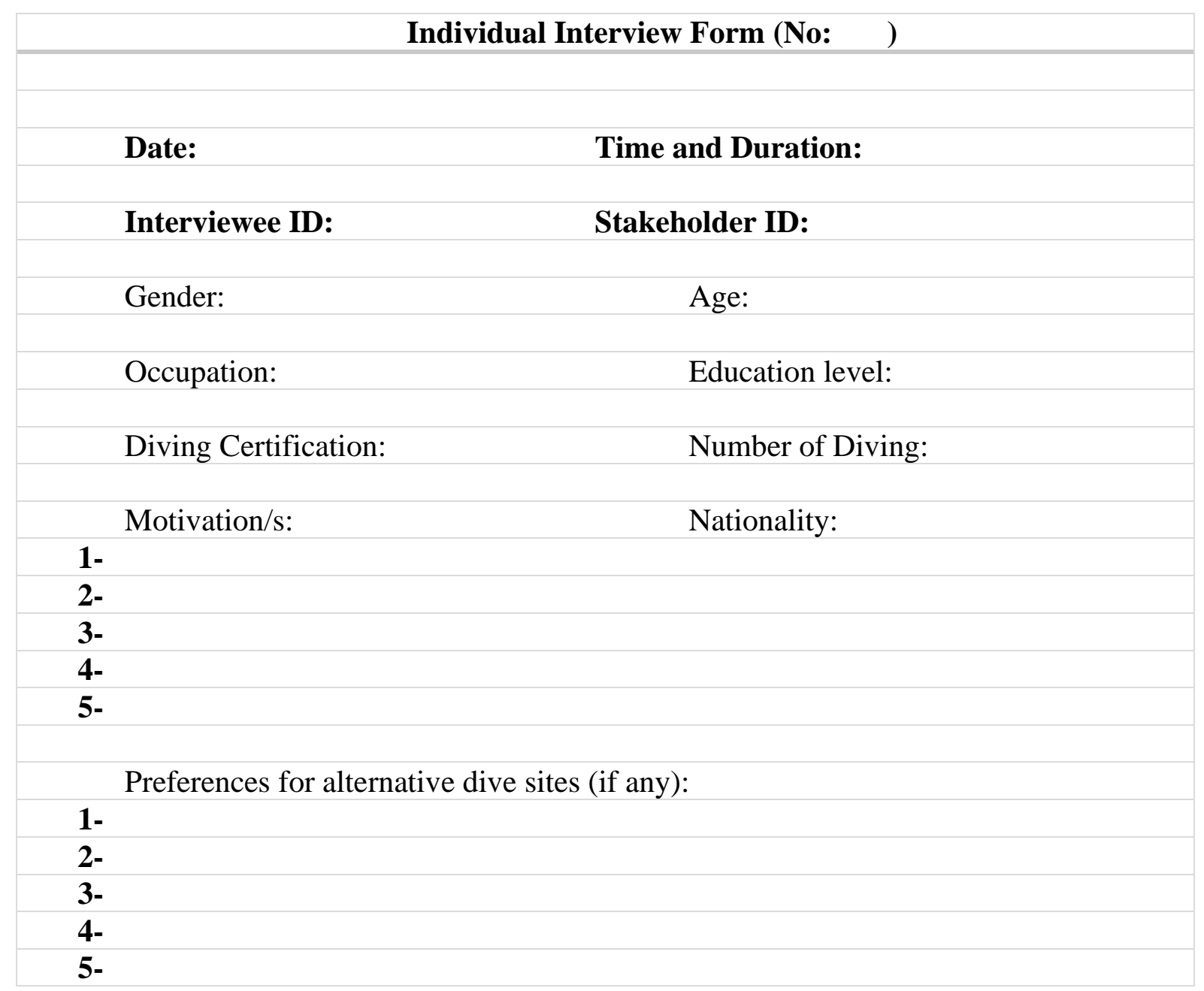




\begin{tabular}{|c|}
\hline Research Question/s \\
\hline $\begin{array}{c}\text { To what extent do the normative aspects of the scuba diving tourism system address } \\
\text { principles of sustainability? }\end{array}$ \\
\hline To Question in following categories \\
\hline - By means of ecological integrity \\
\hline - $\quad$ By means of economic efficiency \\
\hline - $\quad$ By means of social equity \\
\hline - In terms of scuba divers` perceptions \\
\hline - In terms of diving schools` understanding \\
\hline - In terms of local people`s feelings and viewpoints \\
\hline - In terms of local businesses and stakeholders` perspectives \\
\hline - In terms of governance \\
\hline - In terms of institutional attitudes \\
\hline - In terms of media cover \\
\hline Common Semi-Structured Questions to Discover the Matter of Fact \\
\hline $\begin{array}{l}\text { - What does sustainability mean according to your perspective and what do you know about } \\
\text { it? }\end{array}$ \\
\hline - How do you describe the whole scuba diving experience? \\
\hline - How can the scuba diving experience be? \\
\hline $\begin{array}{l}\text { How do you concern sustainability in aspects of ecological integrity, economic efficiency, } \\
\text { and social equity? }\end{array}$ \\
\hline+ as a scuba diver \\
\hline+ as a diving school \\
\hline+ as a local \\
\hline+ as a stakeholder \\
\hline+ as a local business \\
\hline+ as a governance \\
\hline+ as a media \\
\hline+ as an educational institute \\
\hline Questions to Scuba Divers with Regards to Experience and Action \\
\hline - What type of site do you designate in this area? \\
\hline - What is the most important motivation for you to dive here? \\
\hline - What was the special significance of this place? \\
\hline - What did this place make special for you? \\
\hline - How do you describe scuba diving experience in alternative dive sites? \\
\hline - $\quad$ Do you consider reducing the detrimental effect on natural reefs? \\
\hline - $\quad$ To what extent could you define or identify yourself as an eco-friendly diver? \\
\hline - Do you aware of the importance of the reef ecosystem? \\
\hline - $\quad$ Did you research something about this place before coming here? \\
\hline - $\quad$ How much do they consider and take self-regulatory sustainable actions? \\
\hline Questions to Governance / Institution / Media \\
\hline - What are the motivational factors for participating in this destination? \\
\hline - What brings the scuba divers to this region? \\
\hline - Would dive this area help destination to be the more considered sustainable act? \\
\hline Questions to Local and Local Businesses Including Scuba Diving Centres \\
\hline - How many local people are there working in this business? \\
\hline
\end{tabular}


- How does diving tourism contribute to your daily life?

- Are you happy with the development of diving tourism?

- To what extent do you relate or in a relationship with scuba divers?

- Which management program do you involve? AWARE/Green Fins/PADI, etc.

- What has been changed in your local life since the popularity of diving tourism?

- How many people do the locals want them to visit per year, when do they feel disturbed in their private sphere?

- How many guests are manageable in terms of infrastructure, for example, diving school capacity, the public traffic, the waste disposal, or - depending on the region - also for the drinking water disposal?

- Regarding a protected area it is obvious that it has to be controlled how many scuba divers are allowed to enter the place without disturbing or destroying the life of flora and fauna without extravagating the carrying capacity?

\section{Specific to Scuba Diving Centres}

- What are the scuba divers`experiences in alternative dive sites?

\section{To Seek for an Answer Following Question}

How do stakeholders understand principles of sustainability in the scuba diving tourism system?

How do stakeholders prepare operational plans and provide regulations to manage the system with control activities for the sustainable use of scuba dive sites?

How do stakeholders address the triple bottom line of sustainability while interacting with the marine environment within the scuba diving tourism system?

How do stakeholders accommodate personal knowledge about principles of sustainability and their skills in the scuba diving tourism system?

How do stakeholders recognise the philosophical, theoretical, and managerial cores as the normative aspects of the scuba diving tourism system? 


\section{Within the scope of Sustainability, Implications and Practices perspectives:}

1. What does sustainability mean for you and what do you know about sustainability? (Was asked to all participants as authorities and media)

2. Do you think the artificial reef or wreck is important for sustainability for the marine environment?

3. What can be done to be more sustainable? (Was asked to all participants as authorities and media)

4. What do you do to sustain the scuba diving tourism industry in terms of MTA?

5. What do you think to do for the enforcement?

6. What is the most important threat to the scuba diving tourism industry?

7. To what extent do you promote sustainability in Malta via Visit Malta accounts or social media?

8. Why do you still wait for the enforcement?

Within the scope of Scuba Diving Destination Image perspective:

1. How do you designate Malta, in terms of tourism? (Was asked to all participants as authorities and media)

2. How does artificial reef (artificial wrecks) contribute popularity of scuba diving tourism in Malta?

3. To what extent do artificial wrecks provide popularity for scuba diving tourism in Malta?

Within the scope of Scuba Diving Experience and Motivation perspectives:

1. What is the important motivation for a scuba diver to come to Malta?

2. What brings scuba divers to Malta? (Was asked to all participants as authorities and media)

Within the scope of Local People and Local Economy perspectives:

1. Do you think local people have an equal share of scuba diving tourism?

2. Do you think economic investment - like the gaming sector, cryptocurrency - will be a threat to scuba diving tourism in the future?

3. Do you think are local people satisfied or happy with the development of the scuba diving tourism industry?

4. Do you think are local people aware of the importance of marine life?

5. Is it important that attract more local people into scuba diving to help or raise awareness for marine life?

Within the scope of Scuba Diving Investment / Infrastructure and Carrying Capacity perspectives:

1. Do you think the current number of wrecks are enough for Malta scuba diving tourism?

2. Do you think 5\% (2018) of scuba divers for scuba diving out of total inbound tourism is over than carrying capacity in terms of scuba diving tourism infrastructure and marine life? 
Appendix 4. Interview Questions for Scuba Diving Centres` Owners and Managers

Within the scope of Sustainability, Implications and Practices perspectives:

1. What does sustainability mean for you, sustainability in terms of scuba diving tourism perspective? (Was asked to all participants as owners and managers)

2. What can be done to be more sustainable? (Was asked to all participants as owners and managers)

3. What about economic and social sustainability?

4. What about ecological integrity, social equity, and economic benefits? To what extent is it important to protect the environment to be more sustainable?

5. Is it also important to keep in balance the protection and at the same time economic benefits?

6. What can be done more to reduce the detrimental effects on the environment as a scuba diving centre?

7. Do you educate your scuba divers by providing (pre-driving) briefing about being more responsible and sustainable during scuba diving?

8. Do you promote the sustainability of scuba diving tourism in social media apart from your popular scuba diving products?

9. What is the most important solution to raise awareness of the importance of marine life?

10. What do you think about the future of the scuba diving tourism industry?

11. Marine life, especially in Malta, is under threat because of some reasons. So, do you think it is a threat to the scuba diving tourism sector? Does wreck scuba diving is an opportunity?

12. What is the most important or dangerous threat for the scuba diving tourism industry in Malta?

13. Do you involve in some management programs, like green fins, Project AWARE, etc.?

14. What are your practices as a scuba diving centre to be more sustainable?

15. Do you discuss sustainability or alternative sustainable actions with the other scuba diving centres?

16. Do you think are artificial reefs (artificial wrecks) sustainable?

17. Do you think the Marine Reserve Area or designated as the Marine Protected Area is important to the marine environment?

18. Do you consider the negative effects of overfishing and spearfishing in Malta?

19. What does make more effective scuba diving in terms of sustainability?

20. Which one is the most important to protect the marine environment, raising the number of species on it or investing more wrecks?

21. Do wrecks help to create a new marine environment or to protect the marine environment in scuba diving spots?

Within the scope of Scuba Diving Destination Image perspective:

1. How do you designate this area in terms of scuba diving or tourism, in general? What do you offer for scuba divers?

2. What are your most competitive things in Malta among the types of scuba diving opportunities (Wrecks, reef, cave, deep, night)?

Within the scope of Scuba Diving Experience and Motivation perspectives:

1. How do you describe the whole scuba diving experience in terms of your business perspective and scuba divers?

2. What is the most important motivation for scuba divers to dive in Malta? 
3. What did they get from these scuba diving experiences depends on which type of scuba diving they chose, but in general?

4. What kind of feedback do you have from scuba divers regarding wreck diving?

Within the scope of Local People and Local Economy perspectives:

1. How many staff are working here? What about local? (Was asked to all participants as owners and managers)

2. How is the popularity of being a scuba diving instructor or working in the scuba diving centre among locals in Malta?

3. What can be done to encourage local people to work in the scuba diving tourism industry?

4. What do you think is why local people would not prefer to work in the scuba diving sector in Malta?

5. Do you think if you increased the wages, it means more Maltese people would prefer working?

6. Which nationality comes more?

7. What about the local people?

8. Do you think the local people are aware of the importance of the marine environment in Malta?

Within the scope of Scuba Diving Investment / Infrastructure and Carrying Capacity perspectives:

1. Are you happy with the development of scuba diving tourism in Malta?

2. Are you happy with the development of the scuba diving tourism industry in Malta?

3. Are you happy with the development of artificial reefs (artificial wrecks) in Malta?

4. Are you happy with the number of wrecks in Malta? All the investments of wrecks?

5. Do you think the current number of scuba divers are excessive or pressure on carrying capacity for the scuba diving tourism industry?

6. Do you think there can be any restriction on the number of scuba divers in terms of scuba diving in a day?

7. What do you think about the carrying capacity for Malta in terms of scuba diving?

8. Which one is more important, the artificial reefs or wrecks?

9. How many scuba divers are manageable in your business and Malta? 
Appendix 5. Interview Questions for Scuba Diving Instructors

\section{Within the scope of Sustainability, Implications and Practices perspectives:}

1. What does sustainability mean for you? (Was asked to all participants as scuba diving instructors)

2. Do you educate your scuba divers before scuba diving?

3. Do you educate scuba divers before scuba diving to be more sustainable?

4. To what extent do they manage what they learned underwater, during scuba diving?

5. Do you distract, inform, or communicate with scuba divers during scuba diving not to do something?

6. Do scuba divers give any recommendations to you to be more sustainable?

7. Do you have a good relationship with other scuba diving instructors from different scuba diving centres? Do you also discuss with them the way of being sustainable? (Was asked to all participants as scuba diving instructors)

8. What can be done to be more sustainable? (Was asked to all participants as scuba diving instructors)

9. What is the most important threat in Malta for the scuba diving tourism industry?

10. Do you identify yourself as an eco-friendly scuba diver?

11. Do you consider the sustainability of marine life?

12. Do you think is scuba diving business sustainable?

13. Do you think investing in wrecks are more important than protecting the marine environment? Which can come as a priority?

14. What about the protection of the environment to be more sustainable?

Within the scope of Scuba Diving Destination Image perspective:

1. Do you think shipwrecks are the most important motivation for scuba divers?

2. How do you evaluate the marine environments around wrecks?

Within the scope of Scuba Diving Experience and Motivation perspectives:

1. What is the most important motivation for scuba divers to dive in Malta? (Was asked to all participants as scuba diving instructors)

2. How do you describe the experience of wreck scuba diving? (Was asked to all participants as scuba diving instructors)

3. What does Malta offer to scuba divers in Malta?

4. Do you think wreck scuba diving is a novelty for scuba divers like kind of seeking new things in their life?

5. Which is the most important motivation for wrecks divers among scuba divers?

Within the scope of Local People and Local Economy perspectives:

1. What about the popularity of scuba diving among local people or being participated and having a job?

2. Do you also have a relationship with locals and encourage them to dive?

3. Do you think the local people are aware of the importance of the marine environment here?

4. Do you think more local scuba divers help to raise awareness of the importance of marine life?

Within the scope of Scuba Diving Investment / Infrastructure and Carrying Capacity perspectives:

1. Are you happy with developing artificial reefs (artificial wrecks) around Malta?

2. The total number of scuba divers, is a threat to the carrying capacity in Malta? 
Appendix 6. Interview Questions for Scuba Diving Interns

Within the scope of Sustainability, Implications and Practices perspectives:

1. What does sustainability mean for you? (Was asked to all participants as scuba diving interns)

2. What can be done to be more sustainable in terms of scuba diving? (Was asked to all participants as scuba diving interns)

3. Do you also consider having a good relationship with local people, and being more sustainable for future generations?

4. Do you identify yourself as a marine friendly scuba diver?

5. Do you think is scuba diving business sustainable?

6. Do you have a good relationship with the other scuba diving instructors?

7. Do you also discuss being more sustainable?

8. What is the most important threat to scuba diving tourism in Malta?

Within the scope of Scuba Diving Destination Image perspective:

1. Which feature or variety is more important for scuba divers in wreck scuba diving?

Within the scope of Scuba Diving Experience and Motivation perspectives:

1. What is the most important motivation for scuba divers to dive in Malta? (Was asked to all participants as scuba diving interns)

2. How do you describe the wreck scuba diving experience?

3. What about the scuba diving experience?

Within the scope of Local People and Local Economy perspectives:

1. As a local, do you encourage locals to dive?

2. Do you think the local people are aware of the importance of the marine environment in Malta?

3. Do you think more local scuba divers help to raise awareness of the importance of marine life?

Within the scope of Scuba Diving Investment / Infrastructure and Carrying Capacity perspectives:

1. Do you think is there a good future for artificial reef or wrecks development in Malta and do you think it is important for the scuba divers? 
Appendix 7. Interview Questions for Scholars in Tourism Field

\section{Within the scope of Sustainability, Implications and Practices perspectives:}

1. What does sustainability mean for you? (Was asked to all participants as tourism scholars)

2. What about economic sustainability?

3. What does scuba diving centres become more sustainable?

4. Do you think it must be separated that protecting and economic benefit?

5. What is the most important threat to the scuba diving tourism industry in Malta?

6. Do you think the boat traffic and the current are threats for scuba diving in Malta?

7. Do you think the scuba diving tourism industry is a threat to the marine environment?

8. According to scuba diving literature, underwater photography causes the most detrimental effect on the Marine Environment. Do you agree?

9. What is the current problem with communicating with all stakeholders and then taking action?

10. Do you think educating scuba divers, as pre-briefing, is enough to be more sustainable for scuba divers during scuba diving?

11. Is the video watched before scuba diving a suitable solution to be more sustainable for new scuba divers?

12. Do you think protecting the marine environment can be the first primary rather than surviving from the scuba diving which was written in educational materials?

13. The current business model, that they do clean-up, recycling, sells refill bottle and do pre-diving briefing are they enough to identify the business themselves as sustainable?

14. In Malta case, if the weather is bad, 200 or 300 scuba divers go scuba diving to the same place, on the same day. How can be sustainable in this way?

15. What is the most negative effect on marine life in Malta?

Within the scope of Scuba Diving Destination Image perspective:

1. Is there any cultural background of marine life and Malta?

Within the scope of Scuba Diving Experience and Motivation perspectives:

1. What is the main motivation for scuba divers to come and dive in Malta?

Within the scope of Local People and Local Economy perspectives:

1. Do you think is it a threat that decision-makers who are not scuba divers?

2. What is the popularity of scuba diving among local people in Malta?

3. Do you think are local people aware of the importance of marine life? (Was asked to all participants as tourism scholars)

4. Do you think more local scuba divers can help to raise awareness?

5. How can local people be attracted more to dive?

Within the scope of Scuba Diving Investment / Infrastructure and Carrying Capacity perspectives:

1. Do you think is there enough wreck investment in Malta?

2. Do you think wrecks are a good investment for recreational scuba diving and marine life?

3. Do you think scuttling wrecks in a certain area are good for the marine environment?

4. Do you think 5\% (inbound tourists' number in 2018) of scuba divers out of the total number of tourists in Malta is over than carrying capacity in terms of the scuba diving tourism industry and the marine environment?

5. Do you think there can be a limited number of scuba divers in a day?

6. Do you think the authority promotes sustainability in scuba diving tourism in Malta? 
Appendix 8. Interview Questions for Scholars in Marine Biology

Within the scope of Sustainability, Implications and Practices perspectives:

1. What does sustainability mean for you? (Was asked to all participants as marine biology scholars)

2. What is the most important threat to marine life in Malta? (Was asked to all participants as marine biology scholars)

3. What is the best solution to protect marine life in Malta?

4. Do you think wrecks are an effective way to redirect scuba divers from the fragile environment?

5. Do you think creating a scuba diving attraction is a threat to the surroundings of wrecks (which will become an artificial reef)?

6. Do you think investing in wrecks are a safe way to protect the marine environment in Malta?

7. In your opinion, which one is more important for the marine environment, whether to create an artificial reef, which is more environmentally friendly or invest more wrecks for recreational scuba diving?

8. Do you think designating an area as the Marine Protected Area is a solution for being sustainable?

9. For raising the awareness of the importance of marine life, do you think more scuba diving or more education can play a role, efficiently?

10. Do recreational scuba divers distract fish from natural reserves or wrecks?

11. What is the reason not to enforce designated areas, such as the Marine Protected Areas, in Malta?

12. In terms of commercial fishing, to what extent it is a threat to marine life in Malta?

13. What can be done to be more sustainable between marine biology and the scuba diving tourism industry?

14. What can be done to be more sustainable from an ecological perspective?

15. Do you think the scuba diving tourism industry is a threat to marine life?

16. Do you think the scuba diving tourism industry help to raise awareness of the importance of the marine environment?

17. Do you think the current education process -pre-diving briefing and courses- is enough to be sustainable in the marine environment?

18. Do you think pre-diving briefing is a good regulation or enough regulation to prevent from harming the marine environment in terms of scuba divers?

19. Do you think recycling, reducing single-use plastics and clean-up events are enough for scuba diving centres to be identified themselves as marine friendly scuba diving centres?

20. Do you think the wreck can be separated by these protected areas or can be part of it?

21. To what extent, has spearfishing affected the marine environment in Malta?

22. How do you distinguish an artificial reef from wrecks?

23. Do you think wrecks are a threat to sustainability? Can they be taken out from the water after finishing the activities?

24. From a marine biology perspective, is the wreck a good opportunity to protect the marine environment?

25. From the marine biologist perspective, which primary goal is more important than the other; to protect the environment or to keep it balanced with the scuba diving tourism industry and to some extent open to commercial fishing? 
26. The most important diving association called PADI determines the primary goal for scuba divers in scuba diving is surviving from scuba diving instead of protecting the environment? So, do you think it is a threat to marine ecology?

27. How do you designate or identify Malta in terms of marine life?

Within the scope of Scuba Diving Destination Image perspective:

N/A

Within the scope of Scuba Diving Experience and Motivation perspectives:

N/A

Within the scope of Local People and Local Economy perspectives:

1. Do you have any collaboration with the scuba diving tourism industry in person, or as the university to work on mutual projects?

2. Do you also consider the economic benefit from the marine environment, the marine life in general, is it important to sustain the economic benefit?

3. Do you think can tourism industry make economic benefit from artificial reefs including wrecks or can be restricted from recreational activities?

4. Do you have any collaboration with the tourism authority in terms of creating a scuba diving site?

5. Are local people aware of the importance of marine life? (Was asked to all participants as marine biology scholars)

6. Do you think if it is encouraged more local scuba divers help to raise awareness of the importance of the marine environment?

7. Do you have a relationship with local people to explain the importance of the marine environment?

8. Do you collaborate with some international projects or like EU funding for the Marine Environment, which also involved the scuba diving tourism industry?

9. Do you educate and share current issues (research findings) with the scuba diving tourism industry?

10. Do you have any consultancy service before and during scuttling a wreck?

11. Do you think the underwater is a kind of secret place for humanity, especially for local people?

12. Do you think the scuba diving tourism industry or relevant stakeholders can force the government to protect the marine environment?

13. Do you think if more marine ecologists or biologists are involved in the scuba diving tourism industry, would be a good chance to protect the marine environment? What about the owner?

Within the scope of Scuba Diving Investment / Infrastructure and Carrying Capacity perspectives:

1. Do you think the scuba diving tourism industry can be banned, for a while or completely from the marine reserves?

2. Do you think scuba diving can be restricted to certain scuba dive sites?

3. Do you think scuba diving in the winter term is also a threat to marine life due to carrying capacity?

4. According to statistics, the scuba diving tourism industry is responsible for $5 \%$ (inbound tourist numbers in 2018) out of the whole tourism inbound. Is it a problem for carrying capacity in terms of the marine environment in Malta?

5. How many scuba divers in one place is good for carrying capacity due to bad weather conditions?

6. Do you identify wrecks as an artificial reefs? How? 
7. Do you think wrecks are good investments to recreate, regenerate or protect the marine environment by opening and encouraging recreational scuba diving?

8. Some people stated that wrecks become pollution at the end of their life cycle; do you agree with this statement?

9. Do you monitor the wrecks in your department or as personal research?

10. Have the current number of scuttled wrecks reached their maximum limit or can be invested more?

11. Do you think investing in more wrecks is a threat to the marine environment in Malta?

12. Why does the scuba diving tourism industry not use other marine friendly artificial reef structures instead of wrecks?

13. Do you think more shipwrecks can be invested, banned, or limited from now on? 
Appendix 9. Interview Questions for Scholars in Marine Archaeology

Within the scope of Sustainability, Implications and Practices perspectives:

1. What does it mean for sustainability for you in your perspective? (Was asked to all participants as marine archaeology scholars)

2. Which one is primary in your research/es, protection for the marine ecology or protection for history?

3. In underwater heritage site which comes first heritage or ecology?

4. Do you think recreational scuba diving in Underwater Cultural Heritage sites is a threat to destroy the history and the surroundings of the archaeological sites or it's the opportunity to bring awareness to the public? (Was asked to all participants as marine archaeology scholars)

5. Do you educate scuba divers to become more aware of the Underwater Cultural Heritage?

6. Are wrecks a good opportunity to protect real heritage sites?

7. What can be done to be more sustainable in underwater cultural heritage or in general the marine historical environment, in terms of protection, business, economy, social dissemination and international relationship? (Was asked to all participants as marine archaeology scholars)

8. How do you protect the reef around the Underwater Cultural Heritage sites?

9. Is the fishing threat to the Underwater Cultural Heritage a threat to the scuba diving tourism industry?

10. How do you designate an area as to whether an Underwater Cultural Heritage Area or the Marine Protected Area?

11. What is the most important threat to Underwater Cultural Heritage in Malta?

Within the scope of Scuba Diving Destination Image perspective:

1. Malta has a good reputation investing in artificial wrecks which are open recreational scuba diving. Do you think artificial wrecks can eliminate the potential risks on heritage sites through redirecting attention instead of the actual archaeological site?

2. Do you think new findings or archaeological expeditions of the Underwater Cultural Heritage make more popular scuba diving tourism in Malta?

3. Is there any open historical dive site?

4. How important is the Underwater Cultural Heritage for Malta?

Within the scope of Scuba Diving Experience and Motivation perspectives:

N/A

Within the scope of Local People and Local Economy perspectives:

1. Where does scuba diving centres locate in the collaboration of the Underwater Cultural Heritage Unit (UCHU) in Malta?

2. Can the Underwater Cultural Heritage archaeological sites be open to economic benefit and especially for recreational scuba diving? (Was asked to all participants as marine archaeology scholars)

3. What do you do for the dissemination of historical sites, especially for locals? (Was asked to all participants as marine archaeology scholars)

4. Do you think are local people aware of the importance of the Underwater Cultural Heritage in Malta? (Was asked to all participants as marine archaeology scholars)

5. How many stakeholders are involved in the Underwater Cultural Heritage Unit's (UCHU) current project? 
6. Is there any balance between wrecks and the Underwater Cultural Heritage in terms of popularity or business?

7. How many sites are there as the Underwater Cultural Heritage and how frequently do you study on these sites?

8. How many people are working in the marine archaeology department?

9. Which awareness is important internationally or local towards the Underwater Cultural Heritage?

Within the scope of Scuba Diving Investment / Infrastructure and Carrying Capacity perspectives:

1. Is there any threat to being lost of value for historical wrecks?

2. In terms of business perspective, some scholars refer to establishing more recreational wrecks as an artificial reef to protect the historical one, what do you think about this implication or suggestion?

3. As the marine archaeology department in the university, do you have any responsibility in setting up artificial wrecks on the seabed? If yes, what is this process?

4. Do you think is it important to set up a new wrecks area for recreational scuba diving?

5. Do you think the artificial wrecks have a historical value, like a time capsule that we live in this century? 
Appendix 10. Interview Questions for Scuba Divers

\section{Within the scope of Sustainability, Implications and Practices perspectives:}

1. What does sustainability mean for you? What do you understand? (Was asked to all participants as scuba divers)

2. Do you identify yourself as an eco-friendly or marine friendly scuba diver?

3. Do you aware of the importance of marine life?

4. Do you have any other special considerations or any other special self-regulation during scuba diving?

5. Do you consider that your detrimental effect on the reef ecosystem? What do you for it as self-regulation?

6. What can be done to be more sustainable?

7. Do you have some personal interest in marine life ecosystems?

8. How do you see sustainability in the marine environment?

9. Do you also consider economic sustainability?

10.Do you think advanced scuba diving certification may raise your awareness of sustainability in the marine environment?

11.Do you think more scuba diving help raise awareness for marine life or cause a threat?

12.Do you think, is it important to keep protected the marine environment?

Within the scope of Scuba Diving Destination Image perspective:

1. How do you designate or how do you describe the scuba diving tourism industry in Malta?

2. Do you like the variety of scuba diving opportunities in Malta?

3. Did you choose where you dive, or did you go by advice?

4. Did you do research something about scuba diving opportunities before coming to Malta?

5. Are you satisfied with wreck scuba diving opportunities in Malta?

6. How do you designate Malta in terms of scuba diving opportunities?

Within the scope of Scuba Diving Experience and Motivation perspectives:

1. Did you come to Malta to wreck scuba diving?

2. Which features of wrecks are more desirable for you? If you have a choice and if you want to dive into wreck again, which feature would be most important for you?

3. What were the most memorable things for you in scuba diving today and in general?

4. How do you describe your whole scuba diving experience in Malta? What did you expect and what did you experience?

5. What is the most important motivation for you to dive into Malta?

6. How do you describe or identify wreck scuba diving experience?

7. What do you prefer about wreck scuba diving?

8. Which attracts you more to go scuba diving, the rich marine environment, or the wide range of wrecks?

9. How can the wreck scuba diving experience be?

10. What are the most special things about wrecks for you?

11. What was the memorable thing for today (wreck scuba diving)?

12.How do you describe your scuba diving experience of today?

13.Did you choose specifically to dive into this wreck today? Did you go by advice?

14. What is the most significant about this wreck, for you?

15. Which feature or variation does attract you to dive into a wreck? Depth, Size, History-

Story behind, Type, Surrounding, Challenge yourself?

Within the scope of Local People and Local Economy perspectives: 
1. Is it important having the economic benefit from what we protected in the marine environments?

2. Can we also consider making money from what we preserved?

3. Do you think are local people aware of the importance of marine life in Malta?

Within the scope of Scuba Diving Investment / Infrastructure and Carrying Capacity perspectives:

1. Do local people support wrecks investment? 
Appendix 11. Data Coding Process

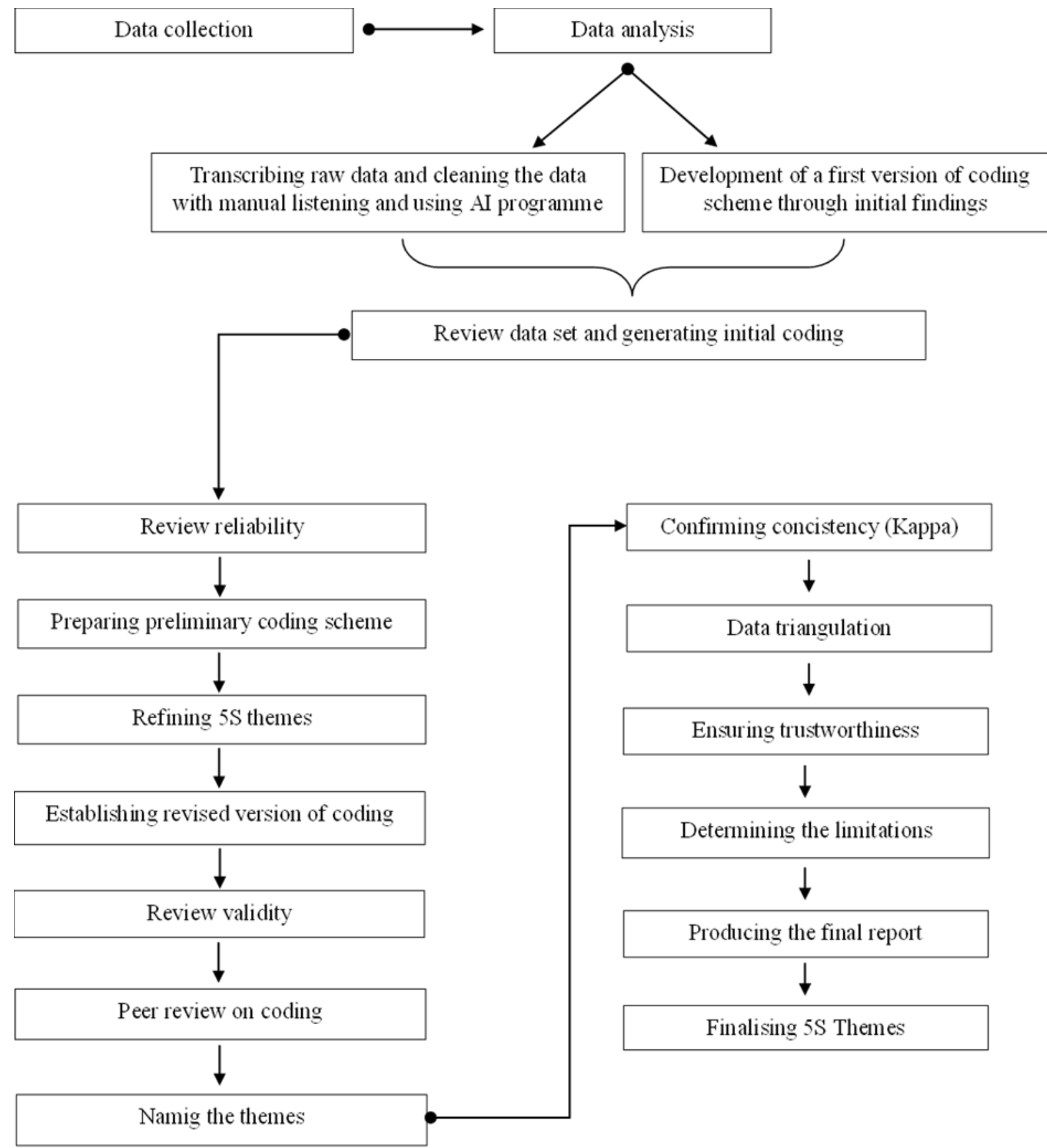


Appendix 12. Emergent Coding Process

\begin{tabular}{|c|c|}
\hline Themes & Themes \\
\hline Stress - Strain - Sustain (3S) / Think Ahead / Every Step Needs to Be Sustainable & Stress - Strain - Sustain (3S) / Think Ahead / Every Step Needs to Be Sustainable (Give a break) \\
\hline Enforcement/s - Management/s - Monitoring/s & Enforcement/s - Management/s - Monitoring/s (location based) (foundation) (waste management) \\
\hline Where is the Marine Life? & Establish a foundation for enforcement / Self-funded job for enforcement \\
\hline Divinvesment / Divinfrastructure & Lack of marine life (Where is the Marine Life?) \\
\hline Not to touch / Hands Off / Not to Chase / Not to Feed & Divinvesment / Divinfrastructure \\
\hline Diving / Diver Congestion / Jacuzzi Diving & Not to touch / Hands Off / Not to Chase / Not to Feed (green fin-logos) \\
\hline The Role of the Wreck & Diving / Diver Congestion / Jacuzzi Diving \\
\hline Careless / Awareness and Education & The Role of the Wreck (Creating interesting artificial reef with a story, value, cleanliness, future) \\
\hline Education standards for both sites adding responsibility for each dive & Careless / Awareness and Education (Clean-ups - Make it visible, make people aware) \\
\hline Clean-ups - Make it visible, make people aware & Education standards for both sites adding responsibility for each dive \\
\hline Responsible diving (pick up rubbish during fun diving if applicable) & Carrying Capacity (Limitation of divers and number of diving) \\
\hline Definition of Proper Diving & Responsible diving (pick up rubbish during fun diving if applicable) Treasure hunter vs trash hunter. \\
\hline Diving Experience and Acting & Definition of Proper Diving \\
\hline Variety and Diversity & Diving Experience and Acting \\
\hline $\begin{array}{l}\text { Marıne Non-Protected Areas (MnPAs) } \\
\text { Marine nrotected areas for what? There need to he criteria for that }\end{array}$ & Variety and Diversity-penetration time (certification trick) \\
\hline Designated areas should be determined & Marine Non-Protected Areas (MnPAs) \\
\hline Education for buoyancy & Marine protected areas for what? There need to be criteria for that. \\
\hline Creating interesting artificial reef with a story & Designated areas should be determined \\
\hline Location based marine management & Education for buoyancy \\
\hline Needs to be studied before submerging new wrecks & Threats (cave-night diving, fishing, land reclamation, commercial practices -fuel) \\
\hline Give a break & Power of pre-diving briefing \\
\hline Dive master education / To what extend they are qualified for marine life? & Needs to be studied before submerging new wrecks \\
\hline Qualification for diving school owners & Diving School / Service quality (instructor service/showman) / Rating, regulation, standardisation \\
\hline Establish a foundation for enforcement / Self-funded job for enforcement & Dive master education / To what extend they are qualified for marine life? \\
\hline Requirements for opening a diving school? & Qualification for diving school owners \\
\hline The role of divers? Treasure hunter vs trash hunter. & Requirements for opening a diving school? \\
\hline The value of scuttled wrecks? & Diving and wreck safety \\
\hline The future of diving? & The future of diving? /Value added tourist vs diver \\
\hline
\end{tabular}


Appendix 13. Malta, Gozo and Comino Popular Dive Sites*

\begin{tabular}{|c|c|c|c|c|}
\hline Dive Site & Type & Depth & Island & Access \\
\hline HMS Maori (Valletta) & Wreck & $10-15$ meters & Malta & Shore \\
\hline Tug 2 (Sliema) & Wreck & $12-18$ meters & Malta & Shore \\
\hline Tugboats (Zonqor Point, Marsascala) & Wreck & $18-20$ meters & Malta & Shore \\
\hline P29 Patrol Boat (Cirkewwa) & Wreck & 18-40+ meters & Malta & Shore \\
\hline Tugboat Rozi (Cirkewwa) & Wreck & 18-32 meters & Malta & Shore \\
\hline Um El Faroud (Wied iz-Zurrieq) & Wreck & 18-36 meters & Malta & Shore \\
\hline Ghar Lapsi & Natural & $10-18$ meters & Malta & Shore \\
\hline East/West Reef and Caves (Wied iz-Zurrieq) & Natural & $10-30$ meters & Malta & Shore \\
\hline Anchor Bay & Natural & $10-18$ meters & Malta & Shore \\
\hline Sugar Loaf and Madonna (Cirkewwa) & Natural & 10-24 meters & Malta & Shore \\
\hline Cirkewwa Arch (Cirkewwa) & Natural & $10-20$ meters & Malta & Shore \\
\hline South Reef (Delimara Point) & Natural & $10-25$ meters & Malta & Shore/Boat \\
\hline Tunnel and Reef (1-Ahrax) & Natural & 05-18 meters & Malta & Shore \\
\hline Qawra Point North & Natural & 05-36 meters & Malta & Shore \\
\hline Exiles (Sliema) & Natural & $05-18$ meters & Malta & Shore \\
\hline Fortizza (Sliema) & Natural & $05-18$ meters & Malta & Shore \\
\hline X127 Lighter `Coralita` (Manoel Island) & Wreck & $10-22$ meters & Malta & Shore \\
\hline Bristol Beaufighter & Wreck & $30-38$ meters & Malta & Boat \\
\hline HMS Hellespont & Wreck & $35-42$ meters & Malta & Boat \\
\hline Bristol Blenheim Bomber & Wreck & $38-42$ meters & Malta & Boat \\
\hline Filfla Island & Natural & $15-50$ meters & Malta & Boat \\
\hline Qammieh Point (Devil's Reef) & Natural & $30-50$ meters & Malta & Boat \\
\hline MV Imperial Eagle & Wreck & $32-42$ meters & Malta & Boat \\
\hline MV Karwela \& MV Cominoland (Xatt 1-Ahmar) & Wreck & $20-45$ meters & Gozo & Shore \\
\hline MV Xlendi (Ghajnsielem) & Wreck & $30-40$ meters & Gozo & Shore \\
\hline Mgarr ix-Xini & Natural & $10-25$ meters & Gozo & Shore \\
\hline Xlendi Reef \& Tunnel & Natural & $05-18$ meters & Gozo & Shore \\
\hline Coral Gardens \& Big Bear (Dwerja) & Natural & $05-30$ meters & Gozo & Shore \\
\hline Blue Hole (Dwerja) & Natural & $5-50+$ meters & Gozo & Shore \\
\hline Inland Sea \& Tunnel (Dwerja) & Natural & $05-55$ meters & Gozo & Shore \\
\hline Cathedral Cave/Blue Dome (Ghasri) & Natural & $10-30$ meters & Gozo & Shore \\
\hline Reqqa Point (Marsalforn) & Natural & 20-70+ meters & Gozo & Shore \\
\hline Double Arch (Marsalforn) & Natural & $20-45$ meters & Gozo & Shore \\
\hline Ras il-Hobz & Natural & 20-100 meters & Gozo & Shore \\
\hline Fessej Rock & Natural & $15-40$ meters & Gozo & Boat \\
\hline Ta' Cenc Reef & Natural & $10-50$ meters & Gozo & Boat \\
\hline Fungus Rock & Natural & $10-40$ meters & Gozo & Boat \\
\hline San Dimitri Point & Natural & 10-60 meters & Gozo & Boat \\
\hline Wied ir-Raheb & Natural & $10-60$ meters & Gozo & Boat \\
\hline Billinghurst Cave & Natural & 20-35 meters & Gozo & Shore/Boat \\
\hline Lantern Point & Natural & $10-50$ meters & Comino & Boat \\
\hline Cominotto Reef & Natural & 18-36 meters & Comino & Boat \\
\hline Santa Marija Caves & Natural & $10-18$ meters & Comino & Boat \\
\hline P31 Patrol Boat & Wreck & $12-20$ meters & Comino & Boat \\
\hline
\end{tabular}


Appendix 14. Demographic Attributes of Interviewees

\begin{tabular}{|c|c|c|c|c|c|c|c|c|c|}
\hline No & Person & $\begin{array}{l}\text { Gender } \\
\text { and Age }\end{array}$ & Occupation & Education & $\begin{array}{c}\text { Diving } \\
\text { Certification }\end{array}$ & $\begin{array}{l}\text { Number } \\
\text { of Diving }\end{array}$ & Nationality & Motivations & $\begin{array}{c}\text { Preferences for } \\
\text { Alternative Dive } \\
\text { Sites } \\
\end{array}$ \\
\hline \multicolumn{10}{|c|}{ Authority (as MTA and Department of Media) } \\
\hline 2 & MTA - 2 & $M-54$ & Deputy & Bachelor & N/A & 1 & Maltese & $\begin{array}{l}\text { Coast and Nature } \\
\text { Sea and Beach } \\
\text { Culture } \\
\text { Wedding } \\
\text { City Break } \\
\text { Close to Europe } \\
\text { Honeymoon } \\
\text { Anniversaries } \\
\text { Sport activities } \\
\text { Language Schools } \\
\text { Dive sites } \\
\text { Clear Water } \\
\text { Water Temperature } \\
\text { Accessibility }\end{array}$ & N/A \\
\hline 3 & MTA - 3 & M - 46 & Director & Bachelor & N/A & N/A & Maltese & $\begin{array}{c}\text { Clear Water } \\
\text { Good Visibility } \\
\text { Range of Family } \\
\text { Activity }\end{array}$ & N/A \\
\hline
\end{tabular}




\begin{tabular}{|c|c|c|c|c|c|c|c|c|c|}
\hline & & & & & & & & $\begin{array}{c}\text { Scuba Diving } \\
\text { Climate } \\
\text { History } \\
\text { City Break } \\
\text { Business / } \\
\text { Conferences } \\
\text { Variability in } \\
\text { Diving } \\
\text { Wrecks } \\
\text { Story / History }\end{array}$ & \\
\hline \multicolumn{10}{|c|}{ Scuba Diving Centre Owners and Managers and PDSA } \\
\hline 4 & OWN - 1 & $\mathrm{~F}-36$ & Manager & College & N/A & +150 & Maltese & $\begin{array}{c}\text { Good Visibility } \\
\text { Try Dive } \\
\text { Wrecks } \\
\text { Value for Money }\end{array}$ & N/A \\
\hline 5 & $\begin{array}{c}\text { OWN }-2 \\
/ \\
\text { PDSA }\end{array}$ & M - 47 & Owner & Bachelor & Dive Master & +10000 & Maltese & $\begin{array}{l}\text { Wide Range of } \\
\text { Scuba Diving } \\
\text { Topography } \\
\text { Wrecks } \\
\text { Clear Visibility }\end{array}$ & N/A \\
\hline 7 & OWN - 4 & M - 26 & Manager & College & Dive Master & +6000 & British & $\begin{array}{c}\text { Wrecks } \\
\text { History / Heritage } \\
\text { Technical Diving } \\
\text { Location } \\
\text { Depth of the } \\
\text { Wrecks }\end{array}$ & N/A \\
\hline 8 & OWN - 5 & M - 38 & $\begin{array}{c}\text { Owner } \\
\text { Chairman of } \\
\text { the PDSA }\end{array}$ & Master & Dive Master & +500 & Maltese & $\begin{array}{c}\text { Wrecks } \\
\text { Variety } \\
\text { Technical Diving }\end{array}$ & N/A \\
\hline
\end{tabular}




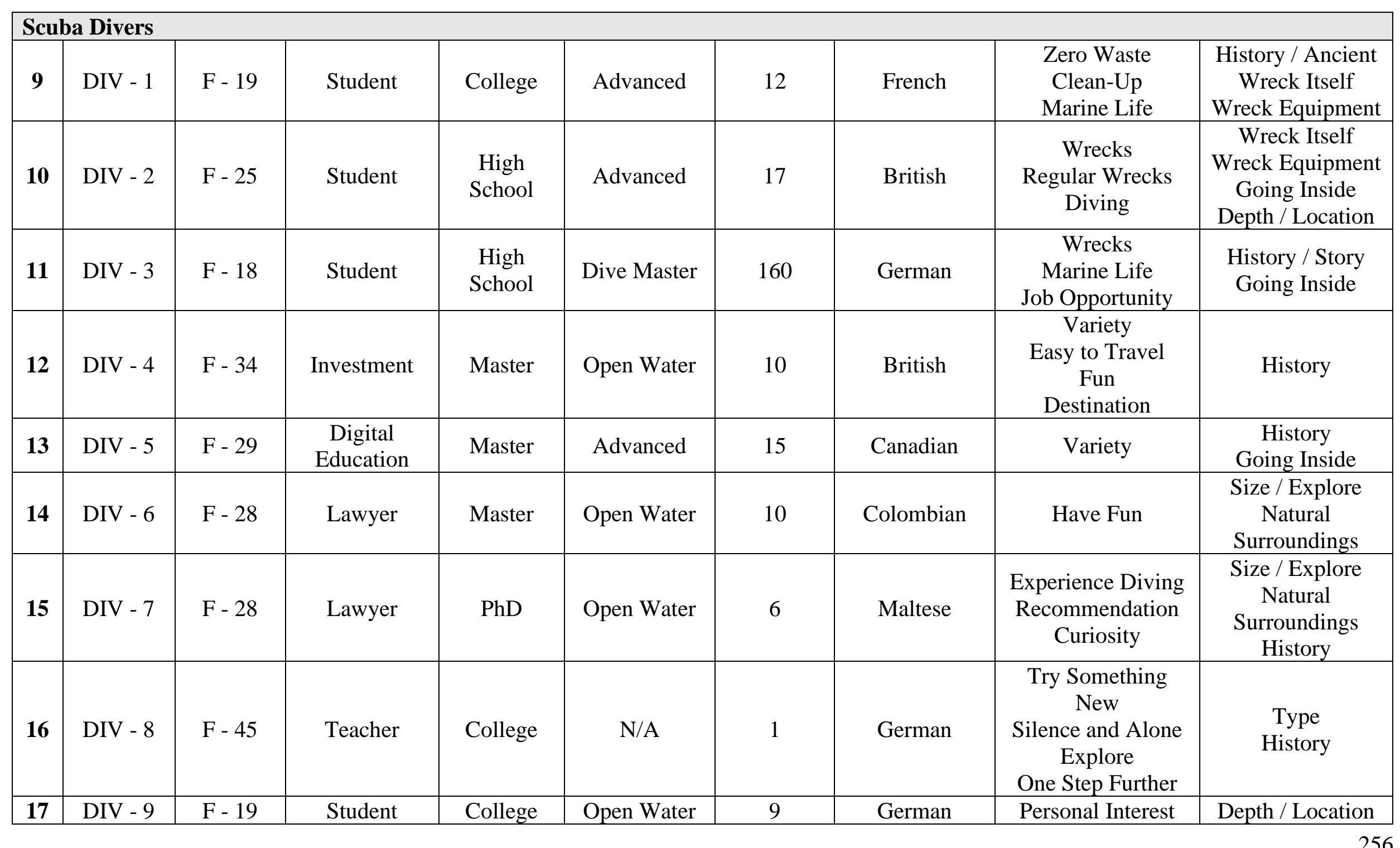




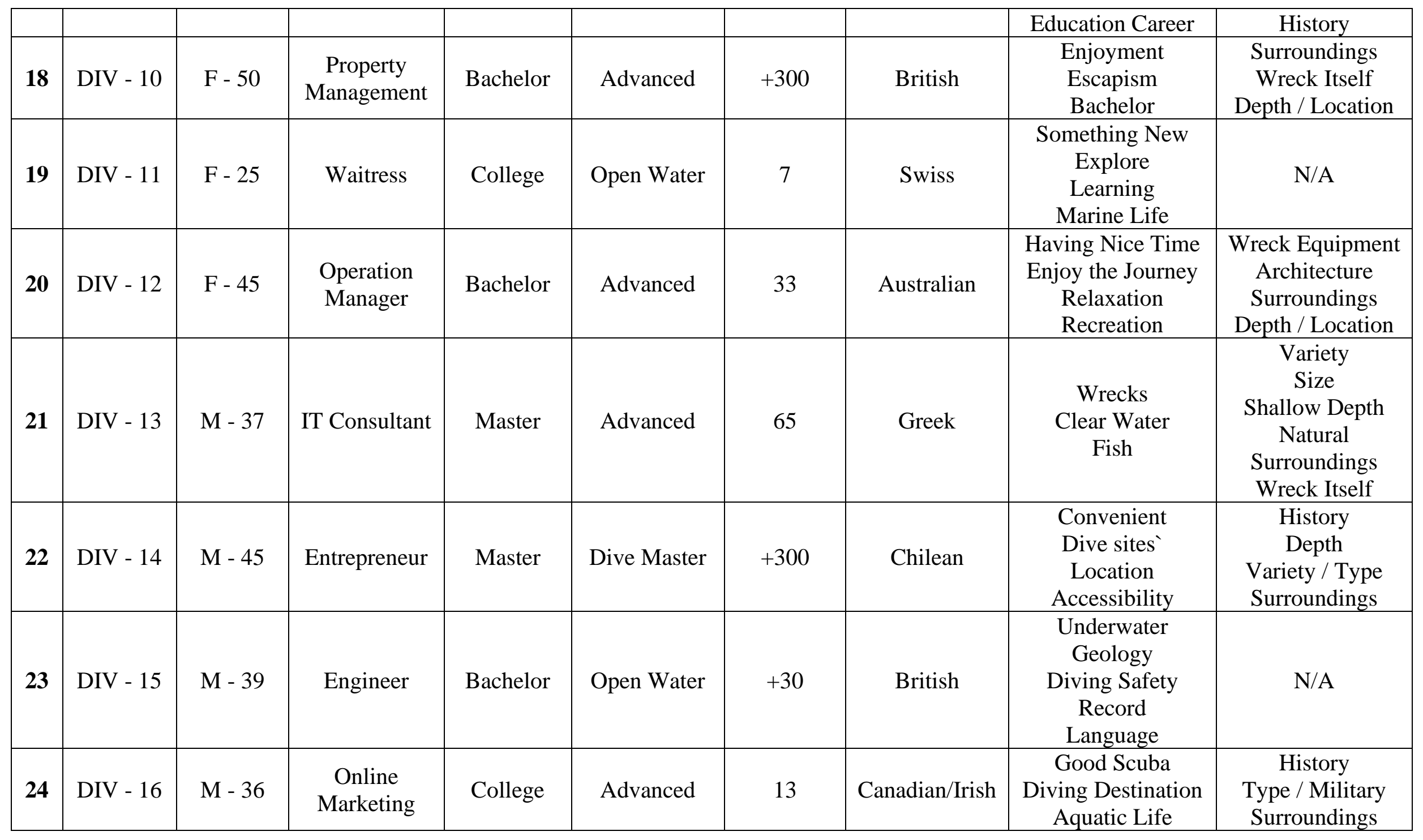




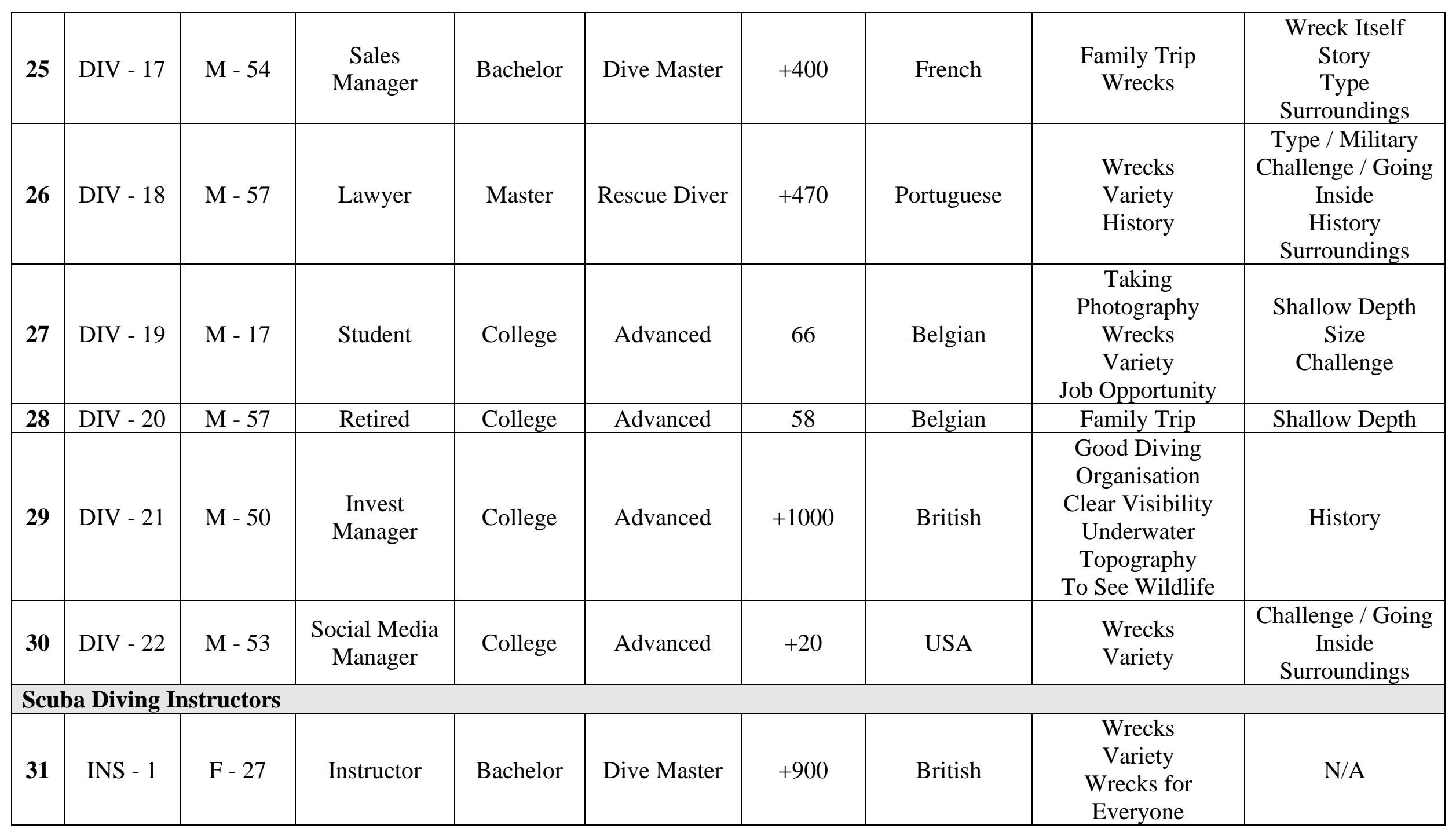




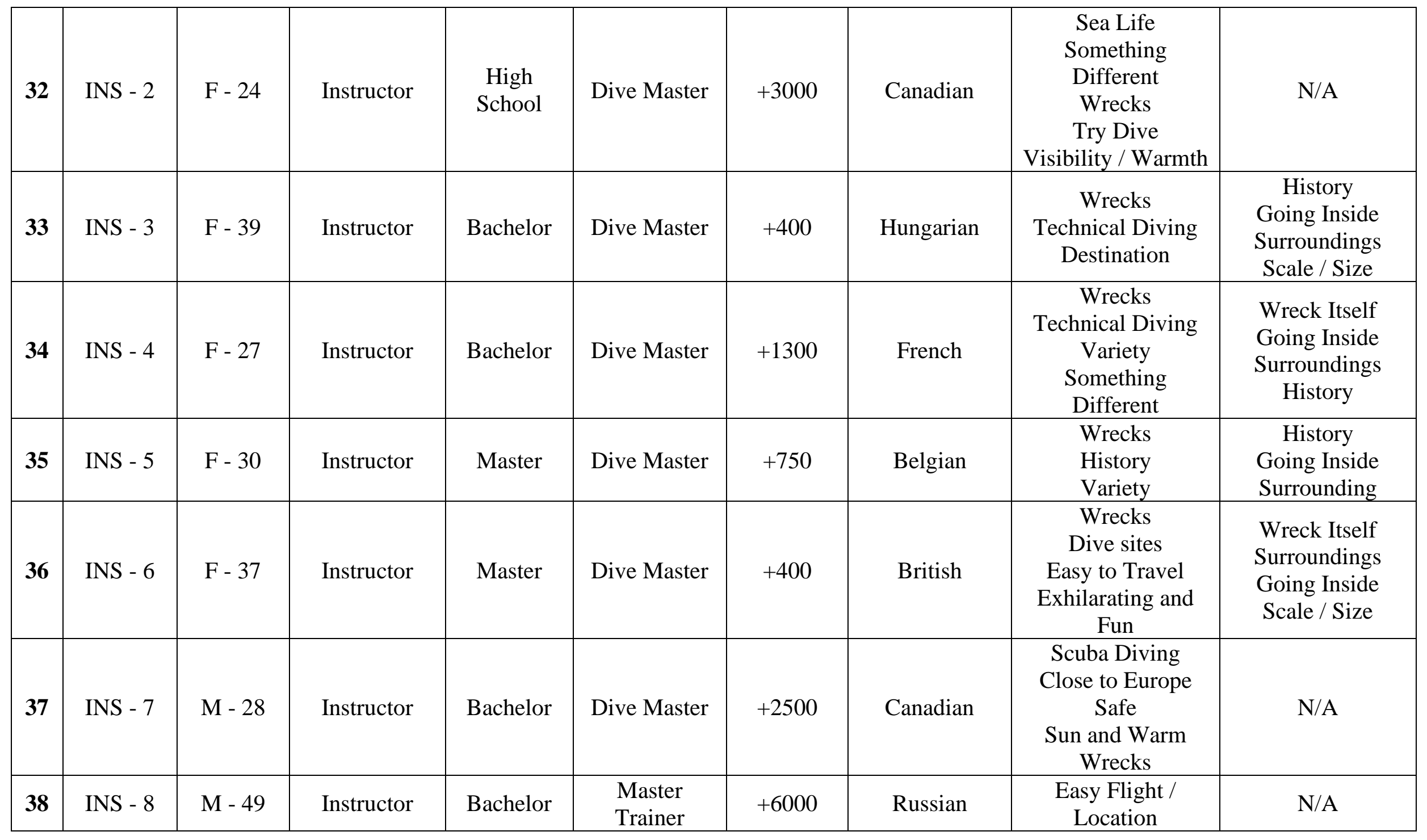




\begin{tabular}{|c|c|c|c|c|c|c|c|c|c|}
\hline & & & & & & & & $\begin{array}{l}\text { Shore Diving } \\
\text { Safe Diving } \\
\text { Dive sites } \\
\text { Caves } \\
\text { Wrecks } \\
\text { Underwater } \\
\text { Landscapes }\end{array}$ & \\
\hline 39 & INS - 9 & M - 33 & Instructor & Bachelor & Dive Master & +170 & British & Wrecks & N/A \\
\hline 41 & INT - 2 & M - 17 & Intern & $\begin{array}{l}\text { High } \\
\text { School }\end{array}$ & Rescue Diver & 19 & Maltese & $\begin{array}{c}\text { Unique Experience } \\
\text { Wrecks }\end{array}$ & N/A \\
\hline 42 & INT - 3 & M - 22 & Intern & Bachelor & Dive Master & 82 & British & $\begin{array}{c}\text { Location } \\
\text { Clear Water } \\
\text { Shore Diving } \\
\end{array}$ & N/A \\
\hline \multicolumn{10}{|c|}{ Scholar in Marine Archaeology (Marine Archaeologists) } \\
\hline 47 & MAR - 1 & M - 51 & Professor & $\mathrm{PhD}$ & Advanced & +1000 & Maltese & $\begin{array}{c}\text { Experience Other } \\
\text { Things } \\
\text { Mix } \\
\text { Variety }\end{array}$ & N/A \\
\hline 48 & MAR - 2 & M - 27 & $\begin{array}{l}\text { Research } \\
\text { Assistant }\end{array}$ & Master & Advanced & +400 & Spanish & N/A & N/A \\
\hline
\end{tabular}




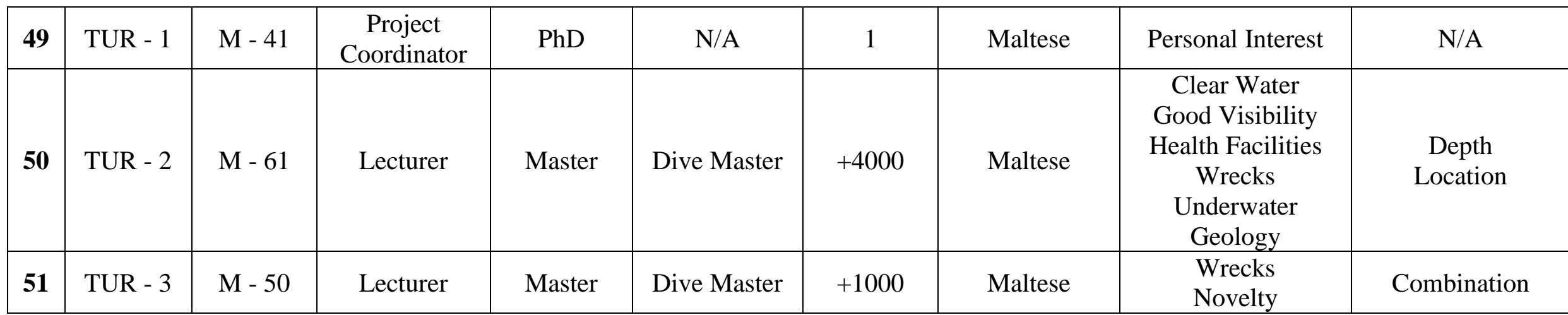


Appendix 15. Overall Interviewees`Knowledge of Sustainability

\begin{tabular}{|c|c|c|}
\hline No & Interviewee & Statement \\
\hline 1 & DIV - 1 & $\begin{array}{l}\text { It's making things more lasting. To me, it means not producing any } \\
\text { waste. Don't get spoiled or we don't use too much resources. }\end{array}$ \\
\hline 2 & DIV - 2 & $\begin{array}{l}\text { Whatever we are doing, we are keeping up diving at regular rate and } \\
\text { those sustaining of that. }\end{array}$ \\
\hline 3 & DIV - 3 & $\begin{array}{l}\text { It's basically like you can keep doing it for a long time and nothing's } \\
\text { going to change and nothing's going to get worse or something ... I } \\
\text { think we shouldn't do to protection for the sake of economic benefit. We } \\
\text { should do it for its own sake. }\end{array}$ \\
\hline 4 & DIV - 4 & $\begin{array}{l}\text { Sustainability is ability to be able to use something over and over again } \\
\text { and do something over and over again without harming the } \\
\text { environment adversely. }\end{array}$ \\
\hline 5 & DIV - 5 & $\begin{array}{l}\text { Make something in a way that isn't taking too much from the earth for } \\
\text { the space in a way that just, it overtakes what is able to rebuild or put } \\
\text { it back. }\end{array}$ \\
\hline 6 & DIV - 6 & $\begin{array}{l}\text { Using the resources but using them in moderate or rational way in } \\
\text { order for the next generations will be able to keep using them. }\end{array}$ \\
\hline 7 & DIV - 7 & $\begin{array}{l}\text { Do not harm the natural resources or the environment, to cause } \\
\text { damage or waste just to take care of the environment. }\end{array}$ \\
\hline 8 & DIV - 8 & $\begin{array}{l}\text { It means to really keep the world, going as it's that I take care of what } \\
\text { I use, what I eat, what kind of materials that I use. }\end{array}$ \\
\hline 9 & DIV - 9 & I think we should keep like open up our mind concerning environment. \\
\hline 10 & DIV - 10 & $\begin{array}{l}\text { Something that does not have an impact on the environment that has as } \\
\text { a prosperous nature to people for doing it. }\end{array}$ \\
\hline 11 & DIV - 11 & I have to get for protection. \\
\hline 12 & DIV - 12 & $\begin{array}{l}\text { I just see it, as where there is a long-term future and whatever activity } \\
\text { it's and that's economically and environmentally sustainable. }\end{array}$ \\
\hline 13 & DIV - 13 & $\begin{array}{l}\text { Something that you can continue doing, let's say consistently over time } \\
\text { without having any others effect in the end. }\end{array}$ \\
\hline 14 & DIV - 14 & $\begin{array}{l}\text { Something that prevails. I would say something that will not be short } \\
\text { term profit but will be for the long term, not be impacting too much. }\end{array}$ \\
\hline 15 & DIV - 15 & $\begin{array}{l}\text { To have an experience and leave environments in such a way that the } \\
\text { people that come after us are sons and daughters will be able to have } \\
\text { the same experience. }\end{array}$ \\
\hline 16 & DIV - 16 & $\begin{array}{l}\text { It means, leaving the place the way that you found it. So not causing } \\
\text { any damage. }\end{array}$ \\
\hline 17 & DIV - 17 & How we preserved. It s taking care of the environment where we are. \\
\hline 18 & DIV - 18 & It's something that allows us preserves about the life on this planet. \\
\hline 19 & DIV - 19 & It doesn't hurt the environment; it doesn't pollute too much. \\
\hline 20 & DIV - 20 & That it lasts as long as possible for the future generation. \\
\hline 21 & DIV - 21 & $\begin{array}{l}\text { It's nothing to do with impact, it's to do with the fact that whatever you } \\
\text { are doing doesn't materially prevent the regeneration of ongoing } \\
\text { nature. }\end{array}$ \\
\hline 22 & DIV - 22 & $\begin{array}{l}\text { It touches way that is sustainable not only through the environment that } \\
\text { no environmental impacts but also doesn't get out of hand. }\end{array}$ \\
\hline
\end{tabular}




\begin{tabular}{|c|c|c|}
\hline 23 & INS - 1 & Long-lasting, able to keep going. \\
\hline 24 & INS - 2 & $\begin{array}{l}\text { Doing our best as professionals and as human beings to preserve the } \\
\text { things that we like to see. }\end{array}$ \\
\hline 25 & INS - 3 & The amount of people who are coming, like the country can handle it. \\
\hline 26 & INS - 4 & Like not leaving any footprints, not damaging, not stressing. \\
\hline 27 & INS - 5 & $\begin{array}{l}\text { Don't put more stress on the earth, on the resources to jeopardize future } \\
\text { development or for future generations. }\end{array}$ \\
\hline 28 & INS - 6 & Preserving it's the key. \\
\hline 29 & INS - 7 & $\begin{array}{l}\text { Continually do something and have it there for future generations, for } \\
\text { more people. }\end{array}$ \\
\hline 30 & INS - 8 & Everything good. Absolutely no problem. It's more healthy and today. \\
\hline 31 & INS - 9 & $\begin{array}{l}\text { Sort of keep to only really use what we can replace ... So, like socially } \\
\text { I feel like sustainability takes second place to other issues ... People } \\
\text { seem more focused on economic growth financially rather than taking } \\
\text { care of the world in which we live in. }\end{array}$ \\
\hline 32 & INT - 1 & $\begin{array}{l}\text { It's a thing to help the planets development, like do some things ... For } \\
\text { the planet, and this isn't just not just talk about that. I think we need } \\
\text { some action. }\end{array}$ \\
\hline 33 & INT - 2 & $\begin{array}{l}\text { Keeping something well maintained something up to scratch, keep it, } \\
\text { maintain its quality for as long as possible depending on what you're } \\
\text { referring to. }\end{array}$ \\
\hline 34 & INT - 3 & $\begin{array}{l}\text { Being able to conduct the practices without leaving any damage to the } \\
\text { environment, the surrounding ecosystems. And to be able to do it in a } \\
\text { way that does not disturb the local, culture or way of life ... The profit } \\
\text { isn't the most important thing for the sustainability. }\end{array}$ \\
\hline 35 & OWN - 1 & Taking care of the environment. \\
\hline 36 & OWN - 2 & $\begin{array}{l}\text { Any action that you do does not put any excessive strain on what you } \\
\text { are doing, which will allow you to continue doing it ... So, your actions } \\
\text { must not impact what you do tomorrow and what tomorrow will bring. }\end{array}$ \\
\hline 37 & OWN - 3 & $\begin{array}{l}\text { Keep running and without causing a lot of damage in the process. We } \\
\text { need to find a balance that's the better sustainability to find a good } \\
\text { balance where you don't cause damage that you cannot repair. }\end{array}$ \\
\hline 38 & OWN - 4 & $\begin{array}{l}\text { I believe in maintaining if we can improve, but I appreciate how } \\
\text { difficult it can be to improve things but at least sustain the level, which } \\
\text { we have now to keep the same and not to allow it to get any worse in } \\
\text { general. }\end{array}$ \\
\hline 39 & OWN - 5 & $\begin{array}{l}\text { Something that will thrive, will does not have a negative effect and that } \\
\text { will grow. }\end{array}$ \\
\hline 40 & MAR - 1 & $\begin{array}{l}\text { It would be just kept on making places accessible to people, closing } \\
\text { them because everything belongs to everyone. At the same time as we } \\
\text { put a very big effort in protecting things in order to make the future ... } \\
\text { able to keep on visiting. }\end{array}$ \\
\hline 41 & MAR - 2 & $\begin{array}{l}\text { The harmony between the protection ... as much as practical and at the } \\
\text { same time where practical and where possible the sharing. }\end{array}$ \\
\hline 42 & MBI - 1 & $\begin{array}{l}\text { See what I have presence ... start off with doing a good survey ... } \\
\text { monitor it and ... look at the impacts. }\end{array}$ \\
\hline
\end{tabular}




\begin{tabular}{|l|l|l|}
\hline 43 & MBI - 2 & $\begin{array}{l}\text { The level of the activity, whatever it's; at a level that you can see it's } \\
\text { continuing it in the long term without any adverse environment that } \\
\text { impact. Well not necessarily protect but make sure that there is no } \\
\text { harm. }\end{array}$ \\
\hline 44 & MBI - 3 & $\begin{array}{l}\text { When you have, for example, an ecosystem or a habitat. Where do you } \\
\text { are using it? But not using it to the extent that you have an adverse } \\
\text { effect, that's what sustainable it s. }\end{array}$ \\
\hline 46 & MBI - 4 & $\begin{array}{l}\text { Not the economics or anything like that, that the ecosystem is stable in } \\
\text { the long term except for natural ... or natural succession or something } \\
\text { like that. }\end{array}$ \\
\hline 47 & MTA - 2 & $\begin{array}{l}\text { Taking into consideration economic, cultural, social and } \\
\text { environmental impacts, looking at decision making ... Taking into } \\
\text { consideration all these impacts and especially looking at it on a long- } \\
\text { term basis as well. }\end{array}$ \\
\hline 48 & MTA - 3 & $\begin{array}{l}\text { Taking what you need without compromising the needs of future } \\
\text { generations. }\end{array}$ \\
\hline 49 & TUR - 1 & $\begin{array}{l}\text { Whouldn't overuse our resources in order to save the garden for our } \\
\text { future genations. } \\
\text { today's financial interests before the interest of tomorrow. }\end{array}$ \\
\hline 50 & TUR - 2 & $\begin{array}{l}\text { Being the meeting the needs of the present generation and not } \\
\text { compromising the needs for the future. }\end{array}$ \\
\hline 51 & TUR - 3 & $\begin{array}{l}\text { Whatever it's beneficial to the local community ... Continue enjoying if } \\
\text { you like the benefits on a permanent basis, not short term. }\end{array}$ \\
\hline
\end{tabular}


Appendix 16. Governance and Enforcement for SDTS in Malta

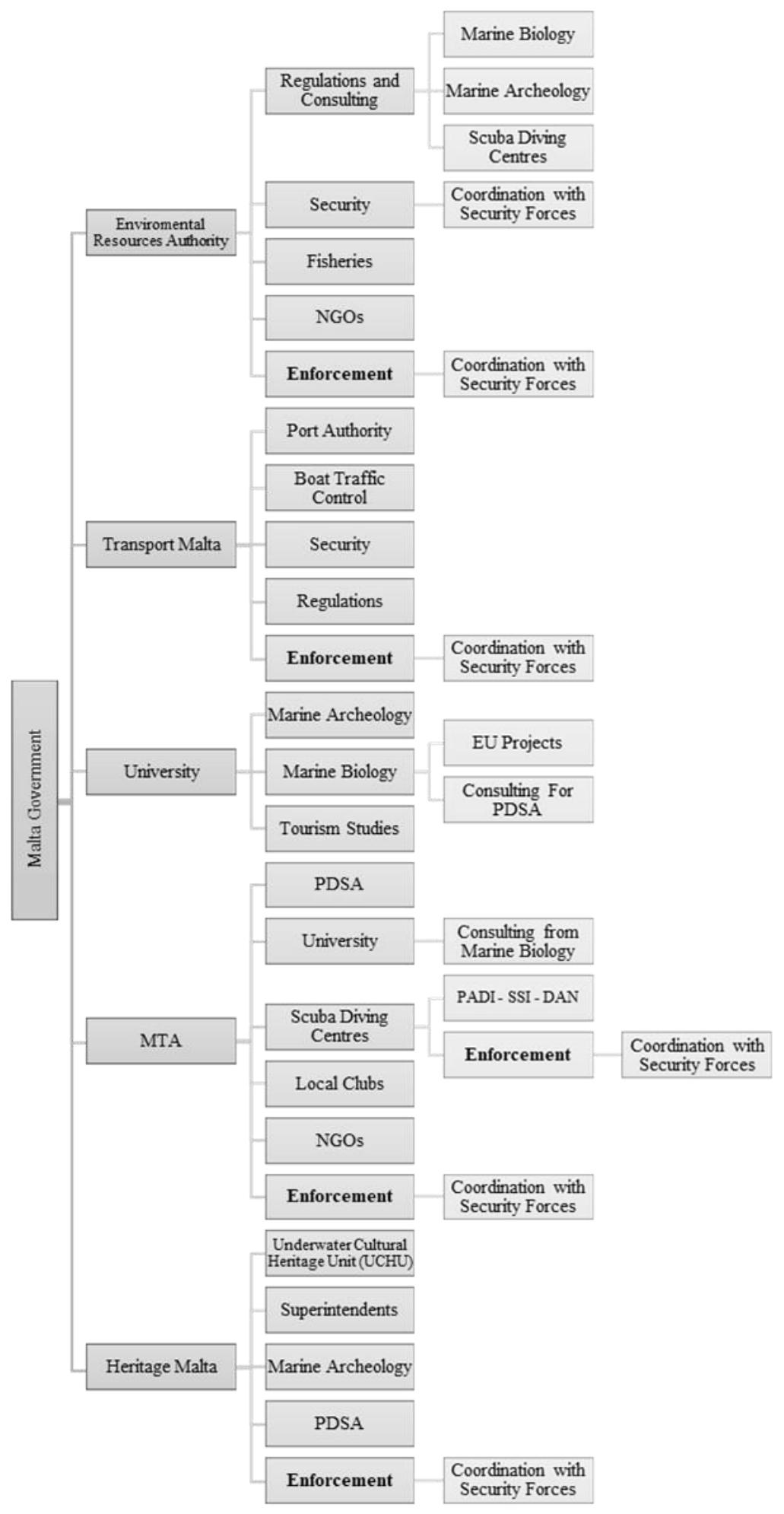




\section{BIBLIOGRAPHY}

Abercrombie, N., Hill, S., \& Turner, B. S. (2006). The Penguin Dictionary of Sociology (5 ${ }^{\text {th }}$ Ed). Penguin Reference.

Ackerly, B., Cabrera, L., Forman, F., Johnson, G. F., Tenove, C., \& Wiener, A. (2018). Grounded Normative Theory: Political Theorizing with Those Who Struggle. Working Paper.

Ackoff, R. L. (1981). On the use of models in corporate planning. Strategic Management Journal, 2(4), 353-359.

Adams, K. M. (2012). Systems theory: a formal construct for understanding systems. International Journal of System of Systems Engineering, 3(3-4), 209-224.

Adams, K. M., Hester, P. T., Bradley, J. M., Meyers, T. J., \& Keating, C. B. (2014). Systems theory as the foundation for understanding systems. Systems Engineering, 17(1), 112 123.

Albayrak, T., Caber, M., \& Cater, C. (2019). Mass tourism underwater: A segmentation approach to motivations of scuba diving holiday tourists. Tourism Geographies, 1-16.

Agardy, T. (2010). Ocean Zoning: Making Marine Management More Effective. Earthscan, London.

Agle, B. R., Mitchell, R. K., \& Sonnenfeld, J. A. (1999). Who matters to Ceos? An investigation of stakeholder attributes and salience, corporate performance, and Ceo values. Academy of management journal, 42(5), 507-525.

Alazaizeh, M. M., Hallo, J. C., Backman, S. J., Norman, W. C., \& Vogel, M. A. (2016). Crowding standards at Petra Archaeological Park: a comparative study of McKercher's five types of heritage tourists. Journal of Heritage Tourism, 11(4), 364-381.

Allison, W. R. (1996). Snorkeler damage to reef corals in the Maldive Islands. Coral Reefs, 15(4), 215-218. 
Alvesson, M., Hardy, C., \& Harley, B. (2008). Reflecting on reflexivity: Reflexive textual practices in organization and management theory. Journal of management studies, 45(3), 480-501.

Amsler, S. S. (2009). Embracing the politics of ambiguity: Towards a normative theory of “sustainability”. Capitalism Nature Socialism, 20(2), 111-125.

Amyx, D. A., DeJong, P. F., Lin, X., Chakraborty, G., \& Wiener, J. L. (1994). Influencers of purchase intentions for ecologically safe products: An exploratory study. In Marketing Theory and Applications, Proceedings of the 1994 American Marketing Association Winter Educators Conference (Vol. 5: 341-347). AMA Chicago.

Anderson, L. E., \& Loomis, D. K. (2011). SCUBA Diver Specialization and Behaviour Norms at Coral Reefs. Coastal Management, 39(5), 478-491.

Anderson, L. E., \& Loomis, D. K. (2012). Normative standards for coral reef conditions: a comparison of SCUBA divers by specialization level. Journal of Leisure Research, 44(2), 257-274.

Arcos-Aguilar, R., Favoretto, F., Kumagai, J. A., Jiménez-Esquivel, V., Martínez-Cruz, A. L., \& Aburto-Oropeza, O. (2021). Diving tourism in Mexico-Economic and conservation importance. Marine Policy, 126, 104410.

Arin, T., \& Kramer, R. A. (2002). Divers' willingness to pay to visit marine sanctuaries: an exploratory study. Ocean \& Coastal Management, 45 (2-3), 171-183.

Argandoña, A. (1998). The stakeholder theory and the common good. Journal of business ethics, 17(9), 1093-1102.

Arnould, E. J., \& Price, L. L. (1993). River magic: Extraordinary experience and the extended service encounter. Journal of Consumer Research, 20(1), 24-45.

Atkins, J. P., Gregory, A. J., Burdon, D., \& Elliott, M. (2011). Managing the marine environment: is the DPSIR framework holistic enough? Systems Research and Behavioral Science, 28(5), 497-508.

Atkins, L., \& Wallace, S. (2012). Qualitative research in education. SAGE publications. 
Au, A. C. S., Zhang, L., Chung, S. S., \& Qiu, J. W. (2014). Diving associated coral breakage in Hong Kong: differential susceptibility to damage. Marine pollution bulletin, 85(2), 789-796.

Augustine, S., Dearden, P., \& Rollins, R. (2016). Are changing diver characteristics important for coral reef conservation? Aquatic Conservation: Marine and Freshwater Ecosystems, 26(4), 660-673.

Badalamenti, F., Ramos, A. A., Voultsiadou, E., Lizaso, J. S., D'Anna, G., Pipitone, C., ... \& Riggio, S. (2000). Cultural and socio-economic impacts of Mediterranean marine protected areas. Environmental conservation, 110-125.

Baggio, R. (2008). Symptoms of complexity in a tourism system. Tourism Analysis, 13(1), 120.

Baggio, R., Scott, N., \& Cooper, C. (2010). Improving tourism destination governance: a complexity science approach. Tourism Review, 65(4), 51-60.

Ballantine, W. J. (1999). Marine Reserves in New Zealand: The Development of The Concept and The Principles. in the Proceedings of an International Workshop on Marine Conservation for the New Millennium, Korean Ocean Research and Development Institute, Cheju Is., 3-38.

Barker, N. H. L., \& Roberts, M. R. (2004). Scuba Diver Behavior and the Management of Diving Impacts on Coral Reefs. Biological Conservation, 120:481-489.

Beaver, D., \& Keily, T. (2015). The Scuba Dive Industry in Australia: Towards Estimates of Economic Size and Impact. Centre for Conservation Geography: Version 1.0, March 2015.

Belhassen, Y., Rousseau, M., Tynyakov, J., \& Shashar, N. (2017). Evaluating the Attractiveness and Effectiveness of Artificial Coral Reefs as a Recreational Ecosystem Service. Journal of Environmental Management 203:448-456.

Belk, R. W. (1975). Situational variables and consumer behavior. Journal of Consumer research, 2(3), 157-164. 
Bennett, N. J., \& Dearden, P. (2014). Why local people do not support conservation: Community perceptions of marine protected area livelihood impacts, governance and management in Thailand. Marine Policy, 44, 107-116.

Bennett, N. J., Teh, L., Ota, Y., Christie, P., Ayers, A., Day, J. C., ... \& Satterfield, T. (2017). An appeal for a code of conduct for marine conservation. Marine Policy, 81, 411-418.

Benney, M., \& Hughes, E. C. (1970). Of Sociology and the Interview. To NK Denzin. Sociological Methods: A Source Book.

Bentz, J., Lopes, F., Calado, H., \& Dearden, P. (2016a). Managing marine wildlife tourism activities: Analysis of motivations and specialization levels of divers and whale watchers. Tourism management perspectives, 18, 74-83.

Bentz, J., Lopes, F., Calado, H., \& Dearden, P. (2016b). Understanding diver motivation and specialization for improved scuba management. Tourism in Marine Environments, 12(1), $35-49$.

Berger, P., \& Luckman, T. (1966). The social construction of knowledge. New York: Doubleday. Blase, J. (1986). Socialization as humanization: One side of becoming a teacher. Sociology of Education, 59, 100-1.

Beritelli, P. (2011). Cooperation among prominent actors in a tourist destination. Annals of Tourism Research, 38(2), 607-629.

Berman, S. L., Wicks, A. C., Kotha, S., \& Jones, T. M. (1999). Does stakeholder orientation matter? The relationship between stakeholder management models and firm financial performance. Academy of Management Journal, 42(5), 488-506.

Bethencourt, M., Fernández-Montblanc, T., Izquierdo, A., González-Duarte, M. M., \& MuñozMas, C. (2018). Study of the influence of physical, chemical and biological conditions that influence the deterioration and protection of Underwater Cultural Heritage. Science of the Total Environment, 613, 98-114.

Bianchi, C. N., \& Morri, C. (2000). Marine biodiversity of the Mediterranean Sea: situation, problems and prospects for future research. Marine pollution bulletin, 40(5), 367-376. 
Bideci, C. \& Bideci, M. (2021). Seeking the unusual but sustainable: Scuba diving experiences. Sharpley, R. (Ed) Routledge Handbook of the Tourist Experience, Routledge, pp. 378390.

Bideci, C., \& Cater, C. (2019a). In search of underwater atmosphere: A new diving world on artificial reefs. In M. Volgger and D. Pfister (Eds), Atmospheric Turn in Culture and Tourism: Place, Design and Process Impacts on Customer Behaviour, Marketing and Branding. Bingley: Emerald Publishing Limited, 245-257.

Bideci, C., \& Cater, C. (2019b). Dive and novelty seeking in experimental artificial reefs. Journal on Tourism \& Sustainability, 3(1), 22-31.

Biggs, D., Ban, N. C., \& Hall, C. M. (2012a). Lifestyle values, resilience, and nature-based tourism's contribution to conservation on Australia's Great Barrier Reef. Environmental Conservation, 39(4), 370-379.

Biggs, D., Hall, C. M., \& Stoeckl, N. (2012b). The resilience of formal and informal tourism enterprises to disasters: reef tourism in Phuket, Thailand. Journal of Sustainable Tourism, 20(5), 645-665.

Bitner, M. J. (1992). Servicescapes: The impact of physical surroundings on customers and employees. Journal of Marketing, 56(2), 57-71.

Blancas, F. J., González, M., Lozano-Oyola, M., \& Perez, F. (2010). The assessment of sustainable tourism: Application to Spanish coastal destinations. Ecological Indicators, 10(2), 484-492.

Blancas, F. J., Lozano-Oyola, M., González, M., Guerrero, F. M., \& Caballero, R. (2011). How to use sustainability indicators for tourism planning: The case of rural tourism in Andalusia (Spain). Science of the Total Environment, 412, 28-45.

Blondel, J. (2006). The 'design' of Mediterranean landscapes: a millennial story of humans and ecological systems during the historic period. Human ecology, 34(5), 713-729.

Boatright, J. R. (1994). Fiduciary duties and the shareholder-management relation: Or, what's so special about shareholders? Business Ethics Quarterly, 393-407. 
Boons, F. (2013). Organizing within dynamic ecosystems: Conceptualizing socio-ecological mechanisms. Organization \& Environment, 26(3), 281-297.

Bramwell, B., \& Lane, B. (2000). Collaboration and partnerships in tourism planning. Tourism collaboration and partnerships: Politics, practice and sustainability, 2, 1-19.

Brander, L., Baulcomb, C., van der Lelij, J. A. C., Eppink, F., McVittie, A., Nijsten, L., \& van Beukering, P. (2015). The benefits to people of expanding Marine Protected Areas. VU University, Amsterdam, The Netherlands.

Brander, L. M., Van Beukering, P., Nijsten, L., McVittie, A., Baulcomb, C., Eppink, F. V., \& van der Lelij, J. A. C. (2020). The global costs and benefits of expanding Marine Protected Areas. Marine Policy, 116, 103953.

Brenner, S. N., \& Cochran, P. (1991). The stakeholder theory of the firm: Implications for business and society theory and research. In Proceedings of the international association for business and society, 2, 897-933.

Brinkmann, S., \& Kvale, S. (2014). Interviews: Learning the craft of qualitative research interviewing (3rd ed.). Thousand Oaks, CA: Sage.

Britannica (2020). Malta. https://www.britannica.com/place/Malta (Access date: 05.04.2020).

Bryant, D., Burke, L., McManus, J., \& Spalding, M. (1998). Reefs at risk: a map-based indicator of threats to the world's coral reefs.

Buckley, R. (2012). Sustainable tourism: Research and reality. Annals of tourism research, 39(2), 528-546.

Budeanu, A., \& Chesworth, N. E. (2007). Sustainable tourist behaviour a discussion of opportunities for change, International Journal of Consumer Studies, 31 (5) (2007), 499508.

Burke, L., Reytar, K., Spalding, K., \& Perry, A. (2012). Reefs at risk revisited in the Coral Triangle: World Resources Institute. In the Nature Conservancy. World-Fish Center, International Coral Reef Action Network. UNEP World Conservation Monitoring Center and Global Coral Reef Monitoring Network Washington, DC. 
Braun, V., \& Clarke, V. (2006). Using thematic analysis in psychology. Qualitative research in psychology, 3(2), 77-101.

Braun, V., Clarke, V., \& Rance, N. (2015). How to use thematic analysis with interview data. In. Vossler, A. \& Moller, N. The Counselling and Psychotherapy Research Handbook (183-197). London, UK: Sage.

Brundtland, G. H., Khalid, M., Agnelli, S., Al-Athel, S., \& Chidzero, B. J. N. Y. (1987). Our common future. New York, 8.

Buzzacott, P., \& Denoble, P. J. (2018). DAN Annual Diving Report 2018 Edition: A Report on 2016 Diving Fatalities, Injuries, and Incidents. Divers Alert Network.

Byrd, E. T. (2007). Stakeholders in sustainable tourism development and their roles: applying stakeholder theory to sustainable tourism development. Tourism Review, Vol. 62 No. 2, pp. 6-13.

Camp, E., \& Fraser, D. (2012). Influence of conservation education dive briefings as a management tool on the timing and nature of recreational SCUBA diving impacts on coral reefs. Ocean \& coastal management, 61, 30-37.

Canavan, B. (2016). Tourism culture: Nexus, characteristics, context and sustainability. Tourism Management, 53, 229-243.

Carù, A., \& Cova, B. (2003). Revisiting consumption experience: A more humble but complete view of the concept. Marketing Theory, 3(2), 267-286.

Caselle, J. E., Rassweiler, A., Hamilton, S. L., \& Warner, R. R. (2015). Recovery trajectories of kelp forest animals are rapid yet spatially variable across a network of temperate marine protected areas. Scientific Reports 5:14102 DOI 10.1038/srep14102.

Cater, E. (1995). Environmental contradictions in sustainable tourism. Geographical Journal, 21-28.

Cater, C., \& Cater, E. (2007). Marine Ecotourism. CABI, Oxford. 
Cater, C. (2008). The Life Aquatic: Scuba Diving and the Experiential Imperative. Journal of Tourism in Marine Environments, 5(4), 233-244.

Cater, C., Garrod, B., \& Low, T. (Ed) (2015). The Encyclopaedia of Sustainable Tourism. CABI, Oxford.

Cater, C. I., Poguntke, K., \& Morris, W. (2019). Y Wladfa Gymreig: outbound diasporic tourism and contribution to identity. Tourism Geographies, 21(4), 665-686.

Cater, C., Albayrak, T., Caber, M., \& Taylor, S. (2020). Flow, satisfaction and storytelling: a causal relationship? Evidence from scuba diving in Turkey. Current Issues in Tourism, $1-19$.

Catlin, J., \& Jones, R. (2010). Whale shark tourism at Ningaloo Marine Park: A longitudinal study of wildlife tourism. Tourism Management, 31(3), 386-394.

Cava, F., Schoedinger, S., Strang, C., \& Tuddenham, P. (2005). Science content and standards for ocean literacy: A report on ocean literacy. Retrieved March 25, 2015.

Chabanet, P., Adjeroud, M., Andréfouët, S., Bozec, Y. M., Ferraris, J., Garcìa-Charton, J. A., \& Schrimm, M. (2005). Human-induced physical disturbances and their indicators on coral reef habitats: A multi-scale approach. Aquatic Living Resources, 18(3), 215-230.

Chao, Y. L., \& Lam, S. P. (2011). Measuring responsible environmental behavior: Selfreported and other-reported measures and their differences in testing a behavioral model. Environment and Behavior, 43(1), 53-71.

Chaperon, S., \& Bramwell, B. (2013). Dependency and agency in peripheral tourism development. Annals of tourism research, 40, 132-154.

Chawla, L. (1998). Significant life experiences revisited: A review of research on sources of environmental sensitivity. The Journal of environmental education, 29(3), 11-21.

Checkland, P., (1981). Systems thinking, systems practice. New York: Wiley. 
Chen, J. L., Chuang, C. T., Jan, R. Q., Liu, L. C., \& Jan, M. S. (2013). Recreational Benefits of Ecosystem Services on and around Artificial Reefs: A Case Study in Penghu, Taiwan. Ocean \& Coastal Management 85:58-64.

Cheng, T. M., \& Wu, H. C. (2015). How do environmental knowledge, environmental sensitivity, and place attachment affect environmentally responsible behavior? An integrated approach for sustainable island tourism. Journal of Sustainable Tourism, 23(4), 557-576.

Cheung, L. T. (2013). Improving Visitor Management Approaches for the Changing Preferences and Behaviours of Country Park Visitors in Hong Kong. In: Natural Resources Forum, Wiley Online Library, 37(4), 231-241.

Chung, S. S., Au, A., \& Qiu, J. W. (2013). Understanding the underwater behaviour of scuba divers in Hong Kong. Environmental Management, 51(4), 824-837.

Clarkson, M. E. (1995). A stakeholder framework for analyzing and evaluating corporate social performance. Academy of Management Review, 20(1), 92-117.

Clément, E. (1996). Current developments at UNESCO concerning the protection of the underwater cultural heritage. Presentation made at the first and the second national maritime museum conferences on the protection of underwater cultural heritage (Greenwich, 3 and 4 February 1995) (London, IMO, 25 and 26 January 1996). Marine Policy, 20(4), 309-323.

Cohen, S. A. (2013). Reflections on reflexivity in leisure and tourism studies. Leisure Studies, 32(3), 333-337.

Coll, M., Piroddi, C., Steenbeek, J., Kaschner, K., Ben Rais Lasram, F., Aguzzi, J., et al. (2010) The Biodiversity of the Mediterranean Sea: Estimates, Patterns, and Threats. PLoS ONE 5(8), e11842. https://doi.org/10.1371/journal.pone.0011842

Collins, H. (2010). Creative research: the theory and practice of research for the creative industries, AVA Publishing 
Comstock, G. (2012). Research ethics: A philosophical guide to the responsible conduct of research. Cambridge University Press.

Cope, R. (2003). The international diving market. Travel \& Tourism Analyst, (6), 1-39.

Corbin, J., \& Holt, N. (2005). Grounded Theory. BSC Lewin, Research methods in the social sciences, 49-55.

Corbin, J. \& Strauss, A. (2008). Basics of qualitative research: Techniques and procedures for developing grounded theory (3rd ed.). Thousand Oaks, CA: Sage.

Corlett, S., \& Mavin, S. (2018). Reflexivity and researcher positionality. In Cassell, C., Cunliffe, A. L., \& Grandy, G. (Eds). The SAGE handbook of qualitative business and management research methods. Sage. London, 377-399.

Cottrell, S. P., \& Graefe, A. R. (1997). Testing a conceptual framework of responsible environmental behavior. The Journal of Environmental Education, 29 (1), 17-27.

Craig, J. (2015). Value of Shipwreck Data in Databases. Journal of Indo-Pacific Archaeology, $36,34-41$.

Creswell, J. W. (1994). Research design: Qualitative \& quantitative approaches. $\left(15^{\text {th }} \mathrm{Ed}\right)$, Sage, Thousand Oaks.

Creswell, J. W. (2013). Qualitative inquiry and research design: Choosing among five approaches. Thousand Oaks, CA: Sage.

Creswell, J. W., \& Poth, C. N. (2007). Philosophical, paradigm, and interpretive frameworks. Qualitative inquiry and research design: Choosing among five approaches, 2(5), 15-34.

Creswell, J. W., \& Poth, C. N. (2016). Qualitative inquiry and research design: Choosing among five approaches. Sage publications.

Crossley, É. (2021). Deep reflexivity in tourism research. Tourism Geographies, 23(1-2), 206227.

Crotty, M. (1996). Phenomenology and nursing research. Melbourne: Churchill Livingstone. 
Crotty, M. (1998). The foundations of social research. Sydney: Allen and Unwin.

Crouch, G. I., \& Ritchie, J. B. (2005). Application of the analytic hierarchy process to tourism choice and decision making: A review and illustration applied to destination competitiveness. Tourism Analysis, 10(1), 17-25.

Csikszentmihalyi, M. (1990). Flow-The Psychology of Optimal Experience. Harper \& Row, New York.

Curiazi, R. (2014). Social dialogue and territorial cooperation in tourist destinations: the "best practices" for sustainability. Turismo y Desarrollo: Revista de Investigación en Turisme y Desarrollo Local, 7(16).

Daily, G. C. (2000). Management objectives for the protection of ecosystem services. Environmental Science \& Policy, 3(6), 333-339.

Danovaro, R., Bongiorni, L., Corinaldesi, C., Giovannelli, D., Damiani, E., Astolfi, P., ... \& Pusceddu, A. (2008). Sunscreens cause coral bleaching by promoting viral infections. Environmental health perspectives, 116(4), 441-447.

Davis, D., \& Tisdell, C. (1995). Recreational scuba-diving and carrying capacity in marine protected areas. Ocean \& Coastal Management, 26(1), 19-40.

De Brauwer, M., Gordon, L. M., Shalders, T. C., Saunders, B. J., Archer, M., Harvey, E. S. \& McIlwain, J. L. (2019). Behavioural and pathomorphological impacts of flash photography on benthic fishes. Scientific reports, 9(1), 1-14

De Groot, J., \& Bush, S. R. (2010). The potential for dive tourism led entrepreneurial marine protected areas in Curacao. Marine Policy, 34 (5), 1051-1059.

De Wit, C. T. (1982). Simulation of living systems. In Simulation of plant growth and crop production (pp. 3-8). Pudoc.

De la Nuez-Hernández, D., Valle, C., Forcada, A., Correa, J., \& Torquemada, Y. F. (2014). Assessing the erect bryozoan Myriapora truncata (Pallas, 1766) as indicator of recreational diving impact on coralligenous reef communities. Ecological indicators, 46, 193-200. 
De Lopez, T. T. (2001). Deforestation in Cambodia: a stakeholder management approach. The International Journal of Sustainable Development \& World Ecology, 8(4), 380-394.

Dearden, P., Bennett, M., \& Rollins, R. (2006). Dive specialization in Phuket: Implications for reef conservation. Environmental Conservation, 33(4), 353-363.

Dearden, P., Bennett, M., \& Rollins, R. (2007). Perceptions of diving impacts and implications for reef conservation. Coastal Management, 35(2-3), 305-317.

Dearden, P., \& Manopawitr, P. (2011). Climate change-coral reefs and dive tourism in Southeast Asia. Disappearing destinations: climate change and future challenges for coastal tourism. UK: CAB International, 144-160.

Decrop, A. (1999). Triangulation in qualitative tourism research. Tourism Management, 20(1), 157-161.

Dedeoğlu, B. B., Taheri, B., Okumus, F., \& Gannon, M. (2020). Understanding the importance that consumers attach to social media sharing (ISMS): Scale development and validation. Tourism Management, 76, 103954.

DEMA (2020). Fast Facts: Recreational Scuba Diving and Snorkelling. https://www.dema.org/store/download.aspx?id=7811B097-8882-4707-A160-F999B49614B6 (Access date: 27.03.2020).

Denoble, P. J. (2019). DAN ANNUAL DIVING REPORT 2019 Edition. https://www.ncbi.nlm.nih.gov/books/NBK562527/pdf/Bookshelf_NBK562527.pdf

Denzin, N. K. (2009). The research act: A theoretical introduction to sociological methods. Transaction publishers.

Di Franco, A., Milazzo, M., Baiata, P., Tomasello, A., \& Chemello, R. (2009). Scuba diver behaviour and its effects on the biota of a Mediterranean marine protected area. Environmental Conservation, 32-40.

Dikou, A., \& Troumbis, A. (2006). Dive Tourism in North Aegean, Greece: Potential and Prospects. Tourism in Marine Environments, 3(2), 131-143. 
Dimmock, K. (2009). Finding Comfort in Adventure: Experiences of Recreational SCUBA Divers, Leisure Studies, 28(3), 279-295.

Dimmock, K., Cummins, T., \& Musa, G. (2013). The business of scuba diving. In: Musa, G., \& Dimmock, K. (Ed), Scuba Diving Tourism: Contemporary Geographies of Leisure, Tourism and Mobility. Routledge, UK

Dimmock, K., Hawkins, E. R., \& Tiyce, M. (2014). Stakeholders, industry knowledge and adaptive management in the Australian whale-watching industry. Journal of sustainable tourism, 22(7), 1108-1121.

Dimmock, K., \& Musa, G. (2015). Scuba Diving Tourism System: A framework for collaborative management and sustainability. Marine Policy, 54:52-58.

Dinsdale, E. A., \& Harriott, V. J. (2004). Assessing anchor damage on coral reefs: a case study in selection of environmental indicators. Environmental Management, 33(1), 126-139.

Ditton, R. B., Holland, S. M., \& Anderson, D. K. (2002). Recreational fishing as tourism. Fisheries, 27(3), 17-24.

Dolnicar, S., Crouch, G. I., \& Long, P. (2008). Environment-friendly tourists: what do we really know about them? Journal of Sustainable Tourism, 16(2), 197-210.

Domínguez-Gómez, J. A., \& González-Gómez, T. (2017). Analysing stakeholders’ perceptions of golf-course-based tourism: A proposal for developing sustainable tourism projects. Tourism Management, 63, 135-143.

Donaldson, T., \& Preston, L. E. (1995). The stakeholder theory of the corporation: Concepts, evidence, and implications. Academy of Management Review, 20(1), 65-91.

Duffus, D. A., \& Dearden, P. (1990). Non-consumptive wildlife-oriented recreation: A conceptual framework. Biological Conservation, 53(3), 213-231.

ECOSOC, U. (2019). Special Edition: Progress towards the Sustainable Development Goals Report of the Secretary-General. Advanced unedited version. New York (US): United Nations. 
Edney, J. (2006). Impacts of Recreational Scuba Diving on Shipwrecks in Australia and the Pacific. Micronesian Journal of the Humanities and Social Sciences, 15(1/2), 201-233.

Edney, J. (2012). Diver characteristics, motivations, and attitudes: Chuuk Lagoon. Tourism in Marine Environments, 8(1-2), 7-18.

Edney, J. (2016). A Framework for Managing Diver Impacts on Historic Shipwrecks. Journal of Maritime Archaeology, 11(3), 271-297.

Edney, J. (2017). Human Dimensions of Wreck Diving and Management: Case Studies from Australia And Micronesia. Tourism in Marine Environments, 12(3/4), 169-182.

Edney, J., \& Boyd, W. E. (2021). Diving under the radar: divers and submerged aircraft. Journal of Heritage Tourism, 16(1), 100-117.

Edney, J., \& Howard, J. (2013). Wreck diving. In G. Musa \& K. Dimmock (Eds), Scuba Diving Tourism, Abington, Oxon, UK: Routledge, (52-56).

Edney, J., \& Spennemann, D. H. R. (2014). Can Artificial Reefs Reduce Impacts on Historic Shipwrecks? Bulletin of the Australasian Institute for Maritime Archaeology, 38:93-110.

Edney, J., Dimmock, K., \& Boyd, W. E. (2021a). Understanding Diver Behavior on Underwater Cultural Heritage: Enriching the Observation Record Using Video Methods. Sustainability, 13(10), 5601.

Edney, J., Dimmock, K., \& Boyd, W. E. (2021b). Diving Deeper into Wreck Diver Motivations and Attitudes. Tourism and Hospitality, 2(2), 195-217.

Eisenhardt, K. M. (1989). Building theories from case study research. Academy of Management Review, 14(4), 532-550.

Eisenhardt, K. M., \& Bourgeois III, L. J. (1988). Politics of strategic decision making in highvelocity environments: Toward a midrange theory. Academy of Management Journal, 31(4), 737-770.

Elliott, V. (2018). Thinking about the coding process in qualitative data analysis. The Qualitative Report, 23(11), 2850-2861. 
Elo, S., Kääriäinen, M., Kanste, O., Pölkki, T., Utriainen, K., \& Kyngäs, H. (2014). Qualitative content analysis: A focus on trustworthiness. SAGE open, 4(1), 2158244014522633.

Epstein, N., Bak, R. P. M., \& Rinkvich, B. (1999). Implementation of a small-scale "no-use zone" policy in a reef ecosystem: Eilat's reef-lagoon six years later. Coral Reefs, 18(4), 327-332.

ERA (2020). Important Natural Areas https://era.org.mt/en/Pages/Important-NaturalAreas.aspx (Access date: 01.07.2020).

Etherington, K. (2004). Becoming a reflexive researcher: Using ourselves in research. Jessica Kingsley Publishers, London.

Evan, W. M., \& Freeman, R. E. (1988). A stakeholder theory of the modern corporation: Kantian capitalism.

Fabi, G., Scarcella, G., Spagnolo, A., Bortone, S. A., Charbonnel, E., Goutayer, J. J., ... \& Trommelen, M. (2015). Practical guidelines for the use of artificial reefs in the Mediterranean and the Black Sea. General Fisheries Commission for the Mediterranean. Studies and Reviews, (96).

Fabinyi, M. (2008). Dive tourism, fishing and marine protected areas in the Calamianes Islands, Philippines. Marine Policy, 32(6), 898-904.

Farrell, B. H., \& Twining-Ward, L. (2004). Reconceptualizing tourism. Annals of tourism research, 31(2), 274-295.

Fath, B. D. (2015). Quantifying economic and ecological sustainability. Ocean \& Coastal Management, 108, 13-19.

Fauville, G., Strang, C., Cannady, M. A., \& Chen, Y. F. (2019). Development of the International Ocean Literacy Survey: measuring knowledge across the world. Environmental Education Research, 25(2), 238-263.

Feighery, W. (2006). Reflexivity and tourism research: Telling an (other) story. Current Issues in Tourism, 9(3), 269. 
Fetterman, D. M. (1989). Applied social research methods series, Vol. 17. Ethnography: Step by step. Sage Publications, Inc.

Fletcher, J., Fyall, A., Gilbert, D., \& Wanhill, S. (2018). Tourism: Principles and practice. Sixth Edition. Pearson UK.

Finlay, L. (2009). Debating phenomenological research methods. Phenomenology \& Practice, $3,6-25$.

Fitzsimmons, C. (2009). Why dive? and why here? A study of recreational diver enjoyment at Fijian eco-tourist resort. Tourism in Marine Environments, 5(2-3), 159-173

Foley, K. (2005). Meta-management: A stakeholder/quality management approach to wholeof enterprise management. Sydney: SAI Global.

Fontaine, C., Haarman, A., \& Schmid, S. (2006). The stakeholder theory. Edlays Education, 1, $1-33$.

Fosse, J., \& Le Tellier, J. (2017). Promoting Sustainable and Inclusive Tourism in The Mediterranean: Guidelines for a Sustainable Tourism in the Mediterranean. Plan Blue Notes, 32. IPB Office Solutions.

Freeman, R. E. (1984). Strategic Management: A stakeholder Approach. Boston, MA: Pitman.

Freeman, R. E., \& Gilbert, D. R. (1988). Corporate strategy and the search for ethics (Vol. 1). Englewood Cliffs, NJ: Prentice-Hall.

Freeman, R. E. (1994). The politics of stakeholder theory: Some future directions. Business ethics quarterly, 409-421.

Freeman, R. E. (1998). Stakeholder Theory in Encyclopedia of Management G.L. Cooper and C. Argryis (Eds), Oxford: Blackwell.

Freeman, R. E. (1999). Response: Divergent Stakeholder Theory. Academy of Management Review, 24(2), 233-36. 
Freeman, R. E. (2001). A stakeholder theory of the modern corporation. Perspectives in Business Ethics Sie, 3, 144.

Freeman, R. E., \& McVea, J. (2001). A stakeholder approach to strategic management. The Blackwell handbook of strategic management, 189-207.

Freeman, R. E., Wicks, A. C., \& Parmar, B. (2004). Stakeholder theory and "the corporate objective revisited". Organization Science, 15(3), 364-369.

Friedman, A. L., \& Miles, S. (2006). Stakeholders: Theory and practice. Oxford University.

Freudenreich, B., Lüdeke-Freund, F., \& Schaltegger, S. (2020). A stakeholder theory perspective on business models: Value creation for sustainability. Journal of Business Ethics, 166(1), 3-18.

Fryxell, G. E., \& Lo, C. W. (2003). The influence of environmental knowledge and values on managerial behaviours on behalf of the environment: An empirical examination of managers in China. Journal of business ethics, 46(1), 45-69.

Gallagher, S., \& Zahavi, D. (2012). The Phenomenological Mind. 2nd Edition. London: Routledge.

Garcia, A. C., \& Barreiros, J. P. (2018). Are underwater archaeological parks good for fishes? Symbiotic relation between cultural heritage preservation and marine conservation in the Azores. Regional Studies in Marine Science, 21, 57-66.

Garcia, O., \& Cater, C. (2020). Life below water; challenges for tourism partnerships in achieving ocean literacy. Journal of Sustainable Tourism, 1-20.

Garriga, E. (2014). Beyond stakeholder utility function: Stakeholder capability in the value creation process. Journal of Business Ethics, 120(4), 489-507.

Garrod, B. (2008). Market segments and tourist typologies for diving tourism. Garrod, B., Gössling, S. (Ed), New Frontiers in Marine Tourism: Diving Experiences, Sustainability, Management. Elsevier Press, Amsterdam, 31-48. 
Garrod, B., \& Fennell, D. A. (2004). An analysis of whalewatching codes of conduct. Annals of Tourism Research, 31(2), 334-352.

Garrod, B., \& Gössling, S. (2008). Introduction. In: Garrod, B., Gössling, S. (Ed), New Frontiers in Marine Tourism: Diving Experiences, Sustainability, Management. Elsevier Press, Amsterdam, 8-29.

Garvare, R., \& Johansson, P. (2010). Management for sustainability-a stakeholder theory. Total quality management, 21(7), 737-744.

Genç, T. Ş., Özgül, A., \& Altan, Lök. (2017). The Use of Artificial Reefs for Recreational Diving. Turkish Journal of Maritime and Marine Sciences, 3(1), 27-33.

Gerovasileiou, V., \& Voultsiadou, E. (2012). Marine caves of the Mediterranean Sea: a sponge biodiversity reservoir within a biodiversity hotspot. PLoS One, 7(7), e39873.

Gerungan, A., \& Chia, K. W. (2020). Scuba diving operators' perspective of scuba diving tourism business in Nusa Penida, Indonesia. Journal of Outdoor Recreation and Tourism, 31, 100328.

Giglio, V. J., Luiz, O. J., \& Ferreira, C. E. (2020). Ecological impacts and management strategies for recreational diving: A review. Journal of Environmental Management, 256, 109949.

Gioia, D. A., \& Pitre, E. (1990). Multiparadigm perspectives on theory building. Academy of management review, 15(4), 584-602.

Girard, L. F., \& Nijkamp, P. (2009). Narrow escapes: pathways to sustainable Local cultural tourism. Cultural tourism and sustainable local development, 1-9.

Glaser, B., \& Strauss, A. (1967). The discovery of grounded theory. 1967. Weidenfield \& Nicolson, London, 1-19.

Goeldner, C. R., \& Ritchie, J. B. (2009). Tourism: Principles. Practices, Philosophies, 2.

Goodpaster, K. E. (1991). Business ethics and stakeholder analysis. Business ethics quarterly, 53-73. 
Goodpaster, K. E., \& Holloran, T. E. (1994). In defense of a paradox. Business Ethics Quarterly, 423-429.

Google, 2020. Maps of Mediterranean Sea. https://www.google.com/maps/place/Mediterranean+Sea/@37.1130947,17.3553205,5z/ data=!4m5!3m4!1s0x131421b81c473c9f:0x2e93598afeccf840!8m2!3d34.5531284!4d1 8.0480105 (Access date: 05.04.2020).

Graneheim, U. H., \& Lundman, B. (2004). Qualitative content analysis in nursing research: concepts, procedures and measures to achieve trustworthiness. Nurse education today, 24(2), 105-112.

Gregory, S. F., \& Edney, J. (2019). Divers or Divas? A Market Analysis of the Mature Aged Female Diver: An Australian Perspective. Tourism in Marine Environments, 14(3), 143162.

Guba, E. G. (1990). The paradigm dialogs. Sage Publications Inc.

Guba, E. G. \& Lincoln, Y. S. (2005). Paradigmatic Controversies, Contradictions, and Emerging Confluences. In Denzin, N. K. \& Lincoln, Y. S. (Eds), The Sage handbook of qualitative research, 191-215. Sage Publications Ltd.

Gubbay, S. (1995). Marine protected areas-past, present and future. In Marine Protected Areas, 1-14. Springer, Dordrecht.

Gunn, C.A. (1994). Tourism planning: Basic concepts cases ( $3^{\text {rd }}$ Ed). Washington DC. Taylor and Francis

Guzner, B., Novplansky, A., Shalit, O., \& Chadwick, N. E. (2010). Indirect impacts of recreational scuba diving: patterns of growth and predation in branching stony corals. Bulletin of Marine Science, 86(3), 727-742.

Haddock-Fraser, J., \& Hampton, M. P. (2012). Multistakeholder values on the sustainability of dive tourism: case studies of Sipadan and Perhentian Islands, Malaysia. Tourism Analysis, 17(1), 27-41. 
Halpenny, E. A. (2010). Pro-environmental behaviours and park visitors: The effect of place attachment. Journal of environmental psychology, 30(4), 409-421.

Hale, L. Z., \& Olsen, S. B. (1993). Coral reef management in Thailand: a step toward integrated coastal management. Oceanus, 36(3), 27-35.

Hall, A. D., \& Fagen, R. E. (1956). Definition of system. Introductory Chapter to Systems Engineering, New York, Bell Telephone Laboratoires [reprinted in:(1956). General Systems 1: 18-28, 81-92.

Hall, C. M., \& Butler, R. W. (1995). In Search of Common Ground: Reflections on Sustainability: Complexity and Process in the Tourism System: A Discussion. Journal of Sustainable Tourism, 3(2), 99-105.

Hall, C. M. (2008). Tourism planning: Policies, processes and relationships. Pearson Education.

Hammond, D. (2002). Exploring the genealogy of systems thinking. Systems Research and Behavioral Science, 19(5), 429-439.

Hammerton, Z., Dimmock, K., Hahn, C., Dalton, S. J., \& Smith, S. D. (2012). Scuba diving and marine conservation: collaboration at two Australian subtropical destinations. Tourism in Marine Environments, 8(1-2), 77-90.

Hammerton, Z. (2017). Low-impact diver training in management of SCUBA diver impacts. Journal of Ecotourism, 16(1), 69-94.

Harding, T., \& Whitehead, D. (2013). Analysing data in qualitative research. In: Nursing \& Midwifery Research: Methods and Appraisal for Evidence-Based Practice. 4th edn. (Schneider Z, Whitehead D, LoBiondo-Wood G \& Haber J), Elsevier - Mosby, Marrickville, Sydney, 141-160.

Hardy, A. L., \& Beeton, R. J. (2001). Sustainable tourism or maintainable tourism: Managing resources for more than average outcomes. Journal of Sustainable Tourism, 9(3), 168192. 
Harriott, V. J., Davis, D., \& Banks, S. A. (1997). Recreational diving and its impact in marine protected areas in eastern Australia. Ambio, 173-179.

Hardy, A. L., \& Beeton, R. J. (2001). Sustainable tourism or maintainable tourism: Managing resources for more than average outcomes. Journal of Sustainable Tourism, 9(3), 168192.

Hasler, H., \& Ott, J. A. (2008). Diving down the reefs? Intensive diving tourism threatens the reefs of the northern Red Sea. Marine Pollution Bulletin, 56(10), 1788-1794.

Hayllar, B., \& Griffin, T. (2005). The precinct experience: a phenomenological approach Tourism Management 26:517-528.

Hawkins, J. P., \& Roberts, C. M. (1992). Effects of recreational SCUBA diving on fore-reef slope communities of coral reefs. Biological Conservation, 62(3), 171-178.

Hawkins, J. P., \& Roberts, C. M. (1994). The growth of coastal tourism in the red sea: Present and future effects on coral reefs. Ambio, 23(8), 503-508.

Hawkins, J. P., \& Roberts, C. M. (1997). Estimating the carrying capacity of coral reefs for scuba diving. In Proceedings of the 8th international coral reef symposium (Vol. 2: 19231926). Panama: Smithsonian Tropical Research Institute.

Hawkins, J. P., Roberts, C. M., Van'T Hof, T., De Meyer, K., Tratalos, J., \& Aldam, C. (1999). Effects of recreational scuba diving on Caribbean coral and fish communities. Conservation biology, 13(4), 888-897.

Hawkins, J. P., Roberts, C. M., Kooistra, D., Buchan, K., \& White, S. (2005). Sustainability of scuba diving tourism on coral reefs of Saba. Coastal Management, 33(4), 373-387.

Haynes, K. (2012). Reflexivity in qualitative research. In G. Symon and C. Cassell (Eds), Qualitative Organizational Research: Core Methods and Current Challenges. London: Sage. p.72-89.

Haywood, K. M. (1986). Can the tourist-area life cycle be made operational? Tourism Management, 7(3), 154-167. 
He, P., He, Y., \& Xu, F. (2018). Evolutionary analysis of sustainable tourism. Annals of Tourism Research, 69, 76-89.

Heidegger, M. (1962). Being and Time, trans. J. Macquarrie and E. Robmson. New York: Harper.

Heil, A. (2018). Systems theory.SPC 330, siue.edu. https://www.siue.edu/ adheil/Systems\%20Theory\%20Paper.pdf (the last date accessed to the source: 10.11 .2021 )

Heron, J., \& Reason, P. (1997). A Participatory Inquiry Paradigm. Qualitative Inquiry, (3) 274294. doi:10.1177/107780049700300302.

Heyman, W. D., Carr, L. M., \& Lobel, P. S. (2010). Diver ecotourism and disturbance to reef fish spawning aggregations: it is better to be disturbed than to be dead. Marine Ecology Progress Series, 419, 201-210.

Heywood, J. L., Manning, R. E., \& Vaske, J. J. (2002). Normative research in outdoor recreation: Progress and prospects for continued development and applications. Leisure Sciences, 24(3-4), 251-253.

Hibbert, P., Coupland, C. \& MacIntosh, R. (2010). Reflexivity: recursion and relationality in organizational research processes. Qualitative Research in Organizations and Management: An International Journal, 5(1), 47-62.

Higham, J. E. S., \& Lück, M. (2007). Marine wildlife and tourism management: In search of scientific approaches to sustainability. Marine wildlife and tourism management: Insights from the natural and social sciences, 1-18.

Hillmer-Pegram, K. C. (2014). Understanding the resilience of dive tourism to complex change. Tourism Geographies, 16(4), 598-614.

Hines, J. M., Hungerford, H. R., \& Tomera, A. N. (1987). Analysis and synthesis of research on responsible environmental behavior: A meta-analysis. The Journal of environmental education, 18(2), 1-8. 
Hirschman, E. C., \& Holbrook, M. B. (1982). Hedonic consumption: emerging concepts, methods and propositions. Journal of Marketing, 46(3), 92-101.

Hodgson, G. (1999). A global assessment of human effects on coral reefs. Marine Pollution Bulletin, 38(5), 345-355.

Honderich, T. (2005). The Oxford companion to philosophy. OUP Oxford.

Hörisch, J., Freeman, R. E., \& Schaltegger, S. (2014). Applying stakeholder theory in sustainability management: Links, similarities, dissimilarities, and a conceptual framework. Organization \& Environment, 27(4), 328-346.

Hoyt, E. (2018). Marine Protected Areas. Encyclopedia of Marine Mammals (Third Edition) (Eds: Würsig, B., Thewissen, J.G.M. \& Kovacs, K.M.). 569-580, Academic Press. doi.org/10.1016/B978-0-12-804327-1.00167-9

Howitt, D. (2019). Introduction to qualitative research methods in psychology: putting theory into practice: Fourth edition. | Harlow, England; New York: Pearson.

Huang, H. P., \& Yore, L. D. (2005). A comparative study of Canadian and Taiwanese grade 5 children's environmental behaviors, attitudes, concerns, emotional dispositions, and knowledge. International Journal of Science and Mathematics Education, 1(4), 419-448.

Huang, P. S., \& Shih, L. H. (2009). Effective environmental management through environmental knowledge management. International Journal of Environmental Science \& Technology, 6(1), 35-50.

Huang, Y., \& Coelho, V. R. (2017). Sustainability performance assessment focusing on coral reef protection by the tourism industry in the Coral Triangle region. Tourism Management, 59:510-527.

Hungerford, H. R., \& Volk, T. L. (1990). Changing learner behavior through environmental education. The journal of environmental education, 21(3), 8-21.

Husserl, E. (1928). On the Phenomenology of the Consciousness of Internal Time, Translated by. Brough, J.B.; Dordrecht: Kluwer, 1990. 
Husserl, E. (1970). The Crisis of European Sciences and Transcendental Phenomenology: An Introduction to Phenomenological Philosophy. Trans. D. Carr. Evanston, IL: Northwestern University Press.

Huth, B., Morgan, A., \& Burkart, C. (2015). Measuring Florida Artificial Reef Economic Benefits: A Synthesis. Florida Artificial Reef Summit 2015.

Hvenegaard, G. T. (2002). Using tourist typologies for ecotourism research. Journal of ecotourism, 1(1), 7-18.

Idczak, S. E. (2007). I am a nurse: Nursing students learn the art and science of nursing. Nurs Educ Perspect 28: 66-71.

Iniesta-Bonillo, M. A., Sánchez-Fernández, R., \& Jiménez-Castillo, D. (2016). Sustainability, value, and satisfaction: Model testing and cross-validation in tourist destinations. Journal of Business Research, 69(11), 5002-5007.

IOC/UNESCO, IMO, FAO, UNDP. (2011). A Blueprint for Ocean and Coastal Sustainability. Paris: IOC/UNESCO, 42.

Ioannides, D. (1995). A flawed implementation of sustainable tourism: the experience of Akamas, Cyprus. Tourism Management, 16(8), 583-592.

IUCN (2021). Issues Brief: Marine protected areas and climate change https://www.iucn.org/resources/issues-briefs/marine-protected-areas-and-climatechange\#: :text=Marine\%20Protected\%20Areas\%20(MPAs)\%20are,by\%20exclusively \%20no\%2Dtake\%20MPAs (Access date: 07.04.2021).

Jaeger, G., \& Selznick, P. (1964). A normative theory of culture. American Sociological Review, 653-669.

Jamal, T. B., \& Getz, D. (1995). Collaboration theory and community tourism planning. Annals of tourism research, 22(1), 186-204.

Jalani, J. O. (2012). Local people's perception on the impacts and importance of ecotourism in Sabang, Palawan, Philippines. Procedia-Social and Behavioral Sciences, 57, 247-254. 
Jawahar, I. M., \& McLaughlin, G. L. (2001). Toward a descriptive stakeholder theory: An organizational life cycle approach. Academy of management review, 26(3), 397-414.

Jeaheng, Y., \& Han, H. (2020). Thai street food in the fast growing global food tourism industry: Preference and behaviors of food tourists. Journal of Hospitality and Tourism Management, 45, 641-655.

Jennings, G. (2010). Tourism research ( $2^{\text {nd }}$ Ed). John Wiley \& Sons, Milton, Qld.

Jensen, A., Collins, K., \& Lockwood, P. (2000). Current issues relating to artificial reefs in European seas. In Artificial Reefs in European Seas, 489-499. Springer, Dordrecht.

Jentoft, S., Pascual-Fernandez, J. J., De la Cruz Modino, R., Gonzalez-Ramallal, M., \& Chuenpagdee, R. (2012). What stakeholders think about marine protected areas: case studies from Spain. Human Ecology, 40(2), 185-197.

Jepson Jr, E. J., \& Edwards, M. M. (2010). How possible is sustainable urban development? An analysis of planners' perceptions about new urbanism, smart growth and the ecological city. Planning Practice \& Research, 25(4), 417-437.

Jewell, N. (2004). The effectiveness of interpretation on diver attitudes and awareness of underwater shipwreck values- SS Yongala, A case study. The Bulletin of the Australasian Institute for Maritime Archaeology 28:43-62.

Johnson, R. A., \& Greening, D. W. (1999). The effects of corporate governance and institutional ownership types on corporate social performance. Academy of management journal, 42(5), 564-576.

Johnson, M. L., \& Sandell, J. (2014). Advances in marine biology: marine managed areas. London: Elsevier, 416.

Jones, P. J. (1994). A review and analysis of the objectives of marine nature reserves. Ocean \& Coastal Management, 24(3), 149-178.

Jones, T. M. (1995). Instrumental stakeholder theory: A synthesis of ethics and economics. Academy of management review, 20(2), 404-437. 
Jones, T. M., \& Wicks, A. C. (1999). Convergent stakeholder theory. Academy of management review, 24(2), 206-221.

Joyce, A., \& Paquin, R. L. (2016). The triple layered business model canvas: A tool to design more sustainable business models. Journal of cleaner production, 135, 1474-1486.

Juvan, E., \& Dolnicar, S. (2014). The attitude-behaviour gap in sustainable tourism. Annals of tourism research, 48, 76-95.

Kastenholz, E. (2004). 'Management of Demand' as a Tool in Sustainable Tourist Destination Development. Journal of Sustainable Tourism, 12(5), 388-408.

Kelleher, G., \& Kenchington, R. (1992). Guidelines for establishing marine protected areas. A marine conservation and development report., IUCN, Gland, Switzerland, U, 79.

Kim, J. H., \& Ritchie, J. B. (2014). Cross-cultural validation of a memorable tourism experience scale (MTES). Journal of Travel Research, 53(3), 323-335.

Kirkbride-Smith, A. E., Wheeler, P. M., \& Johnson, M. L. (2013). The Relationship between Diver Experience Levels and Perceptions of Attractiveness of Artificial Reefs Examination of a Potential Management Tool. PLoS ONE 8(7).

Kirkbride-Smith, A. E., Wheeler, P. M., \& Johnson, M. L. (2016). Artificial reefs and marine protected areas: a study in willingness to pay to access Folkestone Marine Reserve, Barbados, West Indies. Peer Journal.

Kler, B. K., \& Tribe, J. (2012). Flourishing through SCUBA: Understanding the pursuit of dive experiences. Tourism in Marine Environments, 8(1-2), 19-32.

Kler, B., \& Moskwa, E. (2013). Experience, interpretation and meanings. Scuba diving tourism: contemporary geographies of leisure, tourism and mobility. UK: Routledge, 134-151.

Klint, L. M., Jiang, M., Law, A., Delacy, T., Filep, S., Calgaro, E., ... \& Harrison, D. (2012). Dive tourism in Luganville, Vanuatu: Shocks, stressors, and vulnerability to climate change. Tourism in Marine Environments, 8(1-2), 91-109. 
Koop, K., Booth, D., Broadbent, A., Brodie, J., Bucher, D., Capone, D., ... \& Hoegh-Guldberg, O. (2001). ENCORE: the effect of nutrient enrichment on coral reefs. Synthesis of results and conclusions. Marine pollution bulletin, 42(2), 91-120.

Korstjens, I., \& Moser, A. (2017). Series: Practical guidance to qualitative research. Part 2: Context, research questions and designs. European Journal of General Practice, 23(1), 274-279.

Korstjens, I., \& Moser, A. (2018). Series: Practical guidance to qualitative research. Part 4: Trustworthiness and publishing. European Journal of General Practice, 24(1), 120-124.

Krieger, J. R., \& Chadwick, N. E. (2013). Recreational diving impacts and the use of pre-dive briefings as a management strategy on Florida coral reefs. Journal of Coastal Conservation, 17(1), 179-189.

Kraus, G., \& Diekmann, R. (2018). Impact of Fishing Activities on Marine Life. In: Salomon M., Markus T. (eds) Handbook on Marine Environment Protection. Springer, Cham. https://doi.org/10.1007/978-3-319-60156-4_4

Kruger, L. E., \& Jakes, P. J. (2003). The importance of place: Advances in science and application. Forest Science, 49(6), 819-821.

Ku, K. C., \& Chen, T. C. (2013). A conceptual process-based reference model for collaboratively managing recreational scuba diving in Kenting National Park. Marine Policy, 39, 1-10.

Lafferty, W. M., \& Eckerberg, K. (2013). From the Earth Summit to Local Agenda 21: working towards sustainable development. Routledge.

Lamb, J. B., True, J. D., Piromvaragorn, S., \& Willis, B. L. (2014). Scuba diving damage and intensity of tourist activities increases coral disease prevalence. Biological Conservation, $178,88-96$.

Langdridge, D. (2007). Phenomenological psychology: Theory, research and method. London: Pearson Education. 
Laszlo, E., \& Clark, J. W. (1972). Introduction to systems philosophy (p. 24). New York: Gordon and Breach.

Laszlo, A., \& Krippner, S. (1998). Systems theories: Their origins, foundations, and development. Advances in Psychology-Amsterdam-, 126, 47-76.

Lazoc, A., \& Lut, D. M. (2013). An investigation of the experience theory in the context of tourism research. Quality-Access to Success, 14.

Le Pelley, B., \& Laws, E. (1998). A stakeholder-benefits approach to tourism management in a historic city centre: The Canterbury City Centre Initiative. Embracing and managing change in tourism: International case studies, 71-96.

Ledlie, J., Gardner, P., \& Seltzer, M. I. (2007). Network Coordinates in the Wild. In NSDI (Vol. 7: 299-311).

Lee, T. H., \& Jan, F. H. (2019). Can community-based tourism contribute to sustainable development? Evidence from residents' perceptions of the sustainability. Tourism Management, 70, 368-380.

Leenhardt, P., Low, N., Pascal, N., Micheli, F., \& Claudet, J. (2015). The role of marine protected areas in providing ecosystem services. In: Belgrano A, Woodward G, Jacob U, eds. Aquatic functional biodiversity: an ecological and evolutionary perspective. London: Elsevier Inc, 211-239.

Leiper, N. (1989). Tourism and Tourism Systems (Occasional Paper No. 1). Massey University. Palmerston North.

Leiper, N. (2004). Tourism Management (Vol. 455). Frenchs Forest: Pearson Education Australia.

Lenzen, M., Sun, Y. Y., Faturay, F., Ting, Y. P., Geschke, A., \& Malik, A. (2018). The carbon footprint of global tourism. Nature Climate Change, 8(6), 522-528.

Leujak, W., \& Ormond, R. F. (2007). Visitor perceptions and the shifting social carrying capacity of South Sinai’s coral reefs. Environmental Management, 39(4), 472-489. 
Leung, Y. F. (2018). Tourism and visitor management in protected areas: Guidelines for sustainability. A. Spenceley, G. Hvenegaard, R. Buckley, \& C. Groves (Eds). Gland: IUCN.

Lilienfield, R. (1978). ${ }^{\text {Th}}$ e rise of systems theory: An ideological analysis, Wiley, New York.

Lincoln, S. Y., \& Guba, E. G. (1985). Naturalistic inquiry. Thousand Oaks, CA: Sage.

Lindsay, K., Craig, J., \& Low, M. (2008). Tourism and conservation: the effects of track proximity on avian reproductive success and nest selection in an open sanctuary. Tourism Management, 29(4), 730-739.

Lozano-Oyola, M., Blancas, F. J., González, M., \& Caballero, R. (2012). Sustainable tourism indicators as planning tools in cultural destinations. Ecological Indicators, 18, 659-675.

López, I., Tinoco, H., Aragonés, L., \& Garcia-Barba, J. (2016). The multifunctional artificial reef and its role in the defence of the Mediterranean coast. Science of the Total Environment, 550, 910-923.

Lubchenco, J., Guidetti, P., Grorud-Colvert, K., Giakoumi, S., Gaines, S., Micheli, F., ... \& Chakour, S. (2016). The Science of Marine Protected Areas (Mediterranean).

Lucrezi, S., Ferretti, E., Milanese, M., Sarà, A., \& Palma, M. (2020). Securing sustainable tourism in marine protected areas: lessons from an assessment of scuba divers' underwater behaviour in non-tropical environments. Journal of Ecotourism, 1-24.

Lucrezi, S., Milanese, M., Cerrano, C., \& Palma, M. (2019). The influence of scuba diving experience on divers' perceptions, and its implications for managing diving destinations. PloS one, 14(7), e0219306.

Lucrezi, S., Milanese, M., Markantonatou, V., Cerrano, C., Sarà, A., Palma, M., \& Saayman, M. (2017). Scuba diving tourism systems and sustainability: Perceptions by the scuba diving industry in two Marine Protected Areas. Tourism Management, 59:385-403. 
Lucrezi, S., Saayman, M., \& van der Merwe, P. (2013). Managing diving impacts on reef ecosystems: Analysis of putative influences of motivations, marine life preferences and experience on divers' environmental perceptions. Ocean \& coastal management, 76, 5263.

Lucrezi, S., \& Saayman, M. (2017). Sustainable scuba diving tourism and resource use: Perspectives and experiences of operators in Mozambique and Italy. Journal of cleaner production, 168, 632-644.

Lück, M. (2003). Education on marine mammal tours as agent for conservation-but do tourists want to be educated? Ocean \& coastal management, 46(9-10), 943-956.

Lück, M. (2008). In: Lück, M. (Ed), Encyclopedia of Tourism and Recreation in Marine Environments. CABI, Oxford.

Lazoc, A., \& Lut, D. M. (2013). Evaluating skills and challenges as antecedents of compelling online information-seeking experiences. Network Intelligence Studies, (1), 61-67.

Lindsey, T. C. (2011). Sustainable principles: common values for achieving sustainability. Journal of Cleaner Production, 19(5), 561-565.

Lyons, E., \& Breakwell, G. M. (1994). Factors predicting environmental concern and indifference in 13-to 16-year-olds. Environment and Behavior, 26 (2), 223-238.

Maccarthy, M., O'neill, M., \& Williams, P. (2006). Customer satisfaction and scuba-diving: some insights from the deep. The Service Industries Journal, 26(5), 537-555.

Mackenzie, N., \& Knipe, S. (2006). Research dilemmas: Paradigms, methods and methodology. Issues in educational research, 16(2), 193-205.

Malta Dives (2020). All Types of Dive Sites in Malta. https://maltadives.com/map (Access date: 11.04 .2020$)$.

Malta Government (2020). The Maltese Islands. https://www.gov.mt/en/About\%20Malta/Pages/The\%20Maltese\%20Islands.aspx (Access date: 05.04.2020). 
Manente, M., \& Minghetti, V. (2006). Destination management organizations and actors. Tourism business frontiers: Consumers, products and industry, 228-237.

Manning, R. E. (2013). Parks and carrying capacity: Commons without tragedy. Island Press.

Manning, R. E. (2018). Application of normative theory and methods in recreation and tourism. In Nunkoo, R. (Ed), Handbook of Research Methods for Tourism and Hospitality Management, Edward Elgar Publishing.

Marshall, C., \& Rossman, G. B. (2011). Designing Qualitative Research (5th ed.). Thousand Oaks, CA: Sage Publications.

Marshall, C., \& Rossman, G. B. (2014). Designing Qualitative Research (6th Edition). Sage Publications.

Maslow, A. H. (1964). Religions, values, and peak-experiences (Vol. 35). Columbus: Ohio State University Press.

Mathur, V. N., Price, A. D., \& Austin, S. (2008). Conceptualizing stakeholder engagement in the context of sustainability and its assessment. Construction Management and Economics, 26(6), 601-609.

MCI (2021). The Marine Protection Atlas: Current progress toward global marine protection. https://mpatlas.org/ (Access date: 07.04.2021).

McNaught, C., \& Lam, P. (2010). Using Wordle as a supplementary research tool. Qualitative Report, 15(3), 630-643.

Medio, D., Ormond, R. F. G., \& Pearson, M. (1997). Effect of Briefings on Rates of Damage to Corals by Scuba Divers. Biological Conservation, 79:91-95.

MedPAN (2019). The Status of Marine Protected Areas in the Mediterranean Sea 2016 edition. https://drive.google.com/file/d/1-an1aHCqHP1xAJGHaRgKXqZ4-rTPbBzR/view (Access date: 21.11.2020).

MedPAN (2020). Mediterranean Challenges. http://medpan.org/mediterranean-realities/ (Access date: 04.04.2020). 
Meisel-Lusby, C., \& Cottrell, S. (2008). Understanding motivations and expectations of scuba divers. Tourism in Marine Environments, 5(1), 1-14.

Merleau-Ponty, M. (1962). Phenomenology of perception. London: Routledge \& Kegan Paul.

Merriam, S. B., \& Tisdell, E. J. (2015). Qualitative research: A guide to design and implementation. John Wiley \& Sons.

Mesarovic, M. D. (1964). Foundations for a general systems theory. Views on general systems theory, 1-24.

Meyer, L., \& Thapa, B. L. Pennington-Gray. (2002). An exploration of motivations among scuba divers in north central Florida. In Proceedings of the 2002 Northeastern Recreation Research Symposium, 292-295.

Mill, C. R., \& Morrison, M. A. (1985). The Tourism System-An Introductory Text, PrenticeHall. Inc., New Jersey.

Miller, J. G. (1978). Living Systems. McGraw-Hill. New York.

Miller, G., \& Taubman-Ben-Ari, O. (2004). Scuba diving risk taking -A terror management theory perspective. Journal of Sport and Exercise Psychology, 26(2), 269-282.

Miller, G., Rathouse, K., Scarles, C., Holmes, K., \& Tribe, J. (2010). Public understanding of sustainable tourism. Annals of tourism research, 37(3), 627-645.

Miles, M. B., Huberman, A. M., \& Saldaña, J. (2014). Qualitative data analysis: A methods sourcebook, (3rd ed.), London, SAGE.

Mintzberg, H. (1979). An emerging strategy of "direct" research. Administrative science quarterly, 24(4), 582-589.

Moberg, F., \& Folke, C. (1999). Ecological goods and services of coral reef ecosystems. Ecological Economics, 29(2), 215-233. 
Monfils, R., Gilbert, T., \& Nawadra, S. (2006). Sunken WWII shipwrecks of the Pacific and East Asia: The need for regional collaboration to address the potential marine pollution threat. Ocean \& Coastal Management, 49(9-10), 779-788.

Moran, D. (2013). Edmund Husserl and phenomenology, Philosophy of mind: the key thinkers/edited by Andrew Bailey, Bloomsbury Publishing Plc.

Moran, D. (2018). What is the Phenomenological Approach? Revisiting Intentional Explication. Phenomenology and Mind, 15:72-90.

Moran, D. (2019). The Phenomenological Approach, The Oxford Handbook of Phenomenological Psychopathology Edited by Giovanni Stanghellini, Matthew R. Broome, Anthony Vincent Fernandez, Paolo Fusar-Poli, Andrea Raballo, and René Rosfort.

Morgan, G., \& Smircich, L. (1980). The case for qualitative research. Academy of management review, 5(4), 491-500.

Morgenstern, O. (1972). Descriptive, predictive and normative theory. Kyklos, 25(4), 699-714.

Moser, A., \& Korstjens, I. (2017). Series: Practical guidance to qualitative research. Part 1: Introduction. European Journal of General Practice, 23(1), 271-273.

Moser, A., \& Korstjens, I. (2018). Series: Practical guidance to qualitative research. Part 3: Sampling, data collection and analysis. European Journal of General Practice, 24(1), 918.

Mossberg, L. (2008). Extraordinary experiences through storytelling. Scandinavian Journal of Hospitality and Tourism, 8(3), 195-210.

Mota, L., \& Frausto, O. (2014). The use of scuba diving tourism for marine protected area management. Int. J. Soc. Behav. Edu. Econ. Bus. Ind. Eng, 8, 3159-3164.

Mota, L. (2016). 2. Using of Natural Spaces for Tourism Activity Scuba Diving and Impacts on Aquatic Animals. The International Journal of Tropical Veterinary and Biomedical Research, 1(1), 9-20. 
Moyle, B. D., Scherrer, P., Weiler, B., Wilson, E., Caldicott, R., \& Nielsen, N. (2017). Assessing Preferences of Potential Visitors for Nature-Based Experiences in Protected Areas. Tourism Management, 62:29-41.

MSP (2020). https://www.msp-platform.eu/countries/malta (Access date: 04.04.2020).

MTA (2020a). The Profile of Diving Travellers in Malta. Malta Tourism Authority Research Unit. https://www.mta.com.mt/en/file.aspx?f=34514 (Access date: 21.11 .2020 ).

MTA (2020b). Tourism in Malta Facts \& Figures 2019. Malta Tourism Authority https://www.mta.com.mt/en/file.aspx?f=34248 (Access date: 22.11 .2020 ).

Musa, G. (2002). Sipadan: a SCUBA-diving paradise: an analysis of tourism impact, diver satisfaction and tourism management. Tourism Geographies, 4(2), 195-209.

Musa, G., Kadir, S., \& Lee, L. (2006). Layang Layang: An empirical study on SCUBA divers' satisfaction. Tourism in Marine Environments, 2(2), 89-102.

Musa, G., Seng, W. T., Thirumoorthi, T., \& Abessi, M. (2011). The influence of Scuba divers' personality, experience, and demographic profile on their underwater behavior. Tourism in Marine Environments, 7(1), 1-14.

Musa, G., \& Dimmock, K. (2012). Scuba diving tourism. Tourism in Marine Environments, 8 (1/2), 1-109.

Musa, G., \& Dimmock, K. (2013). (Ed), Scuba Diving Tourism: Contemporary Geographies of Leisure, Tourism and Mobility. Routledge, UK.

Mylonopoulos, D., \& Moira, P. (2019) Exploring the profiles and motives of recreational divers: Case study from Greece. TIMS. Acta, 13(1), 5-14.

Nadin, S., \& Cassell, C. (2006). The use of a research diary as a tool for reflexive practice: Some reflections from management research. Qualitative Research in Accounting \& Management, 3(3), 208-217. 
Naidoo, P., Ramseook-Munhurrun, P., \& Li, J. (2018). Scuba diving experience and sustainability: An assessment of online travel reviews. The Gaze: Journal of Tourism and Hospitality, 9, 43-52.

Needham, M. D. (2010). Value orientations toward coral reefs in recreation and tourism settings: a conceptual and measurement approach. Journal of sustainable tourism, 18(6), 757-772.

Needham, M. D., \& Szuster, B. W. (2011). Situational influences on normative evaluations of coastal tourism and recreation management strategies in Hawai'i. Tourism Management, 32(4), $732-740$.

Neuendorf, K. A. (2019). Content Analysis and Thematic Analysis. Brough (Ed), Research Methods for Applied Psychologists: Design, Analysis and Reporting (211-223). New York: Routledge.

Ng, S. I., Chia, K. W., Ho, J. A., \& Ramachandran, S. (2017). Seeking tourism sustainabilityA case study of Tioman Island, Malaysia. Tourism Management, 58, 101-107.

Nicodemus, D. M. (2004). Mobilizing information: Local news and the formation of a viable political community. Political Communication, 21(2), 161-176.

Nicolaides, A. (2015). Tourism Stakeholder Theory in practice: instrumental business grounds, fundamental normative demands or a descriptive application?

NOAA (2020). Why should we care about the ocean? https://oceanservice.noaa.gov/facts/why-care-about-ocean.html (Access date: 27.03.2020).

NTP (2015). National Tourism Policy. Minister for Tourism of Malta. https://tourism.gov.mt/en/Documents/FINALBOOKLETexport9.pdf (Access date: 22.11.2020).

Nyström, M., Folke, C., \& Moberg, F. (2000). Coral reef disturbance and resilience in a humandominated environment. Trends in ecology \& evolution, 15(10), 413-417. 
Oceanwealth (2020). Benefits of Nature Based Tourism. https://oceanwealth.org/ecosystemservices/recreation-tourism/ (Access date: 16.04.2020).

OECD (2016). The Ocean Economy in 2030, OECD Publishing, Paris, https://doi.org/10.1787/9789264251724-en.

O’Gorman, K., \& MacIntosh, R. (2015). Mapping research methods (Chapter 4). Research methods for business and management: A guide to writing your dissertation. Goodfellow Publishers Ltd, 50-74.

Oh, H., Fiore, A. M., \& Jeoung, M. (2007). Measuring experience economy concepts: Tourism applications. Journal of travel research, 46(2), 119-132.

Oh, C. O., Ditton R. B., \& Stoll, J. R. (2008). The Economic Value of Scuba-Diving Use of Natural and Artificial Reef Habitats, Society and Natural Resources, 21(6), 455-468.

Ong, T. F., \& Musa, G. (2011). An examination of recreational divers' underwater behaviour by attitude-behaviour theories. Current Issues in Tourism, 14(8), 779-795.

Ong, T. F., \& Musa, G. (2012). SCUBA divers' underwater responsible behaviour: can environmental concern and divers' attitude make a difference? Current Issues in Tourism, 15(4), 329-351.

Orts, E. W., \& Strudler, A. (2002). The ethical and environmental limits of stakeholder theory. Business Ethics Quarterly, 215-233.

PADI (2021). 2021 Worldwide Corporate Statistics Data for 2015-2020. Retrieved from https://www.padi.com/sites/default/files/documents/2021-

02/2021\%20PADI\%20Worldwide\%20Statistics.pdf

Parham, D. (2006). Scientific diving: code of conduct. Poole, United Kingdom: Centre for Marine and Coastal Archaeology, School of Conservation Sciences, Bournemouth University.

Parmar, B. L., Freeman, R. E., Harrison, J. S., Wicks, A. C., Purnell, L., \& De Colle, S. (2010). Stakeholder theory: The state of the art. Academy of Management Annals, 4(1), 403-445. 
Parsons, T. (1970). On building social system theory: A personal history. Daedalus, 826-881.

Pascal, N., Brathwaite, A., Brander, L., Seidl, A., Philip, M., \& Clua, E. (2018). Evidence of economic benefits for public investment in MPAs. Ecosystem Services, 30, 3-13.

Passafaro, P. (2020). Attitudes and tourists' sustainable behavior: An overview of the literature and discussion of some theoretical and methodological issues. Journal of Travel Research, 59(4), 579-601.

Paterson, S., Young, S., Loomis, D. K., \& Obenour, W. (2012). Resource attributes that contribute to non-resident diver satisfaction in the Florida Keys, USA. Tourism in Marine Environments, 8(1-2), 47-60.

Patton, M. Q. (2002). Two decades of developments in qualitative inquiry: A personal, experiential perspective. Qualitative Social Work, 1(3), 261-283. https://doi.org/10.1177/1473325002001003636

Patton, M. Q. (2003). Qualitative Research and Evaluation Methods. Sage Publications, Thousand Oaks.

Perkol-Finkel, S., Shashar, N., \& Benayahu, Y. (2006). Can artificial reefs mimic natural reef communities? The roles of structural features and age. Marine environmental research, 61(2), 121-135.

Phillips, R. A., \& Reichart, J. (2000). The environment as a stakeholder? A fairness-based approach. Journal of business ethics, 23(2), 185-197.

Pickering, C. M., \& Buckley, R.C . (2003). Swarming to The Summit. Mt Res Dev 23(3), 230233.

Pickering, H., Whitmarsh, D., \& Jensenà A. (1999). Artificial Reefs as a Tool to Aid Rehabilitation of Coastal Ecosystems: Investigating the Potential. Marine Pollution Bulletin, 37(8-12), 505-514.

Pine, B. J., \& Gilmore, J. H. (1998). Welcome to the experience economy. Harvard business review, 76, 97-105. 
Pine, B. J., Pine, J., \& Gilmore, J. H. (1999). The experience economy: work is theatre \& every business a stage. Harvard Business Press.

Plummer, R., \& Fennell, D. A. (2009). Managing protected areas for sustainable tourism: prospects for adaptive co-management. Journal of Sustainable Tourism, 17(2), 149-168.

Polak, O., \& Shashar, N. (2012). Can a small artificial reef reduce diving pressure from a natural coral reef? Lessons learned from Eilat, Red Sea. Ocean \& coastal management, 55, 94-100.

Polit, D. F., \& Beck, C. T. (2012). Nursing research: Principles and methods. Lippincott Williams \& Wilkins.

Polit, D. F., \& Beck, C. T. (2017). Nursing Research: Generating and Assessing Evidence for Nursing Practice (10th Edition). Lippincott, Williams \& Wilkins.

Porter, M. E. (1998). Clusters and the new economics of competition (Vol. 76, No. 6, pp. 7790). Boston: Harvard Business Review.

Preobrazhensky, V. S., Yu, A., Vedenin, A., Zorin, I. V., \& Mukhina, L. I. (1976). Current Problems of Recreational Geography, XXIII International Geographical Congress, Moscow.

Pryce, K. (1979). Endless Pressure; A study of West Indian lifestyles in Bristol Penguin, London.

Pullman, M. E., \& Gross, M. A. (2004). Ability of experience design elements to elicit emotions and loyalty behaviors. Decision Sciences, 35(3), 551-578.

Punch, K. (2014). Introduction to social research ( $3^{\text {rd }}$ ed.), London, SAGE.

Purnell, L. S., \& Freeman, R. E. (2012). Stakeholder theory, fact/value dichotomy, and the normative core: How Wall Street stops the ethics conversation. Journal of Business Ethics, 109(1), 109-116.

Quinn, D. P., \& Jones, T. M. (1995). An agent morality view of business policy. Academy of Management Review, 20(1), 22-42. 
Reed, D. (1999). Stakeholder management theory: A critical theory perspective. Business Ethics Quarterly, 453-483.

Rees, S. E., Mangi, S. C., Hattam, C., Gall, S. C., Rodwell, L. D., Peckett, F. J., \& Attrill, M. J. (2015). The socio-economic effects of a Marine Protected Area on the ecosystem service of leisure and recreation. Marine Policy, 62, 144-152.

Reiners, G. M. (2012). Understanding the differences between Husserl's (descriptive) and Heidegger's (interpretive) phenomenological research. Journal of Nursing \& Care, 1(5), $1-3$.

Riegl, B., \& Riegl, A. (1996). Studies on coral community structure and damage as a basis for zoning marine reserves. Biological Conservation, 77(2-3), 269-277.

Roche, R. C., Harvey, C. V., Harvey, J. J., Kavanagh, A. P., McDonald, M., Stein-Rostaing, V. R., \& Turner, J. R. (2016). Recreational diving impacts on coral reefs and the adoption of environmentally responsible practices within the SCUBA diving industry. Environmental Management, 58(1), 107-116.

Rodríguez, A. M. (2017). The Secret of the Scuba Diving Spider... and More! Enslow Publishing, LLC.

Roman, G. S., Dearden, P., \& Rollins, R. (2007). Application of zoning and "limits of acceptable change" to manage snorkelling tourism. Environmental Management, 39(6), 819-830.

Roos, R. (1979). Are the risks of sport scuba diving being underestimated? Physician and Sports Medicine, 17(7), 132-142.

Romani, S., \& Grappi, S. (2014). How companies' good deeds encourage consumers to adopt pro-social behavior. European Journal of Marketing.

Rountree, R. A. (1989). Association of fishes with fish aggregation devices: effects of structure size on fish abundance. Bulletin of Marine Science, 44(2), 960-972.

Rosenblueth, A., Wiener, N., \& Bigelow, J. (1943). Behavior, purpose and teleology. Philosophy of science, 10(1), 18-24. 
Rossman, G. B., \& Rallis, S. F. (2012). Learning in the field: An introduction to qualitative research (3rd ed.). Thousand Oaks, CA: Sage.

Rouphael, T., \& Inglis, G. (1995). The effects of qualified recreational SCUBA divers on coral reefs. Tech. Rep. CRC Reef Res. Hundred.

Rouphael, A. B., \& Inglis, G. J. (1997). Impacts of Recreational SCUBA Diving at Sites with Different Reef Topographies. Biological Conservation. 82:329-336.

Rouphael, A. B., \& Inglis, G. J. (2001). Take Only Photography and Leave Only Footprints? An Experimental Study of the Impacts of Underwater Photography on Coral Reef Dive Sites. Biological Conservation, 100:281-287.

Rouphael, A. B, \& Hanafy, M. (2007). An Alternative Management, Framework to Limit the Impact of SCUBA Divers on Coral Assemblages. Journal of Sustainable Tourism 15(1), 91-103.

Rukuižienè, R. (2014). Sustainable tourism development implications to local economy. Regional Formation and Development Studies, 14(3), 170-177.

Ryan, L. (2021). Telling network stories: researching migrants' changing social relations in places over time. Global Networks, 21(3), 567-584.

Ryan, L., Mulholland, J., \& Agoston, A. (2014). Talking ties: Reflecting on network visualisation and qualitative interviewing. Sociological Research Online, 19(2), 1-12.

Said, A., Macmillan, D. C., Schembri, M., \& Tzanopoulos, J. (2017). Fishing in a congested sea: What do marine protected areas imply for the future of the Maltese artisanal fleet? http://dx.doi.org/10.1016/j.apgeog.2017.08.013

Sala, E., \& Giakoumi, S. (2018). No-take marine reserves are the most effective protected areas in the ocean. ICES Journal of Marine Science, 75(3), 1166-1168.

Saldaña, J. (2021). The Coding Manual for Qualitative Researchers. Sage.

Salim, N., Bahauddin, A., \& Mohamed, B. (2013). Influence of scuba divers' specialization on their underwater behavior. Worldwide Hospitality and Tourism Themes, 5(4), 388-397. 
Salvador, R., Lúcio, J., \& Ferreira, J. (2011). Sustainable tourism micro-clusters: the case of Alentejo protected areas. Revista Portuguesa de Estudos Regionais, (25-26), 5-23.

Sandelowski, M., \& Barroso, J. (2003). Classifying the Findings in Qualitative Studies. Qualitative Health Research, 13(7), 905-923.

Sangle, S., \& Ram Babu, P. (2007). Evaluating sustainability practices in terms of stakeholders' satisfaction. International Journal of Business Governance and Ethics, 3(1), 56-76.

Sarantakos, S. (2013). Social Research (4 ${ }^{\text {th }}$ Ed). Palgrave Macmillan.

Sautter, E. T., \& Leisen, B. (1999). Managing stakeholders a tourism planning model. Annals of tourism research, 26(2), 312-328.

Saunders, M., Lewis, P., \& Thornhill, A. (2009). Research methods for business students. Pearson education.

Saunders, M., Lewis, P., \& Thornhill, A. (2019). Research methods for business students. (8th edition) Pearson education.

Schaltegger, S., \& Lüdeke-Freund, F. (2012). Business cases for sustainability. In: S. Idowu, N. Capaldi, L. Zu \& A. Das Gupta (Eds), Encyclopedia of Corporate Social Responsibility, 245-252.

Schick, R. S. (2002). When the subject is difference: Conditions of voice in policy-oriented qualitative research. Qualitative Inquiry, 8(5), 632-651.

Schmitt, B., \& Simonson, A. (1997). Marketing aesthetics: The strategic management of brands, identity, and image. Free Press.

Schmitt, B. (1999). Experiential marketing. Journal of marketing management, 15(1-3), 53-67.

Schneider, E., Brooks, E., Cortina, M., Bailey, D., Killen, S., \& Van Leeuwen, T. (2021). Design, construction, and deployment of an affordable and long-lasting moored deepwater fish aggregation device. bioRxiv. 
Schoeman, K., Van der Merwe, P., \& Slabbert, E. (2016). The perceived value of a scuba diving experience. Journal of coastal research, 32(5), 1071-1080.

Scholtz, M., \& Saayman, M. (2018). Diving into the consequences of stakeholders unheard. European Journal of Tourism Research, 20, 105-124.

Sciberras, M., Jenkins, S. R., Mant, R., Kaiser, M. J., Hawkins, S. J., \& Pullin, A. S. (2015). Evaluating the relative conservation value of fully and partially protected marine areas. Fish and Fisheries 16:58-77 DOI 10.1111/faf.12044.

Scitovsky, T. (1992). The joyless economy: The psychology of human satisfaction. Oxford University Press on Demand.

Scott, N., Cooper, C., \& Baggio, R. (2008). 'Destination networks: four Australian cases. Annals of Tourism Research, 35(1), 169-88.

Seaman, W., \& Jensen, A. C. (2000). Purposes and practices of artificial reef evaluation. Artificial reef evaluation with application to natural marine habitats, 2-19.

Seidman, I. (2013). Interviewing as qualitative research: A guide for researchers in education and the social sciences (3rd ed.). New York, NY: Teachers College Press.

Selig, E. R., \& Bruno, J. F. (2010). A global analysis of the effectiveness of marine protected areas in preventing coral loss. PLoS ONE 5(2), e9278 DOI 10.1371/journal.pone.0009278.

SFIA (2020). Scuba Diving Participation Report 2019.

https://www.sfia.org/reports/796_Scuba-Diving-Participation-Report-2019

(Access date: 27.03.2020).

Shafer, C. S., \& Inglis, G. J. (2000). Influence of social, biophysical, and managerial conditions on tourism experiences within the Great Barrier Reef World Heritage Area. Environmental Management, 26(1), 73-87.

Shani, A., Polak, O., \& Shashar, N. (2012). Artificial Reefs and Mass Marine Ecotourism. Tourism Geographies 14(3), 361-382. 
Sharma-Wallace, L., Velarde, S. J., \& Wreford, A. (2018). Adaptive governance good practice: Show me the evidence! Journal of Environmental Management, 222, 174-184.

Sharpley, R. (2020). Tourism, sustainable development and the theoretical divide: 20 years on. Journal of sustainable tourism, 28(11), 1932-1946.

Sheldon, P. J., \& Park, S. Y. (2011). An exploratory study of corporate social responsibility in the US travel industry. Journal of Travel Research, 50(4), 392-407.

Silverman, R. M., \& Patterson, K. L. (2014). Qualitative Research Methods for Community Development. Routledge.

Simão, J. N., \& Partidário, M. D. R. (2012). How does tourism planning contribute to sustainable development? Sustainable Development, 20(6), 372-385.

Sirakaya, E., Jamal, T. B., \& Choi, H. S. (2001). Developing indicators for destination sustainability. The encyclopedia of ecotourism, 411-432.

Sivek, D. J., \& Hungerford, H. (1990). Predictors of responsible behavior in members of three Wisconsin conservation organizations. The Journal of Environmental Education, 21 (2), $35-40$.

Smith, H. D., \& Couper, A. D. (2003). The management of the underwater cultural heritage. Journal of Cultural Heritage, 4(1), 25-33.

Smith, W. K., \& Lewis, M. W. (2011). Toward a theory of paradox: A dynamic equilibrium model of organizing. Academy of Management Review, 36(2), 381-403.

Smithies, D. (2012). The normative role of knowledge. Noûs, 46(2), 265-288.

Snepenger, D., Murphy, L., Snepenger, M., \& Anderson, W. (2004). Normative meanings of experiences for a spectrum of tourism places. Journal of Travel Research, 43(2), 108117.

Sorice, M. G., Oh, C. O., \& Ditton, R. B. (2009). Exploring level of support for management restrictions using a self-classification measure of recreation specialization. Leisure Sciences, 31(2), 107-123. 
Spalding, M., Burke, L., Wood, S.A., Ashpole, J., Hutchison, J., \& Zu Ermgassen, P. (2017). Mapping the Global Value and Distribution of Coral Reef Tourism. Marine Policy 82, 104-113.

Stanley, L., \& Wise, S. (1990). Method, Methodology and Epistemology in Feminist Research Processes. In Stanley, L. (Ed), Feminist praxis. London: Routledge, 20-60.

Starik, M. (1995). Should trees have managerial standing? Toward stakeholder status for nonhuman nature. Journal of business ethics, 14(3), 207-217.

Starik, M., \& Kanashiro, P. (2013). Toward a theory of sustainability management: Uncovering and integrating the nearly obvious. Organization \& Environment, 26(1), 7-30.

Steg, L., \& Vlek, C. (2009). Encouraging pro-environmental behaviour: An integrative review and research agenda. Journal of environmental psychology, 29(3), 309-317.

Sterling, E. J., Betley, E., Sigouin, A., Gomez, A., Toomey, A., Cullman, G., ... \& Filardi, C. (2017). Assessing the evidence for stakeholder engagement in biodiversity conservation. Biological Conservation, 209, 159-171.

Štetić, S., \& Šimičević, D. (2008). How to develop sustainable tourism in rural destinations in Serbia. Bulletin of the Serbian geographical society, 88(4), 19-28.

Stoep, V. G. A., Vrana, K. J., \& Tolson, H. (1997). Shipwreck management: Developing strategies for assessment and monitoring of newly discovered shipwrecks in a limited resource environment. Christian Science Monitor.

Stolk, P., Markwell, K., \& Jenkins, J. M. (2005). Perceptions of Artificial Reefs as Scuba Diving Resources: A Study of Australian Recreational Scuba Divers. Annals of Leisure Research 8(2-3), 153-166.

Stolk, P., Markwell, K., \& Jenkins, J. M. (2007). Artificial Reefs as Recreational Scuba Diving Resources: A Critical Review of Research. Journal of Sustainable Tourism, 15(4), 331350. 
Strickland-Munro, J. K., Allison, H. E., \& Moore, S. A. (2010). Using resilience concepts to investigate the impacts of protected area tourism on communities. Annals of Tourism Research, 37(2), 499-519.

Stuckey, H. L. (2015). The second step in data analysis: Coding qualitative research data. Journal of Social Health and Diabetes, 3(01), 007-010.

Su, L., \& Swanson, S. R. (2017). The effect of destination social responsibility on tourist environmentally responsible behavior: Compared analysis of first-time and repeat tourists. Tourism Management, 60, 308-321.

Subramani, S. (2019). Practising reflexivity: Ethics, methodology and theory construction. Methodological Innovations, 12(2), 1-11.

Susskind, L., \& Cruikshank, J. (1987). Breaking the impasse. New york.

Swain, M. B. (1995). Gender in Tourism. Annals of Tourism Research 22(2), 247-266.

Swarbrooke, J. (1999). Sustainable tourism management. Cabi.

Szuster, B. W., Needham, M. D., \& McClure, B. P. (2011). Scuba diver perceptions and evaluations of crowding underwater. Tourism in Marine Environments, 7(3-4), 153-165.

Tabata, R. S. (1989). The use of nearshore dive sites by recreational dive operators in Hawaii. Coastal Zone, 2865-75.

Tapsuwan, S., \& Asafu-Adjaye, J. (2008). Estimating the Economic Benefit of SCUBA Diving in the Similan Islands, Thailand. Coastal Management, 36(5), 431-442.

Taylor, S. J., Bogdan R., \& DeVault, M. 1. (2016). Introduction to qualitative research methods: a guidebook and resource, 4th edition, John Wiley \& Sons, Inc., Hoboken, New Jersey.

Terrón-Sigler, A., León-Muez, D., Peñalver-Duque, P., \& Torre, F. E. (2016). The effects of SCUBA diving on the endemic Mediterranean coral Astroides calycularis. Ocean \& Coastal Management, 122, 1-8. 
Thapa, B., Graefe, A. R., \& Meyer, L. A. (2005). Moderator and mediator effects of scuba diving specialization on marine-based environmental knowledge-behavior contingency. The Journal of Environmental Education, 37(1), 53-67.

Thapa, B., Graefe, A. R., \& Meyer, L. A. (2006). Specialization and marine based environmental behaviors among SCUBA divers. Journal of Leisure Research, 38(4), 601-615.

Theodoulidis, B., Diaz, D., Crotto, F., \& Rancati, E. (2017). Exploring corporate social responsibility and financial performance through stakeholder theory in the tourism industries. Tourism Management, 62, 173-188.

Theofanidis, D., \& Fountouki, A. (2018). Limitations and delimitations in the research process. Perioperative nursing, 7(3), 155-163.

Thomas, H. L., Macsharry, B., Morgan, L., Kingston, N., Moffitt, R., Stanwell-Smith, D., \& Wood, L. (2014). Evaluating official marine protected area coverage for Aichi Target 11: appraising the data and methods that define our progress. Aquatic Conservation: Marine and Freshwater Ecosystems, 24(S2), 8-23.

Thur, S. M. (2010). User fees as sustainable financing mechanisms for marine protected areas: An application to the Bonaire National Marine Park. Marine Policy, 34(1), 63-69.

Thurstan, R.H., Hawkins, J.P., Neves, L. \& Roberts, C.M. (2012). Are marine reserves and non-consumptive activities compatible? A global analysis of marine reserve regulations. Marine Policy 36:1096-1104 DOI 10.1016/j.marpol.2012.03.006.

Todd, S., Graefe, A., \& Mann, W. (2002). Differences in SCUBA diver motivations based on level of development. Paper presented at the Northeastern Recreation Research Symposium, Radnor, PA.

Torland, M., Weiler, B., Moyle, B. D., \& Wolf, I. (2015). Are Your Ducks in A Row? External and Internal Stakeholder Perceptions of the Benefits of Parks in New South Wales, Australia. Managing Sport and Leisure, 20(4), 211-237. 
Toyoshima, J., \& Nadaoka, K. (2015). Importance of environmental briefing and buoyancy control on reducing negative impacts of SCUBA diving on coral reefs. Ocean \& coastal management, 116, 20-26.

Townsend, C. (2003). Marine ecotourism through education: A case study of divers in the British Virgin Islands. Marine Ecotourism: Issues and experiences, 138-154.

Townsend, C. (2008). Dive tourism, sustainable tourism, and social responsibility: A growing agenda. New frontiers in marine tourism: Diving experiences, sustainability, management, 140-152.

Trave, C., Brunnschweiler, J., Sheaves, M., Diedrich, A., \& Barnett, A. (2017). Are we killing them with kindness? Evaluation of sustainable marine wildlife tourism. Biological Conservation, 209, 211-222.

Tschapka, M. K. (2006). Involvement, Motivations and Setting Preference of Participants in the Adventure Tourism Activity of Scuba Diving. Canberra: University of Canberra.

Tubaro, P., Ryan, L., Casilli, A. A., \& D'angelo, A. (2021). Social network analysis: New ethical approaches through collective reflexivity. Introduction to the special issue of Social Networks. Social Networks, 67, 1-8.

Tung, V. W. S., \& Ritchie, J. B. (2011). Exploring the essence of memorable tourism experiences. Annals of Tourism Research, 38(4), 1367-1386.

Tynyakov, J., Rousseau, M., Chen M., Figus, O., Belhassen ,Y., \& Shashar, N. (2017). Artificial Reefs as A Means of Spreading Diving Pressure in A Coral Reef Environment. Ocean \& Coastal Management, 149:159-164.

UNEP-MAP RAC/SPA (2010). The Mediterranean Sea Biodiversity: state of the ecosystems, pressures, impacts and future priorities. By Bazairi, H., Ben Haj, S., Boero, F., Cebrian, D., De Juan, S., Limam, A., Lleonart, J., Torchia, G., and Rais, C., Ed. RAC/SPA, Tunis; 100 pages. https://www.rac-spa.org/sites/default/files/doc_cop/biodiversity.pdf (Access date: 05.04.2020).

United Nations Environment Programme. (2015). UNEP 2014 Annual report. 
UNESCO (2001). Convention on the Protection of the Underwater Cultural Heritage.

UNESCO (2020). Facts and figures on marine biodiversity.

http://www.unesco.org/new/en/natural-sciences/ioc-oceans/focus-areas/rio-20ocean/blueprint-for-the-future-we-want/marine-biodiversity/facts-and-figures-onmarine-biodiversity/ (Access date: 01.04.2020).

UNESCO (2021). Wrecks. http://www.unesco.org/new/en/culture/themes/underwatercultural-heritage/underwater-culturalheritage/wrecks/\#: :text=An\%20estimated\%203\%20million\%20shipwrecks,and\%20cu ltural\%20dialogue\%20between\%20peoples. (Access date: 03.05.2021).

United Nations Environment Programme. Division of Technology, \& Economics. (2005). Making tourism more sustainable: A guide for policy makers. World Tourism Organization Publications.

UNWTO, E. (2013). Sustainable tourism for development guidebook. World Tourism Organization, European Commission, Madrid.

UNWTO (2020). World tourism barometer (Vol. 18, Issue 1). World Tourism Organization.

Uyarra, M. C., \& Côté, I. M. (2007). The quest for cryptic creatures impacts of species-focused recreational diving on corals. Biological Conservation, 136(1), 77-84.

Uyarra, M. C., Watkinson, A. R., \& Cote, I. M. (2009). Managing dive tourism for the sustainable use of coral reefs: validating diver perceptions of attractive site features. Environmental Management, 43(1), 1-16.

Vaismoradi, M., Turunen, H., \& Bondas, T. (2013). Content Analysis and Thematic Analysis: Implications for Conducting a Qualitative Descriptive Study. Nursing \& Health Sciences, 15(3), 398-405.

Van der Walt, J. L. (2020). Interpretivism-constructivism as a research method in the humanities and social sciences-more to it than meets the eye. International Journal of Philosophy and Theology, 8(1), 59-68. 
Van Treeck, P., \& Eisinger, M. (2008). Diverting pressure from coral reefs: artificial underwater parks as a means of integrating development and reef conservation. Garrod, B., Gössling, S. (Ed), New Frontiers in Marine Tourism: Diving Experiences, Sustainability, Management. Elsevier Press, Amsterdam, 153-169.

Van Treeck, P., \& Schuhmacher, H. (1999). Mass diving tourism-a new dimension calls for new management approaches. Marine Pollution Bulletin, 37(8-12), 499-504.

Varkey, D., Ainsworthy, C. H., \& Pitcher, T. J. (2012). Modelling reef fish population responses to fisheries restrictions in marine protected areas in the coral triangle. Journal of Marine Biology 2012:1-18.

Verbeke, A., \& Tung, V. (2013). The future of stakeholder management theory: A temporal perspective. Journal of business ethics, 112(3), 529-543.

Verkoeyen, S., \& Nepal, S. K. (2019). Understanding scuba divers' response to coral bleaching: An application of Protection Motivation Theory. Journal of environmental management, 231, 869-877.

Viduka, A. (2006). Managing Threats to Underwater Cultural Heritage Sites: The Yongala as a Case Study. Heritage at Risk, 61-63.

Viera, A.J. and Garrett, J.M. (2005). Understanding interobserver agreement: the kappa statistic. Fam med, Vol.37 No.5, pp.360-363.

Vincent, D. R. (1990). The information-based corporation: stakeholder economics and the technology investment. Irwin Professional Pub.

Visit Malta (2020a). About Malta. https://www.visitmalta.com/en/about-malta (Access date: 05.04.2020).

Visit Malta (2020b). Diving. https://www.visitmalta.com/en/diving (Access date: 05.04.2020).

Visit Malta (2020c). Dive Sites. https://www.visitmalta.com/en/dive-sites

(Access date: 05.04.2020). 
Vivier, B., Dauvin, J. C., Navon, M., Rusig, A. M., Mussio, I., Orvain, F., ... \& Claquin, P. (2021). Marine artificial reefs, a meta-analysis of their design, objectives and effectiveness. Global Ecology and Conservation, e01538.

Von Bertalanffy, L. (1949). Problems of organic growth. Nature, 163(4135), 156-158.

Von Bertalanffy, L. (1950). The theory of open systems in physics and biology. Science, 111(2872), 23-29.

Von Bertalanffy, L. (1955). An essay on the relativity of categories. Philosophy of Science, 22(4), 243-263.

Von Bertalanffy, L. (1972). The history and status of general systems theory. Academy of management journal, 15(4), 407-426.

Vrana, K. J., \& Mahoney, E. M. (1995). Impacts on underwater cultural resources: diagnosing change and prescribing solutions. In Underwater Archeology: Proceedings from the Society for Historical Archeology conference. The Society for Historical Archeology, Washington, DC, 176-180.

Wallis, A. M. (2006). Sustainability indicators: is there consensus among stakeholders? International Journal of Environment and Sustainable Development, 5(3), 287-296.

Walls, A. R., Okumus, F., Wang, Y. R., \& Kwun, D. J. W. (2011). An epistemological view of consumer experiences. International Journal of Hospitality Management, 30(1), 10-21.

Wang, M., Jin, Z., Fan, S., Ju, X., \& Xiao, X. (2021). Chinese residents' preferences and consuming intentions for hotels after COVID-19 pandemic: a theory of planned behaviour approach. Anatolia, 32(1), 132-135.

Ward, F., \& Greenberg, J. (1990). Florida's coral reefs are imperiled. National Geographic, 178(1), 114-132.

WCPA, I. (2018). Applying IUCN's global conservation standards to marine protected areas (MPA). Delivering effective conservation action through MPAs, to secure ocean health \& sustainable development. Version, $1,4$. 
Weaver, G. R., \& Trevino, L. K. (1994). Normative and empirical business ethics: Separation, marriage of convenience, or marriage of necessity? Business Ethics Quarterly, 129-143.

Weber, M. (1978). Economy and Society: An Outline of Interpretive Sociology. Berkeley, CA: University of California Press.

Welch, M. (1999). Phenomenology and Hermeneutics. In Polifroni, E.C., Welch, W. (Eds) Perspectives on Philosophy of Science in Nursing: An Historical and Contemporary Anthology. Lippincott Williams \& Wilkins, Philadelphia.

Wheeler, D., \& Sillanpää, M. (1997). The Stakeholder Corporation: A Blueprint for Maximising Stakeholder Value. Pitman Publishing, London.

Wicks, A. C., Gilbert Jr, D. R., \& Freeman, R. E. (1994). A feminist reinterpretation of the stakeholder concept. Business ethics quarterly, 475-497.

Wilks, J. (1991). Balancing recreation and safety: equipment requirements for Queensland SCUBA divers. Journal of Occupational Health and Safety, 7(3), 221-227.

Williams, B. K. (2011). Adaptive management of natural resources -framework and issues. Journal of environmental management, 92(5), 1346-1353.

Wongthong, P., \& Harvey, N. (2014). Integrated coastal management and sustainable tourism: A case study of the reef-based SCUBA dive industry from Thailand. Ocean \& coastal management, 95, 138-146.

Worachananant, S., Carter, R. W., Hockings, M., \& Reopanichkul, P. (2008). Managing the impacts of SCUBA divers on Thailand's coral reefs. Journal of Sustainable Tourism, 16(6), 645-663.

WEF (2019). The Travel \& Tourism Competitiveness Report 2019. World Economic Forum.

WTTC (2021). World Travel \& Tourism Council: Global Economic Impact \& Trends.

Wurzinger, S., \& Johansson, M. (2006). Environmental concern and knowledge of ecotourism among three groups of Swedish tourists. Journal of Travel Research, 45 (2), 217-226. 
Yolal, M., Sevinc, F., \& Gursoy, D. (2021). How do residents perceive tourism development? A small community perspective. Journal of Tourism Quarterly, 3(2), 52-67.

Young, S., \& Loomis, D. (2010). Diver perceptions of Florida Keys Reef conditions by specialization level. In: Watts, Clifton E., Jr.; Fisher, Cherie LeBlanc, eds. Proceedings of the 2009 Northeastern Recreation Research Symposium. Newtown Square, PA: US Department of Agriculture, Forest Service, Northern Research Station: 66, 24-29.

Yuksel, F., Bramwell, B., \& Yuksel, A. (1999). Stakeholder interviews and tourism planning at Pamukkale, Turkey. Tourism Management, 20(3), 351-360.

Zakai, D., \& Chadwick-Furman, N. E. (2002). Impacts of intensive recreational diving on reef corals at Eilat, northern Red Sea. Biological Conservation, 105(2), 179-187.

Zeegers, M., \& Barron, D. (2015). Milestone Moments in Getting your PhD in Qualitative Research, Elsevier Limited.

Zeppel, H., \& Muloin, S. (2008). Conservation and education benefits of interpretation on marine wildlife tours. Tourism in marine environments, 5(2-3), 215-227.

Zeppel, H. (2011). Managing Tourism on Green Island, Great Barrier Reef Marine Park: Conservation, Commerce and Compromises. In: Carlsen J, Butler R (Eds) Island Tourism-Sustainable Perspectives. CABI International, Wallingford, 38-53. 


\section{References from Internet}

${ }^{1}$ https://blog.padi.com/2015/05/12/whats-the-difference-between-padi-master-scuba-diverand-divemaster/ (the last date accessed to the source: 10.06.2021)

${ }^{2} \mathrm{https} / / /$ greenfins.net/action-centre/ (the last date accessed to the source: 10.06.2021)

${ }^{3} \mathrm{https}: / /$ www.projectaware.org/100AWARE?q=/action-zone/100PercentAWARE (the last date accessed to the source: 10.06 .2021$)$

${ }^{4}$ https://drive.google.com/file/d/0Bw8D-TFFFccxNUwyVXBONHdjUVk/view (the last date accessed to the source: 10.06.2021)

${ }^{5}$ https://www.businessinsider.com/coral-reefs-florida-green-burials-eternal-reefs-2021-5 (the last date accessed to the source: 10.06.2021)

${ }^{6} \mathrm{https} / / /$ www.news.com.au/travel/australian-holidays/queensland/hmas-tobruk-scuttlinglabelled-a-stuffup-by-dive-operators/news-story/1c4c3cd6d652cb88b268c84b3876d4a8 (the last date accessed to the source: 10.06.2021)

${ }^{7}$ http://www.costarica-scuba.com/artificial-reefs-made-from-old-tires-a-bad-idea/ (the last date accessed to the source: 10.06.2021)

${ }^{8} \mathrm{https} / / / \mathrm{www}$. sportdiver.com/scuba-diving-rubber-tire-artificial-reefs-france-florida (the last date accessed to the source: 10.06 .2021$)$

${ }^{9} \mathrm{https} / / / \mathrm{www} . g o o g l e . c o m / \mathrm{maps} /$ place/Malta/@36.3048556,4.858661,5z/data=!4m5!3m4!1s0 x130e45281d8647c5:0xf582d86136be4239!8m2!3d35.937496!4d14.375416 (the last date accessed to the sources for A and B: 10.06.2021)

${ }^{10} \mathrm{https}: / /$ www.google.com/maps/place/Sliema,+Malta/@35.9122218,14.49531,15z/data=!3m 1!4b1!4m5!3m4!1s0x130e453980dcb865:0xa7354d721f145949!8m2!3d35.9110081!4d14.50 2904 (the last date accessed to the source for C: 10.06.2021)

${ }^{11}$ https://www.google.com/maps/place/Mediterranean+Sea/@36.6514968,2.9862426,4z/data=!3m1!4b1!4m5!3m4!1s0x131421b81c473c9f:0x2e93598afeccf840!8m2! $3 \mathrm{~d} 34.5531284 ! 4 \mathrm{~d} 18.0480105$ (the last date accessed to the source: 10.06.2021) 
${ }^{12} \mathrm{https}: / /$ maltadives.com/en (the last date accessed to the source: 10.06.2021)

${ }^{13}$ Worldometers (2021). Countries in the world by population (2021).

https://www.worldometers.info/world-population/malta-population/

(The Last Date Accessed to The Source: 19.11.2021).

${ }^{14} \mathrm{https}: / /$ divesystemsmalta.com/dive-sites-recreational/ (the last date accessed to the source: 10.06.2021)

${ }^{15}$ https://www.mta.com.mt/en/research-reports (the last date accessed to the source: 10.06.2021)

${ }^{16} \mathrm{http}: / / \mathrm{msp}$.ioc-unesco.org/world-applications/europe/malta/ (the last date accessed to the source: 10.06 .2021$)$

${ }^{17}$ https://www.projectaware.org/diveagainstdebrismap (the last date accessed to the source: 10.06.2021) 